
\$:

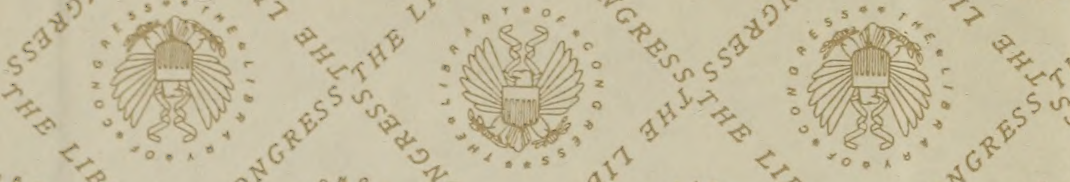

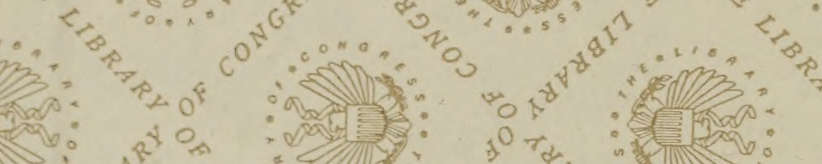

: ents:

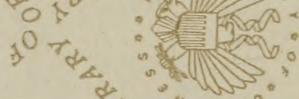

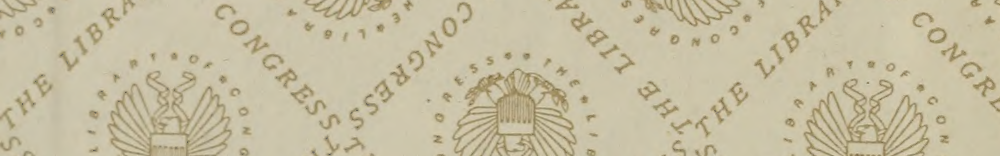

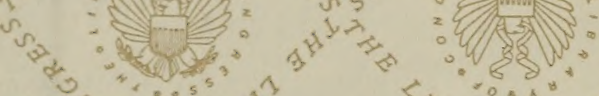

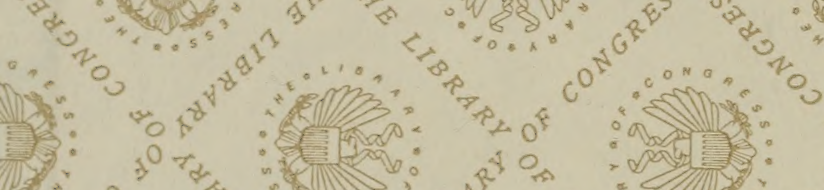

$3^{0} \mathrm{r}^{\alpha / 2}$ is

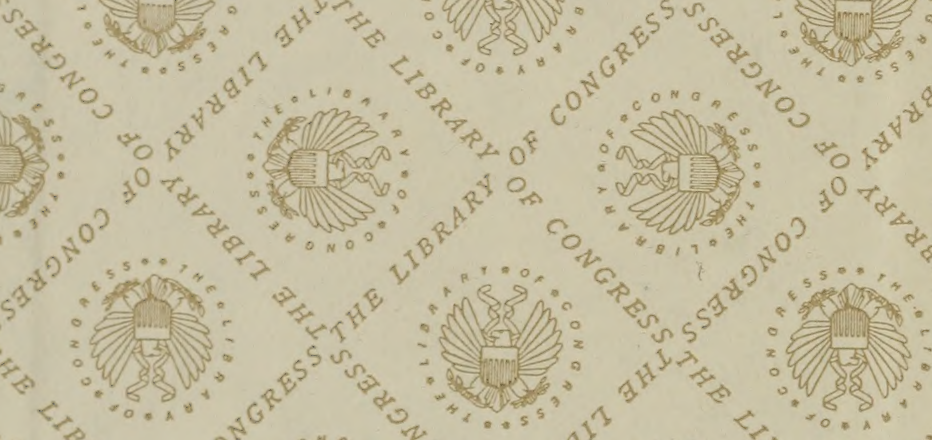

.

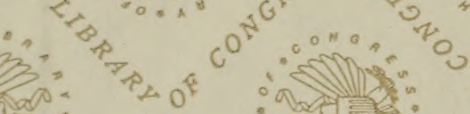

$78:$

से

ant

$\gamma^{10}+0^{2}$

(1)

inf 20 is

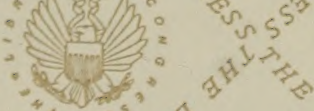

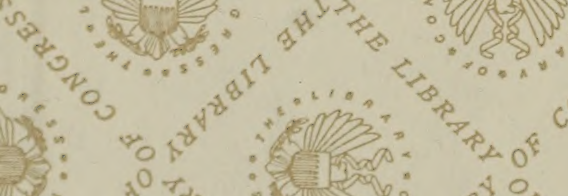

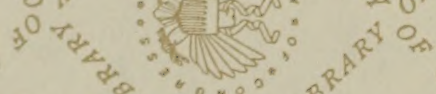

$0^{3}$

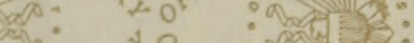

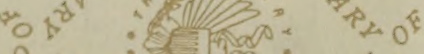




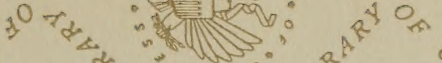

${ }_{1}{ }^{\circ} \gamma_{2}$ का हो the (ind

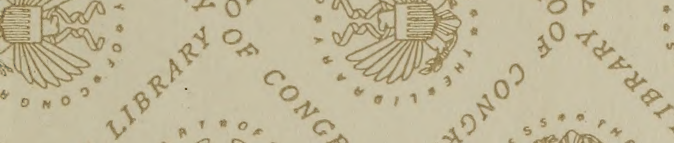
(4)

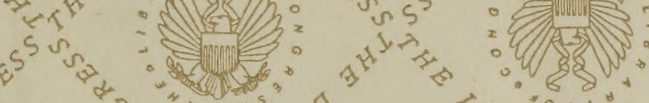<smiles>C1=C[C@@H]2C3CC4C3C2[C@H]14</smiles>

$5^{5}$
0

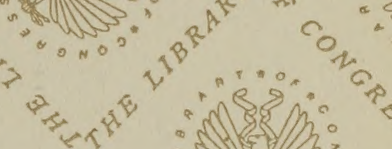

sis

. s. $\left(x^{2}+3^{2}\right.$

and

and

and

(3)

$s^{2}=0$ 






\section{BOOKS BY EMILY A. M. STONEY}

\section{Practical Points in Nursing} I2mo of 5 I I pages, illustrated. Revised by LUCY CORNElia CATlin, R. N. Cloth, $\$ 1.75$ net.

Fifth Edition

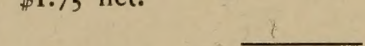

\section{Materia Medica for Nurses}

I2mo of 306 pages. Cloth, $\$$ I.50 net. Third Edition

Bacteriology and Surgical Technic for Nurses I2mo of 342 pages, illustrated. Cloth. Fourth Edition 


\title{
BACTERIOLOGY AND SURGICAL TECHNIC FOR NURSES
}

BY

\section{EMILY A. M. STONEY}

Formerly Superintendent of the Training School for Nurses, Carney Hospital, South Boston, Mass.; Author of "Practical Points in Nursing," "Practical Materia Medica for Nurses"

\author{
F O UR T H EDIT I O N \\ ENLARGED AND RESET
}

"Every bit of knowledge that we cannot use for the uplifting of our physical, intellectual, or emotional life is so much waste of time and labor. Everything taught is worth the knowing, but not worth the putting away in the pigeon-holes of memory to be recalled some day by accident"

FHILADELPHIA AND LONDON

\section{W. B. SAUNDERS COMPANY 1916}




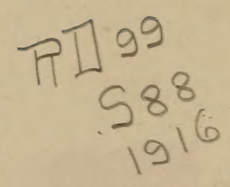

Copyright, 1900, by W. B. Saunders and Company. Set up, electrotyped, printed, and copyrighted September, 1900. Reprinted September, 1902. Revised, reprinted, and recopyrighted January, 1905. Reprinted March, 1906, November, 1907, February, 1909, and August, rgog. Revised, reprinted, and recopyrighted September, 1910. Reprinted July, I912, and January, 1914. Reprinted September, 1915, and December, 1915. Revised, entirely reset, reprinted, and recopyrighted September, 1916

\section{Copyright, 19r6, by W. B. Saunders Company}

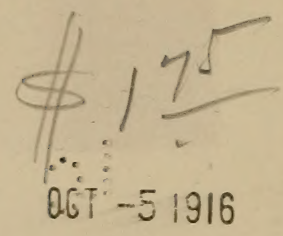

PRINTED IN AMERICA

PRESS OF

W. B. SAUNDERS COMPANY PHILADELPHIA 


\section{DR. JOHN R. SLATTERY}

THIS VOLUME IS DEDICATED BY THE AUTHOR

IN GRATEFUL REMEMBRANCE OF MUCH ENCOURAGEMENT AND PERSONAL, KINDNESS 



\section{PREFACE TO THE FOURTH EDITION}

To bring this new edition down to date the text and illustrations have been gone over in a thorough manner.

While the general plan of the book remains the same, the addition of new matter and the elimination of obsolete material have necessitated the entire resetting of the work.

The chapters requiring the most revision were those on Antiseptics, Disinfectants, and Deodorants; Gauze Sponges, etc.; Minor Surgical Procedures, and Sequels of Operation. So extensive were the changes in the chapters on Bandages and Dressings, Instruments, and Anesthesia that they had to be entirely rewritten. Some of the more important additions are the following: Antityphoid Vaccine; Antitoxin in Cerebrospinal Meningitis; Flexner's Serum in Infantile Paralysis; Serum Reactions; Method of Passing Stomach-tube; Murphy's Method of Continuous Proctoclysis.

It is hoped that the present edition will serve as useful a purpose as its predecessor.

September, I9r6. 



\section{PREFACE}

THE following pages constitute the notes of a series of lectures on "Bacteriology and Surgical Technic" which followed closely upon my lectures on "Materia Medica." The first part of the book is devoted to Bacteriology and Antiseptics; the second part to Surgical Technic, Signs of Death, Autopsies.

No attempt has been made to write a complete treatise on bacteriology, but merely to outline and simplify that branch for nurses.

It was deemed advisable to add the chapter on "Signs of Death and Autopsies," as many nurses are unacquainted with the preparations for an autopsy in private practice.

So many changes have taken place in surgery since the lectures were delivered that it has been necessary to rewrite many of the chapters. In this I was assisted by Dr. A. S. Allen and by Professors J. B. Murphy, Christian Fenger, and Joseph L. Miller, of the Northwestern University Medical College. I am glad of this opportunity to thank them for their assistance. 
Free use has been made of the works on bacteriology by McFarland, Crookshank, and Woodhead; of "Aseptic Surgical Technique," by Dr. Hunter Robb; "Operative Gynecology," by Dr. Howard A. Kelly ; and "Aseptic Treatment of Wounds," by Dr. C. Schimmelbusch.

I am unable to express my indebtedness to Dr. Joseph P. Comegys for his valuable assistance with the manuscript and its preparation for the press.

I wish also to thank Drs. George L. Eyster and Charles C. Carter for their friendly help and interest in the work.

EMILY A. M. STONEY. 


\section{CONTENTS}

\section{PART I.-BACTERIOLOGY; ANTISEPTICS}

CHAPTER I

PAGE

History of BACTERIOLOGY....................... I 7

\section{CHAPTER II}

Bacteria as the Causes of Disease................. 28

CHAPTER III

The Theory of Antitoxins...................... 45

CHAPTER IV

Antiseptics, Disinfectants, And Deodorants........... 53

\section{PART II.-SURGICAL TECHNIC}

CHAPTER V

Bandaging and Dressings......................... 65

\section{CHAPTER VI}

Care of Operating-room; Methods of Sterilization; Care of Instruments.......................... IO2 


\section{CHAPTER VII}

PAGE

Instrinents Necessary in Different Operations, Keeping of Charts, Surgenon's Kit, etc................. it6

Anesthesia

\section{CHAPTER IX}

Gaute Sponges; Pads; Dressings; Tampons; Dressing-room

Outfit; Drainage, Care of Drainage -tubes; Gloves;

Sutures and Ligatures; Surgical Applications........ I 78

\section{CHAPTER $\mathbf{X}$}

INFLAMMATION

\section{CHAPTER XI}

Catheterization; Douches; Enemata; Washing out the Bladder; LAVAge............................. 200

\section{CHAPTER XII}

Minor Surgical Procedures

\section{CHAPTER XIII}

Obstetrtc Nursing; Care of Infants, etc

\section{CHAPTER XIV}

Operations; Preparation of the Operating room; the SurgeON ANd His Assistants...................... 239

\section{CHAPTER XV}

Transportation; Preparation of Patifnt for Operation; Care of Patient During and After Operation........ 249

\section{CHAPTER XVI}

Sequele, of Operations; Shock, Hemorrhage, Septic Peritovitis, A.cidents During Operation, etc............. 263 


\section{CHAPTER XVIII}

Operations in Private Practice................... 278

\section{CHAPTER XIX}

Gynecologic Examinations and Operations.

\section{CHAPTER XX}

Diet Recipes

\section{CHAPTER XXI}

Signs of Death; Autopsies....................... 306

\section{CHAPTER XXII}

Hygiene; Personal Conduct of a Nurse's Life; of the ReWARDS; SUCCESS...................... 3I I

GLOSSARY. 



\section{PART I}

\section{BACTERIOLOGY; ANTISEPTICS}

\section{CHAPTER I}

\section{HISTORY OF BACTERIOLOGY}

THE eye is one of the most beautiful and delicately contrived organs in the body, and yet its vision unaided is very limited in its scope. We see so much that we rarely stop to think of what an enormous world exists in and all about us which we cannot see at alla world peopled by organisms so very small that they can be seen and studied only by the aid of the most powerful magnifying lenses, and so numerous that they are quite beyond any calculation.

Bacteria exist nearly everywhere; they are almost universal, except that they are not found deep down in the ground nor high up in the air. They and their spores, or seeds, float in the air we breathe, swim in the water we drink, grow upon the food we eat, and luxuriate in the soil beneath our feet. Wherever man, animals, and plants live, die, and decompose, bacteria are sure to be present. They are always on the surface of the body, and so deeply are some bacteria situated beneath the epithelial cells that the most vigorous scrub- 
bing and washing and the use of powerful disinfectants are necessary to remove them from the surgeon's hands.

The mouth is said to be always replete with them; and, since many are swallowed, the digestive tract always contains them. The germ of pneumonia, for instance, is said to be habitually present in the mouth of almost every healthy person; consequently, its entrance into the lungs is only a matter of accident.

The existence of these bacteria has been known for many years, but it is only during the past few decades that any great advancement in our knowledge of them has been made.

Over two hundred years ago a man named Athanasius Kircher, a German, mistook blood-corpuscles and pus-corpuscles (leukocytes) for small worms, and built up a new theory of the causes of disease and putrefaction upon this basis. At the same time Christian Lange, a professor in the medical school at Leipzig, expressed his opinion that the rash that appeared on the skin in the eruptive fevers, etc., was the result of putrefaction conveyed by small living worms in the body. Shortly after these observations came those of Anthony van Leeuwenhoek, a native of Delft, in Holland, who, in his early years, had learned the art of polishing lenses, and who was able, ultimately, to produce the first really good microscope that had yet been constructed. He saw, and described with astonishing clearness, various forms of bacteria found in the material taken from the mouth of an old man who never cleaned his teeth. He gave an accurate description of the rod-shaped bacteria, motile and motionless, now called bacilli; of the spiral threads, 
or spirilla; and of rounded micro-organisms, or micrococci. Although he did not attempt to theorize as to the meaning of these organisms at the time, later on, in 1713, after finding similar organisms in the greenish pellicle formed on the surface of the water in an aquarium, he came to the conclusion that the various forms of bacteria found in the material scraped from the teeth found their way into the mouth through the medium of the drinking-water that had been stored in barrels, and that some of these found there a nidus in which they multiplied.

This was the real beginning of bacteriology; and from this origin the study advanced with considerable rapidity in spite of ridicule and much opposition, Various opinions regarding the connection of these germs with disease and putrefaction were put forward, but it was not until I83I that any important advance was made in our knowledge of this connection. Previous to that time a large mass of facts in regard to these little living organisms was being gradually accumulated, and fresh discoveries were constantly made by various workers; but since no systematic attempts to classify the newly observed facts were made, the scientific results were very small.

The first real advance made in our knowledge of the presence of a living contagious element in the production of disease and fermentations was made by Frederick Müller, of Copenhagen, and was the result of a systematic attempt to arrange the knowledge which had been accumulated during all those years. From that time to the present the science has made great strides; so that we have now an accu- 
rate knowledge of the bacteria which cause a number of different diseases. The knowledge of methods and details of work is now so general that the science of bacteriology is rapidly growing, and has already revolutionized very many branches of medicine.

In 1840 Henle was led to believe that the cause of miasmatic, infective, and contagious diseases must be looked for in living fungi or other minute living organisms. Unfortunately, at that time the methods of study employed prevented him from demonstrating the accuracy of his belief. It was left for Pasteur and Koch to complete the work. Davaine, in 1848 , was the first to see and to recognize disease-producing bacteria-he saw anthrax bacilli in the blood of sheep dead of splenic fever.

Pasteur then took up the work; and in 1857 his faultless demonstration of the germ theory of disease was brought out as a result of his experiments on fermentation and putrefaction, and on the bacteria of wine and those of the silkworm. He showed that the acetic fermentation, viscosity, bitterness, and turning flat of wines are due to the action of certain organized ferments, and demonstrated a causal relation between certain lowly organized parasitic organisms and special diseases in animals and insects. Upon Pasteur's observations Lord Lister based his successful system of the treatment of wounds, known as "antiseptic surgery."

We all know of the wonderful success which now marks the operations of major surgery, and of the daring boldness of operators who attempt what was utterly impossible as long as antiseptic surgery was 
unknown. Lister, accepting the truth of Pasteur's statement-that germs are the producers of fermentations-concluded that germs entering. wounds from the outside might be the cause of suppuration; and since germs are always and everywhere floating in the air, suspended in water, and attached to the surgical instruments, dressings, and sponges used in operations, he judged correctly that it was highly advantageous to employ an antiseptic agent in order to kill any of the suspended or adherent organisms before any materials could be allowed to come in contact with wounded tissues; consequently, the hands of the operator and his assistants, the surgical instruments, sponges, dressings, sutures and ligatures were kept constantly saturated with a solution of carbolic acid (I :40), and the operation was performed under a spray of carbolic acid ( $\mathrm{I}: 20$ ). Carbolized dressings were used; and if the discharge was profuse, the dressings were changed once in twenty-four hours under a constant use of the spray. The researches of a later date have shown, however, not only that the atmosphere cannot be disinfected, but also that the air of ordinarily quiet rooms, while containing the spores of numerous saprophytic organisms, rarely contains many pathogenic bacteria. We also know that a direct stream of air, such as is generated by an atomizer, causes more bacteria to be conveyed into a wound than ordinarily would fall upon it, thereby increasing instead of lessening the danger of infection. Lister, we must remember, was not the discoverer of carbolic acid nor of the fact that it would kill bacteria; but, convinced that inflammation and suppuration were caused by the entrance of 
germs from the air, instruments, sponges, and dressings into wounds, he suggested the antisepsis which would result from the use of sterile instruments, clean hands, dressings, towels, and the like; and made applications intended to keep the surface of the wound moistened with a germicidal solution in order to kill such germs as might accidentally enter. $\mathrm{He}$ also introduced the practice of concluding operations by the application of a protective dressing, such as would tend to preclude the entrance of germs at a subsequent period. This procedure defeats its purpose for usefulness by reason of the moisture retained acting as a direct growth medium for those bacteria already upon or in the skin. Listerism has spread slowly but surely to all the departments of surgery and obstetrics.

Since Lister's treatment was first inaugurated, many details of its application have been variously modified and great additions to our knowledge have been made. In bacteriology much important work has been done, and great advances are being constantly made. There are a number of diseases, each one of which has been definitely proved to be caused by a germ of its own, a germ which causes no other disease. There is also a list of diseases in which the proof is not yet conclusive, but for which the probability is that a specific germ will be found. The following data have been gathered chiefly from the works of McFarland and Woodhead:

In I 845 Langenbeck discovered that the specific disease of cattle known as actinomycosis could be communicated to man. His observations, however, were not given to the world until $\mathbf{1} 878$, one year after Bollinger had discovered the cause of the disease in animals. 
In 1847 Semmelweis, on the basis of his own observations, formulated the precept that puerperal fever is the result of the introduction of organic ferments into the puerperal genital tract. This discovery, established by himself and confirmed by the observations of many others, marked an era in obstetrics. The organic ferments have since been identified as specific bacteria. Semmelweis in this way anticipated in practical antisepsis the discoveries of Lister and Pasteur; while the late Oliver Wendell Holmes, in a paper entitled "Puerperal Fever a Private Pestilence," published in I 843 and republished in $\mathbf{I} 855$, in treating of its prophylaxis, anticipated the teaching of Semmelweis. Semmelweis was first led to recognize the source of puerperal infection by the case of Prof. Koletschka, of the University of Vienna, who, having received a dissection wound, became thereby fatally infected. In consequence of this Semmelweis concluded that there was an identity between this infection and that of which so many hundreds of puerperal women died. In the school for instruction in practical obstetrics with which he was connected there were two departments, one for medical students, the other for midwives, the students going, as a rule, directly to the obstetric ward from the autopsy room. He first noted the much greater mortality in the student's ward, and in May, I847, began to require the students to wash their hands in chlorin-water before making vaginal examinations, thereby reducing the puerperal mortality to a point lower than had been ever before reached.

In I 863 Davaine established by experiments the bacterial nature of splenic fever, or anthrax. 
In I869 the first complete study of a contagious affection was made by Pasteur, in two diseases affecting silkworms-pébrine and flacherie-which he showed to be due to micro-organisms.

In I875 Koch described more fully the anthrax bacillus, gave a description of its spores and the properties of the same, and was enabled to cultivate the germ on artificial media; and, to complete the chain of evidence, Pasteur and his pupils supplied the last link by reproducing the same disease in animals by artificial inoculation from pure cultures. The study of the bacterial nature of anthrax has been the basis of our knowledge of all contagious maladies; and most advances in technic have been made first through the study of the bacillus of that disease.

In I879 Hansen announced the discovery of bacilli in the cells of leprous nodules. They were subsequently clearly described by Neisser. From the nature of the symptoms and from the course of the disease, leprosy up to this time was long considered to be a disease similar to tuberculosis, and the discovery of the bacillus paved the way for the reception of Koch's discovery of the tubercle bacillus.

In the same year Neisser discovered the gonococcus to be the specific cause of gonorrhea.

In 1880 the bacillus of typhoid fever was first observed by Eberth, and independently by Koch.

In I880 Pasteur published his work upon Chickencholera, an epidemic disease which affects turkeys, pigeons, chickens, ducks, and geese, and which causes almost as much destruction among them as the occasional apidemics of cholera and small-pox produce among men. 
In the same year Sternberg described the pneumococcus, calling it "Micrococcus Pasteuri," which he secured from his own saliva; and in the same year Pasteur also found the same organism in saliva; though it is to Fränkel, Talamon, and particularly Weichselbaum that we are indebted for the discovery of the relation which the organism bears to pneumonia.

In I882 Robert Koch made himself immortal by the discovery of and work upon the bacillus of tuberculosis, one of the most dreadful and, unfortunately, most common diseases of mankind. While great men of the earlier days of pathology clearly saw that the time must come when the parasitic nature of this disease would be proved, and some, as Klebs, Villemin, and Cohnheim, were "within an ace" of the discovery, it remained for Koch to succeed in demonstrating and isolating the specific bacillus, and to write so accurate a description of the organism and the lesions it produces as to render the discovery one of the most complete ever made in the history of medical science.

In the same year Löffler and Schütz reported the discovery of the bacillus of glanders, an infectious disease almost confined to certain of the lower animals; although occasionally persons whose habitual association with and experimentation upon animals bring them into frequent contact with such as are diseased, have become accidentally infected.

In I884 Koch discovered the "comma-bacillus," the cause of cholera.

In the same year Löffler discovered the diphtheria bacillus, and Nicolaier that of tetanus.

On October 26, I885, Pasteur made the first applica- 
tion of his method for the treatment of hydrophobia, nearly ten years before the time we began to understand the production and use of antitoxins in human medicine.

In 1890 Koch issued to medical men what is known as tuberculin, a brownish, syrup-like fluid used in the diagnosis and treatment of tuberculosis.

In I 892 Canon and Pfeiffer discovered the bacillus of influenza.

In I894 Yersin and Kitasato independently isolated the bacillus causing the bubonic plague then prevalent at Hong-Kong.

The bacterial cause of yellow fever has not been determined, but its method of transmission is known to be through the bite of the mosquito Stegomyia fasciata. This mosquito, to become infected, must bite the patient during the first three days of the disease, and then the mosquito is harmless until the lapse of at least twelve days. After being bitten by the mosquito the period of incubation is from six to ten days. Dr. Chas. Finlay, of Havana, was the first to pronounce clearly a mosquito theory of the transmission of yellow fever, and it was later proved conclusively by a Commission of the United States Army composed of Reed, Carroll, Agramonte, and Lazear. Two of the above, Reed and Lazear, died from allowing themselves to be bitten by infected mosquitoes to prove conclusively that the mosquito, and the mosquito alone, transmitted the disease.

Epidemic cerebrospinal meningitis or spotted fever is caused by Diplococcus intracellularis meningitidis.

Malta fever, a disease of the Mediterranean islands, and occasionally of the Antilles and Central and South 
America, is due to a micrococcus discovered by Bruce, and called Bacillus melitensis.

Malarial fever is an infectious disease; but, unlike those mentioned, it is not caused by a vegetable germ, a bacterium, but by a microscopic animal, the Plasmodium malaria, which is found in the blood of the afflicted individual. Malaria is carried solely by a species of mosquito, the Anopheles.

There is some grounds for a belief that malignant tumors-cancers and sarcomas-are due to microorganisms. The nature of the parasite is as yet unknown.

Spirochæta pallida or Treponema pallidum, discovered by Schaudinn and Hoffmann in 1905, is now generally accepted as the exciting cause of syphilis. The organism is from 6 to $15 \mu$ in length and presents from six to fourteen spiral turns. It is found constantly in primary and secondary and with difficulty in tertiary lesions. Its presence in a suspected lesion is regarded as diagnostic, while its absence does not exclude syphilis. 


\section{CHAPTER II}

\section{BACTERIA AS THE CAUSES OF DISEASE}

Diseases may be divided into two great classesthe constitutional, which are due to such causes as errors in diet, alcoholic excesses, overwork, or age; and the infectious or contagious, which are due to the introduction into the body of a living poison. We no longer look upon infectious and contagious diseases as due to an unexplainable something, whose source we cannot know, whose caurse we cannot predict, and whose end cannot be hastened by any efforts on our part. Investigation has shown that we are no longer fighting an unknown enemy in the dark, but that we have before us a definite, living thing, whose part in the plan of creation is as surely fixed as our own, whose life-history can be told, and whose growth is as dependent on the right amount of light, food, heat, and air as that of the rose in our garden.

The word bacteria is a general name for all the plant micro-organisms. Of these there are many different classes with different names. They vary much in shape and size, some being round, some thread-like, some rod shaped, and some of a spiral form. Each single organism consists of a small speck of protoplasm or vegetable albumin, to which may be given the name of a cell; and these cells are so minute that they can be seen only with the aid of the best microscopes at our command. The 
rounded organisms, or micrococci, as they are called, are seldom more than $\frac{1}{25000}$ inch in diameter; the elongated cells average a little more perhaps, and are from $\frac{1}{12000}$ to $\frac{1}{6000}$ inch in length. Different forms naturally vary from this standard of size; but these figures will give a good idea as to the actual size of the forms under consideration (Fig. I).

The fungi connected with disease in man are divided into three classes:

I. Molds, or hyphomycetes.

2. Yeasts, or blastomycetes.

3. Bacteria, or schizomycetes.

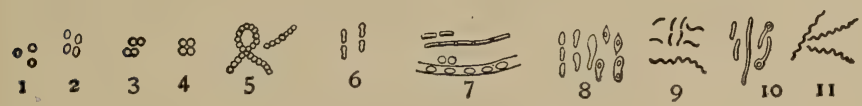

Fig. I. - Various forms of bacteria: I and 2, Round and oval micrococci; 3 , diplococci; 4, tetracocci, or tetrads; 5 , streptococci; 6, bacilli; 7 , bacilli in chains, the lower showing spore formation; 8 , bacilli showing spores, forming drumsticks and clostridia; 9 and Io, spirilla; II, spirochetæ (McFarland).

Some bacteria, or schizomycetes, induce the various fermentations; while others are productive of putrefaction, and are called saprophytes. Others, again, known as the pathogenic bacteria, are the cause of various diseases; while those which do not ordinarily cause disease are known as the non-pathogenic bacteria. The chief forms of bacteria are:

I. The coccus-berry-shaped or spheric bacterium.

2. The bacillus-rod-shaped bacterium.

3. The spirillum-corkscrew bacterium. And these, which are species relatively monomorphous 
-i.e., preserve their shape-are practically the only ones with which we have to do.

The cocci are named according to their arrangement with one another; if, for instance, they are in pairs, they are called diplococci; if in a chain, they are called streptococci; if in a cluster, like a bunch of grapes, they are called staphylococci; and if in an irregular mass, stuck together by a thick substance, they constitute a zoöglea. Those developing in fours are called tetrads; in eights, sarcinæ.

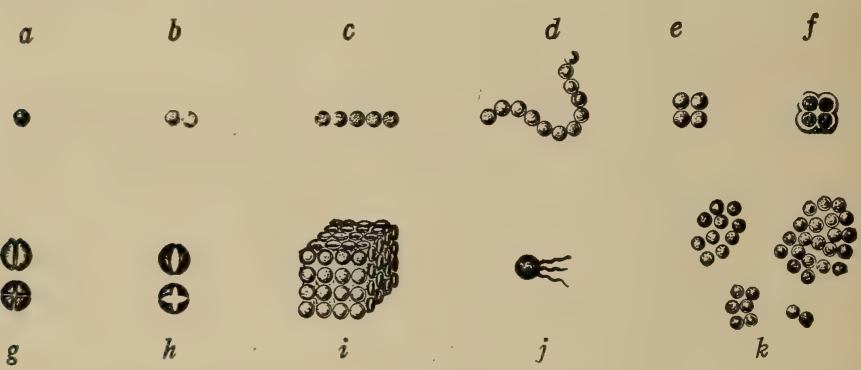

Fig 2.-Diagram illustrating the morphology of cocci: $a$, Coccus or micrococcus; $b$, diplococcus; $c, d$, streptococci; $e, f$, tetragenococci or merismopedia; $g, h$, modes of division of cocci; $i$, sarcinæ; $j$, coccus with flagella; $k$, staphylococci (McFarland).

The cocci are also named according to their functions, as, for instance, "pyogenic," or pus-forming; the specific name also describing the form, arrangement, color, and function; for example, Staphylococcus pyogenes aureus signifies a spheric colorless micro-organism forming a yellow pigment, arranging itself with its fellows into the form of a bunch of grapes, and producing pus.

As the surgical nurse carries on a daily warfare for the destruction of pus micro-organisms and prevention 
of their growth, she cannot be too familiar with every aspect of these germs. The two most constant pus formers are: (I) the staphylococcus (Fig. 2, $k$ ), which, when present in a wound, may cause a free flow of pus; still it generally manifests a milder disease condition than the virulent (2) streptococcus germ (see Fig. I, No. 5 ; Fig. $2, c, d$ ).

Staphylococci may be observed under the microscope by placing a drop of the pus upon a cover-glass, afterward spreading the specimen by applying another cover-glass; dry over an alcohol lamp and stain with a solution of methylene-blue. Wash away the excess and place the specimen face down upon a glass slide. Streptococci are best stained by the so-called Gram method. To a dried and spread drop of pus upon a cover-glass apply an excess quantity of the following:

Anilin, 4 parts.

Saturated alcoholic solution of basic

$\begin{array}{lr}\text { anilin dye, } & \text { I I “ } \\ \text { Water, } & \text { roo }\end{array}$

Stain in this for fifteen minutes; transfer to Gram's solution:

Iodin,

Potassium iodid,

4 parts.

Water,

2 "

300 "

Stain for four minutes; remove and wash the specimen in 95 per cent. alcohol; finally stain in the following for half a minute:

Bismarck brown,

Water,

3 parts.

70 “" 
Wash in 95 per cent. alcohol; clear the specimen by adding a few drops of carbolxylol; place upon a glass slide for observation. Anyone capable of developing an ordinary kodak film will find but little difficulty in learning this apparently deeply mysterious technic of the bacteriologic laboratory.

Bacteria reproduce in two ways: By direct division (fission) and by the development of spores or seeds (sporulation). The most common mode is by binary division, one body dividing itself so as to form two other bodies; these two re-dividing, and so on. It can readily be imagined how quickly an appalling in-
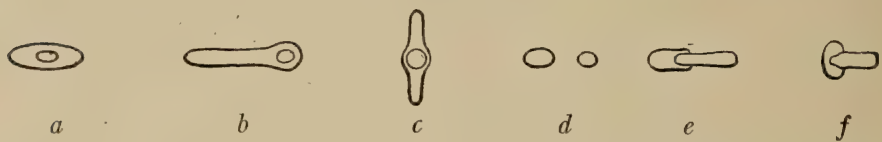

Fig. 3.-Diagram illustrating sporulation: $a$, Bacillus inclosing a small oval spore; $b$, drumstick bacillus, with terminal spore; $c$, clostridium, with central spore; $d$, free spores; $e$ and $f$, bacilli escaping from spores (McFarland).

crease in their numbers can be thus brought about; but, fortunately, this multiplication only takes place to advantage under certain favorable conditions; if these are not present the bacterium begins to degenerate, but usually does not die until it has left behind a spore. When the formation of a spore is about to commence, a small bright point appears in the protoplasm, and increases in size until its diameter is nearly or quite as great as that of the bacterium. As it nears perfection a dark, highly refracting capsule is formed about it. Is soon as the spore arrives at perfection the bacterium seems to die, as if its vitality were exhausted 
in the development of the permanent form. As soon as the young bacillus escapes it begins to increase in size, develops around its soft protoplasm a characteristic membrane, and, having once established itself, presently begins the propagation of its species by fission. In those forms of organism in which spores are not found the germs die very rapidly unless the conditions for their nutrition and multiplication remain very favorable. If all bacteria were of this kind, it would be possible to exterminate them with considerable rapidity. Spores will survive a great heat, a heat which will kill the organism from which the spore came; they will also live under a treatment with germicidal solutions which renders the bacteria inactive. In other words, the spores are much more resistant to the effect of germicides than the bacteria themselves. Cold does not kill them; they live through it and develop whenever favorable surroundings for their growth present themselves. They may lie dormant in the system for years, waking into activity only when they come into contact with some damaged, weakened, or diseased part which affords them a nest in which to develop and multiply, the cellular activity of the weakened part being unable to cope with the organisms.

The conditions which influence the growth of bacteria are, first, a temperature ranging from $85^{\circ}$ to $104^{\circ} \mathrm{F}$., some forms requiring a higher and some a lower temperature. Some forms of bacteria are not influenced in their growth by the presence or absence of light. To some, sunlight is destructive. A few hours' exposure to the sun is fatal to the anthrax bacillus and to cultures of the Bacillus tuberculosis. The rays of the sun, how- 
ever, must come into contact with the germs and are usually active only on the surface of cultures.

The majority of bacteria grow best when exposed to the air. Some develop better if the air is withheld; some will not grow at all if the least amount of oxygen is present. Those that grow in oxygen are called the aërobic bacteria, and those that will not grow in the presence of oxygen are the anaërobic bacteria.

A certain amount of water is always necessary for the growth of bacteria, though the amount required may be very small. If dried, no form will multiply and very many forms will die.

A soil consisting of highly organized compounds is also necessary for their growth and multiplication, and slight modifications in it may prove fatal to some forms of bacterial life, but be highly advantageous to others.

With age bacteria lose their strength and die. So we see that a suitable soil and a proper amount of light, heat, and air are absolutely necessary for the growth and development of bacteria, for they carry on all the functions of a higher organized life; they breathe, eat, digest, excrete, and multiply.

The disease-producing bacteria effect entrance into the interior of the body through the skin and superficial mucous membranes, wounds, alimentary canal, respiratory tract, and placenta.

The entrance of bacteria into the tissues through the sound skin is very rare indeed, although some authorities claim that infection has taken place through the rubbing of bacteria or their spores upon the skin. The dangers of infection through the broken skin are 
well recognized; hence every wound, no matter how slight, should be protected as soon as possible.

Bacteria enter the alimentary canal through the food and drink. Typhoid infection has taken place through the rectum, its occurrence being due to the wearing of underclothing previously worn by typhoid fever patients, and to the use of enema syringe tips which had not been sterilized after their previous use.

Bacteria enter the respiratory tract through the mouth and nose, as in a deep inspiration, or an act of coughing, sneezing, or the like. Pneumonia and tuberculosis are said to be the result of inspiration of the specific organisms. The direct transmission of bacteria from a parent to the fetus has long been a disputed question, but is now generally conceded. The micro-organisms pass through the placenta and infect the fetus. Tuberculosis of the ovaries, Fallopian tubes, and uterus may originate through the blood or from without through the vagina. Infection through the blood is evidenced by the general tuberculosis of all the viscera.

The channels by which bacteria can enter the body are, then, very numerous; and there is scarcely a moment in which some part of the body is not in contact with them. All the disease-producing germs have their favorable seat in some part of the body where they grow more or less luxuriantly, and in the secretions and excretions of which the chief source of their infection lies. The pneumonia germ prefers the lungs; the typhoid fever germ selects the lower portion of the small intestine; the diphtheria germ, the throat; the cholera germ, the intestinal tract; the germ of tuberculosis prefers the lungs, but it is called a "medical tramp," because it will 
lodge in any part of the body and make its home there. Hence we hear of tuberculous glands of the neck, tuberculous knee, intestinal tuberculosis, tuberculosis of the kidney, bladder, uterus, ovaries, Fallopian tubes, tuberculous peritonitis, etc. A tuberculous area is always a danger to the system, and may infect distant organs or give rise to a general tuberculosis.

To prove that a microbe is the cause of a disease it must fulfil Koch's circuit. It must always be found associated with the disease, and it must be capable of forming pure cultures outside the body. These cultures must be capable of reproducing the disease, and the microbe must again be found associated with the morbid process thus reproduced. In other words, we must prove the bacteria to be always present; we must then isolate them, then prove that they can produce the disease in a healthy animal, and, finally, having succeeded in doing all this, we must prove that no other form of bacteria can produce the disease, and that where these bacteria cannot be obtained the existence of the disease is impossible. All these requirements have been met in many instances, and now there are a large number of diseases each one of which has been definitely proved to be caused by a germ of its own, a germ which produces that disease and no other. Most of the germs need a special train of circumstances in order that they may be active, so that, fortunately for us all, the mere presence of the germ itself is not sufficient to produce the disease. For instance, we know that diphtheria is caused by a germ of its own which causes that disease and no other; still, exposure to that germ does not invariably produce 
diphtheria-if it did, we should all be infected with it. This is because other conditions than the mere presence of the germs are needed to produce the disease. The germs must be active, and they can act only under certain conditions. It will usually be found that the attack of the disease has been preceded by a local inflammation of the throat, thus making a suitable place for the specific action of the diphtheria germs. In typhoid fever the germs require a suitable condition of the bowels before they can produce the disease. This is also true of cholera, and explains why taking care of the health makes such a difference in the taking of this disease. The germs find their way into the body through the food and drink. Cases are reported that show how the germs enter drinkingwater which is sprinkled over vegetables sold in the streets of cholera-infected districts, how they are carried about in clothing, and taken to articles of food upon the table by flies which have preyed upon cholera excrement. Healthy lungs are not a suitable location for the development and activity of the germs of tuberculosis. If we are not fully in good health, or if we inherit a tendency to this special disease, we may acquire it very readily, since we often inhale the germs of it. Should the disease take root in our lungs, it may be controlled to a certain extent by a change of climate and surroundings; by going, for example, from a low and damp locality to the mild and dry atmosphere of Colorado, the Carolina mountains, Southern California, or of the other Southwestern States, where there are few cloudy days and where violent atmospheric changes are rare. The germs there cannot be so active, 
for the air is stimulating, pure, and sunlight has an inhibitory action upon the tubercle bacillus. The rarefaction of the air causes deep and strong involuntary respiratory movements, and there is consequently enforced a better ventilation of the lungs and a better oxygenation of the blood, in consequence of which there follow more active tissue changes throughout the body and a strengthening of the respiratory muscles.

On finding favorable conditions it takes germs some days to develop and produce the disease; this time is known as the period of incubation.

The question is often asked, Why, when we are so constantly in contact with disease germs, do we not contract the diseases? All bacteria leave the body through the skin, lungs, kidneys, or bowels; and by a faithful use of disinfectants and antiseptics the germs may be kept confined to their original position. After their escape from the body they are difficult to control. The scales of skin or dandruff from a case of scarlet fever, measles, or small-pox, or the dust that arises from the dried sputum of a pneumonia or tuberculous patient, or the poisonous material which may enter our drinkingwater from too close proximity of the well and the sewer into which typhoid discharges have been emptied, may readily be the means of propagating disease. These sources of infection should be scrupulously avoided. Another protective factor is the natural or acquired power of resistance to disease-producing germs.

Immunity is either natural or acquired. Of acquired immunity we have two varieties, that which comes from having had the disease and artificial immunity produced by injecting special antitoxins. 
By natural immunity is meant the natural and constant resistance to disease-producing germs. The individual is immune by Nature and sometimes by racial characteristics. Acquired immunity is a power of resistance attained through various circumstances. Thus, a single attack of some of the infectious and contagious diseases usually confers immunity against subsequent attacks. Such immunity generally follows an attack of typhoid fever, small-pox, scarlet fever, mumps, whooping-cough, measles, or yellow fever. Second attacks may occur; but, as a rule, a patient who has had an attack of one of these diseases has immunity for life. Influenza, pneumonia, cholera, diphtheria, and erysipelas are among the diseases in which one attack is not protective. Vaccination usually insures immunity against small-pox; but this is ordinarily not so complete or permanent as that resulting from an attack of the actual disease.

Acclimatization immunity is exemplified by various diseases which do not trouble natives or those long resident, but which may affect strangers not inured to the climate.

Racial immunity is that in which certain races are safe from certain diseases; for instance, negroes seldom suffer from yellow fever, but are more susceptible than whites to small-pox. It is asserted that the Arabs seldom or never have typhoid fever. An analogous example is afforded by the fact that white mice are not affected by the same diseases as the gray mice are, even though subjected to the same influences in respect to climate, food, and surroundings. 
Artificial immunity may be produced in various ways. It is said that an injection of the antitoxin of diphtheria will give protection against the disease for from four to eight weeks. Tetanus has been prevented in a similar manner. It is impossible here to enter. except in a slight degree, into the consideration of the many theories of immunity, since they are very intricate, and not one has been advanced so far that can clearly explain it. The theory of phagocytosis

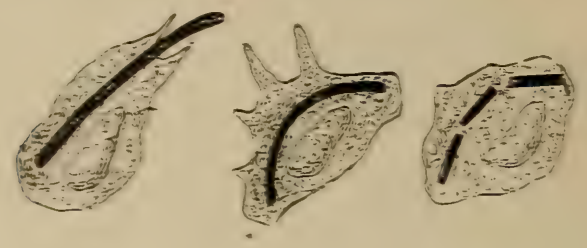

Fig. 4.-Phagocyte destroying a bacillus (Landerer).

and the theory of antitoxins are the two most important.

Phagocytosis is the destruction of bacteria by the white cells of the blood and the cells of fixed tissues. The cells which eat up and destroy the germs are called "phasocytes." When the two meet a battle occurs, the bacteria fighting the cells with their active ferments. while the cells on their side put forth every effort to protect the body against the assaults of the disease. In a majority of the cases the bacteria win to the extent that the phagocytes die; but others take their place until the infection is overcome or the patient dies. The white blood-cells and tissue-cells having 
thus been educated to withstand the poison, their descendants inherit this capacity and are born insusceptible. This theory was suggested by Carl Roser in I88I. Sternberg and Koch afterward put forth the same view, but it is usually credited to Metschnikoff, who published his observations in $\mathbf{I} 884$.

The other theory-the so-called antitoxic theoryis founded on numerous more or less convincing experiments. If an animal be injected with certain pathogenic bacteria or their toxins in gradually ascending doses, it can be immunized to doses that under other circumstances would prove fatal. The bloodserum of an animal thus immunized has the power, when injected into another animal, of rendering it also immune to the bacteria that have originally been used; and in some cases the serum is even capable of curing the disease after it has developed in another animal. These properties with which the blood-serum has become endowed depend upon the presence of what are called antitoxins and antibacterial bodies. In man also, after recovery from certain infectious diseases, it is possible to demonstrate in the blood-serum the presence of antitoxic substances; and it is now the general belief that immunity, at least of the acquired form, is due to such antitoxins. The uses and practical preparation of antitoxins will be described in the next chapter.

The most important of the special surgical microorganisms - $i$. $e$, those most frequently met with in surgical work-are the following, the majority being pus producers: 
I. Staphylococcus Pyogenes Aureus.-This is the most common form; it is quickly killed by carbolic acid ( $1: 20$ ), bichlorid of mercury (I : IO00), or by a few moments' boiling. It is found in the mouth, alimentary canal, and under the nails; it lives in the eyes, nose, ears, mouth, in the superficial layers of the skin, and is distributed in the water, soil, and air, especially in the dust of houses and surgical wards where the proper precautions are not taken.

2. Streptococcus pyogenes is a most important pathogenic micro-organism, and is thought by many authorities to be identical with the streptococcus of erysipelas. The Streptococcus pyogenes is frequently associated with internal diseases, and has been found in the uterus in cases of infective puerperal endometritis, ulcerative endocarditis, acute septicemia, and other diseases. It is one of the most common causes of postoperative peritonitis.

3. The Bacillus coli communis is always present in the intestines, and, while ordinarily active in the processes of digestion, it is thought to be a frequent cause of acute suppurative peritonitis.

4. The Staphylococcus pyogenes albus resembles the aureus in form, but is less virulent. It is a common cause of suppuration, and although it has been found alone in acute abscesses, it is usually associated with other pyogenic cocci, chiefly the Staphylococcus pyogenes aureus.

5. The Staphylococcus epidermidis albus is a micrococcus which is almost always present upon the skin, not only upon the surface, but also in the outer layers. 
6. The Staphylococcus pyogenes citreus is not quite so common nor so pathogenic as the other forms, and is less important.

7. The Bacillus pyocyaneus exists in pus (especially in open wounds), and gives to it a peculiar bluish or greenish color.

8. The Bacillus aërogenes capsulatus is a gas-producing bacillus that sometimes causes death after operations on the uterus; it may also enter through accidental wounds.

9. The Bacillus tuberculosis is the cause of all tuberculous processes. The chief cause of the spread of infection is found in the dried sputum, which becomes pulverized and is then inhaled as dust; and since one patient may expectorate as many as four billion bacilli in twenty-four hours, his capacity for harm is very considerable. The bacilli retain virulence for five months in dried sputum, and in putrid sputum for forty-three days.

Io. The Micrococcus lanceolatus, known also as Streptococcus lanceolatus, pneumococcus, and Diplococcus pneumoniæ, is the cause of croupous pneumonia and of many of the acute inflammations of the serous membranes of the body. It is also a pus producer, and has been found in empyema and acute abscesses.

II. The bacillus of tetanus is found particularly in garden-soil, in the dust of halls, walks, cellars, streetdirt, and in the refuse of stables. It is not a pus producer. Tetanus is a disease due to the absorption of its toxins, which poison the nervous system precisely as would dosing with strychnin. 
12. The diphtheria bacillus causes the dreaded diseases diphtheria and membranous croup, as well as inflammations of the eyes and nose; at times it also attacks open wounds.

The Spirochceta pallida is the cause of syphilis and it is transmitted usually by direct inoculation from one infected with the disease, the primary and secondary lesions being most infectious. 


\section{CHAPTER III}

\section{THE THEORY OF ANTITOXINS}

GREAT progress has been made of late in the field of serum-therapy, though much remains open to question and many recorded facts cannot yet be explained. The field for the investigator is perhaps larger than ever before. For a better understanding of the subject of antitoxins and their therapeutic application, a few essential facts should be borne in mind. An antitoxin is not the direct result of bacterial action, but is properly described as an unknown body resulting from the resistance of the healthy organism to the toxins of pathogenic bacteria. According to the prevailing theory, antitoxins are the products of the body cells, formed under the influence of the bacterial toxin. In therapeutic practice the antitoxic body comes to us in the blood-serum of an animal, usually the horse. When properly prepared and kept in aseptic containers the antitoxins are not at all dangerous; they are as innocuous as an equal amount of blood-serum administered in the same way. Antitoxins are used both to counteract the effects of the toxins which are elaborated by pathogenic bacteria in the body, and to render the system immune, so that it may resist the action of the bacteria should they gain access to the body. The antitoxins do not destroy the bacteria; in other words, they are not germicides. In fact, the antitoxic serums 
are themselves good culture-media. One theory of their action is that they neutralize the toxin, thus giving the natural bactericidal powers of the body an opportunity to exercise their function.

The following is a brief description of the process employed in the laboratory of Parke, Davis \& Co. for the preparation of diphtheria antitoxin:

Young horses in perfect condition are selected and kept under careful observation by an expert veterinarian for three or four weeks. During this time they are carefully tested with tuberculin for the possible existence of unsuspected and undeveloped tuberculosis, and with mallein for glanders. When a horse is found to be perfectly healthy it receives its first dose of diphtheria poison or, more properly, a solution of the toxin of the diphtheria bacillus. This is prepared in the following manner: A culture is obtained from the throat of a patient suffering from a virulent attack of diphtheria. The diphtheria bacillus is isolated from this culture and planted in a flask of bouillon or beef-tea, which is then kept in an incubator from three to four weeks. At the end of this time it has attained its maximum toxicity and the bacteria begin to die of their own poison. The toxin which they have elaborated in the course of their existence is held in solution in the beef-tea. This bouillon solution of toxin is then filtered through porcelain to remove the bacterial cells and any other extraneous matter. It is then ready for injection into the horse. About $\frac{1}{10}$ of $\mathrm{I}$ c.c. is injected intravenously. The horse responds with all the constitutional symptoms of diphtheria, such as a chill, fever, loss of appetite, more or less pharyngeal paralysis, 
with regurgitation of food. Sometimes death occurs from heart paralysis. Upon recovery, which comes within a few days, a slightly larger dose is given. This treatment is continued for about one year, at the end of which time the horse will take from 2000 to 3000 times the initial dose without reaction. It is then ready for bleeding. About 6000 c.c. of blood are drawn from the external jugular vein. This is allowed to clot, and the serum obtained is known commercially as antitoxin. It is customary to add an antiseptic, such as trikresol, to preserve the serum.

In preparing the streptococcus antitoxin a culture is made of bacteria obtained from two sources-erysipelas and puerperal septicemia. This is done because some eminent bacteriologists believe that the streptococcus of erysipelas is not identical with the streptococcus of puerperal fever. It is but fair to say, however, that others equally eminent assert the identity of the two streptococci. To meet the possibility of the non-identity of the organisms a culture obtained from the two sources is used. Its virulence is increased by passing it through rabbits. After passing through about fifty rabbits a culture is planted in beef-tea, and the same course pursued as for diphtheria antitoxin. Antitubercle serum is obtained by immunizing horses with the original Koch's tuberculin.

As to the therapeutic action of antitoxin, little or nothing is known positively. It seems reasonable to conclude from experimental evidence that the antitoxin neutralizes the toxin in the body and thereby gives the natural germicidal powers an opportunity to dispose of the bacteria. It may be that it has the 
additional property of stimulating the phagocytic and possibly other bactericidal functions. The following experiments made by Martin and Cherry, of Melbourne, Australia, and described in the Jour. Amer. Med. Assoc. of August 27, 1898, are of interest in this connection. Behring, Ehrlich, and Kanthack have advocated the theory that the antagonism between toxins and antitoxins is a chemical one, somewhat analogous to the neutralization of an acid by an alkali; while Buchner, Metschnikoff, and others have maintained that it is indirect and operates through the cells of the organism. Martin and Cherry used a snake-venom antitoxin. A large number of guineapigs were used. At $60^{\circ} \mathrm{C}$. the antitoxin was destroyed, while the venom retained its virulence. In the control-experiment with the venom only all the animals died within a few hours. A number of mixtures were made of I c.c. of antitoxin with twice the fatal dose of venom; others with three or four times the fatal dose. These mixtures were allowed to stand at the usual laboratory temperature $\left(20^{\circ}\right.$ to $23^{\circ} \mathrm{C}$.) for two, five, ten, fifteen, and thirty minutes respectively, then heated to $68^{\circ} \mathrm{C}$., and afterward injected.

As remarked above, this heat destroyed the antitoxin, so that none was injected. The animals subjected to the mixture of the stronger doses of ten minutes or less died or were seriously affected; all of those receiving the fifteen-minute mixture survived; while the thirty-minute mixtures produced no symptoms whatever. Similar results were obtained with diphtheria antitoxin and toxin. These experiments seem to show, as far as anything can, that the neutraliza- 
tion of toxins may occur in the test-tube, and that the vital processes in the organism and the body cells are not essential. These gentlemen made further experiments by passing a mixture of toxins and antitoxins through a Pasteur-Chamberland filter. This was porous for toxin, but not for antitoxin, owing to the difference in the size of their molecules. The toxin which passed through the filter, after having been mixed with antitoxin, was neutral. The unavoidable conclusion from this experiment is that the toxin was neutralized before filtration.

Experiments have been tried in order to prove the theory that toxins are albumoses and antitoxins globulins; but these experiments do not appear to be conclusive as to this point.

The supposition that the administration of antitoxin is followed by a stimulation of the germicidal powers of the body seems to be reasonable, at least in the case of the antistreptococcic serum, since the streptococci disappear with the passing away of the signs and symptoms. On the other hand, the Klebs-Löffler bacillus is found in the throat for weeks and even months after the disappearance of all symptoms of diphtheria in cases treated with the antitoxin.

The present status of diphtheria antitoxin may be presented in a few words: It has established itself as a specific in the treatment of this disease. During the past few years the use of larger doses has become more general, and it seems certain that better results were obtained. The administrators of the Chicago Department of Health give 2000 units in all cases of suspected diphtheria, and employ 1000 units as an immunizing 
dose. During the months of November and December, I 898 , this department treated 219 cases of bacteriologically proved diphtheria-all charity cases - with a deathrate of 4.I per cent. Some years ago, when antitoxin was not used, the death-rate from diphtheria treated by this department was about 35 per cent.

Antistreptococcic serum gives promise of being second only to the diphtheria antitoxin in point of therapeutic value. It has been most successful in erysipelas and puerperal septicemia. Cases of scarlet fever are reported in which it has been useful in shortening the duration of the disease and in preventing unfortunate complications and sequelæ, such as otitis media and other suppurative processes due to streptococci.

A mixture of the toxin of the streptococcus of erysipelas and the products of a harmless germ, the Bacillus prodigiosus, is used by Coley and others as an injection in malignant tumors that are past the stage of operation or are so situated that an operation is impossible.

Tetanus antitoxin is valuable as a prophylactic treatment, and if used in large doses in the early stages it is the best known method for the treatment of tetanus. The antitoxin may be introduced subcutaneously, intravenously, and intraduraliy. Small doses are practically valueless, but large and repeated doses are very successful.

Antityphoid vaccine has now practically prevented typhoid fever, but it is useless as a therapeutic agent.

Antitoxin in cerebrospinal meningitis is given intradurally and is moderately successful, especially if given early. 
Flexner's serum in infantile palsy is at present being tried. It is apparently very successful if given early.

The antitubercle serum has not shown itself to have more value than a great number of other remedies vaunted as specifics in tuberculosis.

Method of Injecting Antitoxin.-The serums and toxins are given hypodermically, the injection being made into the back, thigh, side of the breast, or over the chest. Perfect antisepsis for the operation is absolutely necessary. The puncture wound is closed with a collodion dressing. It is not necessary to use massage for the purpose of causing more rapid absorption of the injected serum-the swelling generally disappears in a short time of itself. Sometimes the site of the injection becomes very painful. In certain cases pains in the joints and various skin eruptions (erythema, hives) develop after the injection. They are not of great moment, but the physician's attention should be called to them.

The reaction following an injection of Coley's mixture is sometimes severe, and may correspond to the symptoms beginning an attack of erysipelas-chill, local redness, and high temperature.

Within the last few years certain serum reactions have developed. By the use of these methods the presence or the absence of a disease is detected. For example, syphilis, the presence or absence of it may be determined by a complicated serologic reaction called the Wassermann test. To obtain blood for this test the finger is stuck with a blood sticker and the blood pressed into a test tube until it is three-quarters full. A test for gonorrhea is used, but it is not entirely satisfactory. 
For detecting the presence or absence of tuberculosis, we have three tests: (I) Tuberculin test, which is made by scarifying the skin and rubbing in tuberculin. This gives a cutaneous reaction in forty-eight hours if the disease is present. (2) Tuberculin is injected subcutaneously, and the temperature is taken every hour for forty-eight hours. If tuberculosis is present there will be a marked rise in the temperature. (3) Von Pirquet test: This method consists in dropping tuberculin into the conjunctiva. If the test is positive the conjunctiva becomes reddened. The Widal test consists in mixing a small amount of the blood-serum of the patient with a pure culture of typhoid bacilli. If typhoid fever exists there will be clumping or agglutination of the bacilli. 


\section{CHAPTER IV}

\section{ANTISEPTICS, DISINFECTANTS, AND DEODORANTS}

ARTICLEs and wounds which are entirely free from bacteria and their spores are termed aseptic or sterile.

An antiseptic is a substance which kills or retards the growth of bacteria.

A disinfectant or germicide is a chemical or physical agent which destroys the vitality of bacteria.

Excessive heat, dry or moist, is a disinfectant because it kills bacteria; while cold retards growth, but does not kill bacteria.

A deodorant is a substance which destroys offensive odors.

Occasionally a substance possesses all three qualities, as carbolic acid. In strong solution (5 per cent.) it is a germicide; in I or 2 per cent. it is an antiseptic. Its natural odor makes it a good deodorant.

The power of a chemical agent to destroy bacteria depends on:

(I) The kind of bacteria; some being easily killed by an agent which is harmless to others. Spore-forming bacteria are very resistant, and the spores are much more resistant than the bacteria.

(2) The number of bacteria present.

(3) The temperature of the disinfecting agent. The higher the temperature, the more powerful the agent. 
(4) The strength of the solution, no matter of what substance. The stronger the solution, the more powerful the agent.

(5) The nature and character and quality of the associated material. If they are contained in a large amount of organic material, such as sputum or fecal matter, the chemical agent may combine with these and may thus be converted into an ineffective material before it has had an opportunity to act on the bacteria.

The agents capable of destroying bacteria are chemicals, physical and mechanical. The chemical agents are numberless; but there are many which cannot be employed because they are too weak or act too slow, are too poisonous, are too destructive to objects with which they come in contact, or are too expensive for general use; for example, corrosive sublimate or mercuric bichlorid cannot be used for sterilizing instruments because it corrodes and blackens them. Potassium permanganate stains everything it comes in contact with.

Some forms of physical agents cannot be used in certain instances; for example, boiling water, steam, or hot air could not be used to sterilize a surgeon's hands.

For practical purposes the term "disinfection" is used for the action of chemical agents, and the term "sterilization" for physical agents such as heat.

Among all agents, both chemical and physical, heat is entitled to the first place, and fire, though seldom practical, is superior to all others. Fire should always be used to destroy old clothing, books, and playthings that have been in contact with patients suffering from infectious diseases. 
Heat is used in the form of hot air, steam, and boiling water.

Boiling water kills most germs on contact, and the more resistant types are killed by it in one or two minutes; for example, spores of anthrax.

Steam is the next most powerful agent. It is more penetrating than hot air, but the air must be saturated with it for it to exert its full influence. Steam is used in four forms:

Simple Steam.-Quiescent.

Live Steam.-Circulating.

High-tension Steam.--Under pressure.

Superheated Steam.-That which has been secondarily heated to $100^{\circ} \mathrm{C}$.

Live steam destroys anthrax spores in from five to fifteen minutes.

Disinfection by steam is applicable to clothing, linen, blankets, towels, surgical dressings, instruments, curtains, carpets, brushes, mattresses, pillows (the two latter should be ripped open), and a number of delicate fabrics. It is not applicable to linen soiled by feces, blood, or pus, since the stains would become fixed by the process (soak first in plain cold water), nor to rubber articles. Under certain conditions many articles are exposed to the action of steam for one hour on three successive days, being kept during the intervals at a temperature of $70^{\circ}$ to $80^{\circ} \mathrm{C}$. to favor the development of bacteria. This is called "intermittent" or "fractional" sterilization, the object of which is to kill all bacteria that may have developed from spores that escaped the first steaming. The last sterilization is for the purpose of making sure.

Hot air is inferior to both steam and hot water. 
Steam at a temperature of $100^{\circ} \mathrm{C}$. is more effectual than hot air at a much higher temperature. According to investigations, exposure to a temperature of $150^{\circ} \mathrm{C}$. $\left(302^{\circ} \mathrm{F}\right.$.) for one and a half hours in a hot-air sterilizer will kill all known bacteria and their spores.

The most prominent chemical germicides in use now are:

I. Bichlorid of mercury.

2. Tincture of iodin.

3. Carbolic acid.

4. Potassium permanganate.

5. Alcohol.

6. Creolin.

7. Lysol.

8. Harrington's solution.

9. Argyrol.

Io. Hydrogen dioxid.

II. Chlorid of lime.

(I) Corrosive sublimate or bichlorid of mercury has, like carbolic acid, the advantage of being both efficacious and cheap. It has the disadvantages that it is decomposed by alkalies, that it is precipitated by albumin, and that it corrodes metals. It is used in strengths of from I : 10,000 to I :500. The solution should be made as it is needed, because in old solutions most of the soluble corrosive sublimate has been converted into insoluble calomel, and the solution is not germicidal. By using the compressed tablets now on the market fresh solutions are readily made. A tablet usually contains the requisite amount of corrosive sublimate to make when added to I pint of water a I : 1000 solution, and by increasing or diminishing the 
amount of water the strength of the solution may be altered at pleasure. The tablets are very convenient, and almost compel accuracy in the preparation. Corrosive sublimate is of less value for the disinfection of the excreta than carbolic acid, as it hardens the albuminous material which covers the outside of all fecal masses, and thus protects the inside from the desired action. Tartaric acid, chlorid of sodium, or chlorid of ammonium is often added to prevent this. Compressed tablets, each containing tartaric acid or ammonium chlorid and $7 \frac{1}{4}$ grains of corrosive sublimate, or equal parts of chlorid of sodium and corrosive sublimate, are in common use. The convenient form in which this drug is put up and the readiness with which it can be used in surgical and medical work have made its adoption universal. Its poisonous character must be kept constantly in mind. The first symptoms of poisoning in consequence of the absorption of the bichlorid are profuse salivation, fetid breath, a metallic taste in the mouth, sore teeth, spongy gums, and swollen tongue. Should any of these symptoms appear they should at once be reported to the surgeon. As the solution has no odor, it is occasionally swallowed in mistake. Should this occur, symptoms of a violent gastro-enteritis appear-vomiting, burning pain, bloody stools; the kidneys are also affected and an acute Bright's disease develops. The immediate treatment of this acute poisoning consists in the giving of white of egg, flour or milk and lime-water, and washing out of the stomach.

(2) Tincture of iodin is made by dissolving iodin crystals in 95 per cent. alcohol, the amount of the latter used indicating the strength of the solution: 7 per cent. tinc- 
ture is the standard and is the strength most commonly used; I, 3, and 5 per cent. solutions are also used for various conditions.

This antiseptic is the most common in use for preparing the field of operation, disinfecting wounds, and as a dressing solution in weaker strength. Nearly every surgeon will agree that every lacerated, incised, punctured, or stab wound occurring accidentally should be swabbed out with tincture of iodin. So, should you be present and called on to treat any such accident in the absence of a physician, use tincture of iodin before applying a dressing.

(3) Carbolic acid is a coal-tar product derived by distillation. When pure it is a solid white or faintly rosecolored, crystalline body, soluble in water, alcohol, or glycerin. On exposure to air it absorbs 5 per cent. of moisture.

In making a solution of carbolic acid it is dissolved in hot water and shaken thoroughly. In solution it is used more to disinfect instruments and floors of operating rooms than for dressings or treatment, except in the dressings of furuncles immediately after incision; pure carbolic acid is used here to disinfect the tissues after incision. It has the advantage over corrosive sublimate in that it does not discolor instruments or clothing. Dilute carbolic acid is a reliable disinfectant for instruments. If an instrument that is indispensable happens to fall to the floor during an operation, it may be laid for a moment in pure carbolic acid, then rinsed with sterile water, and it is ready for use. Longcontinued submersion in the acid will, however, deprive knives and scissors of their temper and edge. 
It is not used to any great extent in general dressings because it irritates and causes a numbness of the skin. Symptoms of poisoning have been produced by the absorption of the drug from surgical dressings and from the use of carbolic solutions for irrigation. The first evidences of poisoning are a very dark greenish or a blackish coloration of the urine, headache, giddiness, ringing or singing in the ears, and lassitude. The odor of carbolic acid is, to a certain extent, a protective against accident; yet fatalities occasionally occur. The antidotes of carbolic acid are alcohol, milk, and lime-water, or flour and water. The strength of the solutions used varies from $\mathbf{I}: 80$ to $\mathrm{I}: 20$. The acid is bought usually in the liquid form, having a strength of 95 per cent. To make a solution I : 20 (5 per cent.), I $: 40$ ( $2 \frac{1}{2}$ per cent.), I $: 50$ ( 2 per cent.), I $: 80$ ( I $\frac{1}{4}$ per cent.), I ounce of the 95 per cent. solution is added to $20,40,50$, or 80 ounces of water. When obtained in the solid form, it may readily be liquefied by placing the bottle in a vessel of hot water.

Other coal-tar derivatives which are akin to carbolic acid, but less powerful as disinfectants and less poisonous are: creolin, lysol, sozal, and saprol, the two latter being very rarely used.

(4) Potassium Permanganate.-This drug is an antiseptic, disinfectant, and deodorant. It depends for its action on its oxidizing properties. In contact with organic substances it parts with its oxygen very readily and becomes inert. Its chief disadvantage is that it stains everything a brownish-black color. It is used usually in strengths of I : IOO to I : IO. It was formerly used quite extensively to sterilize the hands. The stain it leaves on 
the hands may be removed by oxalic acid solution. It is used in treating wounds, especially those which have an offensive odor, acting as a deodorant as well as an antiseptic. It is also used to disinfect bowel movements and to flush water-closets. It shows by its changing from a reddish purple to brown whether it is acting or whether it is exhausted.

(5) Alcohol.-Absolute alcohol is an antiseptic and disinfectant used for cleansing and sterilizing the skin, for preparation of sutures and ligatures, and for sterilizing instruments. Alcohol is used by some surgeons in the preparation of the patient for operation. and it makes an excellent dressing medium for fresh wounds which have been sutured.

(6) Creolin and (7) Lysol are both coal-tar derivatives. They are used chiefly by obstetricians and gynecologists. When mixed with water they make a soapy, oily solution very suitable for vaginal douches because they do not irritate the canal. Lysol ordinarily is used in from I to 3 per cent. solutions, but when repeated vaginal douches are ordered 0.50 per cent. ( $\frac{1}{2}$ per cent.) solution is the maximum that the average patient will tolerate. Creolin is less irritant and probably less germicidal.

(8) Harrington's Solution. -This solution, designed by Harrington, of Boston, is becoming more commonly used. It is an excellent disinfectant for the field of operation and for hand sterilization. Its capacity for destroying bacteria is twenty times greater than any known germicide and it is no more irritating than any other drug of this class. Hands washed in this solution for one minute become sterile, so that no bacterial growths can be obtained from the scrapings made from such hands. 
The following is the formula:

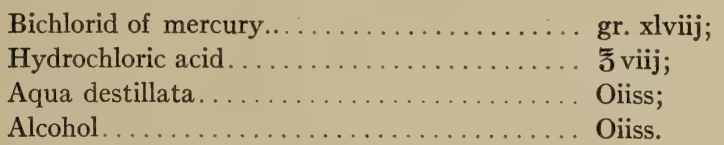

(9) Argyrol is a definite chemical compound of silver containing 30 per cent. of that metal. The various combinations of silver possess more or less antiseptic qualities and are irritating to the tissues to a greater or less extent. But the preparation is very efficient as an antiseptic and practically non-irritating. It is not precipitated by albumin or sodium chlorid. It is used chiefly in infections of the mucous membranes in solutions varying from 2 to 50 per cent. Solutions should be made fresh, as it deteriorates rapidly.

The stains are best removed by washing the materials in a solution of bichlorid of mercury.

(10) Hydrogen dioxid is useless when employed as an antiseptic or disinfectant because it has no such properties. The sphere of its usefulness lies in the fact that it eliminates its oxygen freely when in contact with organic matter. It is therefore used to remove blood-clots, necrosed tissue, and other débris in wounds and ulcers. It possesses some hemostatic qualities and may be used in minor venous oozing.

(I I) Chlorid of lime, when mixed with carbonate of soda and moistened with water to form a paste, eliminates chlorin gas, which possesses antiseptic qualities. Some surgeons use this combination for hand sterilizing.

Other less prominent antiseptics are:

(I) Formaldehyd.-It is a gas formed from the partial oxidation of wood alcohol. It is more commonly 
used as a disinfectant than for treatment purposes. It is very commonly used by health officers in gas form to fumigate rooms after infectious diseases. In solution,

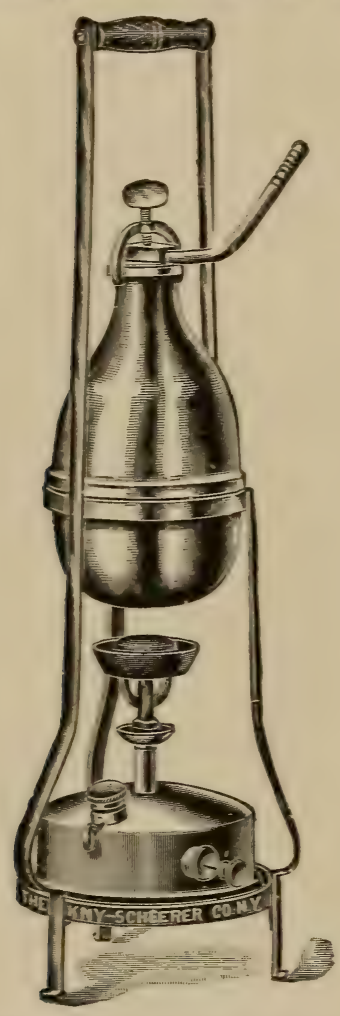

Fig. 5-Formaldehyd generator.

which is made by dissolving the gas in water, it is used for disinfecting floors and walls, especially of operating rooms. Its disadvantages are: after using the solution on the skin the latter begins to smart and burn. Its vapors are irritating to the lungs, eyes, and nostrils. It is a very powerful germicide, being superior to bichlorid of mercury.

(2) Iodoform, a yellow powder with a penetrating odor, derives its antiseptic properties from the fact that it eliminatesiodin. On clean wounds which exude serum it does good by absorbing the serum, thus removing good culture-media for bacterial growth. It prevents decomposition, and inhibits the growth of but does not destroy pus-producing bacteria. By absorption from a large wound surface it sometimes produces poisoning. as evidenced by headache. loss of appetite, elevation of temperature and pulse. restlessness, and insomnia. In severe cases a fine macular eruption appears on the face 
and limbs. Some patients are very susceptible to it. It is used in the form of iodoform gauze for dressings, iodoform ointment, as a dusting-powder, and dissolved in ether or sterile oil for injecting sinuses and tuberculous abscesses.

(3) Aristol (thymol-iodid) is a dusting-powder with action similar to iodoform, but without the disagreeable odor.

(4) Boric Acid.-As a powder and in solution it is a mild antiseptic very commonly used. Its most important seat of usefulness is in eye work and for irrigations of the bladder.

It is a non-poisonous, white, odorless powder, and for this reason is preferred to other dusting-powders.

To get the best effect it must be in a saturated solution.

(5) Oxalic acid is a powerful germicide, but is not commonly used now except to remove the stains left by potassium permanganate. At a temperature of $40^{\circ} \mathrm{C}$. it is a very powerful germicide. It irritates the skin, but this can in a measure be avoided by immersing the hands and forearms in cold water or lime-water.

Abuses of Antiseptics and Germicides.-This class of drugs has been more abused than any other in the anteand postoperative treatment and management of surgical cases. They are useful and necessary in their place, but their place is limited. The cleaner a surgeon or nurse is surgically, the less they will use antiseptics. In infected wounds and other cavities the greater the infection, the milder the solution and the greater the quantity should be used; cleanse the wound by removing all necrotic and foreign material before applying your antiseptic.

Contrarily, strong solutions should be used for the surgeon's hands and for the field of operation. 


\section{ANTISEPTIC SOLUTIONS}

Approxtmate Ways of Making Antiseptic Solutions by ApotheCARIES' MEASURE

To make-

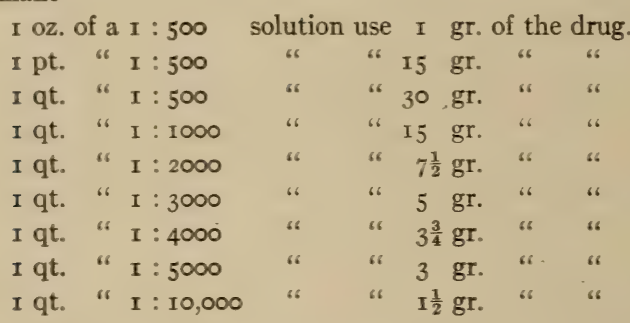

\section{Percentage Solutions (Approximately)}

To make-

I dram of a I per cent. solution use $\frac{1}{2}$ gr. + of the drug.

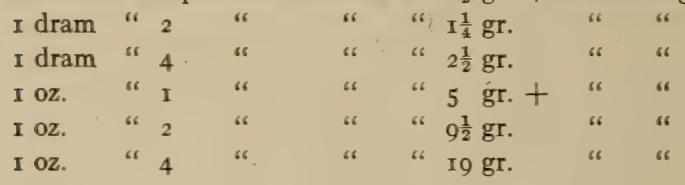

Metric System

\begin{tabular}{|c|c|c|c|}
\hline Solids. & $\begin{array}{l}\text { Approximate } \\
\text { equivalent. }\end{array}$ & Liquids & $\begin{array}{l}\text { Approximate } \\
\text { equivalent. }\end{array}$ \\
\hline I grain & 0.065 gram. & I minim. & 0.06 c.c. \\
\hline ounce & 30.000 grams. & I ounce. . & $30 . \infty 0$ c.c. \\
\hline pound & 500.000 grams. & I pint..... & $\begin{array}{l}500.00 \text { c.c. } \\
\text { I000.00 c.c. or I liter. }\end{array}$ \\
\hline
\end{tabular}

To make-

\section{Examples}

I000 c.c. (I liter) of a I : 500 solution use 2 grams of the drug.

I000 c.c. " " " I : 1000 " " " I gram

rooo c.c. " "I : 2000 " " $\frac{1}{2}$ gram

Labarraque's solution is a solution of chlorinated soda, and is made from chlorinated lime and sodium carbonate. It is used as an antiseptic in solutions of I : IO, and for cleansing purposes. 


\section{PART II \\ SURGICAL TECHNIC}

\section{CHAPTER V}

\section{BANDAGING AND DRESSINGS}

\section{BANDAGING}

A NURSE will be frequently judged by her ability to apply a bandage properly.

Materials.-They may be of unbleached muslin, gauze, black or white, flannel; crinoline, or gauze for plaster-ofParis; or rubber.

Muslin purchased in large rolls is cut in lengths of from 6 to 8 yards. The end of the muslin is cut in the desired widths for bandages and torn in strips.

Rolling by Hand.-One end of the bandage is folded upon itself several times and rolled between the thumb and first finger of the left hand until it becomes firm enough to hold between the fingers. The folded portion is held between the thumb and index finger of the left hand and rotated by the thumb and second finger of the right hand.

The bandage machine consists of an upright and octagonal shaft mounted upon a metallic base which may be screwed to a table. The shaft is turned by hand 
or foot, depending upon the type of machine used. The width of the space on the shaft is regulated by a movable upright. The bandage is fed to the roller by the left hand. It should be rolled tense, and when the bandage is finished the crank is reversed automatically, releasing the bandage from the shaft, allowing it to be pulled out (Fig. 6).

It is now considered cheaper to buy bandages already rolled in yard lengths and cut as needed (Fig. 7).

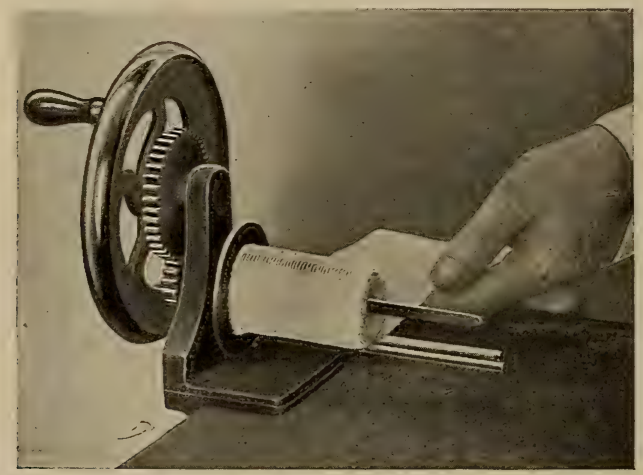

Fig. 6.-Hand roller-bandage machine. (Fowler's Surgery.)

Application of Bandage.-Bandages are used to hold splints and dressings in place, to give support as in fractures. They should be applied moderately tight. If support is the motive, a number of turns will secure this much better than a few tight ones. It is much better to apply a bandage too loosely than too tightly.

In applying wet dressings, always remember to allow for shrinkage. A bandage is started by placing the outer surface of the initial extremity upon the starting-point and holding it with index-finger of the left hand. With 
the roller held in the right hand, two turns are made in the direction which the bandage is to take.

To overlap is to make a second turn cover a certain portion of the preceding turn. This is the procedure in all spiral bandages.

To recur is to catch a turn at some point and turn it in such a way so that it either exactly retraces its course or turns off slightly in another direction.

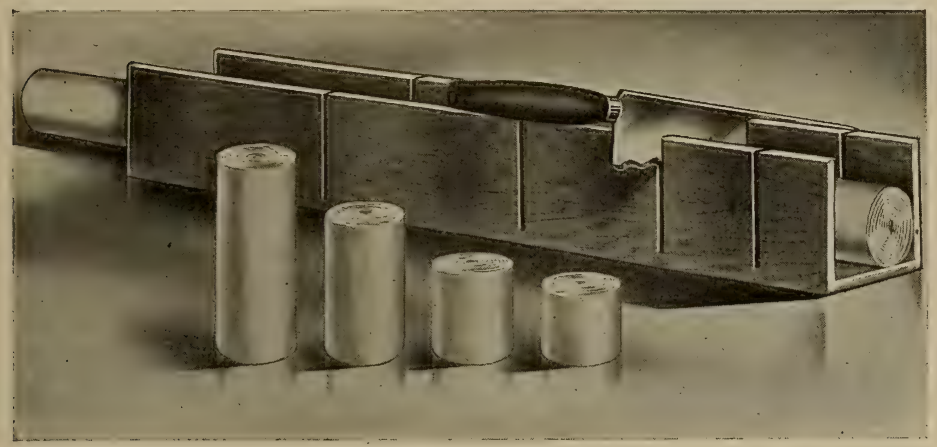

Fig. 7.-Mitre box and Christy knife for cutting bandages. (Fowler's Operating Room and the Patient.)

To Reverse.-The bandage is turned laterally upon itself, so that the part that was external is now internal. This is performed by holding the bandage in place with the thumb of the left hand, slightly relaxing the roller while pronating the right hand (Fig. 8). The thumb is now removed and the bandage tightened and continued around the part until the second reverse is reached, where the same procedure takes place. It is very necessary to have the turns in alignment. This may be made in the opposite direction, i. e., descending or ascending. The 
object of reversing a bandage is to adapt it to the change in diameter of the part.

To Secure.-The end of the bandage is split into two tails. These are passed in opposite directions around the part and tied in place. The end of the bandage may also be pinned, but great care should be used so that the pins do not penetrate the bandage and stick into the part.

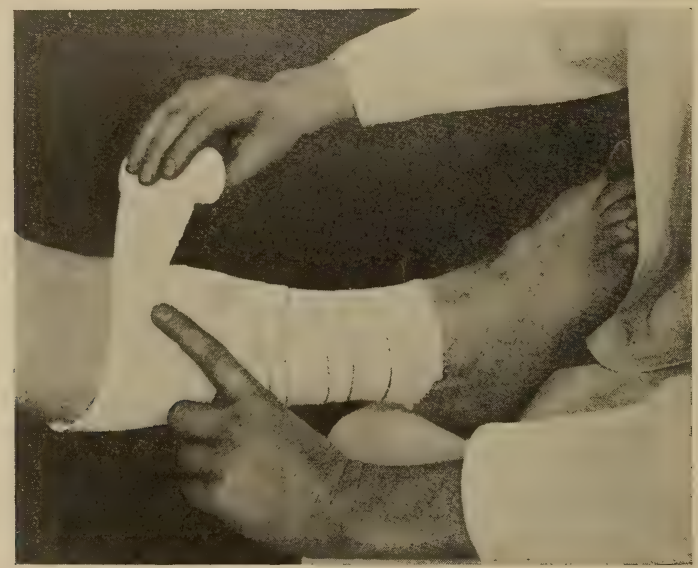

Fig. 8. -Making the reverse. (Fowler's Surgery.)

Removal.-Each turn should be taken off reversely from the way it was put on.

There are three general types of bandage, of which all others are modifications: circular, spiral reversed, and figure-of- 8 .

Barton's Bandage ( 2 inches by 6 yards).-The initial end of the roller is placed on the head under the mastoid process and the bandage is carried upward and in front of the parietal eminence, across the vertex of the skull, 
downward in front of the ear, under the chin, upward in front of the opposite ear, over the top of the head, where it crosses the first turn and back to the starting-point. The bandage is then continued forward below the right ear, in front of the chin, and back to the starting-point. These turns should be continued until the end of the bandage is reached.

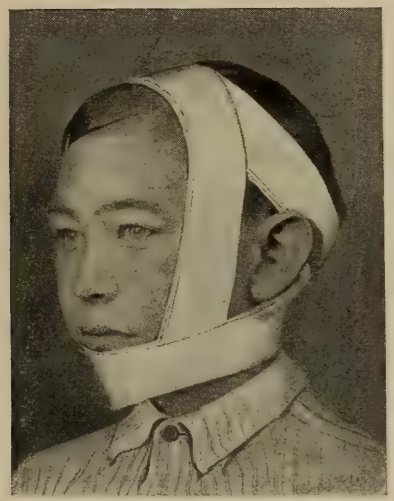

Fig. 9.-Barton's bandage. (Fowler's Surgery.)

Secure with adhesive plaster or pins introduced where the bandage crosses. In applying this bandage great care should be taken to see that each turn overlaps the preceding turn and that the bandage crosses in the median line of the skull (Fig. 9).

Uses.-To retain dressings on face, fractures and dislocations of lower jaw.

Gibson's Bandage ( 2 inches by 5 yards). -This bandage consists of three turns from the occiput to the forehead and back again. On the final turn the bandage is reversed as it reaches the front of the ear. It is then 
carried downward under the chin, thence up on the opposite side, and back to the reversing point. This turn is repeated three times and the occipitofrontalis portion of the bandage is repeated three times.

It is secured by pins placed at the reversing and intersecting points (Fig. IO).

Uses.-Same as Barton's bandage.

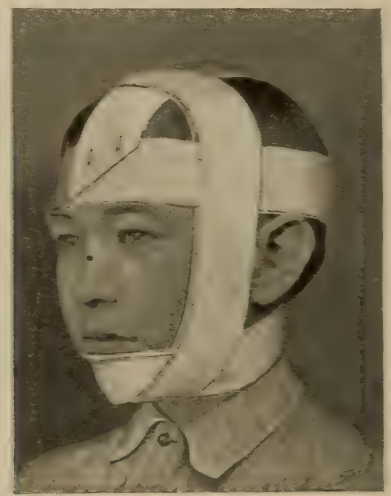

Fig. ro.-Gibson's bandage. (Fowler's Surgery.)

Recurrent Bandage ( 2 inches by + yards). - Fix the roller by a circular turn from the occiput to the forehead and back again. Continue for two turns. Upon reaching the occiput at the end of the second turn the bandage is reversed, carried forward, across the top of the head to the frontal region, where it is held in place by an assistant and reversed backward and forward, first on one side and then on the other, overlapping the previous turn by $\frac{3}{4}$ inch until the entire head is covered. The bandage is then again reversed and the free ends held in place by circular turns around the occipitofrontal 
region and secured by pins at the reversing points (Fig. I I).

Uses.-To retain dressings to the head and scalp and to make compression.

Double Head Recurrent ( 2 inches by 4 yards).-Two bandages. The ends of the bandages are sewed together. Place the portion between the two rollers on the forehead and carry the rollers backward until they meet opposite

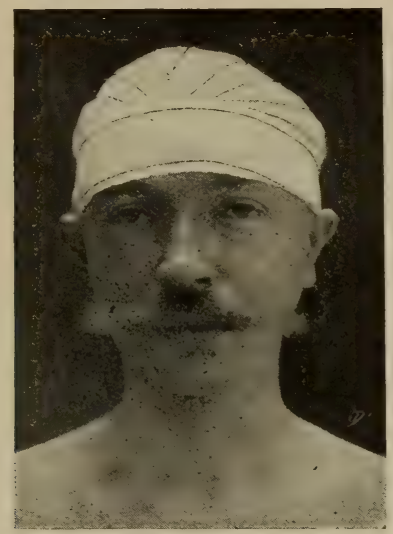

Fig. II.-Recurrent bandage of the head. (Fowler's Surgery.)

the occipital protuberance. At this point the bandages are reversed, one going circularly around the head, the other backward and forward over the scalp, each turn being caught by the circular bandage, and so on until the head is entirely covered. The bandages are then continued as circular turns until the bandage is finished.

Uses.-To retain dressings to the scalp.

Occipitofrontal Bandage ( 2 inches by 4 yards). - The end of the bandage is placed upon the forehead. To fix 
it, a circular turn is made around the forehead and the occiput. A circular turn is then made so that it reaches down as far as possible posteriorly and as far up on the forehead as possible. The next turn is made so that the posterior portion is above the occiput and the anterior portion above the eyebrow. These turns may be repeated as many times as desired (Fig. 12).

Uses.-To secure dressings on anterior and posterior portions of scalp.

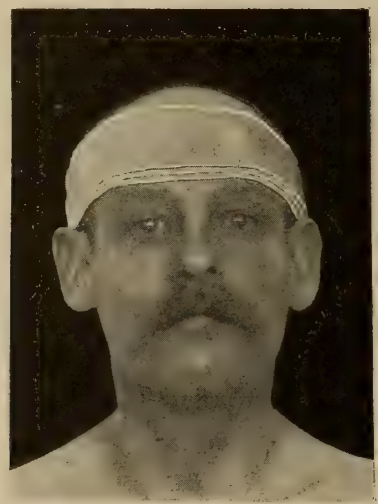

Fig. I2.-Occipitofrontal bandage.

Liebreich's Eye Bandage.- Strip of flannel, white or black, $2 \frac{1}{2}$ inches by 8 to Io inches, fitted with tapes at the extremities. Apply to one eye obliquely, reverse the tapes by crossing at the occiput with a circular turn, and tying. Apply to both eyes transversely with circular turn of the tapes and tie (Fig. I3).

Crossed Bandage of Eye ( 2 inches by 6 yards).-The bandage is fixed by a circular turn from the occiput to the forehead. The bandage is then carried from the 
occiput below the right ear, up over the outer portion of the cheek to the base of the nose, and continued to the occiput, passing below the left parietal eminence. These

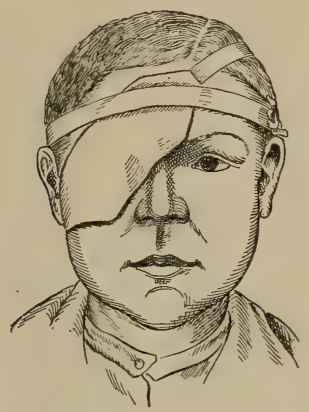

Fig. 13.-Modified Liebreich's eye bandage.

turns are alternated, the one passing below the ear overlaps the former turns two-thirds. Continue until the de-

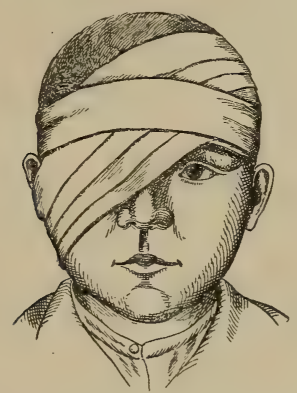

Fig. 14.-Figure-of- 8 of one eye.

sired result is obtained. Flannel bandage is more comfortable (Fig. I4).

Uses.-To retain dressings to the eye. 
Double Crossed Bandage of Both Eyes ( 2 inches by 6 yards).-The bandage is fixed by two occipitofrontal circular turns. The bandage is then carried forward below the ear, crossing the cheek to the root of the nose, and back to the occiput. A circular occipitofrontal turn is then made, and the bandage carried below the right parietal eminence to the root of the nose; downward across the cheek under the left ear, to the occiput. These turns are repeated as described above until the desired result is obtained (Fig. I5).

Use.-To hold dressings on both eyes.

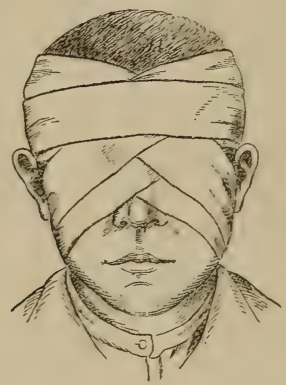

Fig. 15.-Figure-of-8 of both eyes.

Figure-of- 8 of Head and Neck ( 2 inches by 3 yards).Fix the bandage by two circular turns around the neck, starting just below the occiput. Then carry the bandage upward above the right ear over the forehead above the left ear and back to the starting-point. Alternate these turns until the bandage is finished.

Uses.-To retain dressings to the throat and back of the neck.

Suspensory and Compressor Bandages of the Breast ( $2 \frac{1}{2}$ inches by 7 yards).-Place the end of the bandage 
upon scapula of the injured side. Secure by two oblique turns carried over the opposite shoulder and conducted downward under the breast and carried to the axilla of the same side. Then carry the end of the bandage transversely around the chest, covering in the lower portion of the injured or affected breast. Repeat these turns, the oblique turn from the axilla over the shoulder alternating with the transverse turns around the chest until the

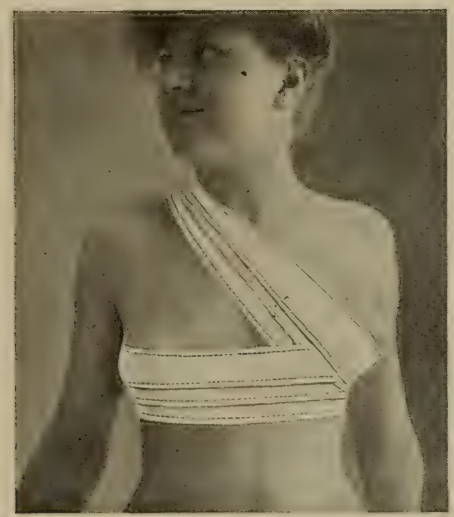

Fig. I6. - Bandage for the breast. (Fowler's Surgery.)

breast is covered in. Each series of turns in ascending should obscure two-thirds of the foregoing turn (Fig. I6).

Use.-This bandage is used to hold dressings to the breast and make compression on the breast at the same time.

Double Breast Bandage.-The roller is started from the scapula of the affected side, and carried over the shoulder of the opposite side to the front of the chest, thence under the affected breast and obliquely along the 
lateral and back of chest to its starting-point. This turn is repeated in order to secure the end of the bandage. The second turn is a circular one around the chest just below the breasts. The third turn is started at the point of the initial extremity, and the bandage is carried around the chest wall to the under surface of the second breast. From here it is carried over the front of the chest, thence over the opposite shoulder, and back over the chest to the starting-point. First, second, and third turns respec-

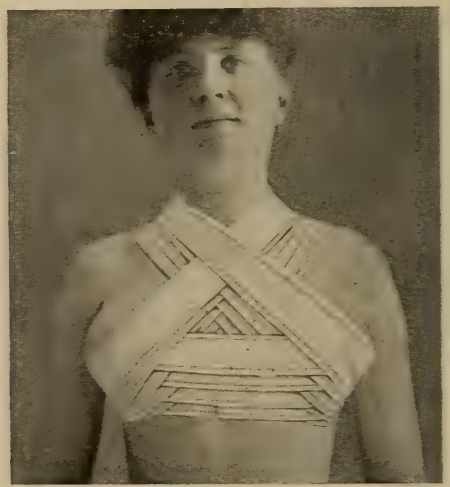

Fig. 17.-Double breast bandage. (Forler's Surgery.)

tively are now repeated, each turn covering in two-thirds of the foregoing turn, and in this way both breasts are securely and neatly covered (Fig. 17).

Use.-Support and pressure of breast.

Figure-of- 8 of Back and Chest ( $2 \frac{1}{2}$ inches by 7 yards).Place the initial end of the bandage on the back between the scapulæ. Carry the bandage upward over the right shoulder, down under the axilla, and back to the startingpoint. Continue over the left shoulder to the axilla and 
back to the starting-point. Continue these turns until the bandage is finished (Figs. I8, 19).

Uses.-To retain dressings on upper part of back and to pull shoulders back.

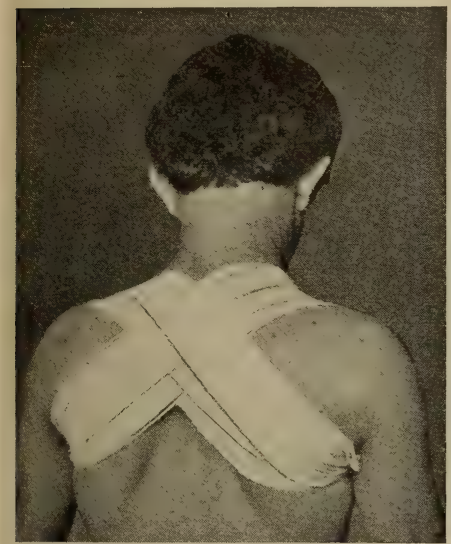

Fig. 18.-Posterior figure-of-8 bandage of the chest. (Fowler's Surgery.)

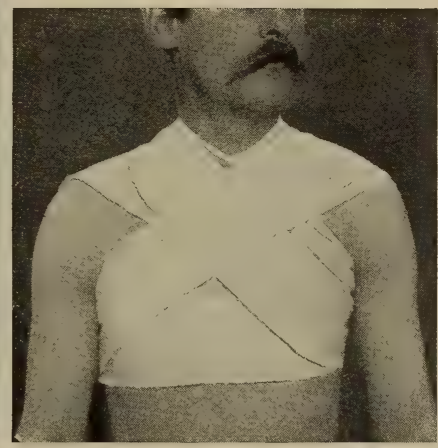

Fig. I9.-Anterior figure-of-8 bandage of the chest. (Fowler's Surgery.)

- Spica Bandage of the Shoulder ( $2 \frac{1}{2}$ inches by 7 yards). -Fix the bandage by circular turns at the insertion of the deltoid. Then carry the bandage across the arm, over the anterior portion of the chest to the axilla, and across the back to the starting-point, then under the arm and repeat as described above, each turn overlapping the previous turn two-thirds. Continue thus until the shoulder is covered. This bandage may be put on in a similar way for the left shoulder, providing one uses the left hand (Fig. 20).

Use.-To retain dressings on shoulder. 


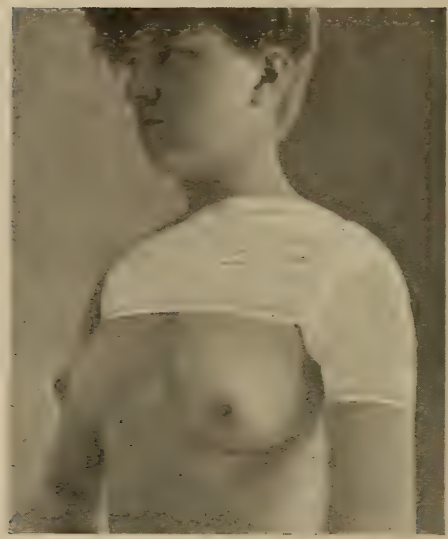

Fig. 20.-Ascending spica of the shoulder. (Forler's Surgery.)

Velpeau's Bandage.-Two to three rollers, $2 \frac{1}{2}$ inches by 7 yards each. The hand of the injured side is placed

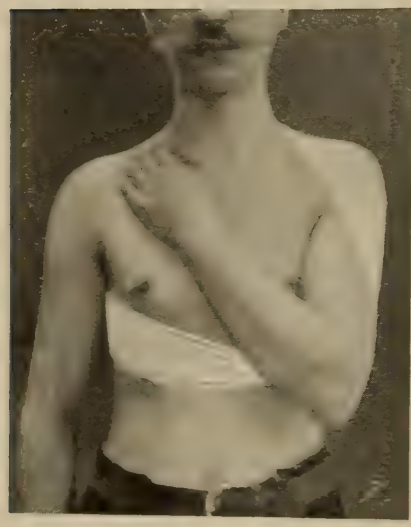

Fig. 21.-Velpeau's bandagefirst turn. (Fowler's Surgery.)

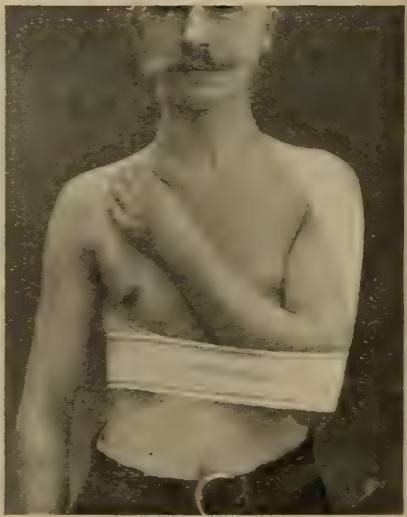

Fig. 22.-Telpeau's bandagesecond turn. (Fowler's Surgery.)

so that the tips of the fingers touch the sound clavicle. The initial end of the bandage is placed over the sound 
scapula and the bandage carried over the point of the affected shoulder, then backward over the outer surface of the arm, behind the elbow, across the chest to the sound axilla, and under it to the starting-point. Repeat this turn, thence making a circular turn around the chest over the top of the injured elbow and back to the starting-point. The first turn is repeated, overlapping three-quarters of the first turn toward the middle line of the body, then a circular turn, then a shoulder turn until the tip of the

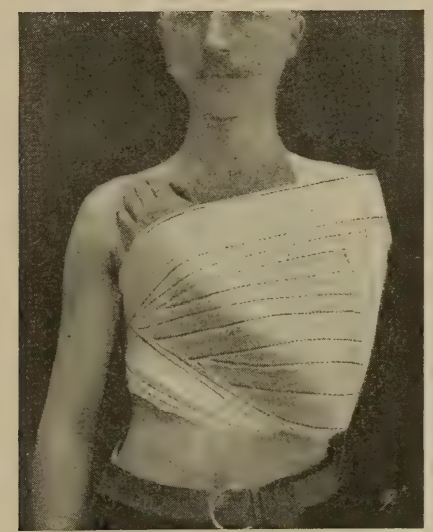

Fig. 23.-Velpeau's bandage completed. (Fowler's Surgery.)

elbow is reached by the shoulder turns, after which only circular turns are made until the arm is encased in the bandage. In applying this bandage, as in any other bandage where skin surfaces come together, a layer of lint or a towel should be placed between the surfaces to prevent excoriation (Figs. 21, 22, 23).

Use.-Fracture of clavicle.

Descending Spica of Shoulder ( $2 \frac{1}{2}$ inches by 7 yards).The initial end of the roller is placed over the sound scap- 
ula and the bandage carried upward over the injured shoulder, downward to the anterior fold, through the axilla, then upward and forward over the shoulder, across the chest, under the opposite axilla to the starting-point, each turn overlapping the preceding turn two-thirds. Repeat these turns until the shoulder is covered.

Use.-To retain dressings on shoulder.

Desault Bandage ( 2 inches by 7 yards). - Three to five rollers. Oval pad for axilla.

First Roller.-The arm is elevated with the oval pad placed in the axilla. The free end of the bandage is

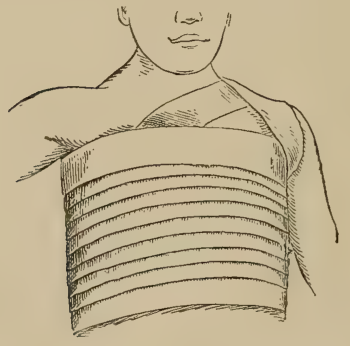

Fig. 24.-Desault's bandage, first roller.

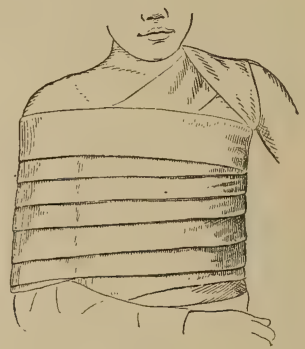

Fig. 25.-Desault's bandage, second roller.

placed over the pad and held in place by two or three circular turns around the chest. Each turn should overlap the preceding one two-thirds of its width. It is then brought across the front of the chest, over shoulder, under the axilla, and back to the starting-point.

Second Roller.-The arm is brought down to the side of the body with the elbow flexed at a right angle and held in place by circular turns around the chest and arm until the arm is covered, each turn overlapping the pre- 
ceding turn two-thirds. This may be started from above downward or the reverse.

Third Roller.-The free end of the bandage is placed in the sound axilla and the bandage carried obliquely across the front of the chest, over the injured shoulder, down the back of the arm to the elbow, thence upward over the forearm to the starting-point. Then upward across the back of the chest, over the injured shoulder, down the front of the arm, around the elbow obliquely, upward across the back to the starting-point. These turns should

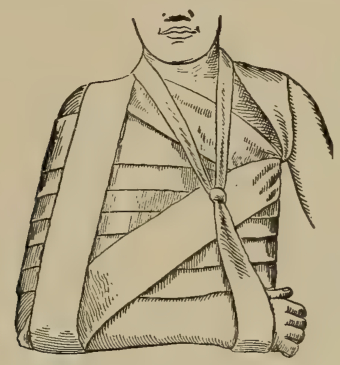

Fig. 26.-Desault's bandage, third roller.

.be alternated, each turn overlapping the preceding turn until three sets have been completed (Figs. 24, 25, 26).

Uses.-Fracture of clavicle and dislocation of shoulder.

Jones' Position for Fracture of the Elbow.-This consists in flexing the forearm upon the arm and by holding it in place by a strip of adhesive plaster wound several times around the arm and forearm, and the arm supported by tying the wrist to the neck by means of a bandage.

Figure-of- 8 Bandage of the Elbow ( 2 inches by 4 yards). - The bandage should be applied with the elbow flexed. The end of the bandage is applied a few inches below the 
elbow-joint. A few circular turns fixes the bandage. The end of the bandage is then carried across the flexure of the joint and a circular turn is made a few inches above the joint. The bandage is then carried obliquely to the starting-point and a circular turn is here made. Alternate the circular turns below the joint with those above the joint, each time obliquely crossing the flexure of the elbow. The turns gradually approach the tip of the olecranon

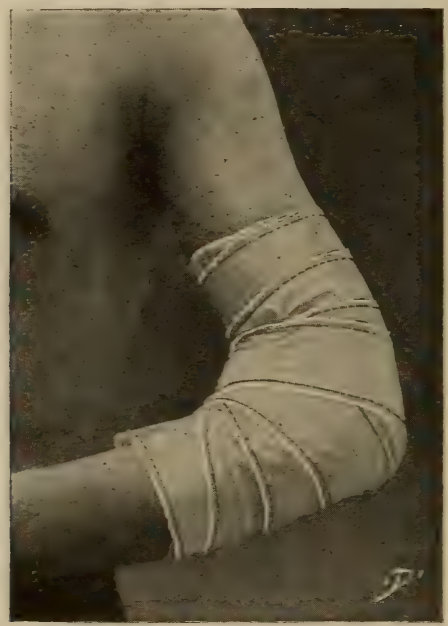

Fig. 27.-Figure-of-8 bandage of the elbow. (Fowler's Surgery.)

from both directions and the bandage is completed by a circular turn (Fig. 27).

Uses.-To retain dressings and as part of the spiral reversed of the upper extremity.

Spiral Reversed of the Forearm ( $2 \frac{1}{2}$ inches by 7 yards). - The end of the bandage is fixed by one or two circular turns around the wrist. It is then carried upward by two or three spiral turns until the increased circumference 
makes reversed turns necessary. These turns are made by holding the bandage in place with the thumb of the left hand, slightly relaxing the roller held in the right hand, and at the same time pronating the right hand. The bandage is now continued around the forearm, where another reverse is made, and so on until the elbow is reached, where the bandage is ended by circular turns.

Use.-To retain dressings on forearm.

Spiral Bandage of the Finger ( $\mathrm{I}$ inch by $\mathrm{I} \frac{1}{2}$ yards).The bandage is secured by circular turns around the

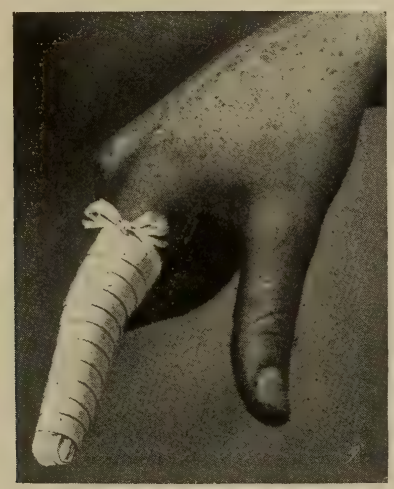

Fig. 28.-Spiral bandage of the finger. (Fowler's Surgery.)

middle phalanx, and carried over the tip of the finger by oblique turns. It is then continued, gradually ascending the finger by circular turns, each turn overlapping the preceding one by two-thirds until the base of the finger is reached. It is then passed obliquely across the back of the hand to the wrist; where one or two circular turns are made. It is then carried to the base of the finger, where it is pinned or tied in place (Fig. 28).

Use.-To retain dressings to fingers. 
Spiral Reverse of Finger (I inch by $1 \frac{1}{2}$ yards). -The end of the bandage is secured by one or two turns of the bandage around the phalangeal joint, and the bandage carried upward by spiral reversed turns until the base of the finger is reached. Finish by circular turns.

Use.-To hold dressings on fingers.

Spica Bandage of Thumb ( $\mathrm{I}$ inch by $\mathrm{I} \frac{1}{2}$ yards). - The bandage is fixed by circular turns around the wrist. The bandage is then continued over the back of the hand to the tip of the thumb, across the tip of the thumb, over the back of thumb to the wrist, where a circular turn is

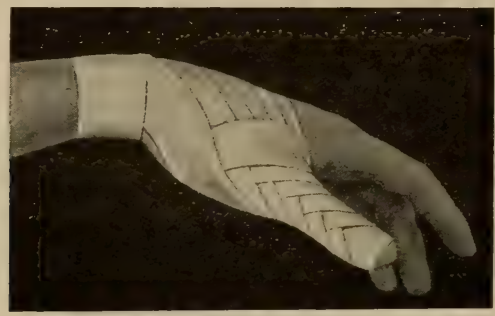

Fig. 29.-Spica of the thumb. (Fowler's Surgery.)

made. These turns are repeated, each turn overlapping the preceding turn by two-thirds, until the thumb is covered (Fig. 29).

Use.-To retain dressings to the thumb.

Demigauntlet Dorsal Bandage (I inch by 4 yards).The bandage is fixed by circular turns at the wrist. It is then carried across the back of the hand to the base of the first finger, where a circular turn is made and the bandage is returned to the wrist. Each finger is encircled in turn and the bandage is finished by a few figure-of- 8 turns around the wrist and hand (Fig. 30).

Use.-To hold dressing on back of hand. 
Demigauntlet Palmar Bandage.-The application is the same as the demigauntlet bandage of the dorsal surface of the hand, with the exception that the turns are made across the palmar instead of the dorsal surface of the hand.

Use.-To retain dressings to palmar surface of hand.

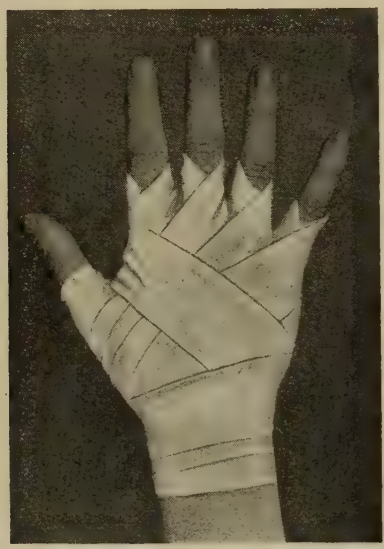

Fig. 30.-Demigauntlet bandage. (Fowler's Surgery.)

Single Spica of Groin, Ascending ( $2 \frac{1}{2}$ inches by 7 yards). - This bandage should be applied with the right hand for the right side and with the left hand for the left side.

The bandage is fixed by circular turns around the abdomen. Upon reaching the anterior superior spine, the bandage descends across the groin around the thigh, up to the anterior superior spine, where a circular turn is made around the abdomen. These turns should be alternated, each turn overlapping the preceding turn by two-thirds. The bandage is completed by a circular turn around the abdomen (Fig. 3I).

Use.-To retain dressings in groin. 


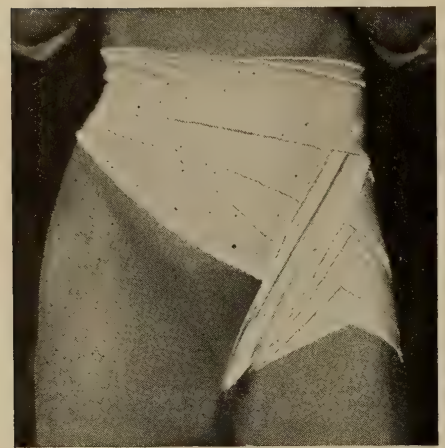

Fig. 31.-Ascending spica of the groin. (Fowler's Surgery.)

Descending Spica of the Groin ( $2 \frac{1}{2}$ inches by 7 yards). - The descending spica of the groin is applied in the same manner as the ascending, with the exception that the

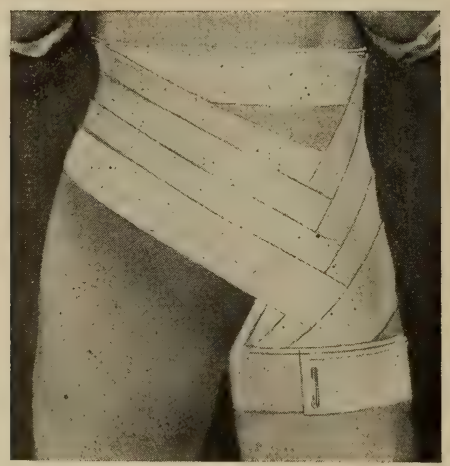

Fig. 32,-Descending spica of the groin. (Fowler's Surgery.)

turns descend instead of ascend. It is necessary to have the first turn, then, as high as possible (Fig. 32).

Use.-To retain dressings to the groin. 
Double Spica Bandage of Groin.-Instead of using the complicated double bandage, it is advisable to apply a right and left single spica.

Figure-of- 8 of the Knee ( $2 \frac{1}{2}$ inches by 2 yards).-The bandage is fixed by circular turns around the upper portion of the leg. It is then carried across the popliteal space and a circular turn made around the thigh, descending across the popliteal space, and by circular turns carried around the leg. These turns are repeated, each turn

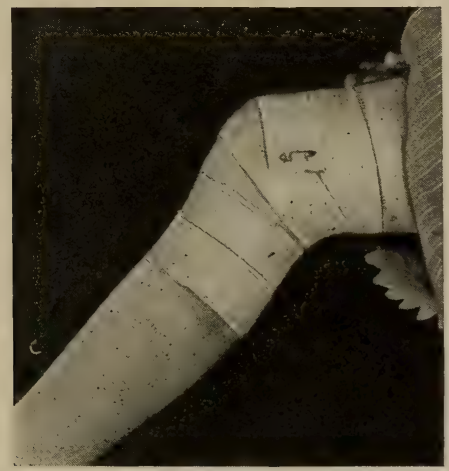

Fig. 33.-Figure-of-8 of the knee. (Fowler's Surgery.)

overlapping the preceding turn two-thirds until the popliteal space is covered in. The bandage is completed by a few circular turns around the thigh (Fig. 33).

Use.-To retain dressings to popliteal space.

Recurrent Bandage for a Stump ( $2 \frac{1}{2}$ inches by 6 yards). -Fix by circular turns near the lower end of the stump. Continue by recurrent turns covering in the end of the stump. Complete by ascending oblique spiral or spiral reversed turns, each turn overlapping two-thirds of the preceding turn (Fig. 34). 
Figure-of-8 Bandage of Leg.-The end of the bandage is fixed by one or two circular turns around the ankle. The bandage is then carried upward by spiral turns until the diameter of the leg increases, necessitating oblique turns. The bandage is then carried up across the leg to just below the knee. where a circular turn is made, then downward across the anterior surface of the leg. These turns are repeated, each turn overlapping the previous

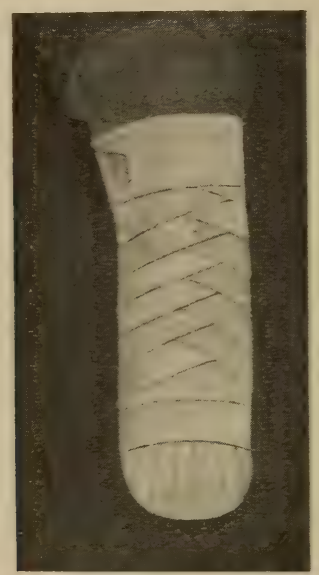

Fig. 34--Recurrent bandage of the stump. (Fowler's Surgery.)

turn two-thirds of its width until the whole leg is neatly covered. The bandage is completed by one or two circular turns just below the knee.

Use--Retaining dressing to leg.

Spiral Reverse of Lower Extremity (2 $\frac{1}{2}$ inches by 7 yards).-The bandage is fixed by circular turns around the ankle, and then carried upward by spiral turns until they no longer lie flat upon the leg. Then, by spiral 
reversed turns, the bandage is continued up to the knee, around the knee by figure-of- 8 turns, and continued up

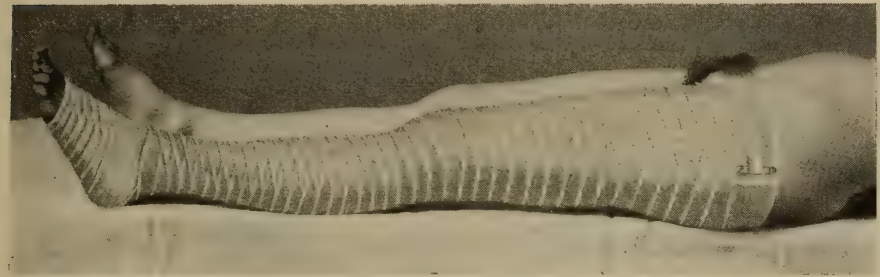

Fig. 35.-Spiral reverse of the lower extremity. (Fowler's Surgery.)

the thigh by spiral reversed turns. The reversed turns are made as in the arm by drawing the bandage taut, holding it in place with the left hand, slightly relaxing the

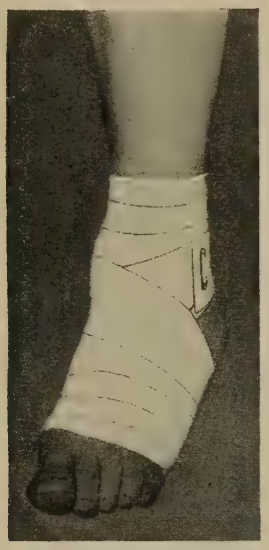

Fig. 36.-Figure-of-8 of the foot and ankle. (Fowler's Surgery.)

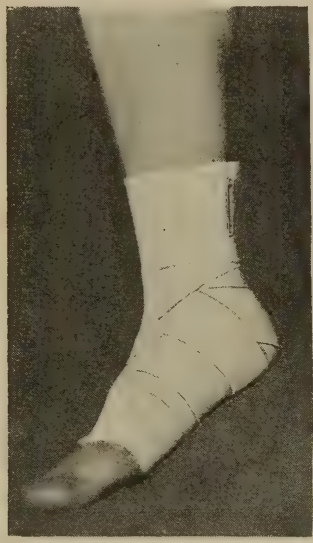

Fig. 37.-Spica of the foot. (Fowler's Surgery.)

bandage, pronating the hand so that the part of the bandage that was against the skin is now away from it. The 
bandage is continued around the leg until you reach the line of the reverse, where a reverse is again made (Fig. 35).

Use.-To retain dressings on the lower extremity.

Spica Bandage of Foot ( 2 inches by 3 yards).-The bandage is fixed by a circular turn around the ankle and is then carried across the anterior surface of the foot to the base of the toes, thence across the sole of the foot, over the anterior surface of the foot, around back to the heel. These turns are repeated, each turn overlapping the preceding turn by two-thirds until the ankle is covered in (Fig. 37).

Use.-To retain dressings to foot.

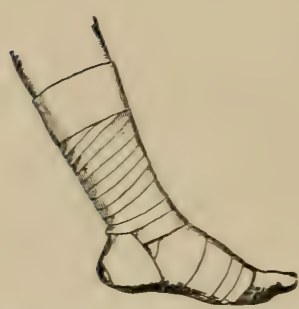

Fig. 38.-Method of covering the heel.

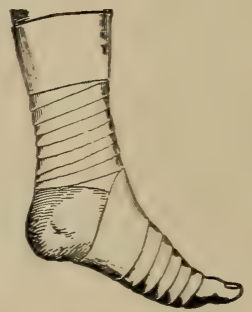

Fig. 39.-Figure-of- 8 bandage of the instep.

To Cover the Heel (American Method) (Fig. 38).Circular turns (3) about the ankle (to fix); descend by oblique turn across the back of the foot; circular turn at the base of the toes. Continue by covering the foot with ascending spiral reversed turns until the instep is reached. Cover the heel by circular turns from the instep to the heel, alternating with figure-of- 8 turns about the sides of the heel. Complete by circular turns, ascending the ankle. 
Bandage of the Foot Not Covering the Heel (French) (Fig. 39).-Circular turns at the ankle (to fix). Oblique turn across the back of the foot, descending to the base of the toes, where a circular turn is made. Cover in the foot to the instep with spiral reversed turns (ascending). Complete by circular turns about the ankle and lower leg.

Complete Bandage of the Lower Extremity (see Fig. 35). - This bandage is used for applying compression to the leg to retain dressings. Circular turns at the ankle (to fix); oblique turn, descending across the dorsum of the

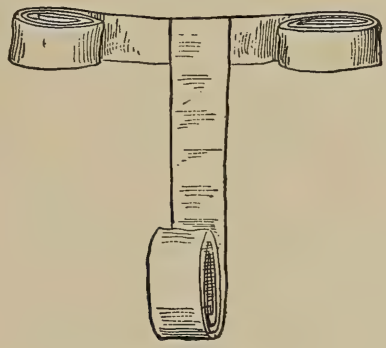

Fig. 40.-T-bandage.

foot, with a circular turn at the base of the toes. Continue by covering in the foot and heel. Ascend the leg by circular, oblique, spiral, or reversed spiral, covering in the calf. Continue by figure-of- 8 turns at the knee. Complete by ascending spiral or reversed spiral of the thigh.

T-Bandages, Slings, and T-Binders.-Materials.These are best made from heavy unbleached muslin or flannel.

A T-binder should consist of two pieces of material about 4 to 6 inches in width. The horizontal portion 
should be sufficiently long to surround the part to be bandaged and the rertical length should be about 18 inches. The second piece is sewed to the middle of the first (Fig. 40).

Slings are most frequently used to support the forearm and are usually designated as the handkerchief and roller. The handkerchief sling consists of a piece of material approximately I yard square folded diagonally. It is preferable to the roller sling.

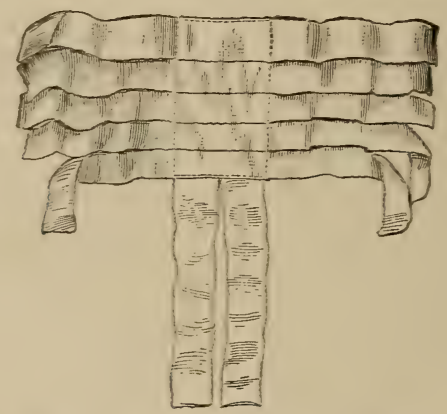

Fig. 4t. - The Scultetus bandage.

A roller sling consists of a 3 -inch roller bandage which is carried around the neck, then under the wrist, and the two ends drawn sufficiently tight to give the desired support and tied.

Scuitetus Bandage.-It is most frequently applied to the abdomen and is made of a piece of muslin or gauze about 16 inches in width and about one and one-half times the circumference of the part. In both free ends slits are made about 2 inches apart and 6 inches deep. It is used to retain dressings that require frequent changing. The opposite ends are tied in a bow-knot. 


\section{ADHESIVE PLASTER}

Adhesive plaster dressings are usually used to fix joints, secure splints in fractures, and in strapping ulcers.

Rubber Adhesive Plaster.-It is a manufactured product consisting of a linen material covered by a composite material with caoutchouc as a base. It has the property of adhering to whatever material it comes in contact with.

Zinc Oxid Adhesive Plaster.-This plaster is prepared by incorporating rubber adhesive plaster with oxid of zinc. It is equally as adhesive as the rubber plaster, and possesses the advantage that it is not apt to produce irritation of the skin. This plaster has largely supplanted both the resin and rubber adhesive plaster in surgical dressings.

Resin plaster is made of resin, lead, and wax spread on linen material, and when it comes from the manufacturer is covered by a thin tissue paper.

It should always be kept in a cool place, otherwise it deteriorates.

For application it is necessary to remove the tissue paper and gently heat.

Moleskin adhesive plaster consists of spreading a zinc oxid material on moleskin or a heavy flannel. It is especially useful in abdominal dressings where support is necessary, such as a Rose binder.

Sayre's dressing for fracture of the clavicle requires two strips of zinc oxid adhesive plaster 3 inches wide and sufficiently long to encircle the chest one and one-half times. A piece of linen encircles the injured arm, then one end of the strip is circled round the arm with the adhesive side toward the chest. The arm is pulled backward and the adhesive plaster carried across the posterior 
chest under the sound arm and then back to the front part of the chest. Now draw the hand of the injured side forward until it touches the sound clavicle. The remaining strip is placed on the back over the injured arm and carried downward over the tip of the elbow of the injured side, up over the back of the hand, over the sound shoulder to the starting-point. It is well to cut a hole in the center of the adhesive where it crosses the elbow (Figs. 42, 43).

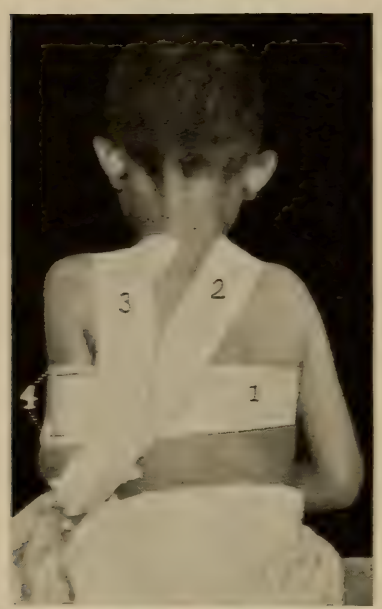

Fig. 42.-Sayre's dressing-posterior viem. Keen's Surgery.?

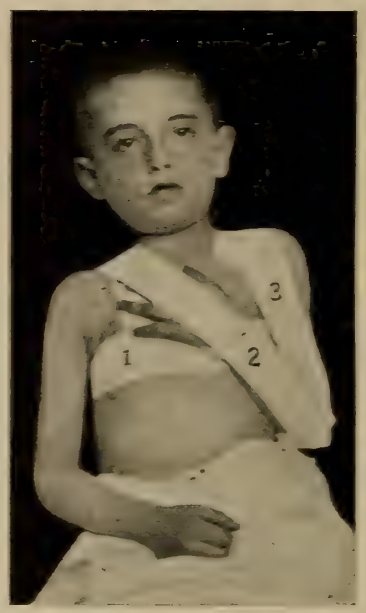

Fig. 43--Sayre's dressing-anterior view. (Keen's Surgery.)

Chest Strapping.--This consists of strips which are cut in widths of $2 \frac{1}{2}$ inches and sufficiently long to reach from I inch beyond the spine of the vertebra to I inch beyond the sternum. With the patient sitting, the arm of the injured side is held up and the patient is told to exhale, at which time the straps are applied one after the other from below upward, each strip overlapping the other one-third (Fig. 44). 
Pelvic Binder.-This consists of a strip of moleskin adhesive plaster sufficiently long to pass one and onehalf times around the hips. One end of the adhesive is placed just above the trochanter of the injured side, carried across the back over the crests of the ilium and back to the starting-point, and continued in this line until all the strip is in place.

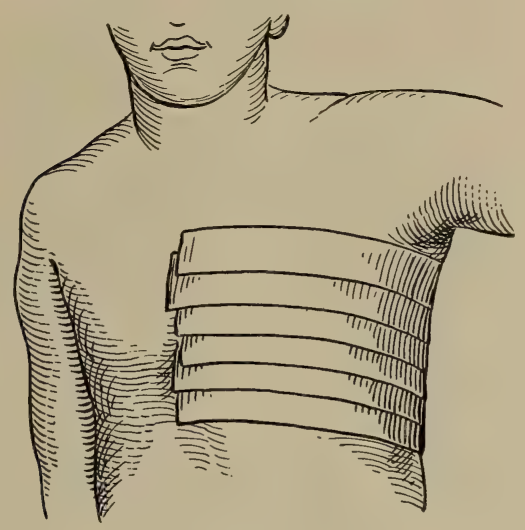

Fig. 44.-Strapping the ribs (after A. S. Morrow).

Figure-of- 8 of the Knee.-This is well illustrated in the accompanying diagram. Strips should be $I$ inch wide and I I to I 5 inches long (see Fig. 33).

Strapping of Ulcers of the Leg.-Ulcer of the leg may be strapped in the circular or oblique method as is shown in the diagram (Fig. 45).

Strapping of the Joints.-This requires strips of zinc oxid adhesive plaster 2 inches wide and sufficiently long to extend two-thirds around the joint. The first strap is applied a few inches below the joint and the strapping 
continued until the joint is covered. Each strap should overlap the preceding strap by two-thirds.

This dressing will be found to be satisfactory in the treatment of sprains of joints, etc.

Strapping of the Ankle-joint.-Straps of zinc oxid adhesive, $\mathrm{I} \frac{1}{2}$ by $\mathrm{I} 8$ inches, are required. The first strap is started at a point midway between the knee and the

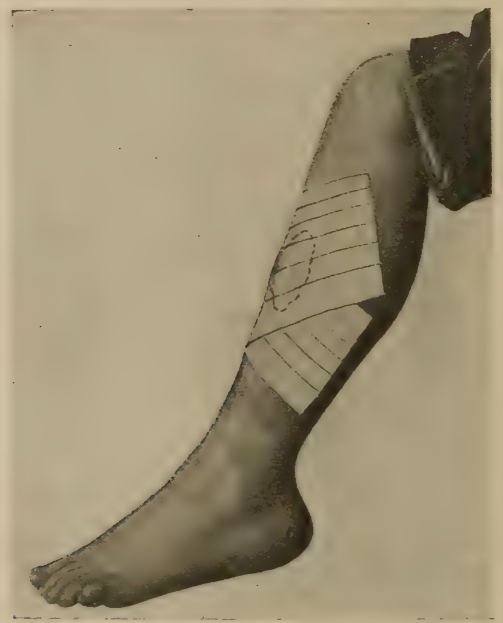

Fig. 45.-Strapping an ulcer of the leg. (Keen's Surgery.)

ankle, applied to the edge of the tendo achilles, carried across the sole of the foot and up the opposite side of the leg. A strap is next placed so that its middle crosses the point of the heel, the ends being carried forward on the inner and outer surface of the foot. These straps should be alternated until the ankle-joint is covered in.

One should avoid having these straps meet in the front of the foot or make circular constriction (Fig. 46). 
Buck's extension is a method of obtaining traction upon the leg and thigh. The attachment is made by

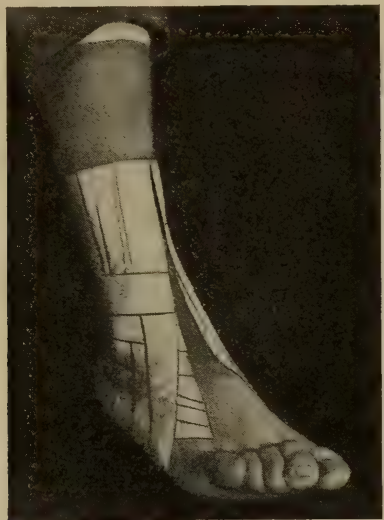

Fig. 46.-Strapping the ankle-joint. (Keen's Surgery.)

adhesive plaster and consists of straps $4 \frac{1}{2}$ inches wide and long enough to reach from well above the knee to

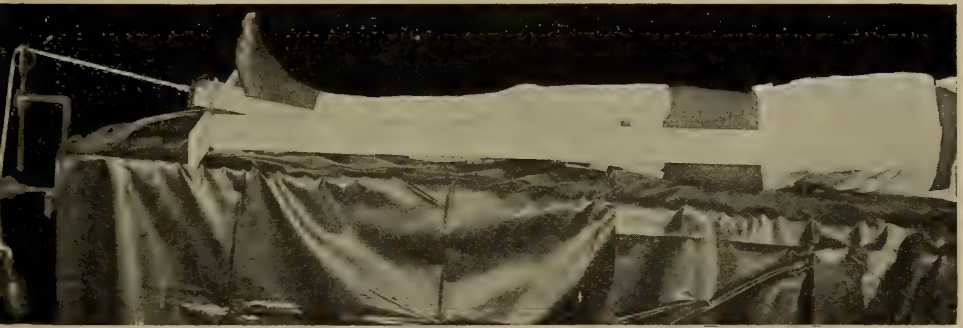

Fig. 47.-Fracture of the thigh. Completed apparatus and, in addition, a long outside T-splint, straps, and swathe. Weights applied. (Scudder.)

loosely around the sole of the foot and up the opposite side of the leg to a point opposite the starting-point. A piece of wood, 5 by 3 inches, is then placed in the center 
of the strap. A hole is cut in the center of the board through which a rope is passed. The adhesive surfaces of the plaster are placed on either side of the leg and thigh and are held in place by figure-of- 8 turns of adhesive followed by a muslin bandage.

The extension may be obtained by elevating the foot of the bed and tying the rope thereto, or by passing the rope over a pulley and attaching weights (Fig. 47).

Montgomery Straps.-They consist of a strip of zinc oxid adhesive from $\mathrm{I}$ to 2 inches in width and from 3 to 6 inches in length. The corners of one end of the adhesive are turned in and this end punctured. A strip of tape is sewed or tied to this. These are placed to either side of the wound and tied over the dressing.

Use.-To hold dressings in place.

Catheter straps are similar to the above, but are narrower and shorter.

\section{PLASTER-OF-PARIS}

Plaster-of-Paris bandages, like all other bandages, are made in various lengths and widths.

This bandage consists of unwashed crinoline or gauze with the mesh filled with the best dental plaster-of-Paris.

The material may be cut in the desired width or length, or the whole width of the material may be rolled at once. If not used at once, they should be kept in covered metal boxes to keep out the dampness.

Plaster bandages can be purchased at any good apothecary shop.

Application of Plaster-of-Paris Bandage.-The part should first be covered by a flannel roller or a bandage made of raw cotton and held in place by a gauze bandage. 
In applying body casts, a union suit of heavy material is advisable.

The plaster bandage should be immersed in water until the bubbles cease to escape, the excess water squeezed out, and the bandage applied by circular turns. Reverses in the bandage are allowable, but not advisable. After the application of each bandage, plaster of the consistency of thick cream should be rubbed in, as in this way less bandage will be required. In applying casts to the leg three to five bandages are usually sufficient. Strips of tin, zinc, or binder's board may be placed between the layers of the bandage to increase the tensile strength.

Plaster bandages set better on dry days.

Heavy rubber gloves are desirable to keep the hands of the operator free from plaster, or if they are not used, sugar and glycerin will assist in removing the plaster.

After the bandages are applied, great care should be used so that none of the plaster gets into the plumbing, as it will close the drain.

Removal of Cast.- This is best done with a heavy knife, cutting obliquely to the plaster. Vinegar, peroxid of hydrogen, etc., are useful to soften the plaster and assist in its removal.

Windows or fenestrations may be cut in the cast.

After the cast is dry it is well to confine the free ends in adhesive to prevent rubbing.

\section{SPLINTS}

Splints, padded with cotton-batting, oakum, wool, or hair, may be constructed from white pine, poplar, or willow wood, $\frac{1}{8}$ to $\frac{1}{2}$ inch $(3-12 \mathrm{~mm}$.) in thickness, cut to measured length and width; they may be of 
pasteboard or binder's board. molded to shape by soaking in boiling water, or of rawhide similarly worked; of felt; plaster-of-Paris; starch (dissolved in cold water, after which boiling water is added until the proper consistence is secured) requires from twelve to forty-eight hours to dry thoroughly (Fig. 48); gum and chalk (equal parts of gum arabic and precipitated chalk, add sufficient boiling water, stirring to obtain a proper consistence of solution) applied upon bandages; hatter's felt or binder's

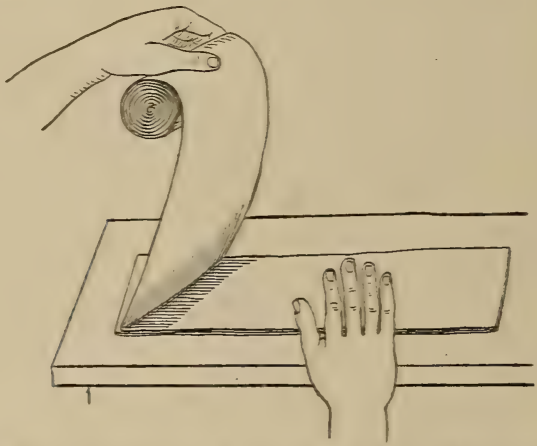

Fig. 48.-Splint made from plaster-of-Paris bandage. Complete by molding to the part: trim aiter setting has taken place.

board may be softened in hot water and molded to the injured parts. The coaptation splint consists of thin and narrow board strips (of bass wood or pine) placed in position (side by side, with a slight interval) upon a sheet of adhesive plaster, or they may be quilted between two pieces of sheeting. The splint is held in position by bandaging or by adhesive straps, and may be employed in emergency or to reinforce the ordinary board or bracket splint. Fracture-box consists of a stout board 6 to 8 inches $(\mathrm{I} 5-20 \mathrm{~cm}$.) wide by $\mathrm{I} 8$ to 30 inches $(45-75 \mathrm{~cm}$.) 
long, with hinged sides, a foot-board, upright, firmly attached at right angles to the bottom board, padded with a pillow, cotton-batting, or bran; may be used in treating fractures of the lower leg and knee. Bags made from stout muslin or light duck canvas cut $\mathrm{I} 4$ inches $(35 \mathrm{~cm}$.) wide by 3 feet $(90 \mathrm{~cm}$.) to 5 feet (I.5 m.) long, doubled, sewed, and inverted before filling with sand or bran, closed with a draw-string or by stitching, are employed in fractures of the leg and thigh. Compresses to prevent displacement may be made of cotton, lint (folded), oakum, and held in place by adhesive straps, bandage, or placed upon splints when padding.

Prevent infection of the soft parts from maceration of the skin surfaces after fracture by a thorough cleansing of the parts before applying the first permanent dressing and by "alcohol rubs" at each subsequent dressing. Neuralgic pain in the region after fracture is due to organized blood-clot or exudate. Treat by massage. Swelling, loosening, infection, malposition of the parts will demand an examination or change of dressings and correction by the surgeon. 


\section{CHAPTER VI}

\section{CARE OF OPERATING-ROOM; METHODS OF STERILIZATION; CARE OF INSTRUMENTS}

In almost all large hospitals there are three operating-rooms, one for general surgical, one for gynecologic, and one for septic operations. This is ideal, but unnecessary if correct methods of sterilization are employed.

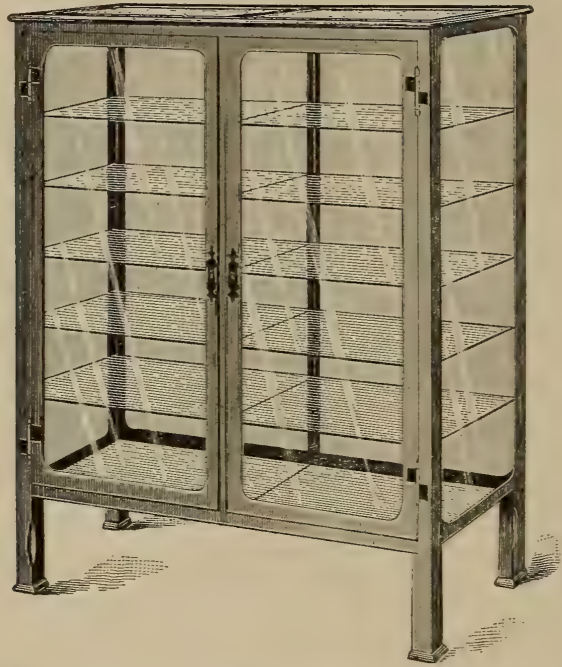

Fig. 49.-Kny-Scheerer instrument cabinet, having adjustable shelves and a plate-glass partition in the center, which practically divides it into two closets.

Dressing-rooms on each floor are very desirable, for besides having everything at hand with which to 


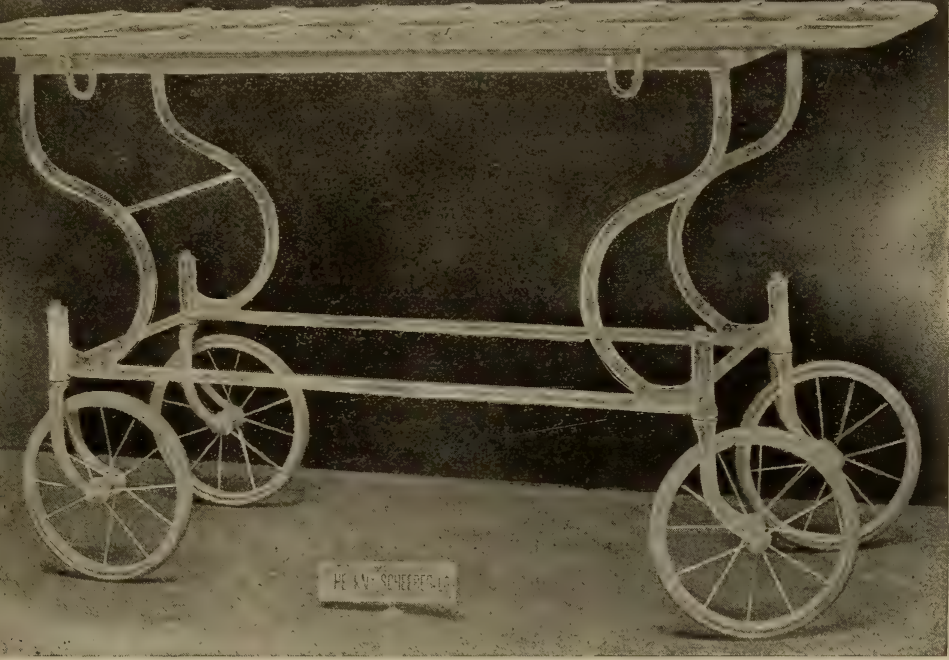

Fig. 50.-Wheeled stretcher.

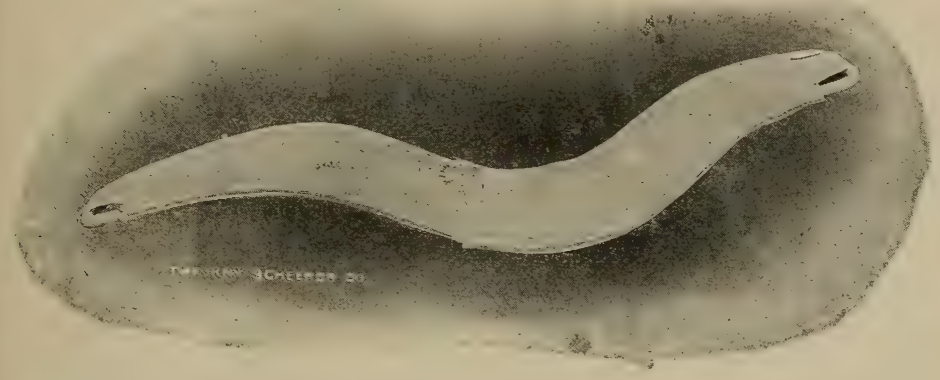

Fig. 51.-House stretcher.

do a dressing properly, the nurse in charge of the patient has the opportunity to return and make up the bed afresh during the patient's absence. Stretchers are 


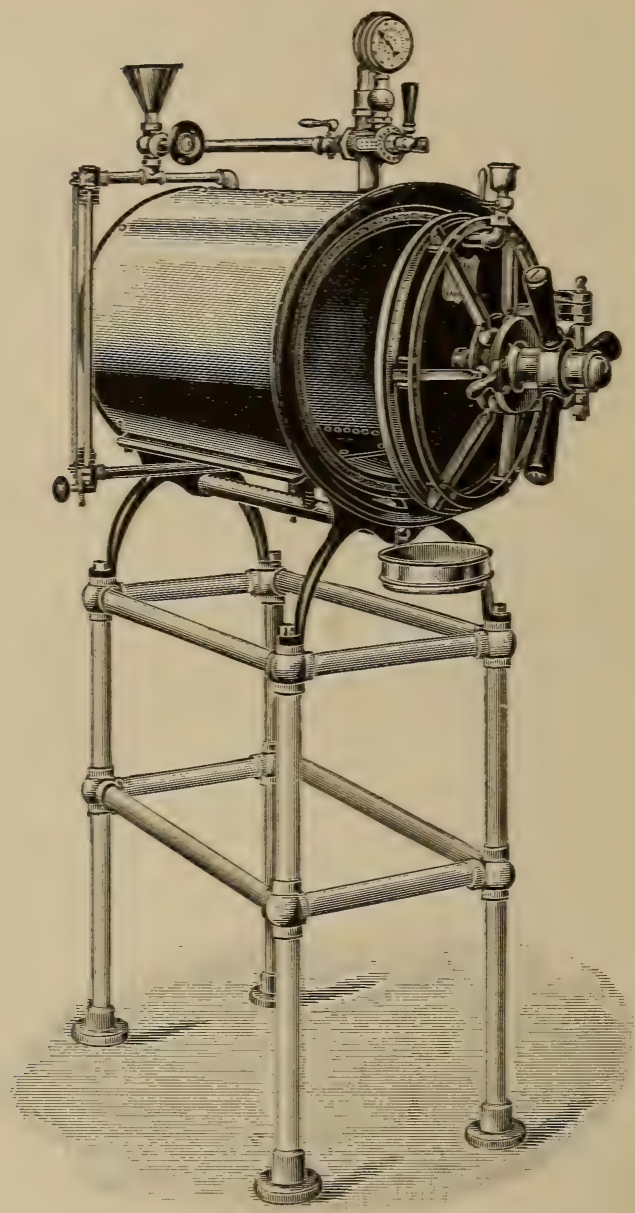

Fig. 52.-Improved model sterilizer.

used to convey patients to and from the operating- and dressing-rooms. The wheels generally have rubber tires, the top-board is detachable and has four handles, 
two at each end. At least two stretchers are necessary on each floor.

The material used in the construction and furnishing of an operating- and dressing-room should be of marble, metal, porcelain, and glass, all of which can readily be made aseptic. The water-faucets should be controlled by automatic foot- or elbow-valves, so as to avoid contamination by turning on the spigots with the hands after they have been rendered aseptic.

The operating-room should be kept clean, and should be damp-swept and wiped every day; in short, it should be in such a condition as to be ready for an operation

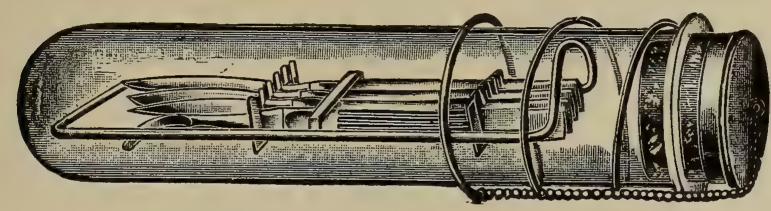

Fig. 53.-Sterilizing tube for edged instruments.

at a few moments' notice. The supplies for dressings should not be allowed to run down, and the instruments should always be in a first-class condition. An emergency bundle, containing everything necessary for an emergency operation, should be kept in readiness.

Sterilization may be either dry or moist; moist heat is preferable, because it is more thorough and more penetrating than dry heat. For dry sterilization the towels and dressings may be placed in covered tin pans in an oven the temperature in which ranges from $160^{\circ}$ to $212^{\circ} \mathrm{F}$. This method is only used in an emergency. For moist or steam sterilization a Kellogg, a Sprague, or an Arnold steam sterilizer is 
used. The heat must be continued for fully one hour before the operation.

Regarding the sterilization of instruments surgeons differ; some prefer to have their instruments wrapped in a towel and put into the sterilizer and allowed to boil for fifteen minutes in a I per cent. solution of carbonate of sodium to prevent their rusting. All edged instruments to be boiled in the soda solution should be wrapped

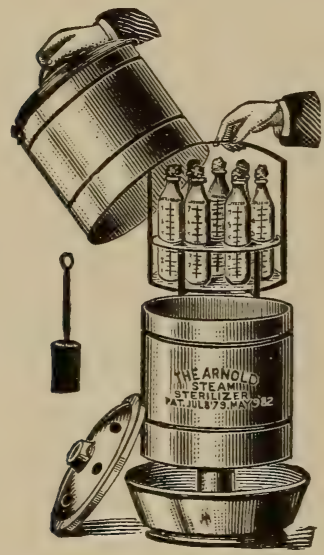

Fig. 54.-Arnold sterilizer.

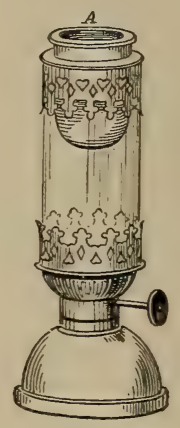

Fig. 55.-Formalin lamp.

in cotton and packed so firmly that they will not be tossed against one another by the solution as it becomes agitated in boiling. This agitation seems to be one of the reasons why they lose their edge. In a private house a tray or basin deep enough to allow the instruments being covered by the water are placed on a stove and boiled for fifteen minutes. Many operators prefer to have their edged instruments and needles placed in a dish containing 95 per cent. alcohol for half an hour; then just before 


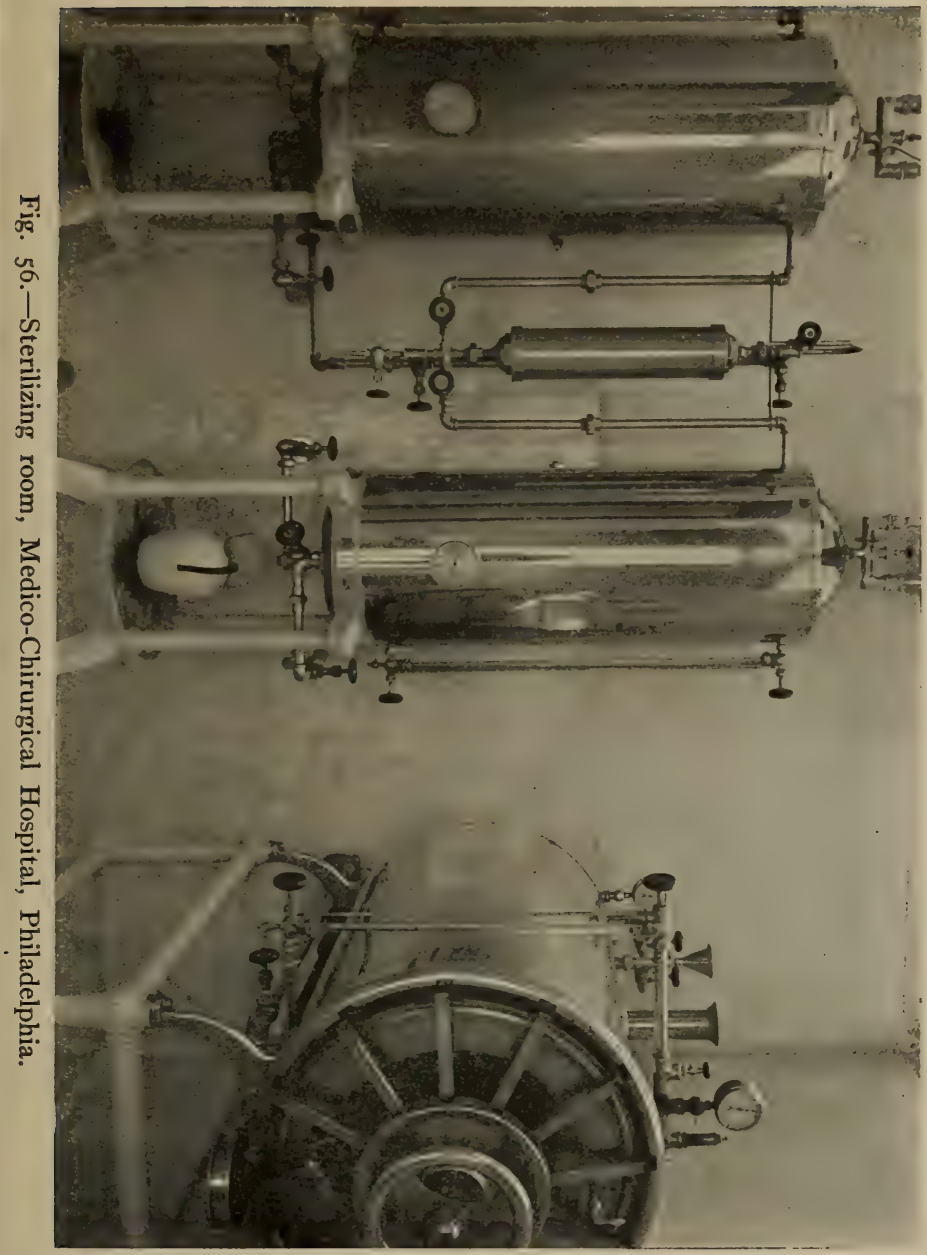

the operation they are taken out and rinsed with sterilized water. Usually the knives are placed in the last three minutes of the boiling time. 
After sterilization the instruments are transferred to the instrument-table or to shallow porcelain trays, in

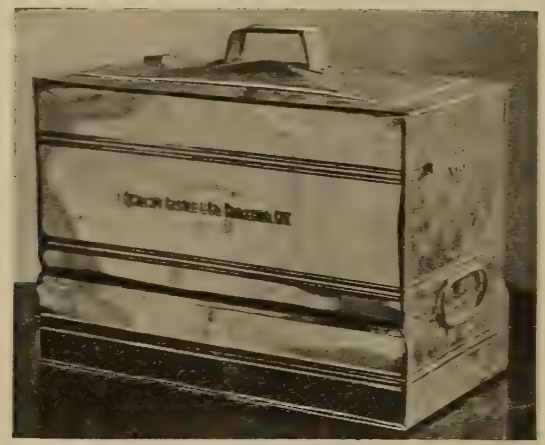

Fig. 57.-The Rochester sterilizer for instruments and dressings. (De Lee.)

which they lie covered with sterilized towels until required.

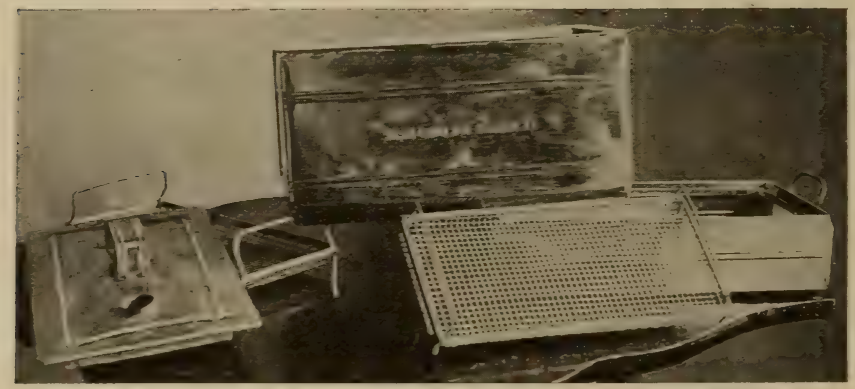

Fig. 58.-The Rochester sterilizer open. (De Lee.)

After the operation the instruments should be taken apart, washed in cold water to remove all blood, pus, and tissue particles, and then thoroughly scrubbed with 
green soap. Instruments with permanent joints, which fortunately are seldom seen now, must receive special attention, since it is difficult to get them surgically clean. After being scrubbed the instruments are rinsed in hot sterilized water, wiped dry with a soft towel, locks oiled, and then laid away in the case. The knife-blades must be rolled in cotton. The important points to be re-

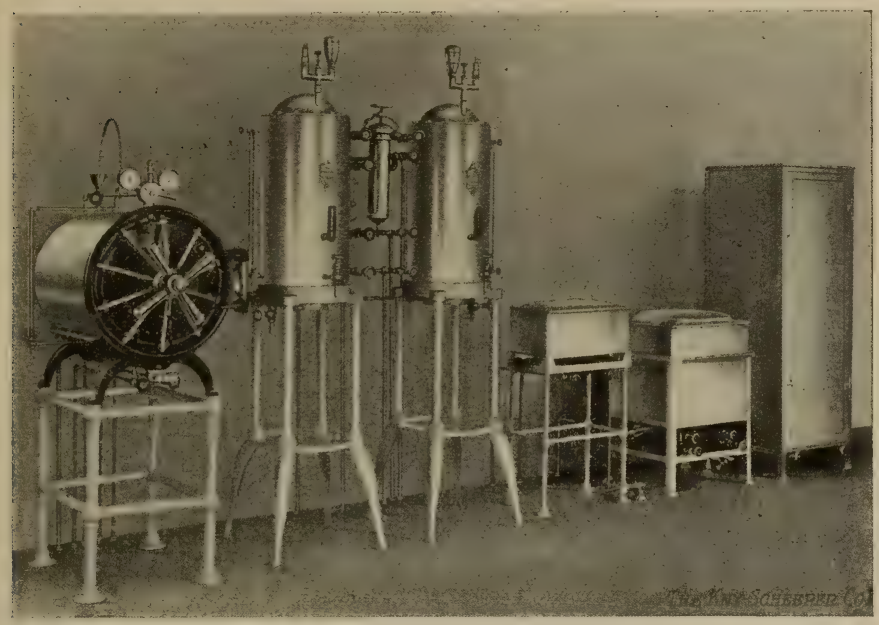

Fig. 59.--Latest form of complete sterilizing outfit for dressings, water, instruments, sheets, towels and operating gowns, basins and trays.

membered in cleaning instruments after the operation are:

First, all instruments that can be so dealt with must be taken apart and the rough catches thoroughly cleansed in cold water.

Second, they must be dried carefully in order to prevent rusting; for instruments once rusted seem always to have a tendency to return to that condition. 


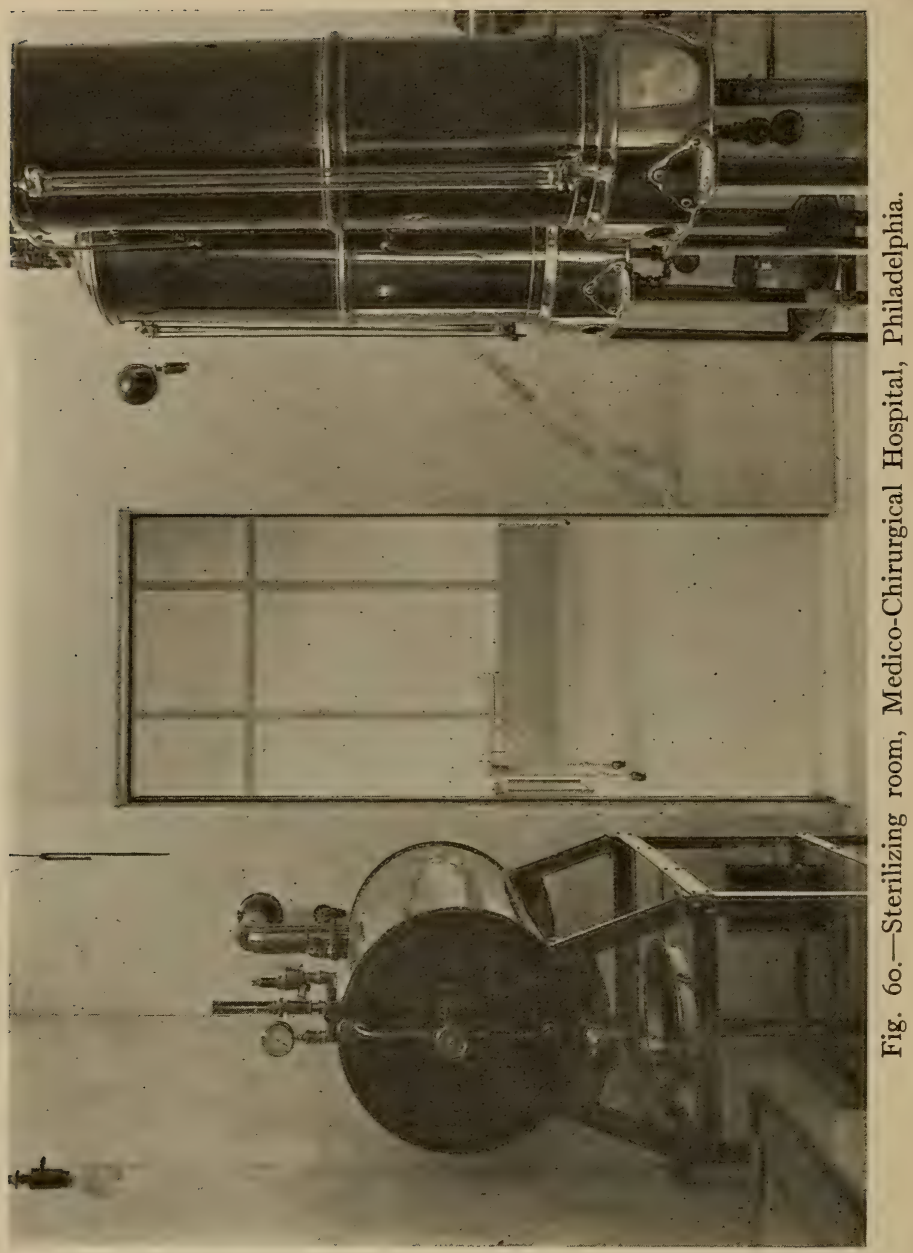

Instrument trays are made of porcelain or agate-ware. Instrument trays, pitchers, etc., are best sterilized in a large steam sterilizer built especially for this purpose. 
They should be allowed to remain in the sterilizer until used. Special sterilizers come for the disinfecting of bed-pans, douche-pans, etc. They are placed in a sterilizer containing the soiled contents with the lid of the sterilizer dropped in place and are then sterilized by steam. Later, by turning a spigot, the contents are

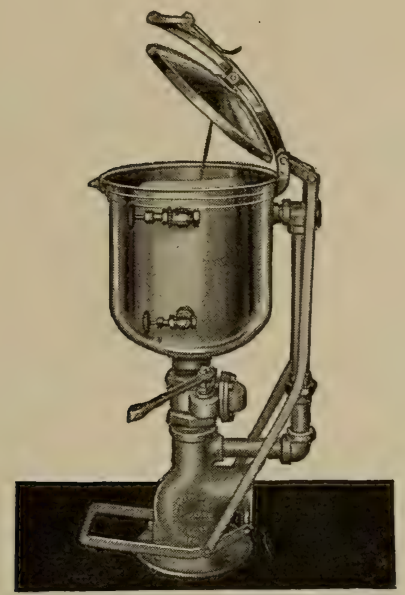

Fig. 6r.-Sterilizer for the disinfecting of bed-pans, douche-pans, etc. (Courtesy of Bernstein Manufacturing Co.)

drained off and the receptacles are ready for use. All hospitals should be equipped with this apparatus.

Every operating-room nurse should be familiar with the names of the instruments necessary for each different operation, so as to be able to lay them out when occasion requires. Many nurses get together after school hours and "make believe" an operation is to take place. Each nurse has her duty assigned to her, and each tries 
to fulfil it in a thoroughly professional, dignified, and quiet manner. Practice of this kind is never lost.

In the operating-room should be kept two large ledgers,

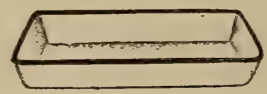

Fig. 62.-Glass tray.

in one of which the house-surgeons, after making the morning rounds with the visiting surgeons, should record

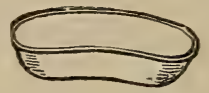

Fig. 63.-Pus basin.

the number of operations to be performed the next day, the time, name of operator, etc. The operating-room nurse is thus made acquainted, by consulting the book,

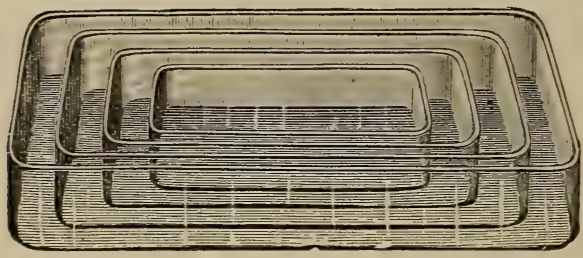

Fig. 64.-Glass trays.

of the amount of work before her for the next day, and the character of the operations for which she has to prepare.

On the morning of the operations she makes out a list of the floor and number of private room or letter of ward and number of bed from which the patients are to be brought to the operating-room, and the order 
in which the operator wishes them. This list is given to the male attendant, who brings up the patients in succession, in such a way that while one patient is being operated on the next is being anesthetized. The head nurse in the operating-room has two or three sets of instruments, and during one operation an assistant nurse is sterilizing the instruments and making

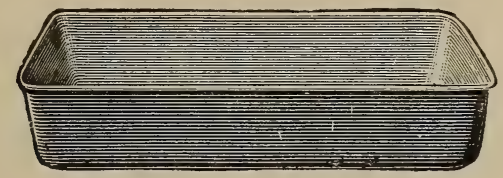

Fig. 65.-Metal tray.

preparations for the next operation. There is then no waiting on the part of the operator, for as the patient operated on is wheeled out of the operating-room the next patient is wheeled in. The following chart will give an idea as to the way the book is made out and the order in which the operations are written. The emergency operations, accidents, etc., are also recorded, but after the performance of the operation.

\begin{tabular}{|c|c|c|c|c|c|c|c|c|}
\hline Date. & Operation. & Floor. ${ }^{1}$ & Time. & Operator. & Room & Ward. & نं & Floor. \\
\hline $\begin{array}{c}\text { Mar II. } \\
\text { " } \\
\text { " } \\
\text { " } \\
\text { " } \\
\text { " } \\
\text { " } \\
\text { " } \\
\text { " }\end{array}$ & $\begin{array}{l}\text { Laparotomy. } \\
\text { Vaginal hysterec- } \\
\text { tomy. } \\
\text { Cholecystostomy. } \\
\text { Appendicectomy. } \\
\text { Amputation, breast. } \\
\text { " } \\
\text { Appendicectomy. } \\
\text { Cesarean section. } \\
\text { Appendicectomy. }\end{array}$ & $\begin{array}{c}4 \text { th } \\
\text { " } \\
" 6 \\
" 6 \\
" 6 \\
" 6 \\
3 \text { d }\end{array}$ & 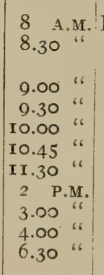 & $\begin{array}{l}\text { Dr. Murphy. } \\
\text { " } \\
\text { " } \\
\text { " Johnson. } \\
\text { " Fenger. } \\
\text { " } \text { Morgan. } \\
\text { " } \text { Cartig. } \\
\text { ". } \\
\text { " Andrews. } \\
\text { " Fenger. } \\
\text { " } \\
\text { Eyster. } \\
\text { Comegys. }\end{array}$ & $\begin{array}{l}19 \\
21 \\
\\
24 \\
16\end{array}$ & $\begin{array}{l}B \\
D \\
D\end{array}$ & $\begin{array}{r}\text { I0 } \\
6 \\
9\end{array}$ & $\begin{array}{l}\text { 4th } \\
2 \mathrm{~d} \\
4 \text { th } \\
2 \mathrm{~d}\end{array}$ \\
\hline
\end{tabular}

${ }^{1}$ Clean operating-room, fourth floor; septic, third floor. 8 
The second book gives the date on which the patient was prepared for operation, by whom prepared, etc., as, for example-

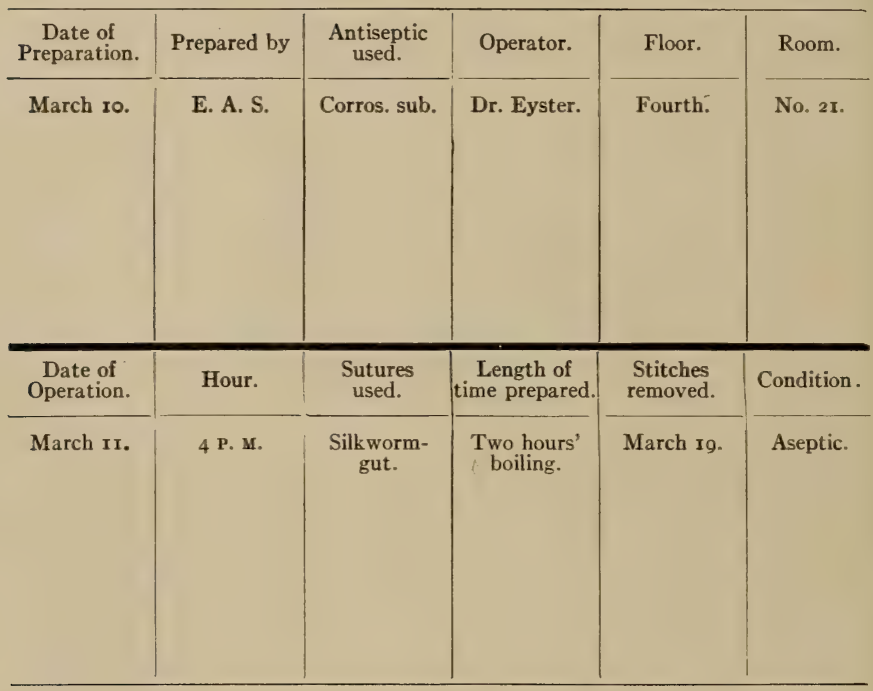

A book should also be kept in each dressing-room showing the number of cases dressed each day, the dressing used, and progress since the last dressing. It should be kept for the convenience of the dressingroom nurse in making an estimate of dressings for the next day, and for the convenience of the surgeon in knowing what patients are dressed, their condition, and in knowing when they are to be again dressed. It will also recall condition of last dressing. 


\begin{tabular}{|c|c|c|c|c|c|c|}
\hline $\begin{array}{l}\text { Room or } \\
\text { Ward. }\end{array}$ & Diagnosis. & Operated. & Operator. & Dressed. & $\begin{array}{c}\text { Died or } \\
\text { Discharged. }\end{array}$ & Remarks. \\
\hline $\begin{array}{l}\text { No. } 29, \\
\text { 2d floor. }\end{array}$ & Appendicitis. & March II. & $\begin{array}{l}\text { Dr. Come- } \\
\text { gys. }\end{array}$ & March 17. & $\begin{array}{c}\text { Discharged } \\
\text { April } 2 .\end{array}$ & \\
\hline
\end{tabular}




\section{CHAPTER VII}

\section{INSTRUMENTS NECESSARY IN DIFFERENT OPERATIONS, KEEPING OF CHARTS, SUR- GEON'S KIT, ETC.}

In many hospitals, small ones especially, where there are no medical students or house doctor, the nurse has more responsibility than in larger institutions, and becomes closely familiar with such details as taking the history of the patient; the arranging and sterilization of instruments; assisting the operator, giving the anesthetic, and writing out the report of the operation. The following charts will be of use in keeping the important features of this line of duty in mind. When taking the patient's history it is a good plan to allow her to describe her condition in her own words. Any peculiarities of the patient's manner and other points which may be observed can be noted, and afterward the questions necessary for making out the charts may be asked.

\section{Family History.}

Father.

Age. Health. Disease. Cause of death if dead.

Mother.

Brothers (number).

Sisters (number).

Wife or husband.

Children (number).

Uncles or aunts with epilepsy, insanity, tuberculosis, or cancer. 


\section{Personal History.}

When born. Where lived. Peculiarities of climate. Occupations. Habits (as to eating, drinking, sleeping, etc.). Appetite. Condition of bowels. Nervousness.

(When Female.)

\section{Sexual History.}

I. Menstruation:

(a) First at what age.

(b) Regularity. No. days.

(c) Duration. No. days.

(d) Amount.

(e) Character of discharge $\left\{\begin{array}{l}\text { Color. } \\ \text { Consistency. } \\ \text { Odor. }\end{array}\right.$

(f) Intermenstrual discharge.

(g) Dysmenorrhea-when.

II. Pregnancies $\left\{\begin{array}{l}\text { Number. } \\ \text { Sickness or peculiarities. }\end{array}\right.$

III. Miscarriages $\left\{\begin{array}{l}\text { Number. } \\ \text { Sickness. } \\ \text { Fever. }\end{array}\right.$

IV. Labors:

(a) Number.

(b) Character $\left\{\begin{array}{l}\text { Easy. } \\ \text { Difficult. } \\ \text { Spontaneous. } \\ \text { Instrumental. }\end{array}\right.$

(c) Peculiarities.

(d) Sickness postpartum, if any. 


\section{Previous Illness.}

Starting with childhood, give different sicknesses and age at which same occurred, following life of patient to present time simply with reference to sickness, including appetite, bowels, urine, headaches, pains, coughs.

\section{Present Sickness.}

Date.

Onset. Character. $\left\{\begin{array}{c}\text { Chills, pains, locations, se- } \\ \text { verity, etc. Peculiarities. }\end{array}\right.$ Progress and changes to present time.

Changes. Appetite. Bowels. Urine, etc.

\section{Examination.}

Surgeon's Kit.-The packing of a surgeon's bag is of ten done by the operating-room nurse. Many surgeons use the telescope valise, or kit, as it is more commonly called; while others employ a regular surgeon's bag. Before the bag is packed the nurse makes out the list of necessary articles, and as each article is put in it is checked off the list. When packed, a copy of the list is securely pinned upon a towel inside, where the surgeon can see it on first opening the bag. The kit is packed by first laying in two large sterilized towels, the ends of which hang over the edges of the bag. Together with the instruments, which are placed in a linen instrument-roll, and the dressings the kit should contain three new nailbrushes, soap, razor, hypodermic syringes with tablets of strychnin sulphate (gr. $\frac{1}{30}$ ), atropin sulphate (gr. $\frac{1}{150}$ ), and morphin sulphate (gr. $\frac{1}{6}$ ), cocain hydrochlorate (gr. $\frac{1}{4}$ ), sterile camphorated oil, ether, and chloroform (with 
cone and mask), alcohol (95 per cent.) I pint, tincture of iodin ( 5 per cent.), tablets of corrosive sublimate and sodium chlorid, iodoform gauze, plain gauze, gauze sponges, white suits, caps, and canvas shoes for the

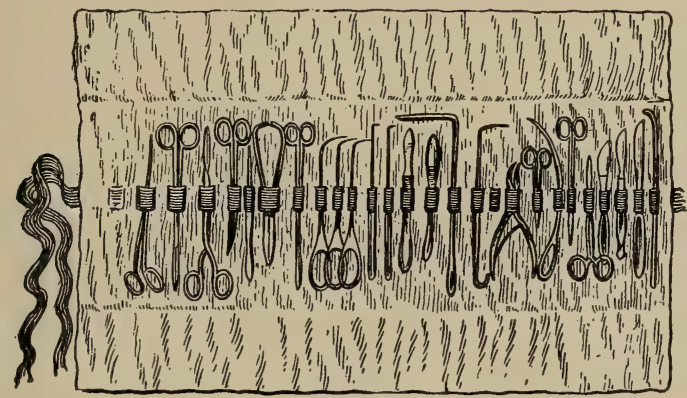

Fig. 66.-Canton-flannel roll for instruments.

operator and assistants, Kelly pad, rubber gloves, safety-pins, absorbent cotton, twelve towels, a rubber apron, ligatures, sutures, and rubber and glass drainagetubes. The glassware should be packed in the middle,

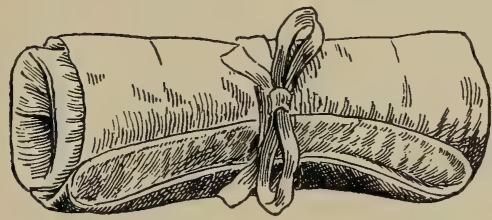

Fig. 67.-Instruments wrapped in canton-flannel roll.

to prevent breakage. When the kit is packed a third towel is laid over the contents, the edges of the other two are brought up, and all pinned together with safety-pins.

The instrument-rolls are very serviceable in economizing space and in keeping the instruments aseptic. 


\section{OPERATION BLANK}

Service of $\mathrm{Dr}$.

Date. March Io, I9I6.

Name. .

I. PREPARATION OF PATIENT FOR OPERATION.

II. ANESTHETIC. ANESTHETIST.

Temperature.

Before operation.

After operation.

Pulse and Respirations.-To be taken continuously during operation.

III. PREPARATION OF FIELD OF OPERATION.

IV. POSITION OF PATIENT DURING OPERATION:

V. PRIMARY MANIPULATIONS.

VI. INCISION AND HISTORY OF OPERATION.

VII. TREATMENT OF WOUND.

VIiI. DRAINAGE.

IX. CLOSURE OF WOUND.

X. DRESSING.

XI. RECOVERY FROM ANESTHETIC.

XII. AFTER-TREATMENT. 


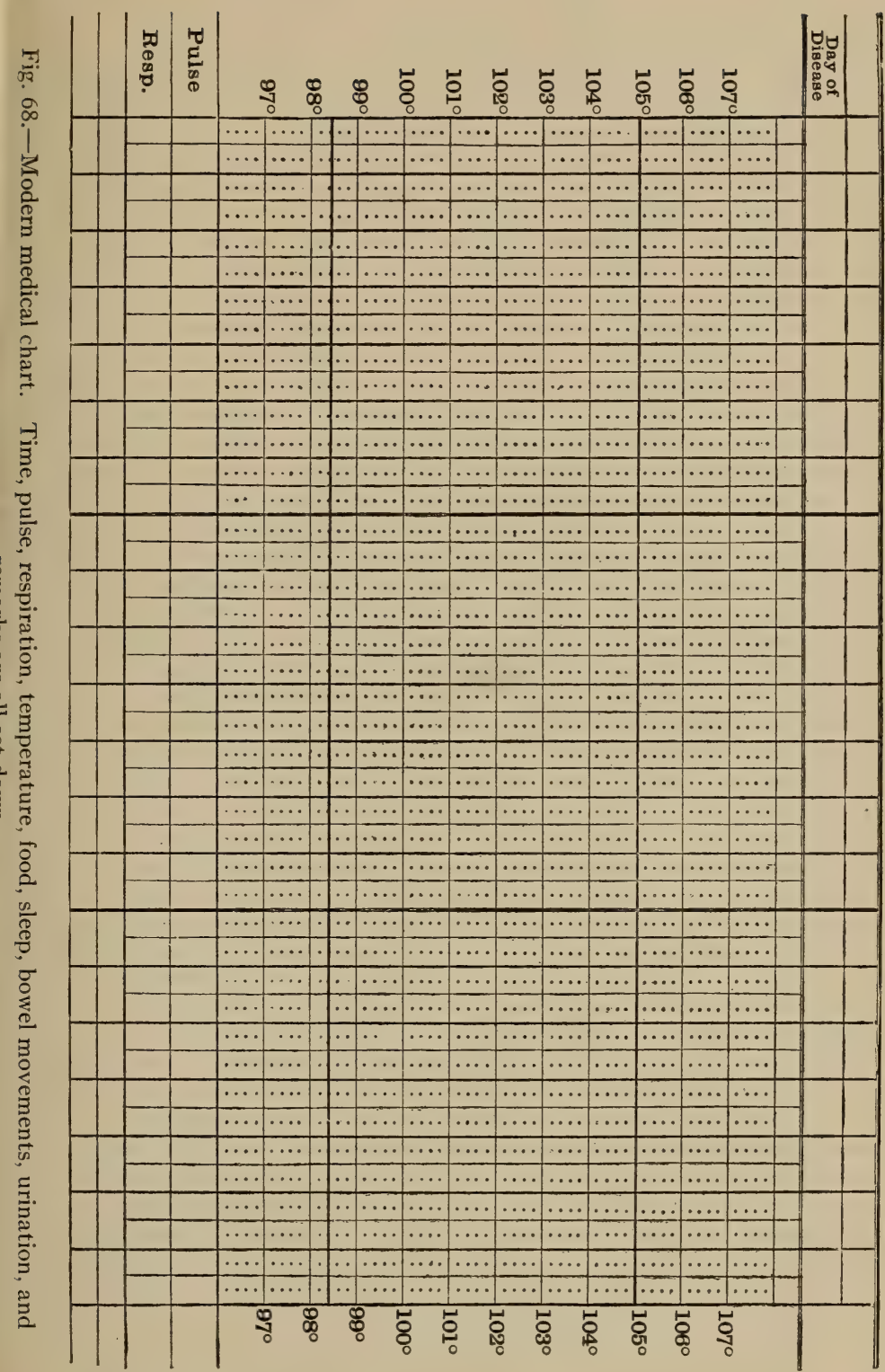


They are made of linen, canton flannel, or toweling, I yard long; and through the middle of each are adjustable loops in which the instruments are placed. When soiled the rolls may be washed and sterilized.

Needles of various shapes and sizes required for an operation are sterilized with the instruments. Many operators prefer the needles to be threaded, then attached to a towel, which is folded, enveloped in another towel, and securely fastened. These bundles are dry sterilized and are not opened until called for by the operator or his assistants. After the operation is completed the sutures and ligaments which have not been used are carefully dried and resterilized. In choosing the needles care must be taken that only sharp needles and strong sutures and ligaments are selected for use.

\section{INSTRUMENT LIST}

The following is a list of instruments generally used. Each operator will require additional instruments. The operating-room nurse should make out a list of the additional instruments each operator requires:

Simple Dressing Tray

Forceps, I pair. Groove director.
Scissors, I pair

Probe.
Hemostats, 2 pairs.

Glass syringe.

\section{Head Operations}

Trephining, Brain Tumors, Etc.

Knives.

Tourniquet.

Gigli's wire saw.

I)ural separator.

Retractors, toothed.

Necrlle-holder.

Scissors.
Trephines.

Cranial rongeur for- Chisel. ceps.

Periosteal elevator.

Electrodes.

Fine dural needles.
Hemostats.

Mallet.

Dural separator.

Forceps.

Head mirror or head light. 


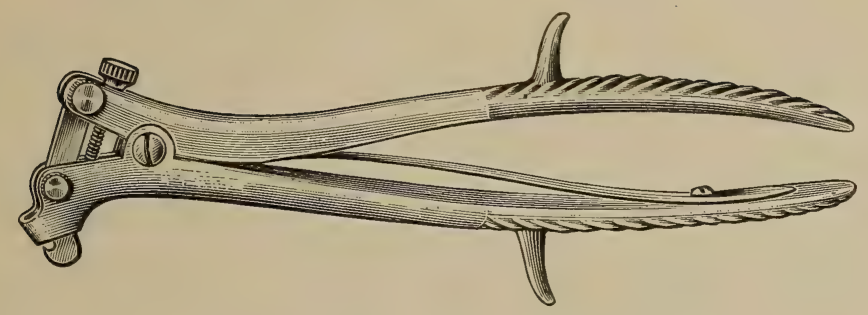

Fig. 69.-Hudson's cranial rongeur forceps.

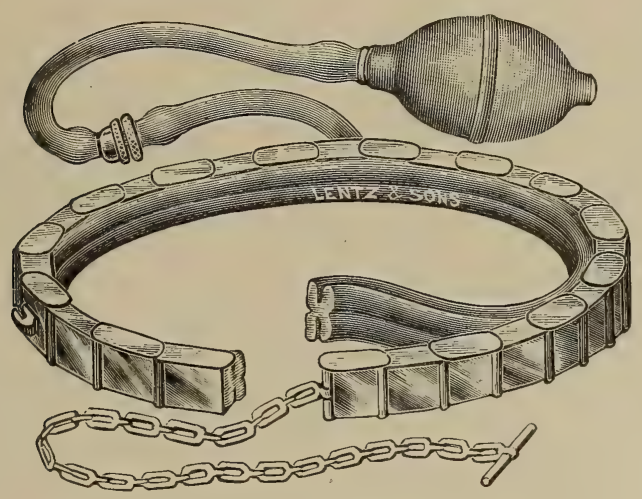

Fig. 70.-Lentz's cranial chain tourniquet.

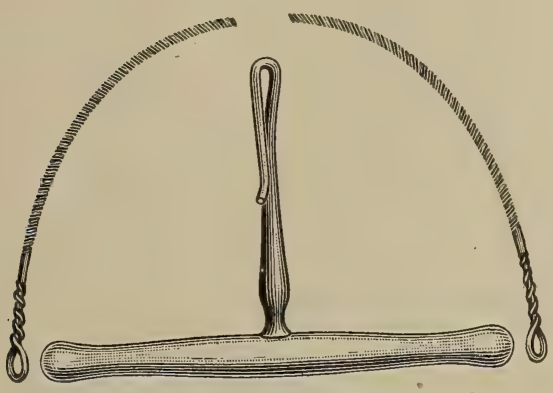

Fig. 71.-Gigli wire saw and handle. 

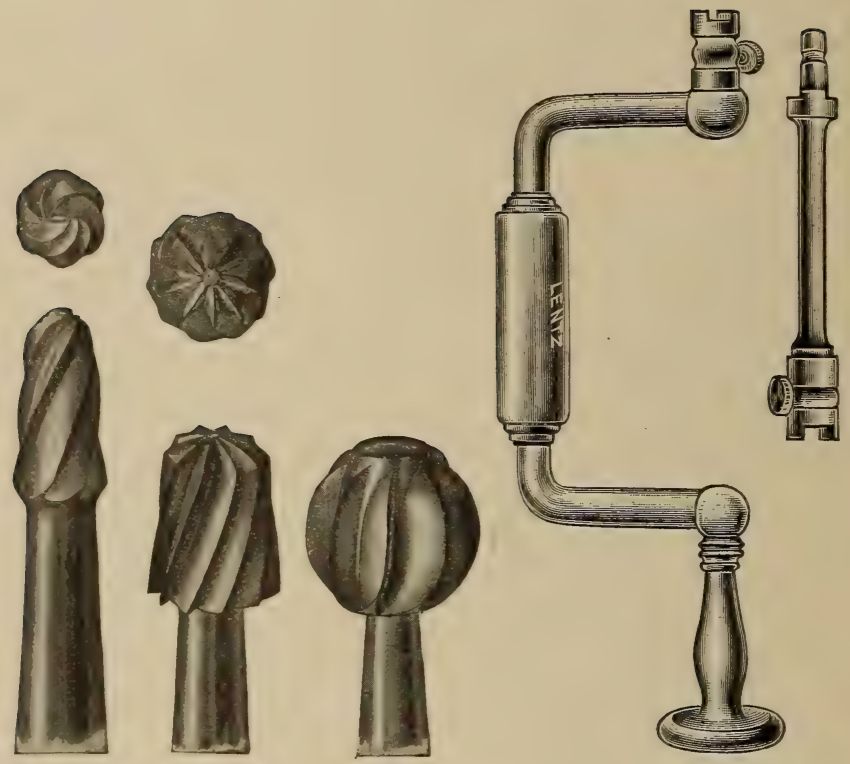

Fig. 72.-Hudson's cranial trephine, burs and brace.

\section{Spinal Puncture}

Glass or Record syringe and spinal needle.

\section{LAMINECTOMY}

Knives, 2.

Periosteal elevator

Forceps, 2 pairs.

Forceps, bone-cutting, Retractors.

2 pairs.
Scissors, 3 pairs.

Needles.

Chisels.
Rongeur forceps, 2 pairs. Needle-holder. Mallet.

Gigli saw. 
EAR Operations

\section{Mastoid}

Knives.

Scissors.

Probe.

Forceps.

Needle-holder.

Guard for facial nerve.

Retractors, self-retaining.

Head mirror or head

Hemostats.

\section{light}

Needles.

Curets, four sizes.

Chisels, Alexander's.

Periosteal elevator.

Syringe.

Mallet. Rongeur forceps.

Ear speculum.

Groove director.

\section{Nose and Throat Operations}

\section{Cleft Palate}

Knives.

Scissors.

Head mirror.

Fine needles.

Mouth-gag, self-retaining.

\section{Tonsillectomy}

Knives.

Mouth-gag.

Hemostat, tonsil.

Hemostats.
Snare, Beck-Schenk.

Scissors.

Head mirror.

Tonsil punch.
Hemostats, I 2.

Periosteal elevator.

Needle-holder.

\section{Adenectomy}

Instruments necessary for Tonsillectomy and the following:

Adenoid curet.

Rubber ear syringe.

Nasal dilator.

Cotton-holding ceps.

\section{Tracheotomy}

Knives. Needle-holder.

Retractors.

Scissors.
Hemostats, I 2.

Sharp hooks, 2.
Postnasal cutting forTongue depressor. Forceps, tonsil-holding. Sponge-holders. 


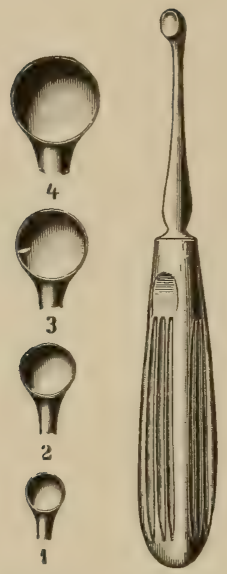

Fig. 73.-Buck's mastoid curet (four sizes).

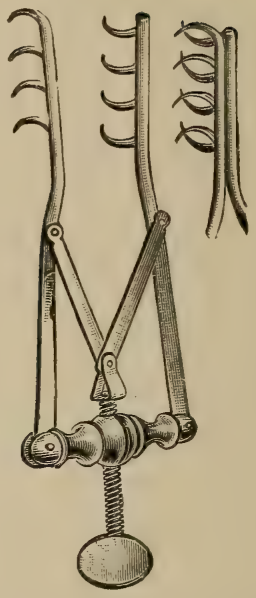

Fig. 74.-Allport's mastoid retractor (self-retaining).

Fig. 75.-Langenbeck's periosteal elevator

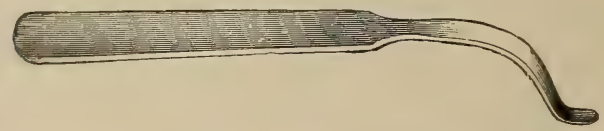

Fig. 76.-Stacke's guard for facial nerve.

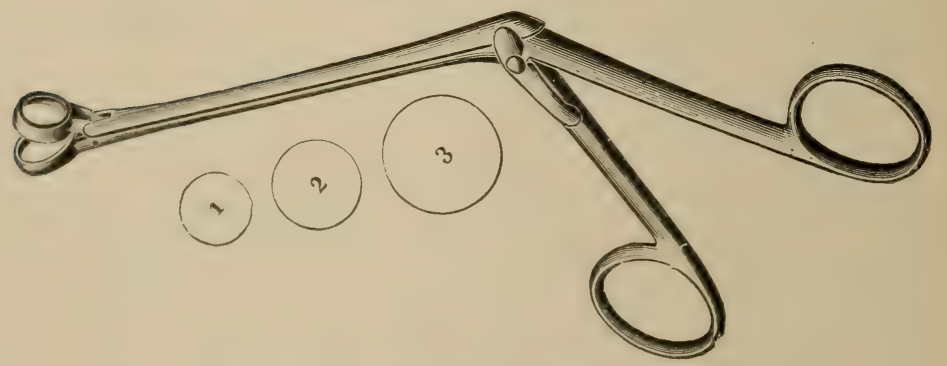

Fig. 77.-Hartmann's round tonsil punch. 


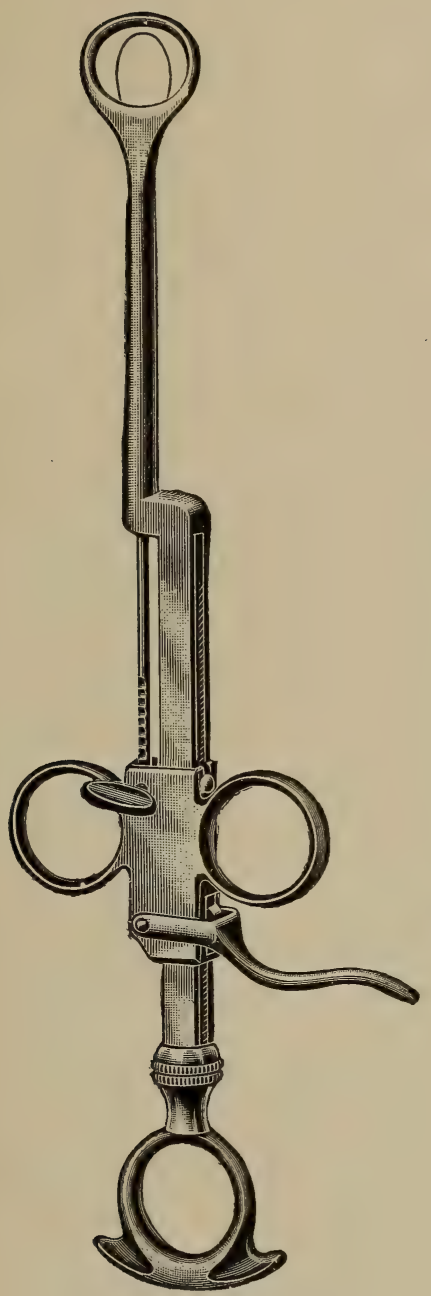

Fig. 78.-Tonsil snare.

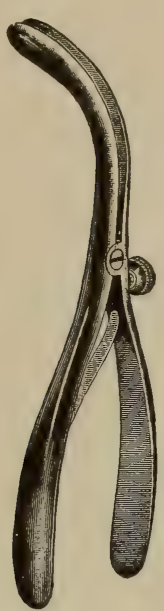

Fig. 79.--Sinexon's nasal dilator.

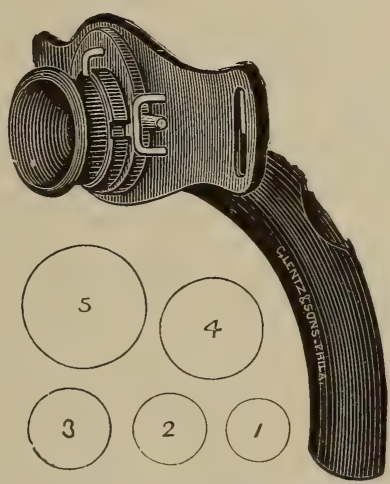

Fig. 80,-Luer's trachea cannula. 

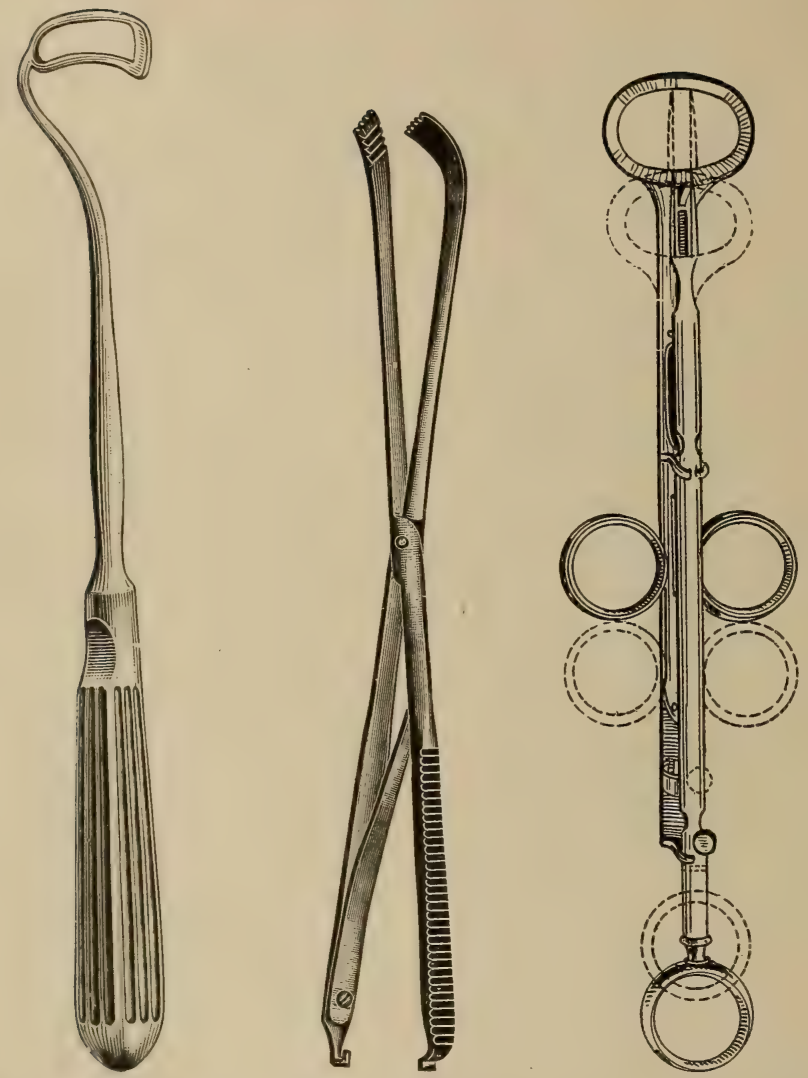

Fig. 81.-DeRoalde's Fig. 82.-Richards' Fig. 83.-Ermold's tonadenoid curet. tonsil-holding forceps. sillotome.

Submucous Resection.

Applicators.

Scissors.

Septum punch.

Nasal specula, Killian.

Nasal specula, Bal- Knives. linger.

Head mirror.

Nasal tampons.
Septum elevator.

Ballinger's swivel knife. 
Tongue, Removal of

Knives.

Hayes' saw.

Hemostats.

Scissors.
Tongue forceps.

Needles.

Forceps, rat-toothed

Forceps, plain.
Forceps, bone-cutting.

Needle-holder.

Mouth-gag.

\section{Glands of Neck, Removal of}

Knives.

Retractors.

Needle-holder.

Scissors.

Forceps, plain and Mayo dissecting scissors. toothed.

Hemostats.

Needles.

Crile clamp.

Aneurysm needle.

\section{GOITER}

Same instruments as for Removal of Glands of Neck with these added:

- Goiter forceps.

Goiter compressing. Kocher director. forceps.

\section{Ligation of Arteries, Carotid}

Same instruments as for Removal of Glands of Neck.

\section{Eyes}

\section{Iridectomy}

Eye speculum.

Cataract knife.

Iris spatula.
Iris scissors.

Iris forceps, straight Lid retractor. and curved.

\section{Cataract Extraction}

The same instruments as are required for Iridectomy and the following in addition:
Cystotome.
Lens tractor.
Lens scoop.

\section{Removal of Eye and Tenotomy}

\section{Self-retaining lid re- Strabismus hooks, Scissors.}

tractor.

Forceps, toothed. small and large.

Hemostats.
Small curved needles.

Needle-holder. 

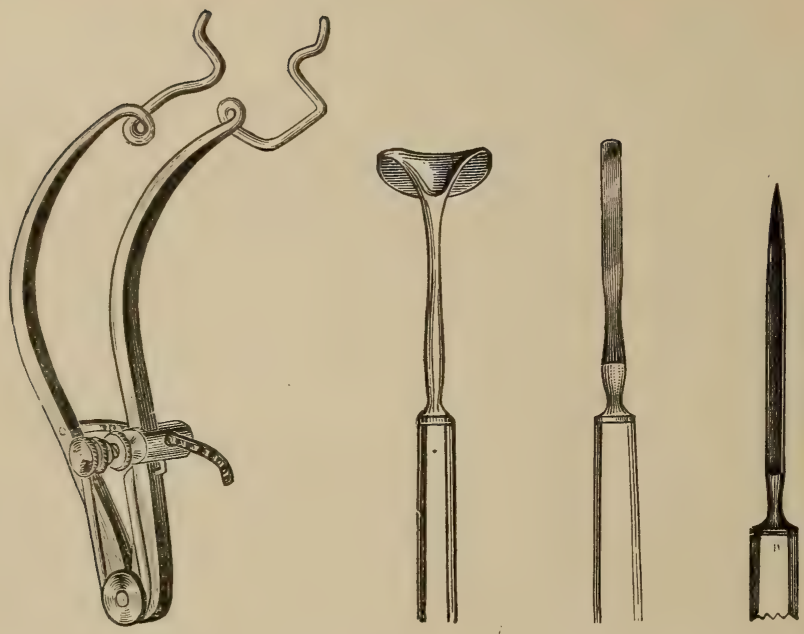

Fig. 84.-Fox's eye specu- Fig. 85.-Des- Fig. 86.- Fig. 87.-Iris lum. marre's lid re- Iris spatula. knife. tractor.

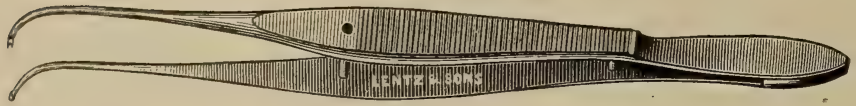

Fig. 88.--Iris forceps.
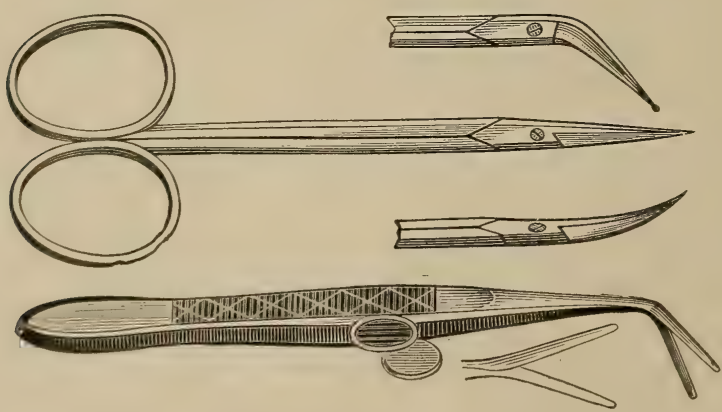

$a$

Fig. 89.-Iris scissors; $a$, Wecker's. 


\section{Chest Operations}

\section{Empyema}

Aspirating set.

Scissors.

Drainage-tubes.

Knives.

Periosteal elevator.

Needles.

Hemostat forceps, Bone-cutting forceps. Needle-holder. plain and toothed.

\section{Amputation of Breast}

Knives.

Scissors.

Needles.

Grooved director.

Forceps, toothed and

Retractors plain.

Hemostats.

Needle-holder.

\section{Abdominal Operations \\ Abdominal Section}

Usual instruments for any abdominal section, to which will be added instruments required for any special abdominal operation.

Knives.

Hemostats.

Aneurysm needle.

Intestinal clamps, medium.
Scissors.

Clamps, Kocher or Kelly. Needles.

Allis' forceps.
Forceps, toothed and plain.

Retractors, abdominal.

Needle-holder.

\section{HERNIOTOMY}

Same instruments as are required in above operation and small retractors.

\section{STOMACH Operations}

Same instruments as for Abdominal Section and the following additions:

$$
\text { Stomach clamps: Murphy button. }
$$

\section{INTESTINAL OpERATIONS}

\section{Resection}

Same as Abdominal Section.

\section{Gall-Bladder and Liver Operations}

Same as for Abdominal Section with the following additions:
Gall-duct probes.
Gall-stone scoops.
Special drainage-tubes.

Trocar. 

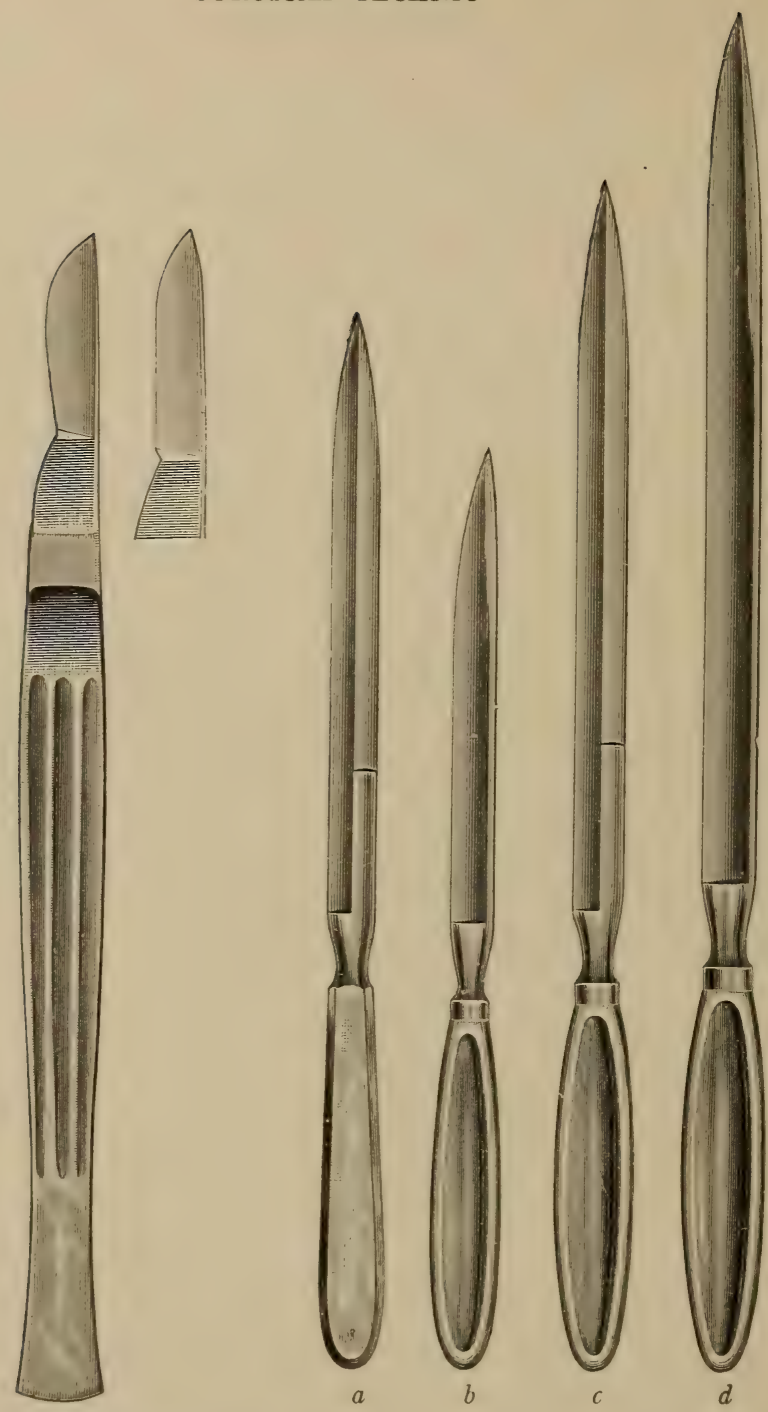

Fig. 90.-Mayo's operating knife or scalpel.

Fig. 9I.-Amputating knives: $\vec{a}_{s}$ Catling's medium; $b$, Liston's small; $c$, Catling's long; $d$, Liston's long. 


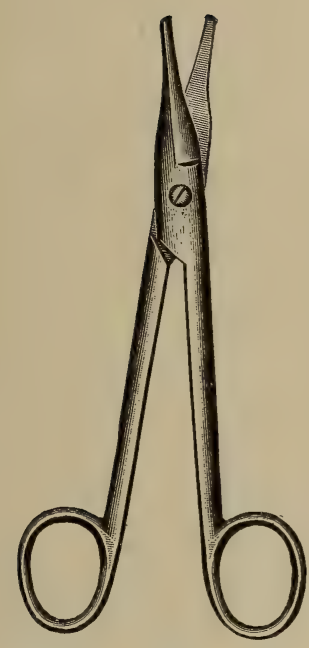

Fig. 92.-Mayo's operating scissors.

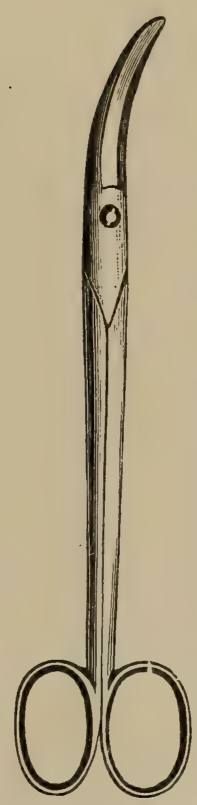

Fig. 93.-Curved scissors.

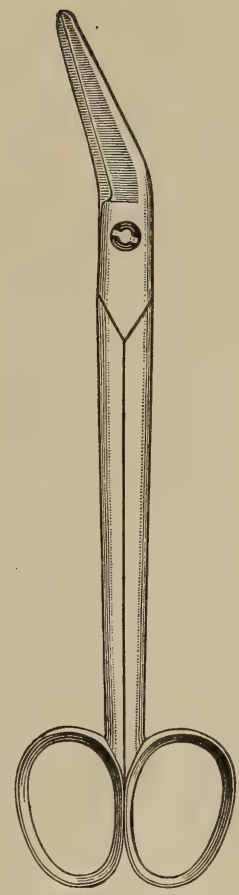

Fig. 94.-Emmet's angular bent scissors.

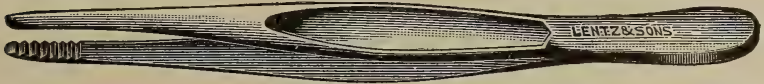

Fig. 95.-Dressing forceps.

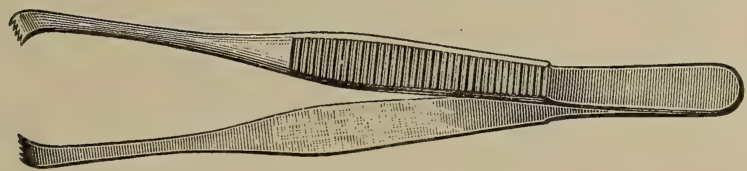

Fig. 96.-I. S. Stone's tissue forceps. 


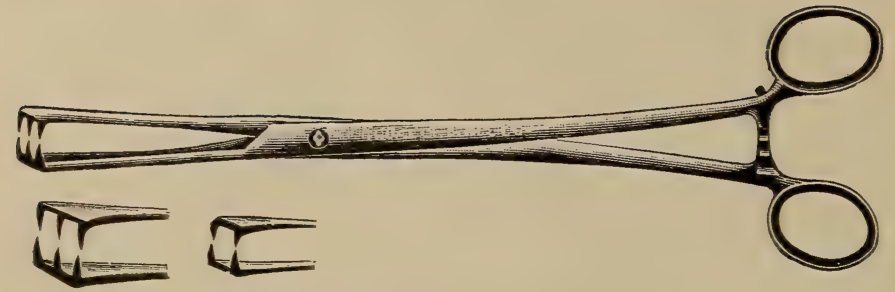

Fig. 97--Segond's volsella forceps.

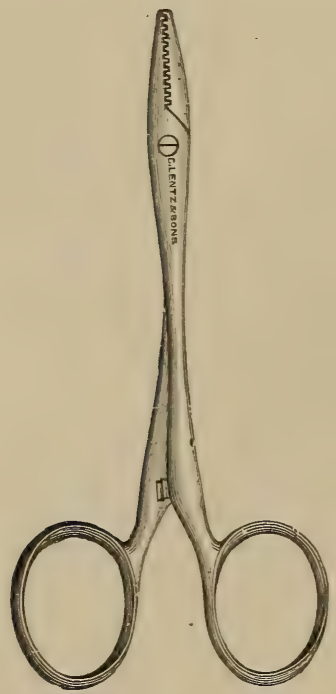

Fig. 98.-Tait's hemostat forceps.

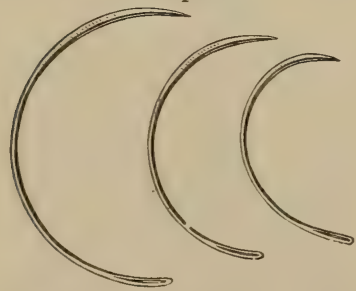

Figs. 99-тот--Kelly's curved round needles.

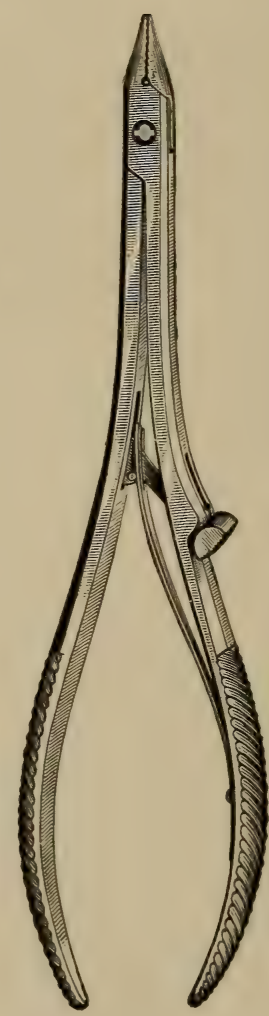

Fig. 102.-Noble's improved Reiner's needle-holder. 


\section{Operations ${ }^{*}$ Upon the Uterus \\ Hysterectomy, Suspension, Etc.}

Same instruments as for Abdominal Section and the following:

Hysterectomy clamps. Forceps, large.

\section{Dilation and Curetment}

Specula, self-retaining. Curet, irrigating.

Specula, Sims'.

Irrigator, uterine.

Sound, uterine.

Curets, dull and sharp.

Curet, Martin's.
Tenaculum, single and double.

Dilators, Goodell, large and small.

Dilators, Hegar's.

Dilators, Metranoikter.
Forceps, uterine.

$\begin{array}{ll}\text { " } & \text { dressing. } \\ \text { " } & \text { tenaculum. } \\ \text { "lacental. }\end{array}$

Scissors.

Norris or Wiley drain.

\section{Perineorrhaphy and Repair of Cervix}

Same as above and-

Hemostats.

Knives.

Scissors.
Needle and needleholder.

Hooks.
Tenacula.

Emmet scissors.

Shot forceps.

\section{Kidney Operations}

Knives.

Scissors.

Kidney clamp.

Needle-holder.
Forceps.

Retractors, large.

Ureteral probe.

Ureteral catheter.
Hemostats.

Kidney elevator forceps.

Needles.

\section{Operations Upon EXtremities}

\section{Amputations}

Martin's rubber ban- Saws. dage.

Tourniquet.

Hemostats.

Knives.

Scissors.
Periosteal elevator.

Retractors, metal.

Retractors, muslin, two or three-tailed.

Amputating knives.
Forceps, lion-jaw.

$\begin{array}{ll}\text { " } & \text { requestrum. } \\ \text { " } & \text { boneur. } \\ \text { " } & \text { plain. } \\ \text { " } & \text { rat-toothed. }\end{array}$

\section{Resection}

Same and the following additions. 


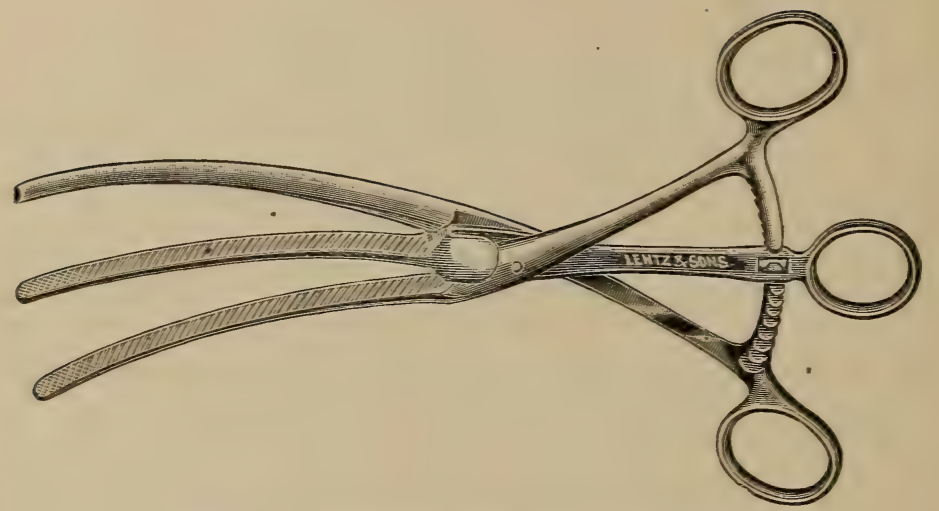

Fig. I03.-Linnartz's stomach clamp forceps.
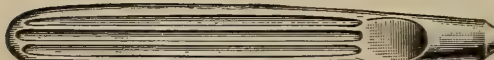

Fig. I04.-Deschamp's aneurysm needle.
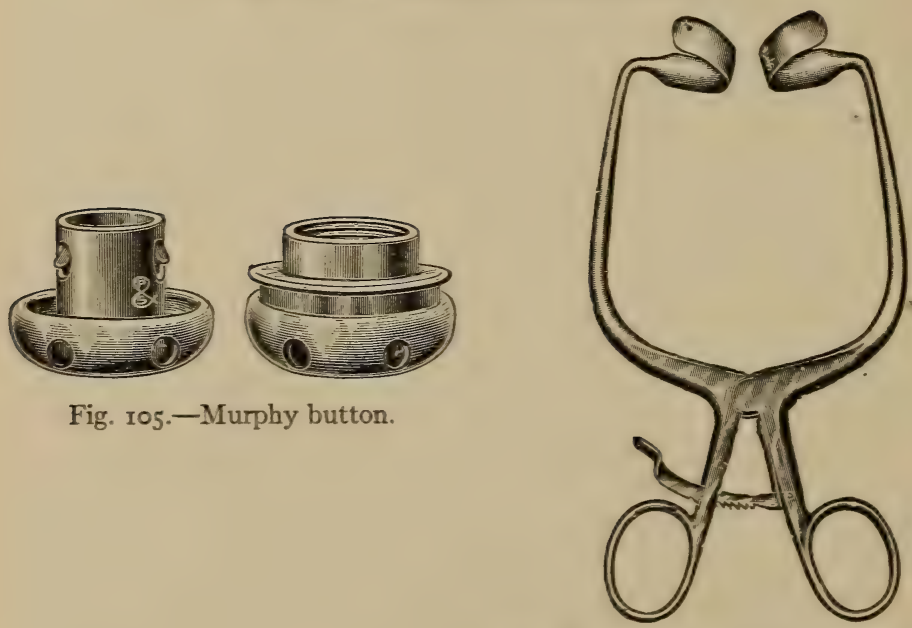

Fig. ro6.-Mayo-Simpson's self-retaining retractor. 


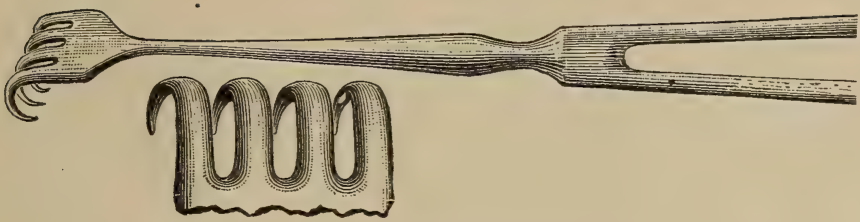

Fig. I07.-Volkmann's retractor.

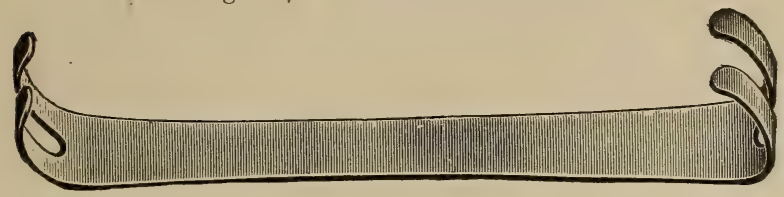

$a$

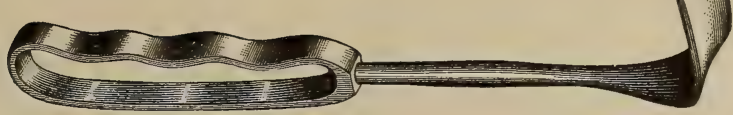

$b$

Fig. I08.-Retractors: $a$, Collin's; $b$, Kelly's.

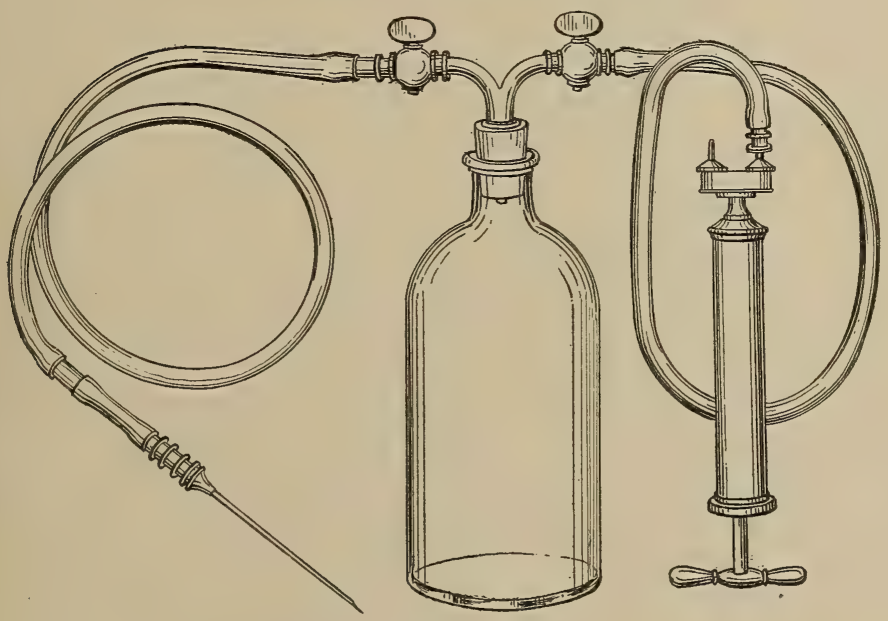

Fig. Io9.-Potain's aspirator. 


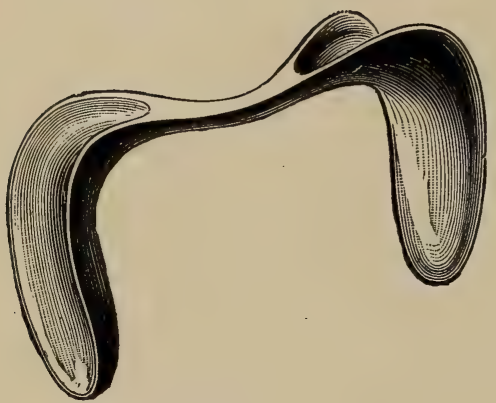

Fig. Iro.-Sims' speculum.

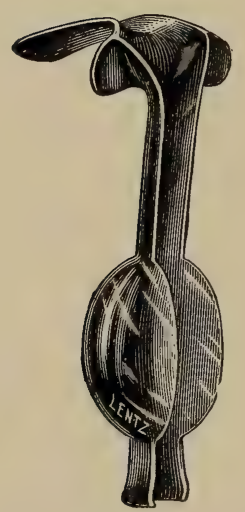

Fig. II I.-Auvard's self-retaining speculum.

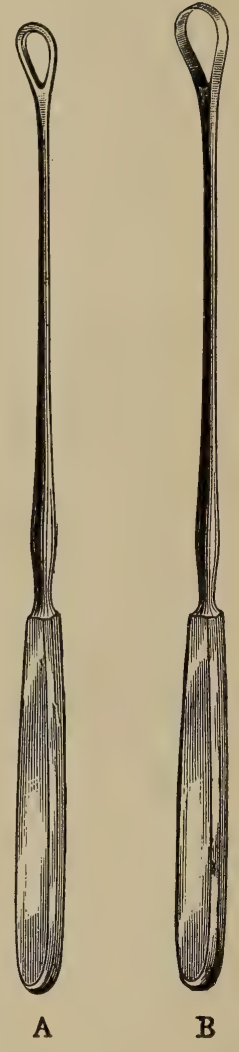

Fig. Ir2.-Curets: A, Thomas' dull; B, Sims' sharp

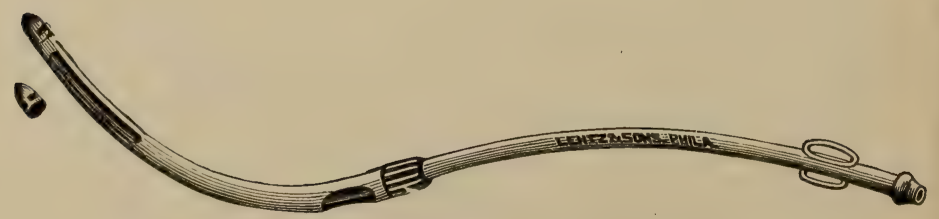

Fig. II3.-Hoffman's uterine irrigator. 


\section{Bone-plating and Osteoplastic Grafting}

$\begin{array}{lll}\text { Tourniquet. } & \text { Hemostats. } & \text { Forceps. } \\ \text { Scissors. } & \text { Saws. } & \text { Grooved director. } \\ \text { Chisels. } & \text { Bone-plates. } & \text { Drills. } \\ \text { Retractors, toothed } & \text { Electric engine and } & \text { Screws. } \\ \quad \text { and plain. } & \text { saws. } & \text { Screw-driver. } \\ \text { Nails. } & \text { Needles. } & \text { Gouges. } \\ \text { Curets. } & \text { Towman bone-holding } & \text { Needle-holder. } \\ \text { Knives. } & \text { clamp. } & \end{array}$

Operations Upon Male Genital Organs

Suprapubic Cystotomy

Knives.

Forceps.

Needle-holder.

Scissors.

$\begin{array}{ll}\text { Retractors, toothed } & \text { Needles. } \\ \text { and plain. } & \text { Hemostats. } \\ \text { Sounds. } & \text { Drainage-tubes. }\end{array}$

Suprapubic Prostatectomy

Same as foregoing, with-

Hemostats.

Double tenaculum.

\section{Perineal Prostatectomy}

Same as Suprapubic Cystotomy and-

Guide.

Lobe forceps.

Young's tractor.

Retractors.

\section{Lilholapaxy}

Catheters.

Syringe.

Lithotrite.

Cystoscope.

Catheters.

Stone-searcher.

Internal and External Urethrotomy.

Sounds, urethral. Catheters, filiform. Guide.

Urethrotomes, dilat- Catheters, Gouley. Forceps. ing.

Knives.

Hemostats.

Scissors.

Needles and needle-

Retractors.

Grooved director.

Varicocele and Hydrocele

Scissors.

Forceps.

Knives.

Grooved director.

Hemostats.
Needles and needleholder. 

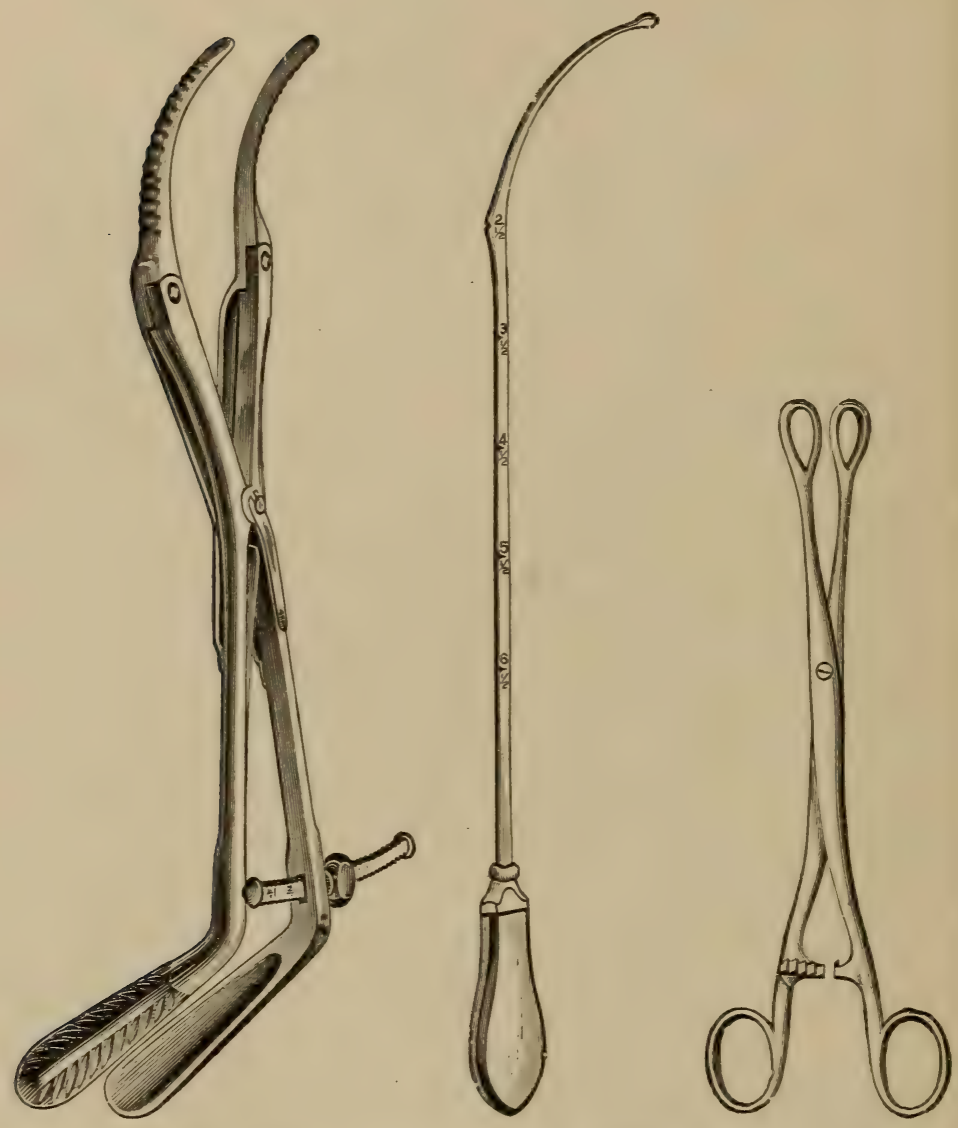

Fig. II4.-Goodell-Lentz uterine Fig. II5.-Simpson's Fig. II6.-Placental dilator. uterine sound. forceps.

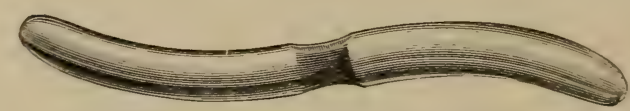

Fig. II 7.-Uterine dilator. 

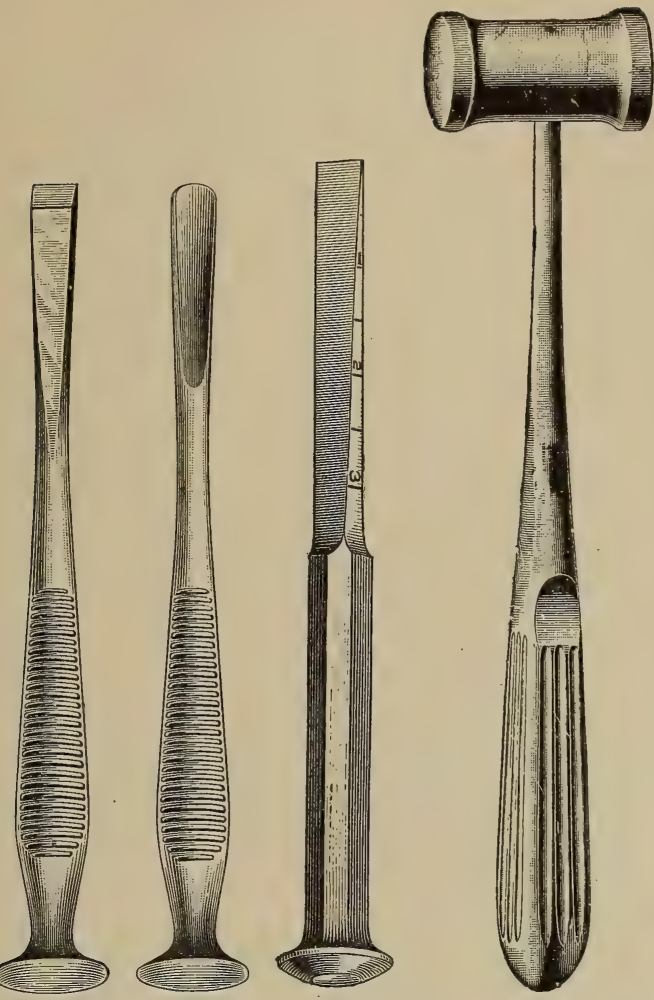

Fig. Ir8.-Bone chisels, gouge, osteotome (Macewen's), and mallet.

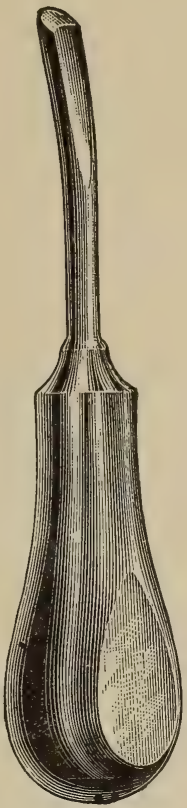

Fig. rig.-Bone gouge.

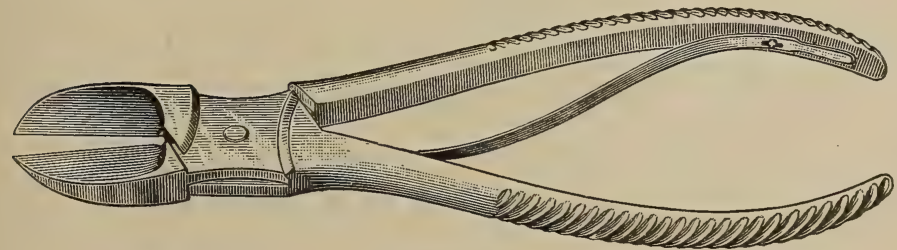

Fig. I20.-Bone-cutting forceps. 


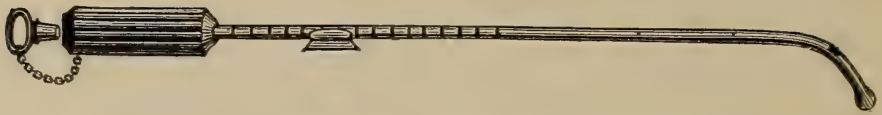

Fig. I21.-Thompson's evacuating stone-searcher.

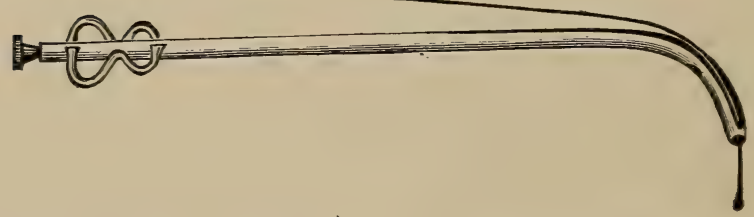

Fig. 122.-Gouley's tunneled catheter threaded on a filiform bougie.

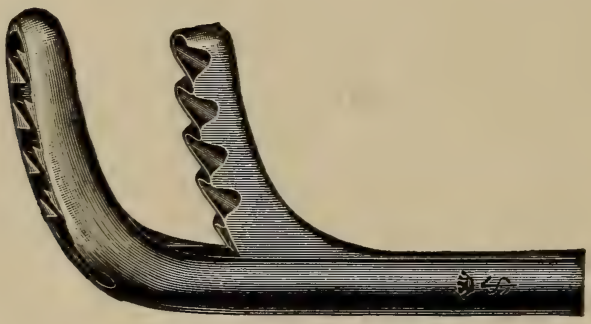

Fig. I23.-Lithotrite.

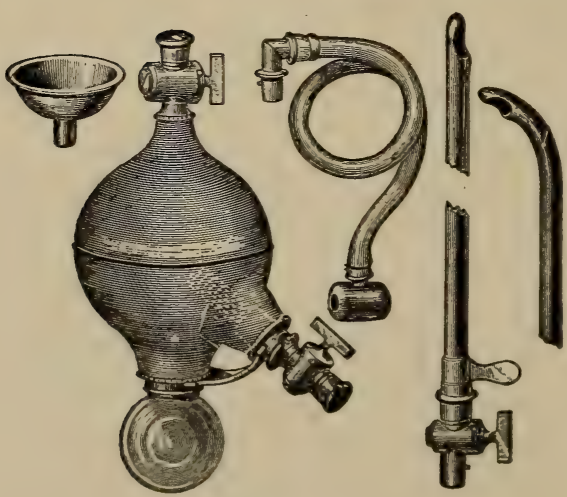

Fig. 124.-Bigelow's evacuator. 


\section{Catheters, Varieties of, Including Gouley}

See pictures of all varieties.

\section{Cystoscopy}

Electric attachments for cystoscope.

Syringe.

Urethroscope.

Knives.

Forceps, phimosis.
Knife, small.

Key's installator. Irrigating apparatus.

Local anesthetic.

\section{Circumcision}

Scissors.

Needles.
Catheters.

Sterile glycerin.

Rectum, Resection of

Knives.

Forceps.

Specula.

Proctoscope.

Scissors.

Probe.

Grooved director.

Double tenaculum.

Retractors, toothed and plain.

Clamp and cautery. Hemostats.

Hemostats.

Needle-holder.

\section{HEMORRHOIDS}

Same as above.

Needles and needleholder.

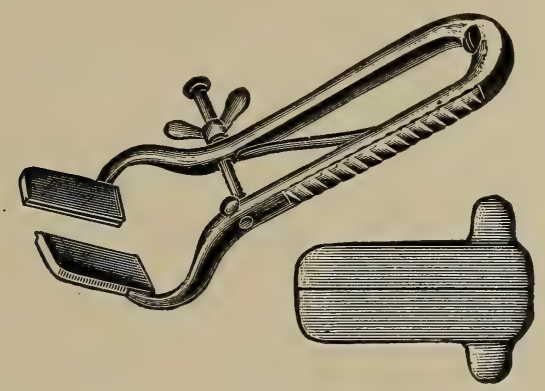

Fig. I25.-Gant's pile clamp. 


\section{CHAPTER VIII}

\section{ANESTHESIA}

Anesthetics are divided into three classes: local, spinal, and general.

Local anesthetics are agents which abolish sensation by their local action on the sensory nerves.

Spinal anesthetics are those that produce anesthesia by their action upon the spinal ganglion within the spinal canal.

General anesthetics are those which produce loss of consciousness.

No general rule can be given as to the selection of the anesthetic, but in describing each we will indicate where it is best applicable.

Preparation for Anesthesia and Precautions.-A preliminary preparation of the patient is advisable before the administration of a general anesthetic. The anesthetic is taken better if the patient has been placed upon a light diet for several days and the bowels regulated. Upon examination of the patient it may be found advisable to give a special preparation for several weeks in order to secure the best results from the operation. Where only a light anesthesia is administered, such as nitrous oxid (laughing-gas), practically no preparation is necessary.

Care of the Bowels. - Whenever possible the intestinal canal should be emptied several hours before the administration of the anesthetic. The usual method is 
to give a cathartic, such as castor oil, magnesia citrate, or magnesium sulphate, the night before and a low soapsuds enema two hours before the operation.

Frequently it will be found to be impossible to carry out the above procedure. In such cases a high purgative enema is advisable.

Diet.-For twenty-four hours before the operation a light diet should be taken. If the operation is to take place in the morning, practically no food should be taken after $8 \mathrm{P}$. M. the night before. If the operation is to take place in the afternoon, nothing should be taken after $8 \mathrm{~A}$. M. If the patient complains of weakness or great hunger a cup of beef-tea may be given up until within three hours of the operation. If the stomach is full at the time of operation, vomiting usually occurs, thereby adding to the dangers of the anesthetic.

In cases of emergency, preliminary washing out of the stomach is advisable, especially if the operation is upon the stomach.

It should always be practised if the operation is for intestinal obstruction, because in intestinal obstruction patients have drowned from vomiting occurring during anesthesia.

Preparation of Mouth and Teeth.-It is advisable to thoroughly cleanse the teeth with a tooth-brush, and if marked Riggs' disease exists, paint the roots of the teeth with iodin, in this way lessening the danger of aspiration pneumonia.

Preliminary Use of Drugs.-The patient should have a good night's sleep before the operation. Some patients will sleep without any assistance; others will require trional or bromids. Many surgeons order a morphin 
hypodermic one hour before the anesthesia. It has the advantage of lessening the stage of excitement and the amount of anesthetic required. It is especially indicated in excitable, vigorous, and alcoholic patients. The chief objections are that it has a tendency to diminish respiration and masks symptoms of overnarcosis. It is contraindicated in children and in the aged.

Atropin or scopolamin is frequently combined with the above to diminish the amount of secretion.

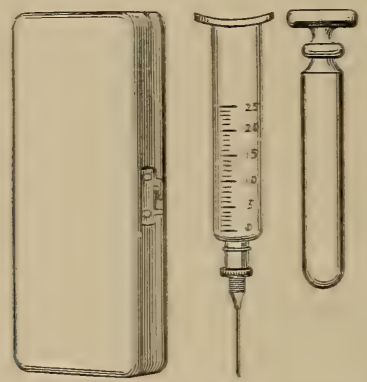

Fig. I 26.-Luer's hypodermic syringe.

Physical Examination.-A thorough examination is necessary if one would have a low ether mortality, for in this way contra-indications will be detected. This should include complete physical, blood-pressure, and urine examinations. When possible, the total elimination for twenty-four hours should be noted. For example, if albumin be present, it would be advisable, when possible, to delay the operation until the kidneys have returned to the normal, or to use some other form of anesthetic. If sugar is found to be present in the urine, the amount of acetone or diacetic acid should be noted and the patient carefully prepared. In 
the case of high blood-pressure, it might be advisable to use a local anesthetic.

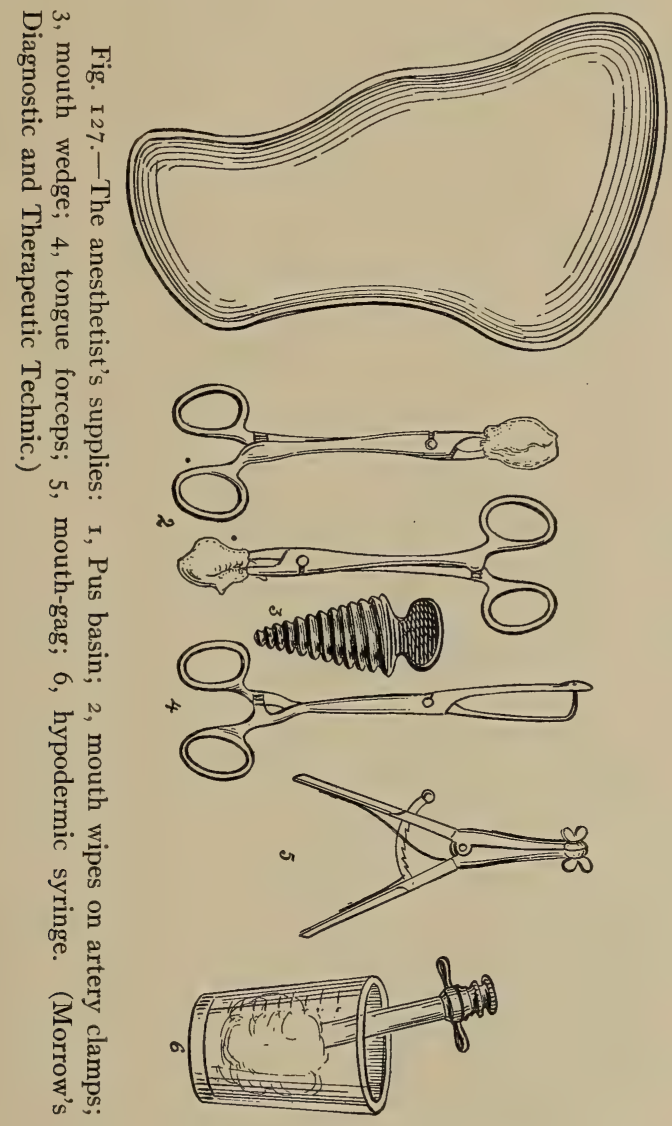

Care of the Patient.-When the patient is placed upon the operating-table, care should be taken to maintain the body heat and to prevent chilling. Frequently we find that patients are allowed to lie for several minutes 
in pools of water or in damp towels. The patient should be made as comfortable as possible upon the operatingtable and a small pillow should be placed in the hollow of the back to prevent postoperative backache.

Before the anesthetic is administered it should be noted that there are no tight bandages or clothing around the neck or chest. The mouth should be carefully examined and false teeth removed so that they do not fall into the larynx and cause obstruction.

Be sure to have the patients securely fastened so that they cannot injure themselves or the assistants.

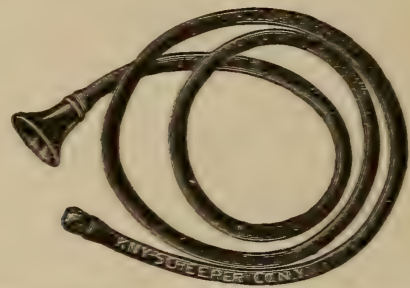

Fig. I2S.-Griffith's single-eared anesthetizing stethoscope, which will enable the anesthetist to have constant bnowledge of the patient' $s$ heart and respiratory action while allowing the hands to be free.

Anesthetist's Supplies.-Besides the apparatus used by any particular anesthetist, there should be a mouthgag, wedge-shaped tongue forceps. hypodermic syringe. camphor, adrenalin, atropin, strychnin, sponge-holders, sponges. and small pus basin. Oxygen apparatus should be ready for use.

Stages of Anesthesia.-Anesthetics usually- have three stages:

First-Stage of irritation.

Second-Stage of excitement.

Third-Stage of surgical anesthesia. 
First Stage.-A few preliminary whiffs produce an irritation of the mucous membrane, with coughing and secretion of mucus and a temporary holding of the breath. If the vapor is given too rapidly or in too concentrated form, violent coughing will occur and the patient will experience a sensation of suffocation. If given slowly, drop by drop, these symptoms will be obviated or greatly diminished and the patient will become etherized with a slow increase of the pulse and respiratory rate; pupils react to light, but there will be moderate dilatation and the conjunctival reflex is present.

Second Stage.-The patient now passes into the stage of excitement, in which he talks, laughs, and hallucinations are present. He sometimes throws his arms around, tries to tear off the mask, and injures the assistants unless he is securely held down. Here the anesthetic should be rapidly pushed until the stage of surgical anesthesia is reached.

Third Stage.-Now one notices a general relaxation; the pulse becomes slow and regular, the breathing superficial, with a more or less snoring sound; pupils are moderately contracted; the conjunctival and more superficial reflexes disappear and the patient is ready for operation. The conjunctival reflex is obtained by drawing up the upper lid and noting whether the lower lid contracts toward the nose.

It is now that the skill and experience of the anesthetizer will be determined. If the anesthetic is dropped slowly and uniformly the patient will be kept on the border-line of surgical anesthesia. The danger signs are increased, pulse-rate slower, dilatation of the pupils, which react less promptly to light. 
If the pupils dilate and the conjunctival reflex is present, you will know that the patient is coming out. The art of anesthetizing is that of keeping midway between the two.

The less anesthesia administered, the more rapid the recovery. Vomiting frequently occurs, laughing or crying, and the gradual recovery of the mental equilibrium. At times patients will pass into a deep sleep which will last for several hours.

Ether Anesthesia.-Ether is a colorless, volatile, sweetish liquid. It is very inflammable and should not be administered near an open flame, cautery, or $x$-ray tube. If artificial light is necessary it should be high above the patient, as ether fumes tend to sink downward. The ether fumes are irritating to the mucous membrane and frequently produce increased secretion of saliva. It is estimated that ether is about fifty times as safe as chloroform. The reason is that it is less rapid in its action and the danger signs appear earlier, and it is slower in its action than chloroform.

Suitable Cases.-When a general anesthetic is necessary and the operation is not suited to nitrous oxid, ether is preferable in the average case to all other anesthetics. On account of its irritating action ether should be avoided in cases of bronchitis, lung trouble, or in advanced Bright's disease. Ether may be administered by an expert by the drop method, semi-open, closed, or the vapor method, but with the novice or beginner the open method is the safest.

Open Method.-Any of the chloroform masks are satisfactory, or several layers of gauze resting on the etherizer's hand. A new can of ether should be opened for 
each anesthetic, as in this way pure ether will always be obtained. Some manufacturers have cans with special dropping mouths attached.

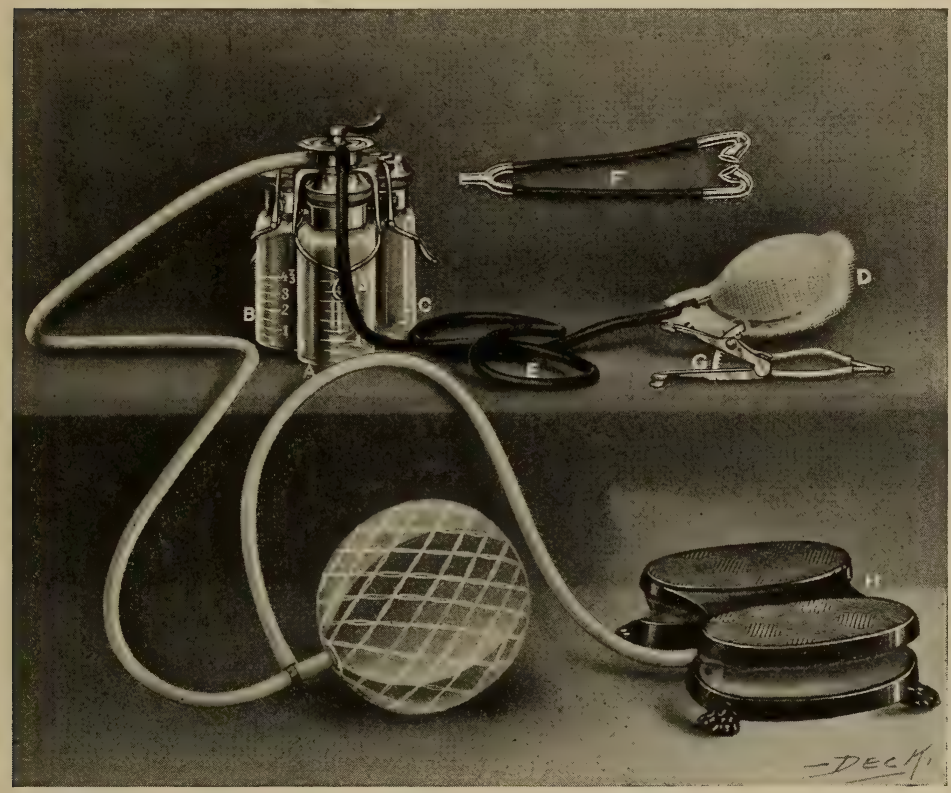

Fig. I29.- Vapor apparatus for anesthesia: A, bottle containing hot water and essence of orange; $\mathrm{B}$, ether bottle; C, chloroform bottle for ether or chloroform at discretion of anesthetist; D, mask for ordinary anesthesia, connected to bottles by delivery tube E; F, Lombard nasal tubes for nasal insufflation anesthesia; G, vapor delivering mouth-gag for work about the mouth and throat; N, foot-pump. (Fowler's Operatingroom and the Patient.)

Semi-open method, such as Allis' inhalers, consists of an outer metal form provided with slots through which a cotton or flannel bandage is threaded.

Closed Inhaler.-This consists of a closed face-piece 
surrounded by an inflatable rubber rim, connected to a chamber and rubber bag filled with gas. The chambers have openings so that air or the anesthetic may be introduced, or rebreathing may be obtained by closing the openings. To obtain the benefits of warm vapors, the bottles of the inhalers are heated.

Vapor Method.-This method is especially indicated in operations around the mouth and throat. It can be administered by a tube introduced into the mouth or

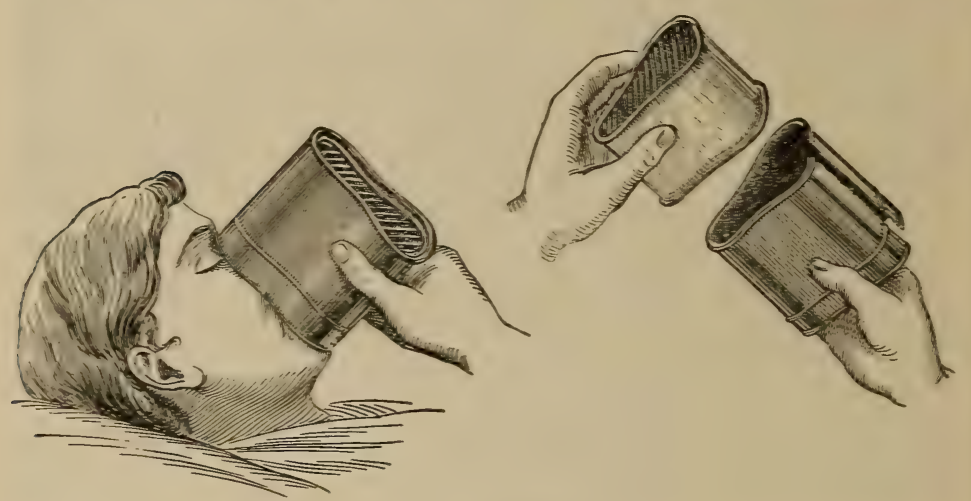

Fig. I30.-Allis' aseptic ether inhaler.

nose. The Gwathmey apparatus is as satisfactory as any, and as described by himself consists of two 6-ounce bottles, one for chloroform and one for ether. Both are placed in a tin ressel containing warm water. If the heat is to be continued, renew the water from time to time. In each of the bottles there are three tubes. varying in length from one that reaches to the bottom of the bottle to one that penetrates only the stopper. These represent three degrees of vapor strength. By turning a cock at the mouth of the bottle ether or chloroform may 
be used, or by turning another cock pure air or oxygen may be given. By pressing the hand-bulb air or oxygen may be forced into the apparatus and the ether or chloroform is carried to the patient by a tube. Whatever inhaler is used, the part that comes in contact with the patient should be sterilized.

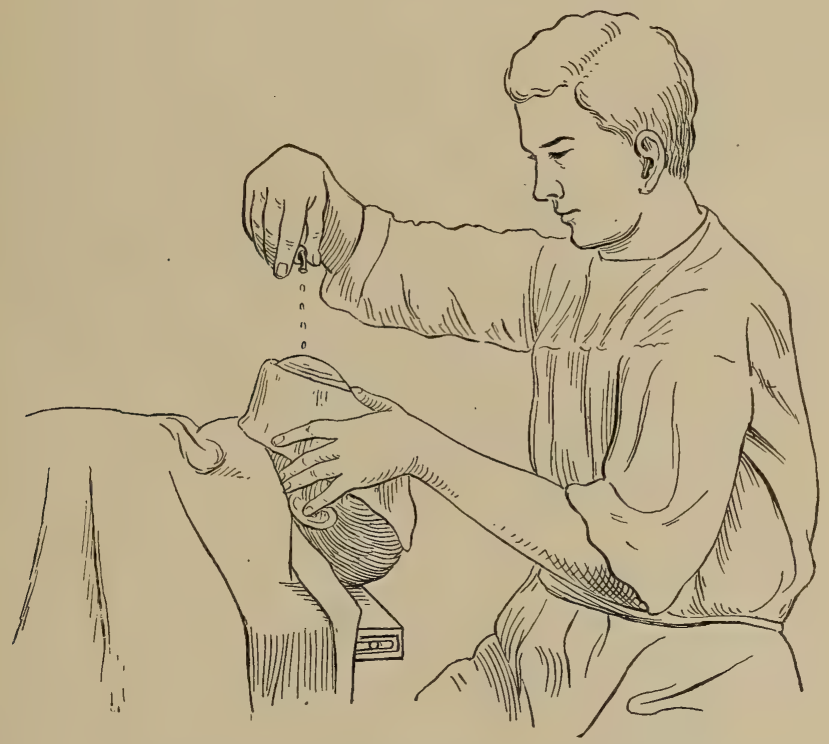

Fig. I31.-Showing the administration of ether by the drop method. (Morrow's Diagnostic and Therapeutic Technic.)

Drop Method.-The eyes of the patient should be protected by a folded towel or piece of rubber dam and the mask or gauze placed over the mouth. The patient is instructed to breathe naturally and regularly. After several breaths have been taken, a few drops of ether are dropped upon the mask. If the patient struggles, coughs 
or chokes, the mask should be removed and the procedure started again. When the stage of excitement is reached, less time should be allowed to elapse between the drops, but care should be exercised not to change the rate of dropping too suddenly, as this has a tendency to irritate the respiratory tract by its density, thereby causing the patient to choke or hold his breath. By the drop method it is possible for the patient to lose consciousness without moving in about fifteen to twenty minutes. As soon as the patient reaches the stage of surgical

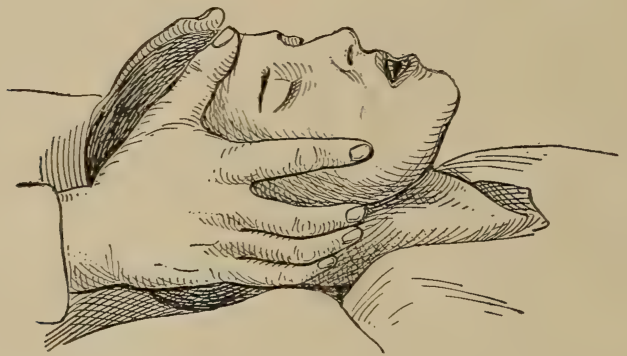

Fig. 132.-Proper method of holding the jaw forward. (Morrow's Diagnostic and Thereapeutic Technic.)

anesthesia only sufficient ether should be given to keep him under its influence. During the anesthesia the pulse-rate, respiration, and eye reflexes should be frequently noted. To prevent the tongue from falling back and causing obstruction the jaws should be held forward by placing the fingers back of the angle, for if the jaw is pushed forward, the tongue, which is attached to it, will also be pushed forward. If the tongue continues to drop back, it should be held forward by tongue forceps or a thread, or a heavy piece of silk pierced through the 
more agreeable to take, quicker in its action, and consciousness returns more rapidly. Fatalities from it are sudden and without premonitory signs. It is best administered warm and with the head low. Always remember to pay minute attention at all times. Do not confuse with ether, where large amounts are required to produce anesthesia. Here only a few drops are necessary. At present it is considered a dangerous anesthetic, as it causes subsequent changes in the liver and other organs. It is safer in the presence of a cautery or open flame, as it is not inflammable. Its use at the present time is becoming more limited.

Nitrous Oxid Anesthesia.-Nitrous oxid is a colorless gas heavier than air. It is sold in liquid form in steel containers, from which when liberated it escapes as a gas. It has anesthetic properties, but its result is mostly due to diminution of the amount of oxygen inhaled. It is considered the safest anesthetic. The death-rate is said to be $I$ in 100,000 . When used with the proper admixture of air or oxygen, anesthesia may be continued indefinitely. The amount of oxygen necessary is from 8 to 18 per cent. Nitrous oxid is very rapid in its action and produces complete unconsciousness in about two minutes, and the patient recovers in approximately the same time. The disadvantages of nitrous oxid are that it does not produce complete relaxation and requires a complicated apparatus for its administration. It is contra-indicated in any obstruction of the airpassages. For long operations it is advisable to precede it by preliminary medication of morphin.

Apparatus.-It consists of a mask with a pneumatic rim which accurately fits the face. This is connected to 
a chamber which has valves or openings for intake and outgo joined with rubber bags into which the oxygen and nitrous oxid flow. These openings may be controlled by a switch to definitely establish the administration, or by valves which the operator controls, increasing or diminishing the quantity as indicated. Most apparatus have a rebreathing chamber attached, so that the same gases are used several times, in this way diminishing the amount of oxygen and nitrous oxid.

All parts which come in contact with the patient should be carefully sterilized after using.

Administration.-In giving pure nitrous oxid for short operations the apparatus is connected with a supply cylinder and the rubber bag partially filled with gas. The face-piece is then applied to the mouth and nose so that air cannot enter around the rim; the outlet valve is opened and the patient is requested to breathe. After two or three inhalations, when the patient has become accustomed to the apparatus, the stop-cock is opened and the gas is allowed to enter the bag. In this way the patient breathes pure nitrous oxid. After the first few inspirations of gas the face gradually changes color and becomes dusky and finally a dark blue. There is usually at first a mumbling speech which is rapidly followed by snoring, and at times rigidity of the muscles. A minor operation may now be performed, as the surgical anesthesia will last approximately two minutes. Reaction is rapid and the face gradually assumes its normal color. For long operations sufficient oxygen to keep the patient just under the point of unconsciousness is allowed to enter the bag. Duskiness of the skin and irregular breathing is a signal for more oxygen. Often anesthesia 
is best obtained from the form of apparatus by which the percentage of oxygen can be regulated.

Nitrous Oxid and Ether.-The patient is first anesthetized with gas, which is either continued with ether or

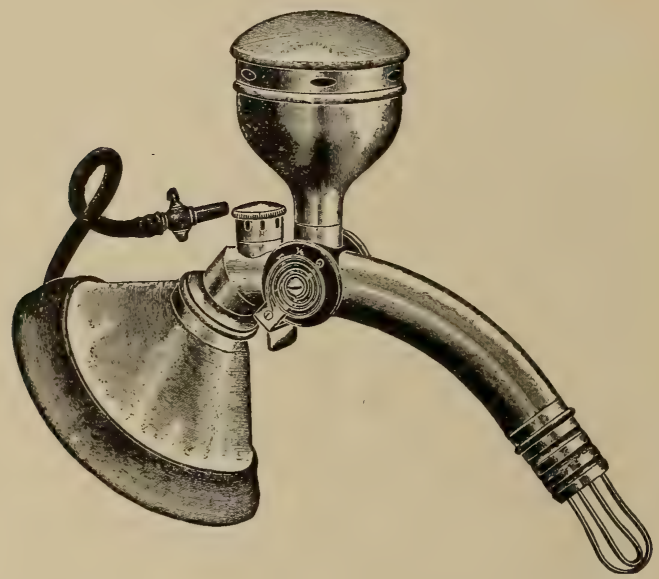

Fig. I35.-Griffith's combined inhaler for gas and liquid anesthetics.

the admixture of ether and nitrous oxid. This is the most careful method of anesthetizing and gives the relaxation required, at the same time diminishing the amount

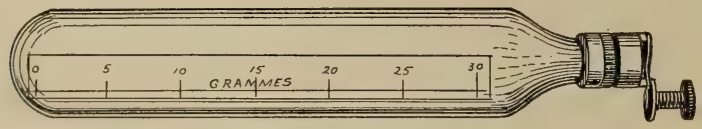

Fig. 136.-Ethyl chlorid tube. (Morrow's Diagnostic and Therapeutic Technic.)

of anesthetic necessary. The ether is admitted to the chamber by a special dropper which can be regulated.

Ethyl chlorid is a harmless volatile liquid. For general 
anesthetic purposes only the pure product should be used and the bottle should be labeled "For General Anesthesia." It is put up in metal or glass containers with a special spring stop-cock. Anesthesia is produced in from thirty to sixty seconds, and is continued until from two to three minutes after the anesthetic has been discontinued.

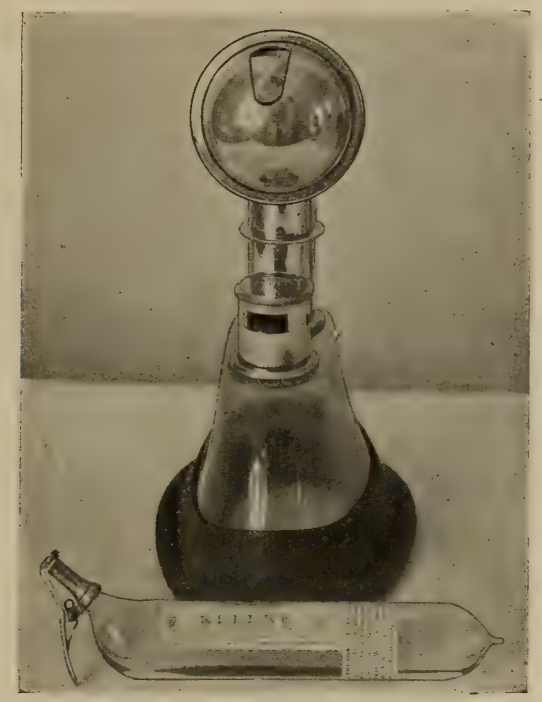

Fig. 137.-Mask and tube for ethyl chlorid (Hirst).

It is more dangerous than nitrous oxid, but is frequently followed by headache, nausea, vomiting, etc. Its advantage is that it may be administered without any special apparatus. It is used for short operations or as a preliminary to a general anesthetic. It is dangerous and should not be used except by some one with special training. 
SPECIAL METHODS OF ANESTHESIA

Intrapharyngeal Inhalation Anesthesia.-In operations about the mouth, face, etc., this method, by which tubes are passed into the pharynx through the nose (Crile's method), will be found to be very convenient. The advantages are that the anesthetizer and his apparatus

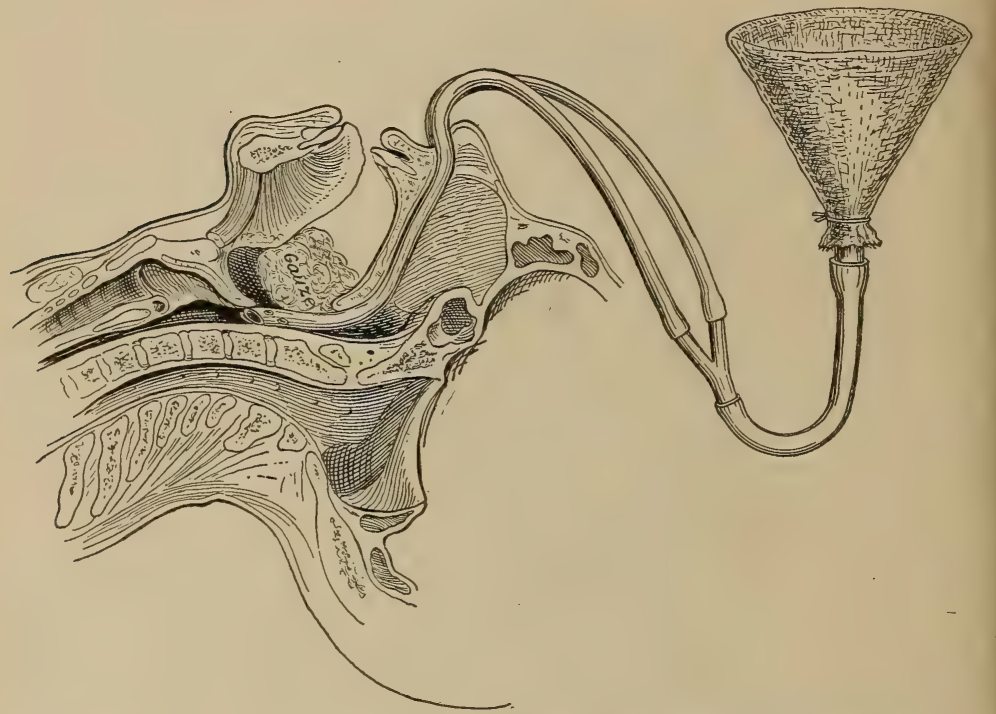

Fig. 138.- Showing the method of inserting the tubes and packing the pharynx for intubation anesthesia. (Morrow's Diagnostic and Therapeutic Technic.)

are removed from the field of operation so that he will not interfere with the operator, nor will the operator have to stop at frequent intervals while more anesthetic is being administered, as is necessary in the ordinary method of anesthesia. The pharynx may or may not be packed with gauze. 
The apparatus consists of two rubber tubes that can be passed through the nose. They are about 8 inches long and have side openings cut into the lower 2 inches. The outer ends are connected to two ends of a $\mathbf{Y}$-shaped tube, the other end of which is connected to a funnel by a rubber tube. The funnel is loosely packed with gauze.

Technic.-After full anesthesia has been produced by the usual method, a mouth-gag is inserted, the throat cleared of mucus, and two tubes well lubricated are passed through the nose down into the lower back part of the pharynx. At this point the pharynx may or may not be packed with gauze. The tubes are then connected as described above and the anesthetic is continued by dropping the ether upon the gauze in the funnel. After the operation is completed the tubes are gently removed.

Intratracheal Insufflation Anesthesia.-Intratracheal anesthesia, first developed by Meltzer and Auer, consists in the introduction into the trachea of a flexible woven tube which is slightly less in diameter than the lumen of the trachea. This tube is connected to a special apparatus by which air and ether are forced through the tube into the trachea. The space between the tube and the trachea permits the exhalation of air from the lungs. By this method it has been found that it is not necessary for respiration to take place at all, as the interchange of oxygen, etc., is carried on by the continuous entrance and exit of air. It was especially developed for operations upon the chest and in cases of respiratory paralysis. It is now used for operations upon the mouth, etc., as the continuous reflux of air prevents blood from being sucked into the larynx and thereby causing pneumonia. It is also frequently used in operations upon 
the head, neck, and brain, as by this method the anesthetizer is away from the field of operation and in this way lessens the danger of sepsis.

Apparatus.-There are several good intratracheal insufflation machines on the market, such as Elsberg's, Janeway's, Boothby's, and Müller's, which are elaborate in their completeness. A very simple and inexpensive apparatus which answers all purposes is described by Meltzer (Keen's Surgery, Vol. VI) as follows:

"By means of a glass-blower's foot-bellows (B) air is driven through a system of branching tubes into the intracheal tube (In.-T.). The first branching of the tubes is introduced for the purpose of regulating the interruption of the air-stream. From the right branch a tube is led off laterally, carrying a stop-cock (St. 3) which is to be used for the interruptions of the air-current. During the opening of the stop-cock a part of the aircurrent continues through the left tube, thus preventing too great a reduction of the pressure, which is undesirable. By means of a screw-clamp (S. C.) the amount which is to pass through the left tube can be regulated; a narrowing of this tube causes a greater collapse of the lung during the interruption. The second branching of the tubes is introduced for the purpose of regulating the anesthesia. The ether bottle (E) is interpolated in the left branch; the right branch runs uninterrupted outside of the bottle to unite with the part of the left tube which comes from the ether bottle. When the stop-cock in the right branch (St. 2) is closed, all the air passes through the ether bottle; when, instead, both stop-cocks in the left branch (St. I and St. 4) are closed, only pure air reaches the intratracheal tube, and when all three stop- 
cocks are open only one-half of the air is saturated with the anesthetic. By partial closing of the stop-cocks various degrees of anesthesia can be obtained. The third opening in the ether bottle carries a tube with a funnel (F) through which the bottle is filled with the anesthetic; the tube is otherwise kept tightly closed by means of a screw-clamp (S. C.). All three rubber stoppers are firmly and permanently wired down to resist various pressures. When the ether bottle is to be refilled during insufflation both stop-cocks on the left side are closed, while the one on the right side is open.

"The tube which connects the anesthesia circle of tubing with the intratracheal tube (In.-T.) carries two lateral tubes; one is connected with a manometer (M.), which needs no description, and the other leads to a safetyvalve (S. V.) of simple construction. To the rubber tubing is attached a graduated glass tube, the lower end of which is immersed under the surface of the mercury in this bottle to a depth corresponding to the pressure which is desired for the intratracheal insufflation. For instance, if the pressure should be not more than $20 \mathrm{~mm}$. of mercury, the glass tube is immersed just $20 \mathrm{~mm}$. below the surface of the mercury. The glass tube is kept in the desired place by means of a rubber ring resting upon the opening of the mercury bottle. This device gives great safety to the working of the method. No matter how strong and irregular the bellows is worked, the intratracheal pressure could never rise above the one arranged for; the surplus of air escapes through the tube from under the mercury."

The tracheal tube should be flexible and elastic, about I 4 inches $\left(35 \mathrm{~cm}\right.$.) long, with a mark IO $\frac{1}{2}$ inches $(27 \mathrm{~cm}$.) 
from the distal end and with the opening preferably at the end. A silk-woven catheter, No. 22 to 24 French, and

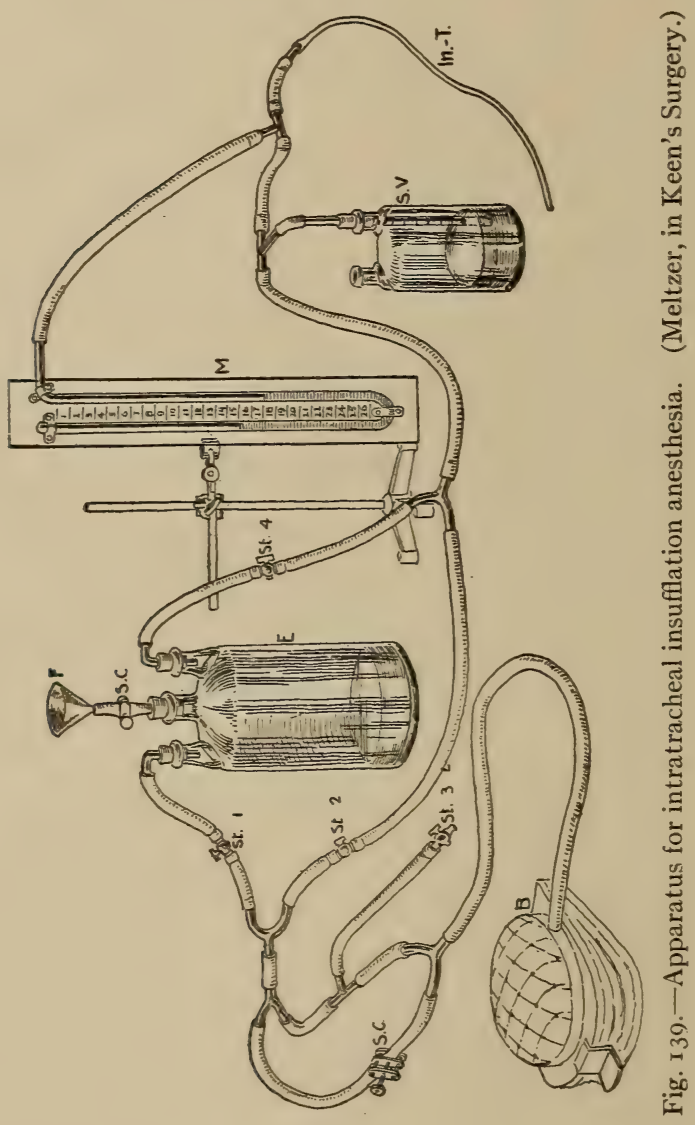

for children of a correspondingly small size, is frequently used. There will be required in addition a mouth-gag and a Jackson's direct view laryngoscope (Fig. I40). 
Elsberg has devised a special bit or holder to keep the tube from slipping up or down after it has been properly introduced, but in its absence adhesive plaster may be employed for this purpose.

Asepsis.-The tracheal tube and the laryngoscope must be sterile.

Preparation of Patient.-The patient is prepared in the usual way as for any other anesthetic.

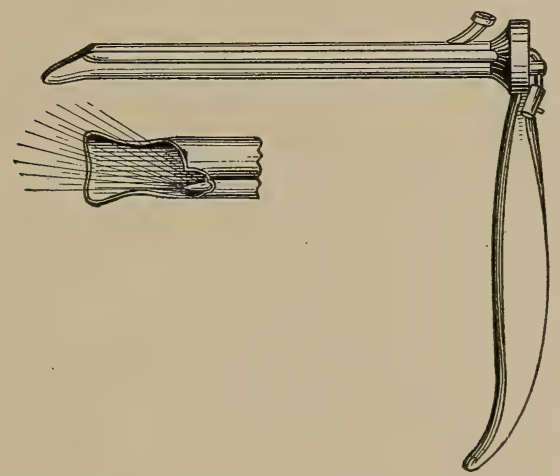

Fig. 140.-Jackson's direct view laryngoscope. (Morrow's Diagnostic and Therapeutic Technic.)

Technic.-The patient is etherized by the open method and the tube introduced into the larynx by means of a Jackson laryngoscope, with the head well extended. No force should be used upon the tube. After it has been introduced the Jackson speculum should be removed. The tube should be pushed down until a slight resistance is felt. It should then be withdrawn approximately 2 inches which is indicated by a white mark upon the tube. Care should be used to see that the tube is in the trachea and not in the esophagus. This is determined by the 
fact that air will not be drawn in and out through the tube if it is in the esophagus. After it has been determined that the tube is in the trachea, the tube should be connected to a special apparatus which prevents it from changing its position. It is then connected to the intratracheal apparatus with the air under the pressure of I $_{5}$ to $20 \mathrm{~mm}$. of mercury. After the operation is completed the ether is discontinued and pure air insufflated for a minute or two, and then the tube is withdrawn.

Rectal anesthesia consists of producing etherization by means of a warm ether vapor gradually introduced into the rectum. This method has been more or less abandoned on account of the irritation of the ether, which produced colicky pains, diarrhea, and at times distention of the intestines. With the improved technic of Cunningham these faults are said to have been eliminated.

Oil-ether Colonic Anesthesia.-Recently Gwathmey, of New York, has developed a method of rectal anesthesia by means of a mixture of olive oil and ether injected into the rectum, to which he applies the name "oilether colonic anesthesia" (New York Medical Journal, Dec. 6, I9I3).

\section{Scopolamin-morphin Anesthesia, "Twilight Sleep."-} Hypodermic injections of scopolamin or hyoscin (which are claimed to be chemically the same) have been used in combination with morphin to produce anesthesia. From the number of deaths reported from this combination it would appear to be a very dangerous form of anesthesia. "Twilight sleep" is the frequent hypodermic administration of small doses of the above. In small doses, however, hyoscin and morphin may be used with good results as an adjunct to local or general anesthesia. 
In such cases they can be given as follows: Hyoscin, gr. $\frac{1}{100}\left(0.00065 \mathrm{gm}\right.$.), and morphin, gr. $\frac{1}{6}$ to $\frac{1}{4}$ (0.0108-0.0162 $\mathrm{gm}$.), by hypodermic, one to two hours before operation. This combination is more efficacious than morphin alone, and has the effect of producing a drowsy state and even sleep, which may last five to six hours after the operation. It is contra-indicated in patients with heart disease or when there is a tendency to pulmonary edema. In the young and the aged hyoscin and morphin should be used with great caution.

Postoperative Anesthetic Paralyses.-These are usually peripheral in origin, and are due to pressure upon the nerve during the period of unconsciousness. At times paralysis due to cerebral hemorrhage may occur during anesthesia. Paralysis due to pressure may affect the arm, leg, or face. The most frequent form encountered is wrist-drop, due to pressure upon the musculospiral nerve, and is caused by the arm being allowed to hang over the table, or by injury to the brachial plexus while the patient is in the Trendelenburg position.

Delayed Poison.-Many deaths formerly credited to anesthesia, shock, and hemorrhage are now known to be due to acid intoxication. The symptoms do not appear for several hours after the operation. Persistent vomiting is frequently due to acid intoxication. Sodium bicarbonate, by the mouth, may be given as a preventive, or after the operation by enteroclysis or hypodermoclysis. It is considered the most valuable remedy at our command. This should be assisted by free elimination from the skin, bowels, and kidneys. 


\section{LOCAL ANESTHESIA}

Local anesthetic agents are divided into two classes: those which act by freezing the part, such as cracked ice and salt, ether, and ethyl chlorid; and those which act directly upon the sensory nerves, as cocain, novocain, eucain, alypin, akoin, tropocain, stovain, and phenol.

Cracked Ice and Salt.-Take $\frac{1}{2}$ pound of cracked ice and mix thoroughly with $\frac{1}{4}$ pound of salt. This is applied to the part from ten to fifteen minutes. The part becomes tallowy-white and anesthetic. The objections to this form of anesthesia are: it offers great resistance to the knife, it devitalizes the tissue, and produces a sensation of burning after the part has thawed.

Ethyl Chlorid.- It is sprayed upon the part and evaporates quickly, and in so doing it carries off the heat and produces anesthesia. Ether acts in the same manner locally applied.

The objections to these agents are: they produce a resistance to the knife, a burning sensation, and congestion of the vessels of the part after thawing.

Cocain.-It was first used as a local anesthetic in the eye clinic of Dr. Koller (1884) when he succeeded in anesthetizing the conjunctiva by instilling a few drops of a 4 per cent. solution of cocain into the eye, anesthesia resulting five minutes after the instillation.

Cocain when applied to any mucous surface is absorbed readily and anesthetizes the sensory nerve-endings of the part. It is, therefore, very useful in operations upon the nose, throat, ear and eye, urethra and bladder, and is administered internally for its anesthetic action on the mucous membrane of the stomach in cases of vomiting. 
When employed to anesthetize the skin, local application of the anesthetic solution will not suffice, and it is, therefore, necessary to inject the solution hypodermically, when the nerve-endings in or under the skin are - rendered insensitive by being bathed in the solution employed; this process is called infiltration anesthesia.

Conduction anesthesia is the interruption of the conductivity of smaller or larger nerve branches which supply a given tissue complex.

Endoneural anesthesia is the injection of the anesthetic solution into the nerve-tissue.

Perineural anesthesia is the injection of the anesthetic solution into the tissues surrounding the nerve.

Cocain is a very powerful local anesthetic having an extreme toxic action which may readily poison the patient, resulting in delirium, talkativeness, and respiratory paralysis. It is very difficult to sterilize, as it decomposes on boiling, forming ecgonin, which has no anesthetic value; it is, therefore, necessary to use fractional sterilization or add carbolic acid, which makes it less valuable.

Cocain is used in solutions varying from $I$ to Io per cent. It is never necessary to use over I per cent. solution for infiltration anesthesia. When applied locally to mucous surfaces it may be used up to Io per cent.

The following are the formulas for the solutions used by Schleich for producing local anesthesia:

No. I-STRONG

Cocainæ hydrochloridi . . . . . . . . . . . . gr. iij;

Morphinæ hydrochloridi.............. gr. $\frac{2}{5}$;

Sodii chloridi (sterilized) . . . . . . . . . gr. iij;

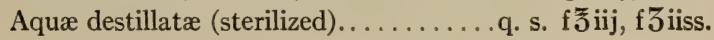


No. II-NORMAL

Cocainæ hydrochloridi.............. gr. iss;

Morphinæ hydrochloridi.............. gr. $\frac{2}{5}$;

Sodii chloridi (sterilized) ............ gr. iij;

Aquæ destillatæ (sterilized) ............ s.. f

No. III-WEAK

Cocainæ hydrochloridi. .............. gr. $\frac{1}{6}$;

Morphinæ hydrochloridi............... gr. $\frac{1}{12}$;

Sodii chloridi (sterilized) ............ gr. iij;

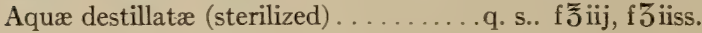

One drop of a 40 per cent. solution of formalin should be added to each of these solutions to preserve them. The fluid is injected in such a manner that the part to be operated upon is completely surrounded by wheals of the injected fluid.

The dose should be in proportion to the extent of the surface to be anesthetized, but should never exceed $\mathrm{I} \frac{1}{4}$ gr. It is well to divide the dose into several portions, leaving an interval of several minutes between each injection. If toxic manifestations follow the first portion, further injection must be abandoned.

Treatment of Cocain-poisoning.-Give morphin and atropin hypodermically, or administer chloral hydrate, chloroform, alcohol, or ether; these are physiologic antidotes.

For cardiac weakness strychnin should be administered. A large teacupful of coffee, administered either hot or cold, has proved very beneficial in this condition.

Novocain, introduced by Braun, is a white crystalline powder, soluble in water, is less toxic than cocain in proportion to its local anesthetizing power, does not cause damage to the tissues, is easily sterilized when in solution, and is capable of being combined with adren- 
alin. It can be heated to $120^{\circ} \mathrm{C}$. without decomposition, and large doses may be employed without toxic effects $-7 \frac{1}{2}$ to $22 \frac{1}{2} \mathrm{gr}$. have been employed without unpleasant symptoms resulting. It is seven times less toxic than cocain and one-third less than any of the other substances mentioned. Vomiting is not rare after injection, but is free from significance.

The toxic symptoms are nausea, sweating, pallor, weak pulse, acceleration of the respiration, feeling of oppression, and vomiting.

Solutions employed are 0.5 to I or 2 per cent., the former two usually being sufficient for the production of conduction anesthesia. Where there are thick nerve trunks 2 or 3 or even 4 per cent. have been employed.

There are tablets on the market containing $0.125 \mathrm{gm}$. of novocain and $0.00012 \mathrm{gm}$. of suprarenin. One tablet dissolved in 25 c.c. of sterile physiologic salt solution will give a 0.5 per cent. solution.

To I liter of physiologic salt solution should be added 3 drops of hydrochloric acid to preserve the adrenalin during the process of boiling.

Eucain occurs as a white powder, soluble in water, can be boiled, is less toxic than cocain, but is not as strong an anesthetic.

Alypin, akoin, and tropacocain are other drugs which are used in place of cocain because their anesthetic value is not destroyed by boiling and they are less toxic in their action, but novocain is by far the superior of these agents, as has been proved by results.

Phenol has been used, acting both as an antiseptic and anesthetic, but sloughing has frequently followed its use, and for this reason it is no longer used for this purpose. 


\section{SPINAL ANESTHESIA}

The injection of anesthetic fluid into the spinal canal. The entire technic must be done under strict surgical asepsis. A solution of iodin, full strength, should be applied locally to the entire back by means of a sterile gauze sponge. A line drawn parallel with the superior border of the crests of the ilia divides the fourth lumbar

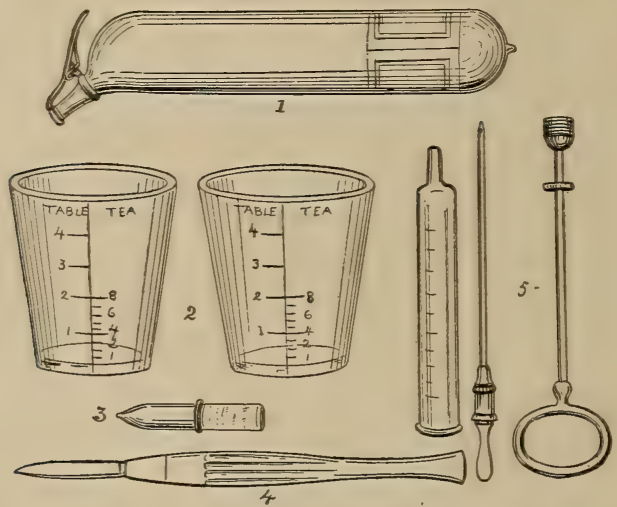

Fig. I4I.-Apparatus for spinal anesthesia: I, Ethyl chlorid; 2, medicine glasses, one for receiving the spinal fluid and the other for the anesthetic solution; 3, ampule containing sterile cocain and salt crystals; 4 , scalpel; 5, syringe and trocar. (Morrow's Diagnostic and Therapeutic Technic.)

spine. Have the patient in the sitting position, with arms folded upon the chest and bending forward; this being done to widen the interspaces.

A platinum or iridoplatinum needle about 3 inches long should be used for this purpose. The needle should contain a trocar and be properly beveled.

When the needle has passed into the deeper structures the trocar is removed and the needle is tilted downward 


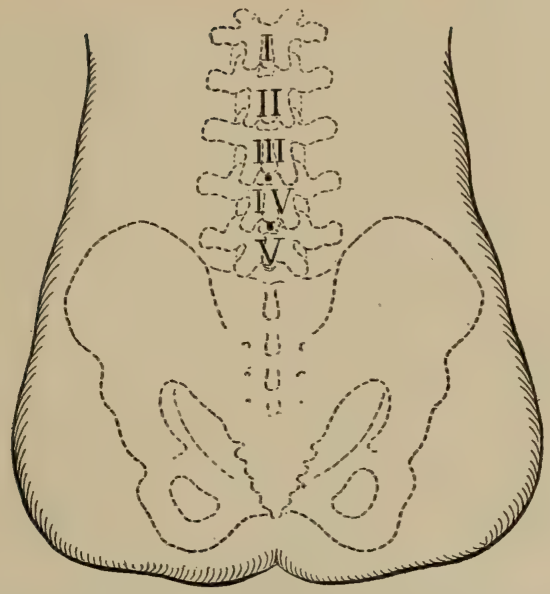

Fig. 142. - Points for injecting the anesthetic solution in spinal anesthesia. (Morrow's Diagnostic and Therapeutic Technic.)

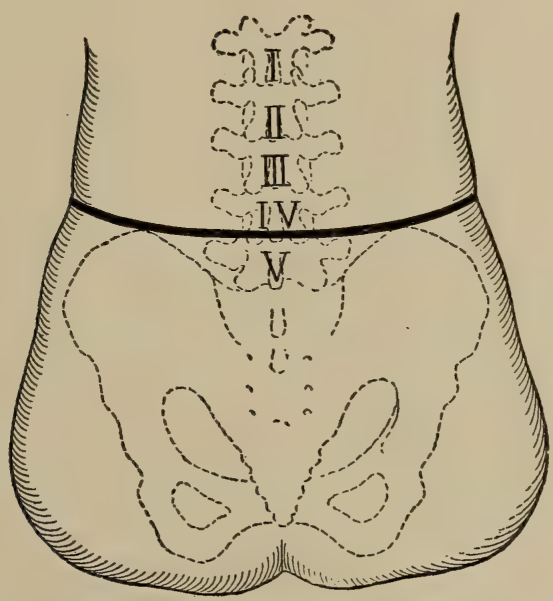

Fig. 143.- Showing the method of locating the fourth spinous process by passing a line through the highest points of the iliac crests. (Morrow's Diagnostic and Therapeutic Technic.) 
and pushed gently forward in the direction of the canal. When the needle has entered the canal drops of spinal fluid will exude. Allow about the same amount of fluid to escape as you intend to inject into the canal.

Now attach the barrel of the hypodermic syringe to the needle and inject the anesthetic solution. Remove the

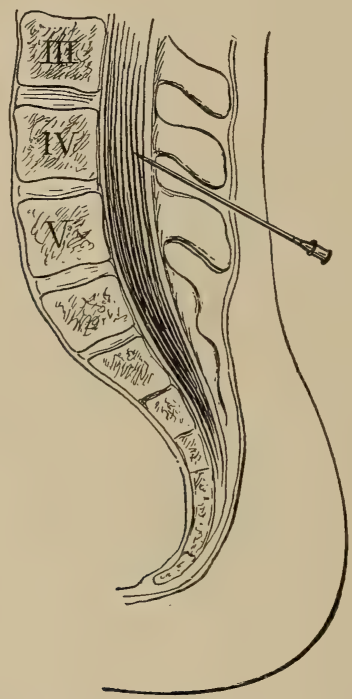

Fig. 144.-Showing the direction of the needle in entering the spinal canal.

(Morrow's Diagnostic and Therapeutic Technic.)

needle quickly and place patient in the recumbent position. If the solution is injected into the fourth lumbar interspace anesthesia will be incomplete at the level of the navel, and if it is injected into the second lumbar interspace anesthesia of the entire abdomen will be complete.

If the solution used has a lesser specific gravity than 


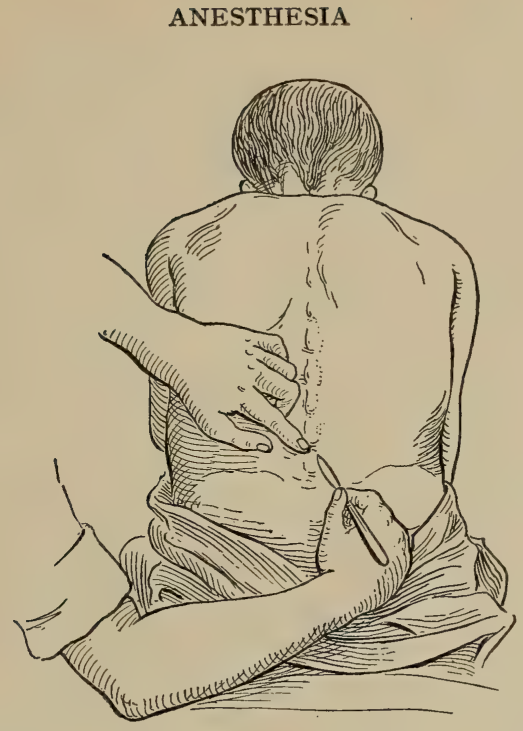

Fig. I45.-Spinal anesthesia. First step, nicking the skin at the site of puncture. (Morrow's Diagnostic and Therapeutic Technic.)

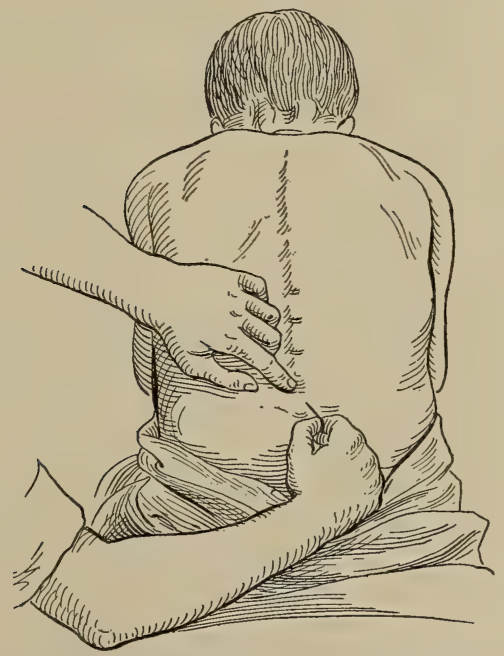

Fig. I46.-Spinal anesthesia. Second step, inserting the needle. (Morrow's Diagnostic and Therapeutic Technic.) 


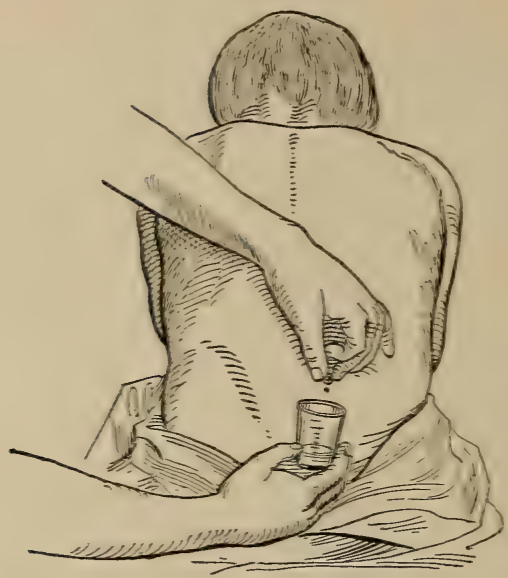

Fig. I47-C Spinal anesthesia. Third step, allowing the cerebrospinal tluid to escape. (Morrow's Diagnostic and Therapeutic Technic.)

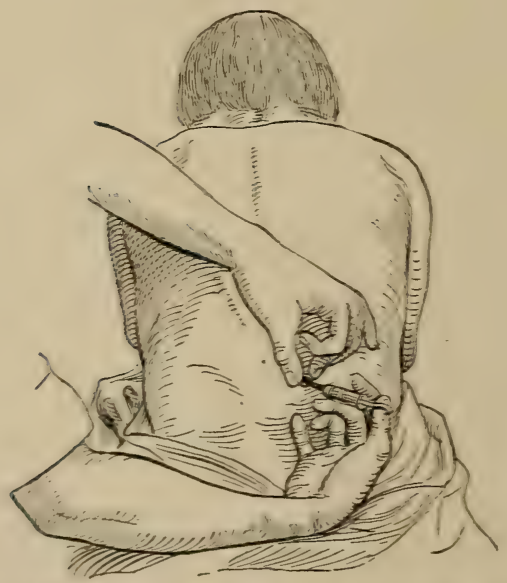

Fig. I48.-Spinal anesthesia. Fourth step. injecting the anesthetic solution. (Morrow's Diagnostic and Therapeutic Technic.) 
the spinal fluid the head and upper portion of the body should be lowered, and the opposite position assumed if the solution has a greater specific gravity.

A solution used for this purpose having a lower specific gravity than the spinal fluid is that of Babcock. The solution is on the market in glass ampules hermetically sealed and consists of the following:

\section{BABCOCK'S FORMULA}

(Approximately.)

(A) Stovain $\ldots \ldots \ldots \ldots \ldots \ldots \ldots, 0.08$ gm... $\mathbf{I}_{4}^{\frac{1}{4}} \mathrm{gr}$.

Lactic acid............... 0.04 c.c.. $\frac{2}{3}$ gr.

Absolute alcohol. ........... o.2 c.c... 3 minims.

Distilled water............ 1.8 c.c.... 30 minims.

(B) Tropacocain.............. o.I gm... I $\frac{1}{2}$ gr.

Absolute alcohol........., ... 0.2 c.c... 3 minims.

Distilled water............ I.8 c.c... 30 minims.

(C) Novocain .............. 0.16 gm... $2 \frac{1}{2} \mathrm{gr}$.

Absolute alcohol. ........... 0.2 c.c... 3 minims.

Distilled water. . . . . . . . r. 8 c.c.... 30 minims.

Dose.-r to I. 5 c.c. ( $16-25$ minims) of these mixtures is given to adults.

Postoperative Treatment.-The foot of the bed should be elevated for at least two hours. If vomiting occurs, give cracked ice; for headache, application of ice-cap affords great relief.

Contra-indications.-Very nervous patients, children, the very aged, and scoliotics.

Never use old solutions, as this is frequently the cause of severe headache. 


\section{CHAPTER IX}

\section{GAUZE SPONGES; PADS; DRESSINGS; TAMPONS; DRESSING-ROOM OUTFIT; DRAINAGE, CARE OF DRAINAGE-TUBES; GLOVES; SUTURES AND LIGATURES; SURGICAL APPLICATIONS}

BEFORE going into the details of this chapter let us state here that gauze is the most commonly used material for sponges and dressings because of its great absorptive powers, its softness and pliability, and the ease with which it can be sterilized and handled.

There are various grades on the market, each having a different mesh. The mesh varies according to the number of fibers in a square inch. This fact is important, as will be seen later.

Gauze Sponges.-Nearly every surgeon has his own particular size and pattern of sponge. Whatever size is decided on, be sure that there are no raw edges. They must be folded and invaginated in such a way that when ready for use no raveling or fiber is apparent, because these little particles if left in a wound will prevent healing and may cause suppuration. Three sizes are generally used and should be of about a 14 by 20 mesh, so as to absorb easily: (a) Small or wide sponge for external use; $(b)$ a larger sponge usually used wet for sponging in the abdominal cavity; $(c)$ a large gauze pack for use in keeping the intestines from the field of operation. 
In operations on the brain small pledgets of cotton are most commonly used, and are usually moistened with normal salt solution.

If marine sponges are required for an operation, the dark-colored ones should be bought. They do not look so attractive, but they are the finest sponges; they are "uncut" and "unbleached," and give more service than the clearer-looking ones, which are partly or wholly bleached. The bleached and cheaper sponges have been made by cutting one large sponge into several small ones, or by cutting off portions that were torn in taking the sponges from the ocean.

Marine sponges should be prepared as follows: I. Lay them in a stout cloth and pound sufficiently to break up grit and lime. 2. Rinse with warm water until it remains clear. 3. Immerse in hydrochloric acid solution ( 2 drams to I quart of water) for twenty-four hours. 4. Immerse in saturated solution of permanganate of potassium, followed with oxalic acid, then pass them through lime-water to take out all the oxalic acid, and rinse well in plain sterile water; after which they are immersed for twenty-four hours in a I : 1000 corrosive sublimate solution. They are preserved until used in a 3 per cent. carbolic acid solution.

When wanted for use the sponges are lifted out of the jar with long dressing-forceps and rinsed in plain sterile water.

Gauze pads for abdominal operations are made of eight thicknesses of gauze about 8 inches square, with the edges tucked in and hemmed to prevent fraying.

Pads are usually made in sets of five, seven, or nine for purposes of identification. As a further precaution 
to prevent a pad being left within the abdominal cavity they should have tapes attached. A weighted or gravity pad made by quilting flat bits of lead within the layers of gauze may be useful at times to act as a retractor of the intestines.

Absorbent cotton used in dressing cases is prepared in the same way.

Some hospitals find it expedient to sort, wash, resterilize, and use over soiled bandages and gauze. Cotton waste, after being boiled, sterilized, and dried, is used in place of absorbent cotton and gauze for the filling of pads.

To sterilize oils or glycerin place in a water-bath and boil for fifteen minutes.

Dressings.-The most common dressings are gauze, cotton-gauze, medicated gauze, and gauze packing.

Gauze for dressings is usually of a 20 by 24 mesh. Ordinary gauze dressing is about $2+$ to 36 ply and usually about 8 by 2 inches in size. The edges may be raw or folded in.

Cotton-gauze Dressings. - These are used in connection with ordinary gauze dressings when considerable drainage is expected. They are sometimes called cotton pads. They are made by covering an ordinary size strip of absorbent cotton with 2-ply gauze with the edges of the latter folded in. They are usually packed in pairs with four pieces of ordinary gauze dressing and sterilized the proper length of time.

Medicated Gauze.-The two principal forms of medicated gauze are: Sublimate gause, which is gauze soaked in bichlorid of mercury solution of a definite strength and then dried. It is seldom used at the present time. 
Iodoform gauze is a sterile gauze soaked in a mixture of iodoform, ether, alcohol, and glycerin. The nurse should bear in mind that every step must be aseptic, because, once made, it should not be sterilized.

I. Have the following ingredients at hand:

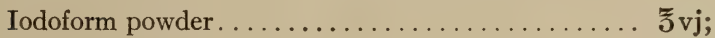

Glycerin........................ Oj;

Alcohol.............................. కviij;

Ether.......................

2. Sterilize the following: one basin, one spatula, and one pair of dressing forceps.

3. Sterilize hands and don sterile gown and a pair of rubber gloves.

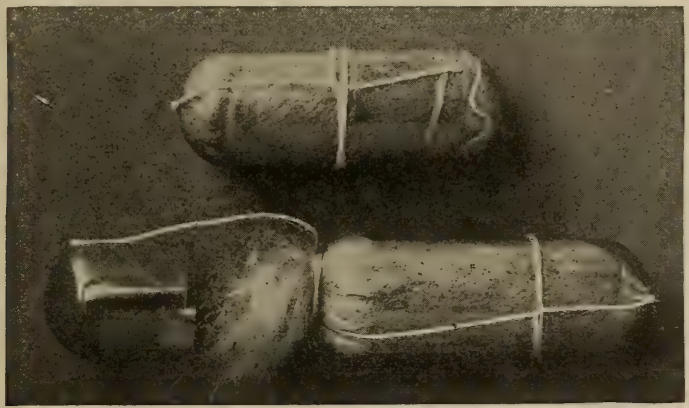

Fig. 149.-Vaginal tampon, sterilized and placed in a gelatin capsule ready for use. (Hirst.)

4. Carefully mix the iodoform powder and glycerin into a smooth paste in the basin with the spatula, then add the alcohol, and finally the ether.

5. Now take the gauze, which has been cut into strips I yard long and I or 2 inches wide, and immerse slowly in the mixture. 
6. Fold the gauze in layers in sterile test-tubes and cover with sterile cotton gauze plug.

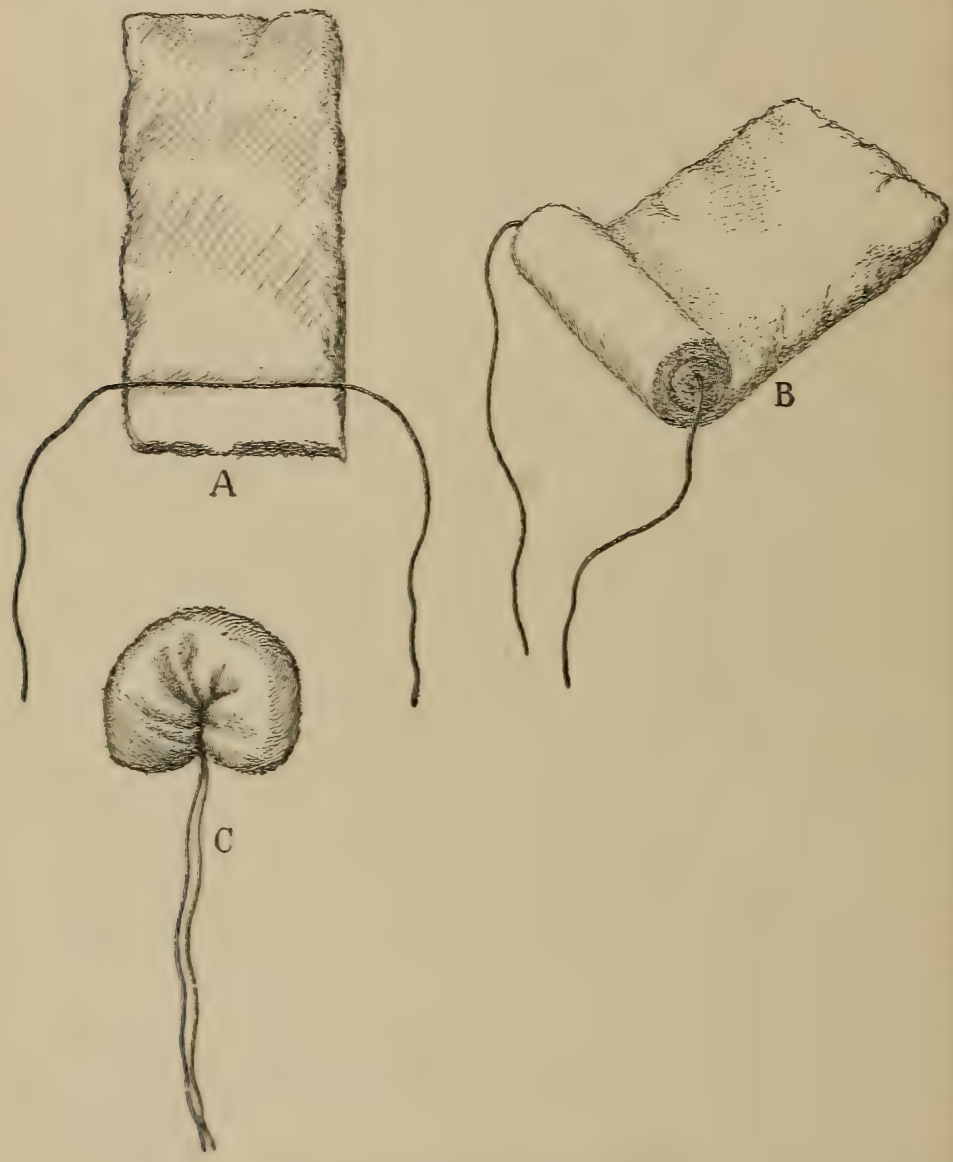

Fig. 150.-Cotton vaginal tampons.

Tampons are made of absorbent cotton, lambs' wool, or gauze, and are about 7 inches long, $I_{2} \frac{1}{2}$ inches wide, 
and $\frac{1}{2}$ inch thick. They are folded and tied in the middle with a strong white thread or fine twine, leaving long ends by which to remove the tampon. The socalled kite-tail tampon is made by fastening several of these pieces of cotton to a thread about 2 inches apart. The tampons may, after sterilization, be kept in a dry, sterile jar or in wax paper. Tampons are principally used for introduction into the vagina. Previous to introduction they may be dipped into various special solutions. They are generally removed from the vagina on the day after the application.

Collodion Dressing.-Collodion is a preparation of pyroxylin in alcohol and ether. On evaporation of the alcohol and ether a thin, impervious film of collodion is left. The collodion is either painted over the surface of the wound by means of a clean stick of wood or an applicator with sterile cotton. A thin layer of absorbent cotton may be saturated with it, laid on the wound, and allowed to dry. Collodion is used only when the wound is aseptic. Various antiseptic agents, such as iodoform, boric acid, etc., may be dissolved or suspended in the collodion. The surface of the wound must be perfectly dry or the collodion will not adhere. An ordinary dry dressing may be applied over the collodion as a further protective.

Gauze packing is made by cutting gauze in strips 2 yards long and 2, 4, and 6 inches wide. It is then folded so that there are no raw edges, and placed in layers in glass test-tubes. The tube mouth is closed with cotton over which is tied 2- or 3-ply gauze, and the whole sterilized in the autoclave.

Other materials used for dressing purposes are: rubber 
dam, rubber mesh, and rubber tissue. They are used to protect dressings in cases of freely discharging wounds, in skin-grafting, and for drainage. Rubber dam is cut into various strips and applied in a criss-cross fashion to the wound area and orer this is placed gauze. Rubber mesh is sheet rubber dam with small perforations arranged in rows. It is the best dressing for skin-graft cases because of its being one piece and, therefore, not liable to slip. Gauze is always placed over the rubber.

Rubber tissue is sterilized in $\frac{1}{20}$ carbolic acid in cold water. Hot solutions will destroy it.

Dressing-room Outfit.-Double wrapped packages containing the following articles are sterilized and kept in stock for use in the wards and private rooms:

I. Package of cotton-ball sponges.

2. Gauze dressings (usual size).

3. Towels.

Rubber-dam and drainage are kept in antiseptic solution, and the instruments are sterilized as needed.

Sheets, gowns, and towels used in operations are all made into convenient bundles and sterilized for two hours prior to an operation. Bundles once opened are not used again for other operations until they are resterilized.

Emergency bundles containing everything necessary for an emergency operation are stored in cases provided for them; but if not used for forty-eight hours, are again sterilized before being used.

Brushes.-Small hand brushes having a strong wooden back and stiff bristles are used for scrubbing the hands, field of operation, and the instruments. 
They should be boiled for fifteen minutes before the operation, then placed in a jar containing a I : Iooo corrosive sublimate solution. A separate brush should be reserved for the patient, and should be so marked. The same brush should never be used twice by the same person without being resterilized, and no two persons should use the same brush.

Drainage.-The object of drainage is to carry off to the surface the secretions and discharges of wounds and cavities. The retention and accumulation of these

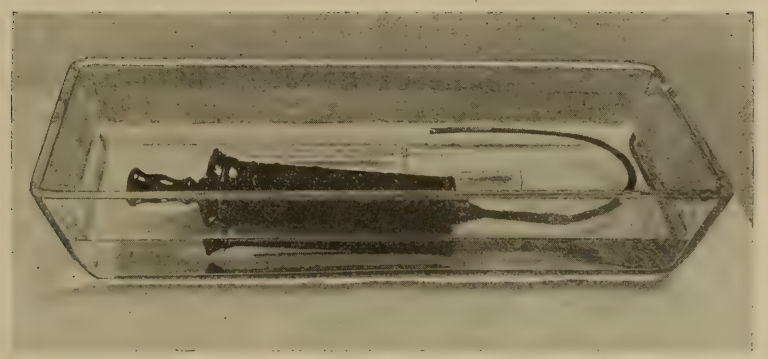

Fig. 151.-Drainage-tubes and syringe for sucking them out. (Hirst.)

would interfere with healing and, in the case of septic discharge, involves the danger of general infection. Drainage may be secured by means of rubber or glass tubes, by strands of gauze, catgut, silkworm-gut, horsehair, or silk. In case of abdominal section drainagetubes are usually preferred to gauze drainage, because it gives freer drainage, does not require a large opening in the abdominal walls, and is less likely to cause hernia; a sinus is more apt to follow the use of gauze drainage, and without anesthesia its removal is painful. Gauze soils the dressings and edges of the wound. The "ciga- 
rette-drain" is made by rolling a loose twist of gauze in rubber dam.

The technic of posural draimage through the abdomen. which has met with such good results, is very
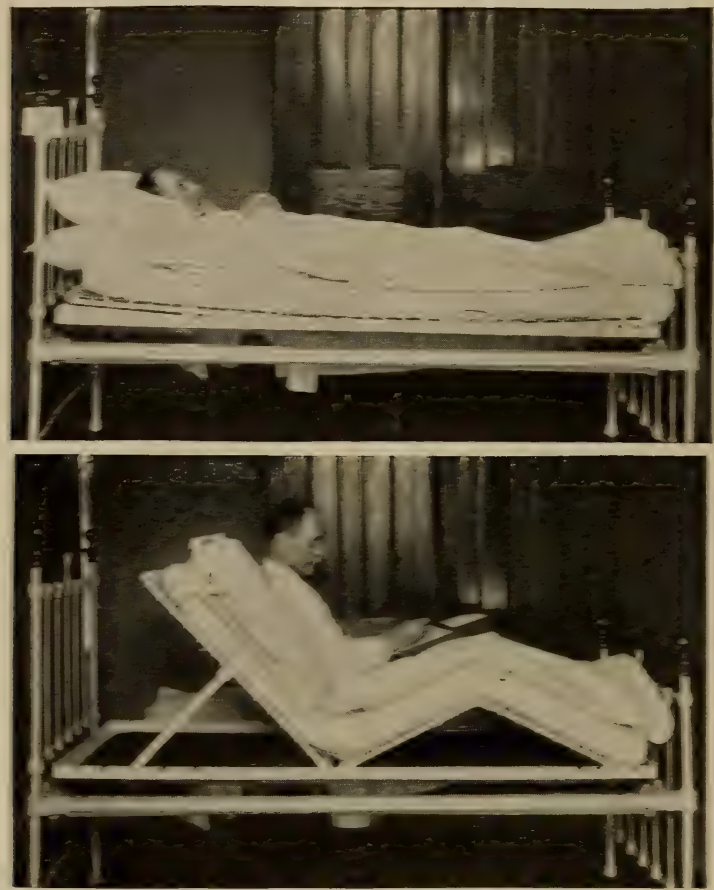

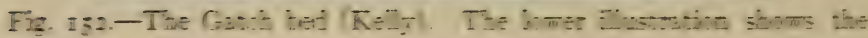

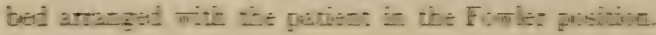

simple, and known as the Forder positiens, which is in reality a sitting position for the patient. In this way the oontents of the abdomen tend to drain to the lower portion. The lower abdomen seems to be much better atte to take care of infection than the upper. 
The Gatch bed is the best method of obtaining this position.

Care of Drainage-tubes. - If a glass drainage-tube is in the abdomen, the care of it is usually left to the nurse. She must, each time before drainage, thoroughly scrub and sterilize her hands. A syringe is used to withdraw any fluid remaining and for injecting irrigating solutions. The syringe must be sterilized by boiling and the nurse's hands disinfected.

The rubber tube attached to the syringe is passed down the center of the drainage-tube to the bottom, then withdrawn a little, so that only the fluid will be drawn up, and not the tissue of the pelvis. The syringe-piston is to be slowly and steadily drawn up. When removing the syringe the nurse should be careful that blood does not drop on the dressing. The mouth of the tube is to be covered while the syringe is being emptied.

Some surgeons place a piece of twisted gauze into the tube, which sucks up the fluid. This gauze is changed at stated intervals, and the tube is cleaned with a small piece of sterilized cotton or gauze fastened on the end of a pair of long forceps; then a fresh twist of gauze is inserted. The amount of fluid drawn and its character must always be reported by the nurse. When the drainage-tube is to be removed the nurse should observe the same precautions as she would for a dressing.

Glass drainage-tubes are made aseptic by boiling for fifteen minutes before the operation.

Preparation of Rubber Drainage-tubes.-Cut tubing into desired lengths, slip each piece over a glass rod, and scrub with a stiff brush and green soap. Rinse 
in sterile water until entirely free from soap. Boil for fifteen minutes in a I per cent. solution of sodium bicarbonate (enough to impart a greasy feel to the water); rinse again several times in sterile water, and put into sterile jars and cover with carbolic acid, I :20. The jar is kept covered except when the tubes are being put in and taken out by sterilized forceps.

Rubber dam is sterilized by boiling in I per cent. soda solution, and is afterward transferred to a glass jar containing I : 20 carbolic acid solution.

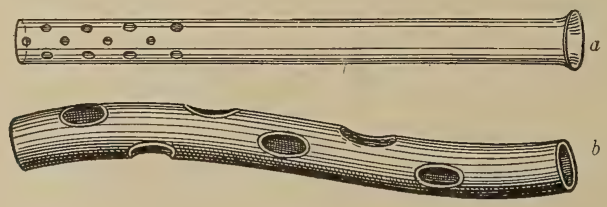

Fig. I53.-Drainage-tubes: $a$, Glass; $b$, rubber.

Cargile membrane, tissue made from the peritoneum of the ox, is used as a protective against adhesion formation, particularly in operations upon the bowels.

Gloves.-Rubber and cotton gloves are much employed in surgical work, and with very good results. They prevent infection by the surgeon's and assistant's hands, which even with the greatest care cannot be rendered completely sterile. The cotton gloves are sterilized by dry heat. The rubber gloves may be sterilized by the wet or the dry method. The wet method consists in boiling the gloves for fifteen minutes. In the dry method the gloves are dried, powdered with talcum, wrapped in towels, and placed in a pressure sterilizer, where they are allowed to remain for the length of time that dressings are sterilized. They are, however, 
sterilized for only one day. In putting on the dry gloves the hands are first thoroughly dried and powdered. The advantage of the dry method is that the hand is not so liable to perspire, so that less bacteria is extruded in the event of the glove being punctured. Before putting on wet gloves they are distended with sterile water or a weak solution of bichlorid. Cotton gloves are frequently worn over the rubber gloves so as to protect them from injury, as in cases of bone operations, etc.

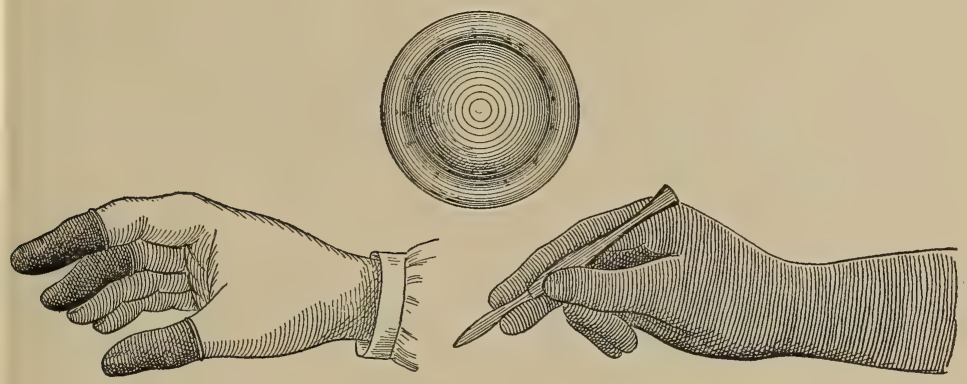

Fig. I 54.-Finger cots and rubber glove.

Rubber-glove Solution.-Murphy suggests an aseptic film covering sufficiently tenacious to last during several hours' work, to be made by dipping the hands and arms into a 4 per cent. solution of pure guttapercha chips dissolved in sterile benzin or acetone (use chloroform or carbon tetrachlorid in place of these, owing to inflammability). The solution must not be boiled. Apply by immersion, allowing excess to drip from the fingers; the acetone solution dries in a few seconds, that of benzin requires two or three minutes. Remove from the skin, which is left pliant, by washing in benzin. 


\section{SUTURES AND LIGATURES}

A suture, as applied to surgery, is some material used for stitching.

A ligature is some means used for tying.

The materials used for sutures and ligatures are of two general types: Absorbable and non-absorbable. Among the former are catgut and kangaroo tendon, while among the latter may be classified silk, Pagenstecher, silkwormgut, horse-hair, and wire. It will be seen from this that all animal sutures are not necessarily absorbable. A perfect suture or ligature must have the following qualities:

I. Non-irritative to tissues.

2. Be capable of sterilization.

3. Of sufficient tensile strength to accomplish the purpose for which it is used.

4. Pliable, so that once tied it will remain so.

5. Absorbable, so that if buried in the tissues it will not have to be removed.

6. Durable, so that its longevity will be sufficient to accomplish the purposes for which it was intended.

Catgut.-This material seems to fulfil all these purposes better than any other. It is obtained from the connective tissue of the sheep's intestine, preferably the European animal, as the quality of this gut seems to be of a higher standard.

There is one fact that should always be borne in mind in its preparation. Catgut is dead animal tissue and, therefore, a good culture-media for bacteria; hence it must not only be sterilized, but made antiseptic. One of the simplest and best methods of sterilizing catgut is as follows: 
I. The strands are cut into convenient lengths, say 30 inches, and rolled into coils about the size of a quarter. These are then strung on a thread so as to be easily handled.

2. This string of catgut is now dried for four successive hours by hot air at the following temperatures, $160^{\circ} \mathrm{F}$., $200^{\circ} \mathrm{F}$, and $220^{\circ} \mathrm{F}$., the changes in temperature being gradually accomplished, and care being taken that the catgut does not touch metal or glass.
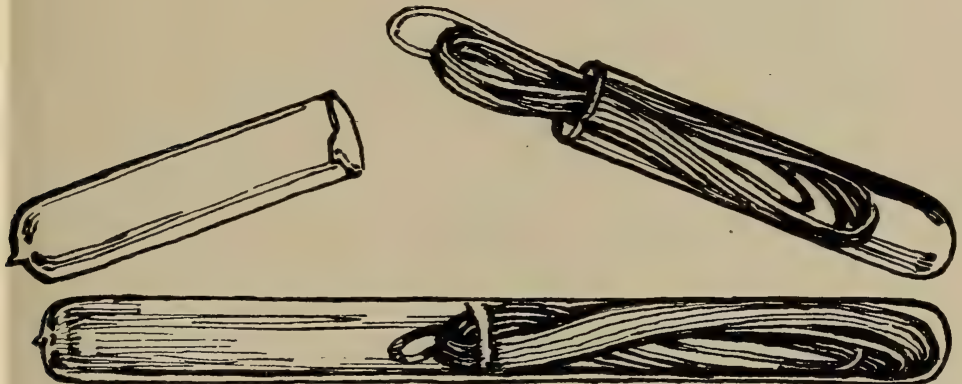

Fig. I55.-Sterile catgut in glass tubes ready for use.

3. It is then placed in liquid albolene until it is clear enough for strong light to pass through. It is usually left in this oil over night.

4. The vessel containing the oil is placed upon a sandbath and the temperature raised during one hour to $320^{\circ}$ $\mathrm{F}$., which is maintained for a second hour. It is then placed in sterile jars or, if iodin catgut is desired, placed in the following:

5. Iodin Catgut.-The thread is then lifted with a sterile forceps and the gut placed in a mixture of I part iodin crystals and Ioo parts Columbian spirits (deodorized methyl alcohol). It is kept in this solution until used. 
The above fluid prevents the catgut from softening. unraveling, and slipping when used. The iodin permeates the strand and in a short time it becomes black. This is an antiseptic gut.

Another simple but not reliable method is to place the catgut in iodin I part, potassium iodid I part, water IoO parts. Allow to remain eight days.

Kangaroo tendon is obtained from the Australian animal, but is not used very much since the introduction of chromicized catgut.

Chromicized Catgut.-This is made by taking the above plain catgut from the oil, and instead of placing it in the iodin-alcohol it is placed in a solution of potassium bichromate ( 15 grains to I pint of absolute alcohol).

Both plain and chromicized catgut come in various sizes, namely, $\infty, 0,1,2$, and 3 .

The preparation of catgut has been minutely studied by commercial firms, so that the gut is always tested as to its strength and sterility. Without a careful technic it is better to employ one of the standard catguts. They are put up in glass tubes, jars, or paper folders.

Sillk.-It comes in various sizes, 00 to $I 0$, and in two forms, white and iron dyed, the latter being black makes it more visible for removal. It is being used less as time goes on for the following reasons: It absorbs fluids into its meshes and thus beromes a favorable culture-medium for bacterial growth. Being non-absorbable it sooner or later beowmes an irritant, and therefore should not be used in lange sizes as a buried ligature. It has been supplanterd in intestinal work by Pasenstecher thread. It is sterilized by boiling or in the autoclave.

Pagenstecher Material.-This material is linen thread 
coated with celluloid which forms practically an impervious covering. Its tensile strength is greater than silk, so that a much finer thread can be used. It is extensively used in intestinal sutures. It is sterilized by boiling or in the autoclave.

Silkworm-gut.-To obtain this material the silkworm is killed just about the time it is to spin its cocoon. It possesses a high tensile strength and is practically impervious to moisture. It varies somewhat in size. Some surgeons use it entirely in closing the skin, while others employ it in vaginal operations because of its impermeability. It is easily sterilized by boiling.

Horsehair is obtainea from the tail of the horse. It is im- permeable to moisture, the strands are very fine, and can be used with very small needles. It is of a fairly high tensile strength and more easily tied than silkworm-gut. It serves an excellent purpose in the

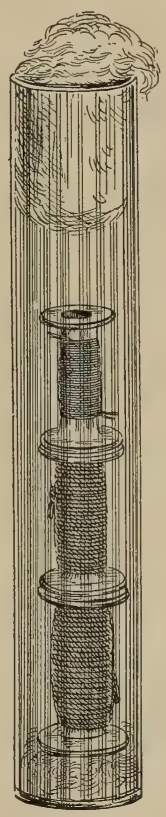

Fig. I 56:-Silk in glass tube on glass reels; the tube is stoppered with cotton. (Hirst.) cosmetic surgery of the face, neck, and mouth. It comes in hanks of one hundred strands and, after being thoroughly washed in soap and water, is sterilized by boiling.

Wire.-There are three varieties used: Aluminumbronze, silver, and gold, in the order of their usefulness. 
Their sphere is very limited, being at the present time used chiefly to approximate fragments of bone. Silver wire is used as a skin suture.

The wire must have a fairly good tensile strength and be sufficiently flexible to be twisted without breaking, The aluminum-bronze wire possesses these to a greater extent than the softer metals.

Michel's clamps consist of modified metal clamps which are applied to the skin by a special holder. After the wound is healed they are removed by a special instrument. The advantages claimed for them are that they are quickly applied and are less liable to cause infection.

Surgical Applications.-They comprise ointments, pastes, etc., which are used in the treatment of local surgical conditions.

Ichthyol.-This is a brownish-black semiliquid preparation with a strong penetrating odor of tar. It is mildly anesthetic and analgesic and slightly counterirritant. It also has to a certain extent the action of a poultice when used in treatment of abscesses before incision.

It is not often used pure. From Io to 25 per cent. ointment is the most common strength used.

Balsam of Peru.-This is a semi-liquid vegetable product. Has a pleasant odor. It is a deodorant and mildly stimulating to granulating tissues.

Beck's Bismuth Paste.-This is used for diagnostic purposes and treatment of chronic discharging tissues. The formula is as follows:

Bismuth subnitrate $33 \frac{1}{3}$ per cent.

White or yellow vaselin. 
The vaselin is sterilized and while liquid the bismuth is stirred into it. When used it is melted and sucked up into a glass or specially made metal syringe and injected into the discharging sinus. Care must be taken to keep water away from it. For this reason the syringe is dry sterilized, and if the piston needs lubrication, oil is used instead of water. Always use a blunt-pointed syringe.

Occasionally a paste of firmer consistency is used. This is composed of:

Bismuth subnitrate............. 30 per cent.

Paraffin................... 5

White wax................. 5 "

White or yellow vaselin...........6. 60

Mosetig-Moorhof wax is a combination for the filling in of infected bone cavities. It is composed of:

Iodoform...................... 6 parts.

Spermaceti..................... 40 "

Oil of sesame................... 40 "

Heat to $100^{\circ} \mathrm{C}$. and then allow to cool. When needed, heat to $50^{\circ} \mathrm{C}$., constantly stirring, so as to thoroughly distribute the iodoform. It is poured into the bonecavity which has previously been made aseptically clean and dry. It becomes absorbed the same as a bone-graft and new bone grows into the cavity.

Unna's paste is made up of:

Gelatin 5 parts.

Zinc oxid....................... 5

Boric acid..................... I part.

Glycerin...................... 8 parts.

Water. 
It is heated until it becomes a soft liquid paste. The principal use of it is as a supporting and antiseptic dressing for varicose leg ulcers. When liquid the paste is applied with a brush over the whole surface of the leg, including the ulcer, then a layer of gauze bandage applied; then more paste and another layer of bandage, and so on until three or four layers are applied. Depending on the amount of discharge, this dressing is allowed to remain on for from two days to a week.

Horsley's wax is used to stop hemorrhage from bleeding bone. It consists of:

Beeswax...................... 7 parts.

Almond oil. ................... I part.

Salicylic acid.................... I "

\section{Green Soap.-}

Caustic potash.................. I3 ounces.

Linseed oil. .................... 40 "

Alcohol. ....................... 4 "

Heat the oil in a vessel to $140^{\circ} \mathrm{F}$. Dissolve the potash in 67 ounces of hot water. Add the alcohol and let it cool. Then add the heated oil, stirring constantly until mixed.

To make a tincture of green soap:

Green soap....................... 3 parts.

Alcohol, 95 per cent................... 2 "

Ether....................... I part.

To prepare cold, mix and stir for a few minutes every hour until a clear solution is formed, or the soap may be melted first over a slow fire. Remove to a safe cool place, stir occasionally, and just before complete hardening recurs add the alcohol and ether. 


\section{CHAPTER X}

\section{INFLAMMATION}

INFLAMMATION is the reaction of a part to an irritant.

The first changes are in the vessels and circulation; second, a passing out of fluids and solids from the vessels; and third, changes in the perivascular tissue $-i$. $e_{\text {., }}$ the tissues about the blood-vessels. These

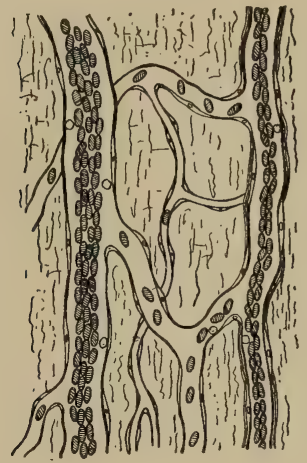

Fig. 157.-Normal vessels and blood-stream.

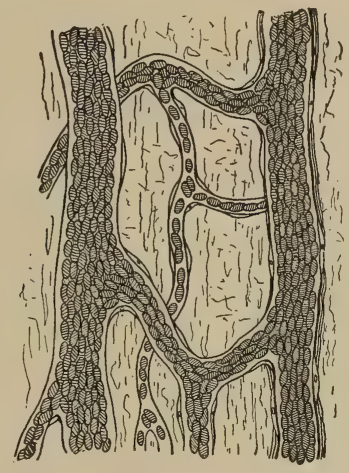

Fig. 158.-Dilatation of the vessels in inflammation.

(American Text-Book of Surgery.)

three changes produce the characteristic phenomena of inflammation-heat, redness, swelling, pain, and loss of function.

The first change in an inflamed area is a dilatation of all the vessels-the arterioles, capillaries, and venules. As a result there is an increased activity in the circu- 
lation and an increased flow of blood to the part, a condition known as active hyperemia. After a time the blood-current begins to slacken; then the white cells approach the vessel wall and begin to pass through it (emigration of white cells). There is also a passing out of plasma or fluid from the blood, and in severe cases of inflammation the red cells may also pass out. If we now examine the inflamed area with a microscope we

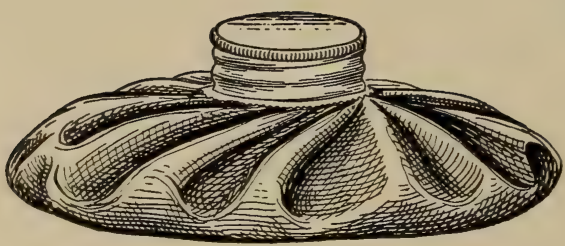

Fig. 159.-Ice-bag (Ashton).

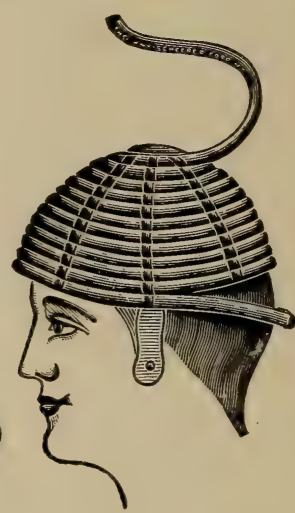

Fig. 160.-Water coil.

find an enormous number of cells, chiefly white bloodcells, in the tissues about the vessels. Fibrin in the form of delicate granules and fibrils may also be present.

Inflammation is a process which is directed to the removal of an irritant, which may be either a portion of an injured tissue or a foreign body or material. After this result has been accomplished, healing or regeneration takes place. If the inflammation was caused by bacteria, suppuration is likely to follow. In that 
case the tissues will liquefy and the cells will be thrown off suspended in a liquid (liquor puris), the whole being known as pus. In suppuration there is always loss of tissue, and healing, if it occurs, is brought about through the formation of a scar. In order to produce healing granulation tissue is formed. Granulation tissue consists of new cells and tiny capillary loops. It is sometimes called "proud flesh," and bleeds very easily. The scar has a marked tendency to contract and may cause great deformity.

Among the causes of inflammation are injuries, chemical irritants, heat and cold, and bacteria. 


\section{CHAPTER XI}

\section{CATHETERIZATION; DOUCHES; ENEMATA; WASHING OUT THE BLADDER; LAVAGE}

THE use of the catheter is ordinarily very simple, and yet it may truthfully be said that there is no operation which is performed with so little regard for asepsis. Asepsis and antisepsis are as important here as they would be in preparing for an abdominal operation.

Cystitis is often caused by the introduction of germs into the bladder by means of a dirty catheter, or by not cleansing the external genitals, vestibule, and meatus before the operation. Normal urine is to be considered sterile unless there is some disease of the kidneys or bladder; and when infection occurs we may assume that the germs have gained entrance from without. The catheter may be of glass. When a glass catheter is not at hand, a silver or rubber one may be used. When of glass or silver or rubber it should be boiled twenty minutes before being used.

Glass catheters are the best; they are easily rendered aseptic, and show whether they are or are not perfectly clean. Sterilization is most important before using the catheter and immediately afterward. There is no danger of the catheter breaking, as so many patients fear, if it is not cracked before being introduced. Besides the catheter, which is taken to the bedside in a basin of very hot water, there are needed a basin of corrosive sublimate 
solution ( 1 : IO0O), sterilized gauze or cotton, and a vessel to receive the urine. A lubricant of sterilized oil to render the entrance of the instrument as easy as possible is used only when a gum-elastic or rubber catheter is

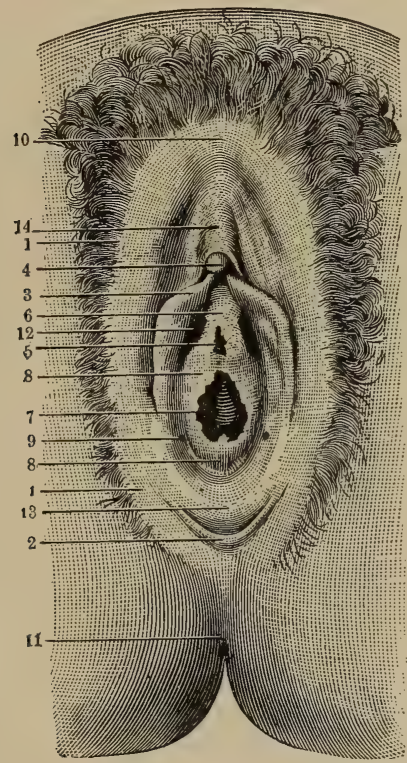

Fig. 16r.-Virginal vulva: I, Labia majora; 2 , fourchet; 3 , labia minora; 4, glans clitoridis; 5 , meatus urinarius; 6 , vestibule; 7 , entrance to the vagina; 8 , hymen; 9 , orifice of Bartholin's gland; ro, anterior commissure of labia majora; II, anus; I2, blind recess; I3 , fossa navicularis; I4, body of clitoris. (Modified from Tarnier.)

employed. A mixture of carbolic acid solution (I : 40) and glycerin serves for this purpose.

Introduction of the Catheter.-The patient lies on her back with the knees drawn up and separated, the upper clothing being divided over each knee to guard 
against unnecessary exposure. The labia are separated with sterilized sponges and the parts washed with the corrosive solution. The catheter is inserted into the urethra, the opening of which is just above the vaginal entrance. If there is any difficulty, the catheter should be withdrawn a little and gently pointed a little downward or upward, to the right or to the left. If the flow should cease before enough urine has been drawn, the catheter is withdrawn a little or is inserted a little farther than before. Before removing the catheter a finger should be placed over its end to prevent any drops of urine wetting the bed. After the operation the parts are again washed, and the catheter boiled and placed in a bottle containing a solution of carbolic acid ( $\mathrm{I}: 2 \mathrm{O})$, unless the catheter is of rubber, for carbolic acid ruins rubber.

When the bladder is partially paralyzed from result of an operation or otherwise, a rectal injection of very warm water will often cause the bowel and bladder to empty themselves at the same time, thus doing away with the necessity of using a catheter.

The urine for examination by the physician is best drawn with the catheter, to prevent contamination from vaginal discharges.

A distended bladder must be emptied gradually; several sittings, at intervals of four to six hours, may be necessary in some cases, and as the last amount of urine is being drawn the flow should be slowed, to prevent any injury to the mucous membrane of the bladder from drawing it into the eye of the catheter.

Irrigation of the Bladder.-To irrigate the bladder a fountain-syringe or irrigating apparatus is cleansed by boiling; also a glass catheter, which is sterilized in the 
same way as for catheterizing. The parts, of course, are cleansed in the manner described. The patient is first

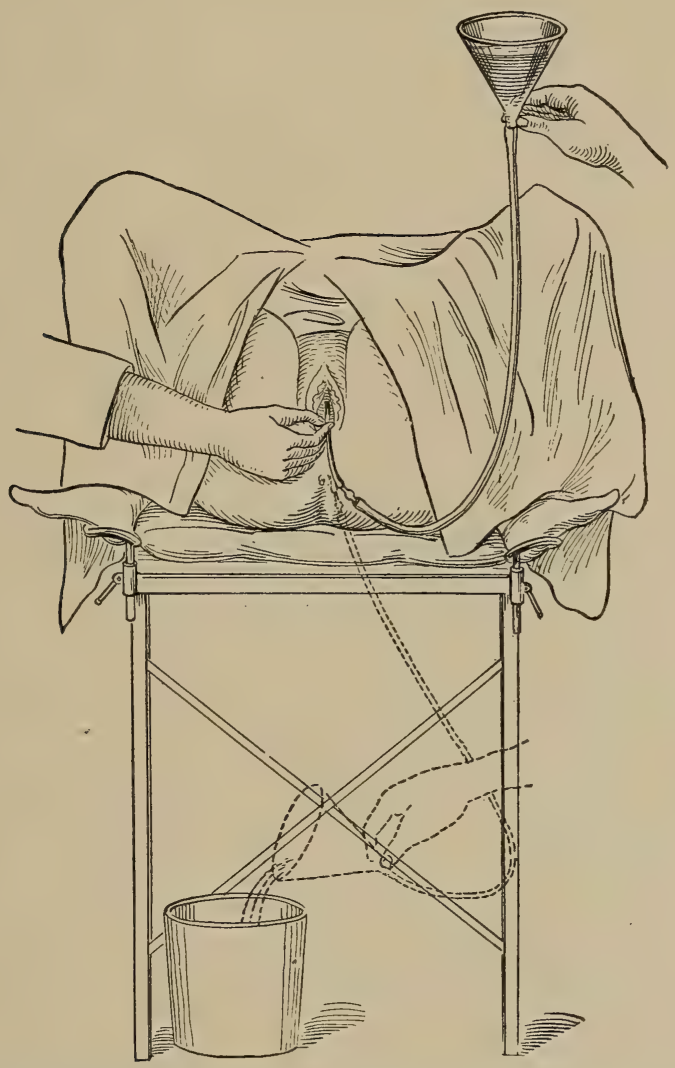

Fig. 162.- Showing the method of irrigating the bladder by the singlecatheter method. (Morrow.)

catheterized; the catheter is then attached to the rubber tubing of the syringe which contains the irrigation solution (boric acid or salt solution), the temperature of the 
latter being about $100^{\circ} \mathrm{F}$. The solution must run warm before the catheter is inserted. The rapidity of the flow is regulated by raising or lowering the irrigator. The

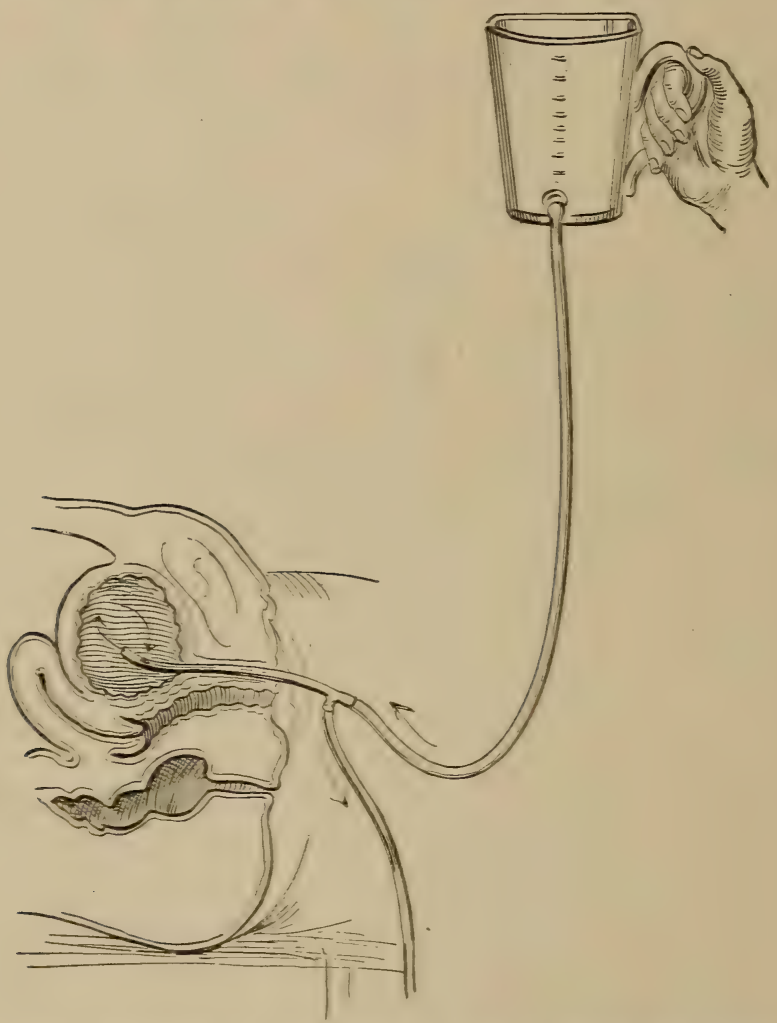

Fig. I63. - Irrigation of the bladder with a double-flow catheter. (Morrow.)

quantity of solution introduced is governed by the feelings of the patient; usually 200 c.c. is all that can be tolerated, after which the tube is disconnected and the fluid is 
drawn off. If a double catheter is used, the tubing is not removed. The irrigation is repeated until the washings come away perfectly clear and clean.

Examination of Stomach Contents.-Many times the nurse is called upon to give a test-breakfast and to send the stomach contents to the laboratory for examination.

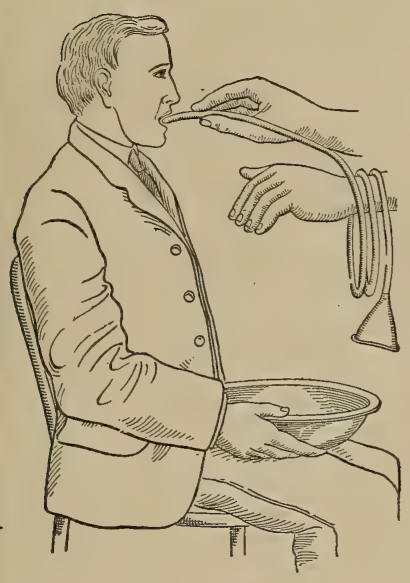

Fig. I64.-Position of the patient for introduction of stomachtube; also method of passing tube into the mouth. (Boston.)

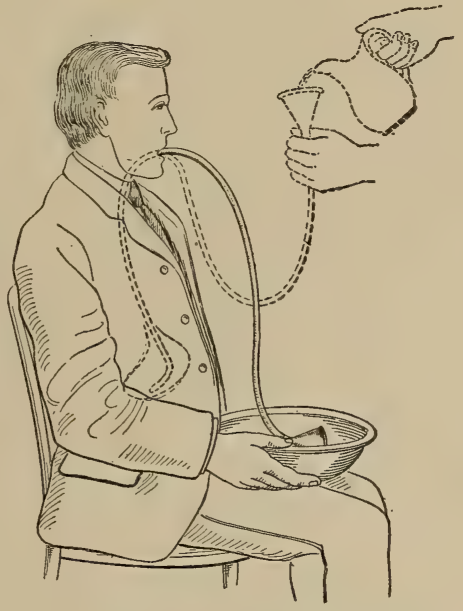

Fig. 165.-Method of inducing expulsion of gastric contents by siphonage. (Boston.)

A test-breakfast usually consists of a cup of tea without milk or sugar and two soda-crackers, or instead of the crackers a small piece of toast or small piece of bread without butter is given. One hour after the stomach contents are obtained by passing the stomach-tube.

Method of Passing a Stomach-tube.-The stomach-tube should be used from ice-water, with the patient, covered 
with a sheet, sitting in a chair. He should be advised that the procedure will be unpleasant but is not dangerous, and that he must not under any circumstances pull your hand away or bite the tube, but at all times must swallow. Have the patient extend the head and open the mouth, then introduce the cold stomachtube into the throat through the mouth, at the same

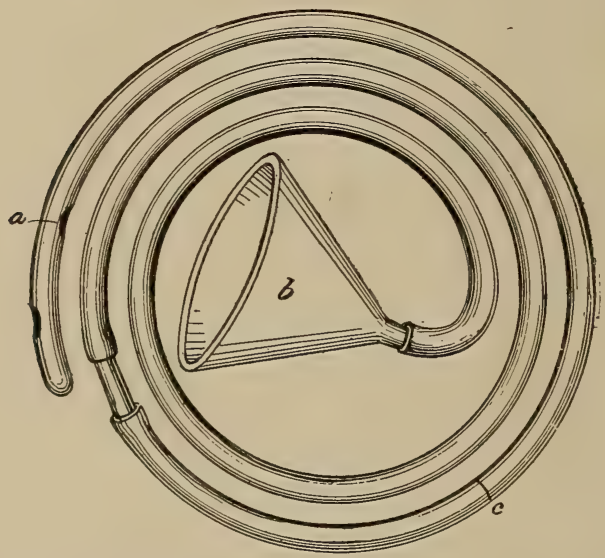

Fig. 166. - Stomach-tube and funnel for expressing the stomach contents: $a$, Showing the lateral fenestræ; $b$, funnel; $c$, mark to indicate the distance from the incisor teeth to the stomach. (Morrow's Diagnostic and Therapeutic Technic.)

time asking the patient to swallow; rapidly push the tube down, provided that there is no obstruction, until you come to the white mark on the tube; then lower the bulbous end of the tube to drain the stomach by siphonage. On some stomach-tubes there is a bulb to assist the siphonage; in others you will have to compress the tube near the mouth and draw the fingers of the other hand toward the exterior extremity of the 
tube. Suddenly remove the fingers near the mouth and it will produce a small degree of suction. It may be necessary to introduce a small amount of water to start siphonage. Elevate the funnel portion higher than the mouth and then suddenly drop the funnel portion, in this way producing a siphonage. At times it may be necessary to introduce the tube a little farther down the throat. Vomiting may occur, in which event it will be necessary to repeat the entire performance. If water has been necessary to assist in the siphonage, this fact should be noted in the report. In very nervous patients it is advisable to cocainize the throat.

The contents are measured and placed in a clean bottle, labeled with the patient's name, the date, quantity, and hour that the breakfast was given and contents secured; the bottle is then sent immediately to the laboratory.

Gastric lavage consists in introducing the stomachtube and allowing a pint or two of warm water to run into the stomach, and then by quickly dropping the funnel portion of the tube, removing the same by siphonage. This should be continued until the fluid comes away clear.

Douches.-Properly given, the vaginal douche relieves inflammation, checks hemorrhage, acts as a stimulant, cleansing agent, and checks secretion. The amount of water used is from 5 to 6 quarts, of a temperature of $110^{\circ} \mathrm{F}$. The temperature must always be tested with a bath-thermometer (Fig. I67), not with the hand. The douche apparatus is an excellent contrivance. In its absence a fountain-syringe may be used.

When taking a douche the patient should lie on her 
back, with the thighs flexed on the abdomen and the legs flexed on the thighs. In this position the water comes in contact with the whole vagina.

The douche can or fountain-syringe must be hung about 4 feet above the bed, so that it will take about twenty minutes for the water to run

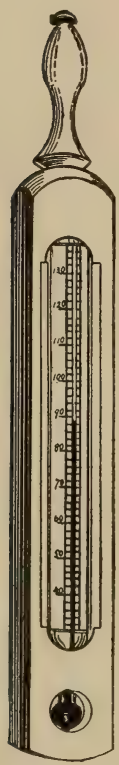

Fig. I67.-Baththermometer. out. Air must be expelled, and the water must run warm before the tube is inserted into the vagina. The vaginal tube must always be sterilized before and after using, and every patient should have her own tube.

Many patients in private practice object to taking douches, and will neglect them on account of the inconvenience; but this they can overcome by taking the douches in the bath-tub. Half-way across the bottom of the tub a piece of board is placed on which the patient can lie.

Antiseptic Douches.-Corrosive sublimate, creolin, boric acid, and permanganate of potassium are used for antiseptic douches; and to prevent absorption and irritation a plain water douche is often given after any of these antiseptics.

After any intra-uterine douche too forcibly given uterine colic with dangerous collapse may occur.

A patient should lie quietly for one hour after taking a douche; if only one is used a day, it is best to give it at night, because then the uterus is most congested and needs the hot water most, and the tempo- 
rary weak feeling which follows a douche will be gone before morning.

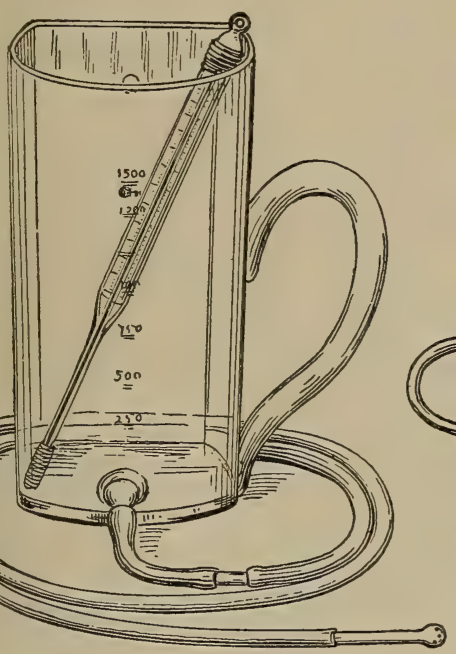

Fig. I68.-Apparatus for vaginal douching. (Morrow.;

\section{Rectal Injections (Enteroclysis) and Irrigation.-} The therapeutic range of this procedure is not confined to the treatment of local troubles. It has long been used

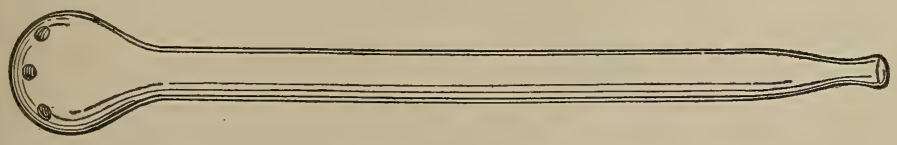

Fig. I69.-Enlarged view of a glass vaginal douche nozzle. (Morrow.)

as a means of cleansing the lower bowel of accumulated feces. In the treatment of rectal ulcers and inflammations it has been employed both to relieve the irrita- 
tion produced by fecal matter and to apply various medicaments to the parts. For the prevention of shock normal saline solution is injected-

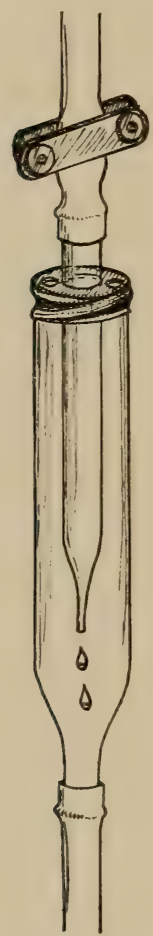

Fig. I70.-Modification of Dewitt's appliance for regulating flow, and allowing escape of flatus. (Crandon and Ehrenfried.)

I or 2 pints. This, by filling the blood-vessels, enables the patient to withstand the loss of blood. After an operation shock and hemorrhage are counteracted by its use, and at the same time the thirst is relieved and restlessness quieted. In septic conditions, both local and general, by diluting the toxic materials in the circulation and promoting their excretion by the skin, kidneys, and bowels, saline rectal injections play an important part in the treatment.

Dr. John B. Murphy has devised a method whereby salt solution, if given by the drop method, it is possible to have the patient receive a continuous supply of this solution. There are numerous apparatus, the simplest of which consists of a douche bag and tubing held in place about 2 feet above the bed. The tubing is connected to a specialized dropper as shown in the diagram. A clamp placed immediately above regulates the flow. The temperature of the solution is usually about $105^{\circ} \mathrm{F}$. Many procedures have been devised to keep the water 
at an even temperature. The simplest method of noting the desired temperature is to have the tube run under a hot-water bottle placed at the side of the bed.

In patients whose digestive tracts are too weak to hold food or medicine rectal feeding or rectal medication is

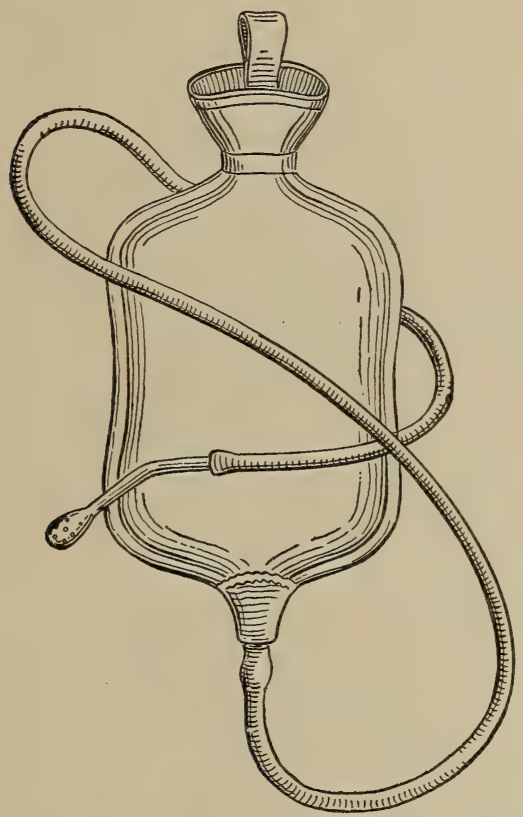

Fig. I7r. - A very simple apparatus for continuous proctoclysis. (Morrow.)

employed. The rectum should be washed out thoroughly before the injection is given. If the rectum is intolerant and will not retain what is injected, it is well to turn the patient on her left side and raise the hips on a pillow or a folded blanket. A long rectal tube should be used as for a high enema. The physician will give directions as to 
the temperature of the solution. In fever patients and in the hemorrhage of typhoid fever great relief and comfort are afforded by using very cold or iced water. In shock or hemorrhage a temperature of $100^{\circ} \mathrm{F}$. is usually preferable. In long-continued lavage for local trouble the patient's preference as to the temperature is generally consulted.

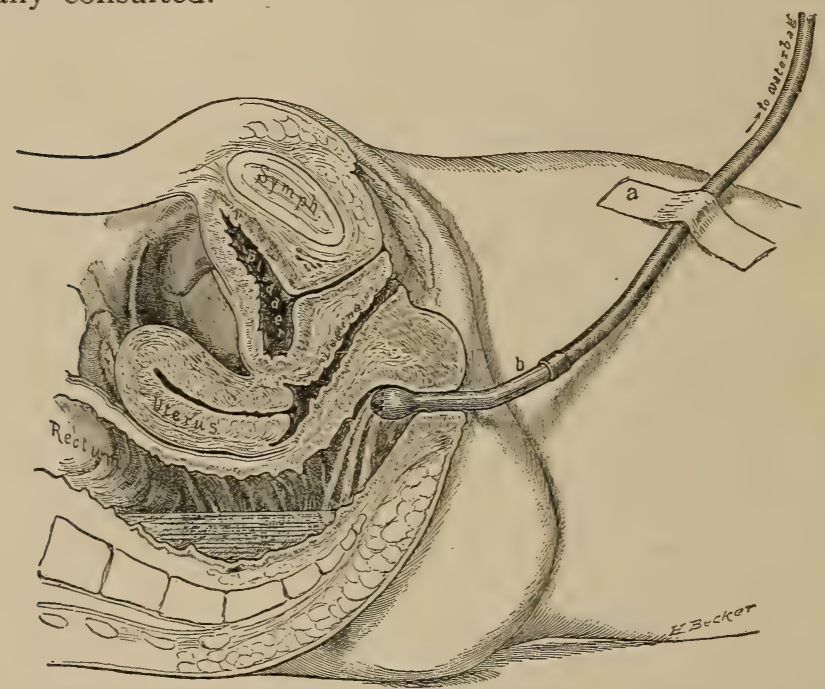

Fig. I72.- Showing the method of administering continuous proctoclysis: $a$, Adhesive strap fastening the tubing to the thigh; $b$, vaginal nozzle bent at an angle of 35 degrees. (Kelly and Noble.)

A stimulating and nutrient enema, black coffee, or hot saline solution is given when symptoms of shock appear either during or after an operation; it should be injected high up into the colon. The rectum should be thoroughly cleansed at least once daily with warm saline solution, which will also aid the absorption of the nutrient enema. When feeding by rectum in gyneco- 
logic cases, it should be remembered that tight tamponing of the vagina may interfere with absorption in the rectum. If the presence of hemorrhoids is a drawback, a

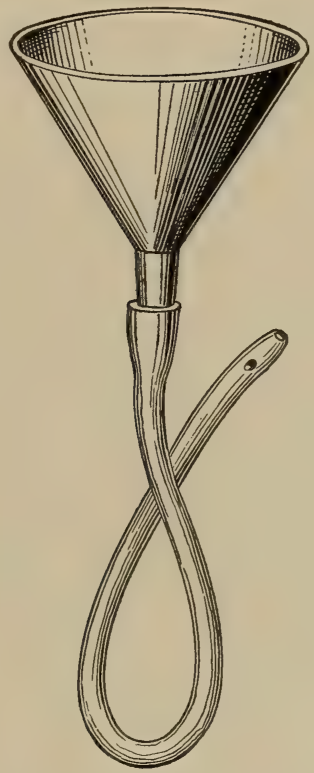

Fig. 173.-Funnel and colon tube for administering nutrient enemata. 2 per cent. solution of cocain may be used before injecting the fluid.

Stimulating enema:

Whisky,

2 ounces.

Ammonium carbonate, I5 grains.

Beef-tea,

4 ounces.

Or,

Brandy,

2 ounces.

Tincture of digitalis, 20 minims.

Milk,

4 ounces. 
For tympanites:

Tincture of asafetida, Spirits of turpentine, Magnesium sulphate (Epsom salt), Warm water,

Purgative enemata:

I. Warm soap-suds

2. Glycerin,

Magnesium sulphate, Spirits of turpentine, Warm soap-suds,

3. Glycerin,

Turpentine,

Magnesium sulphate (Epsom salt),

5. Inspissated ox-gall, Warm water,

5. Spirits of turpentine, Mucilage of acacia,

To be given high.

6. Senna,

Magnesium sulphate,

Olive oil,

Boiling water,
2 ounces.

I ounce.

2 ounces.

I pint.

$\frac{1}{3}$ pint.

4 ounces.

I ounce.

I ounce.

8 ounces.

4 ounces.

I ounce.

2 ounces.

$\frac{1}{2}$ ounce.

I quart.

Io drops.

$\frac{1}{2}$ ounce.

$\frac{1}{2}$ ounce.

$\frac{1}{2}$ ounce.

I ounce.

I pint.

Infuse the senna in the water. Then dissolve the magnesia, add the oil, and thoroughly mix by stirring. 


\section{CHAPTER XII}

\section{MINOR SURGICAL PROCEDURES}

Hypodermic Injection.-This procedure is employed to secure rapid medication or in obtaining local anesthesia by the injection method. When used in the latter capacity it is called intradermic injection.

The aseptic method of employment requires that the syringe, needle, and solution should be sterile. To cleanse the skin about the point of intended puncture

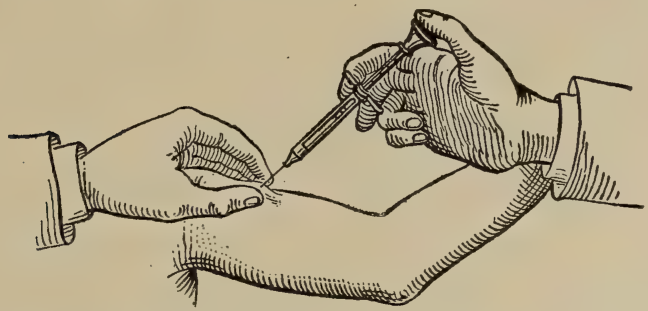

Fig. 174. - Showing the method of giving a hypodermic injection. (Morrow.)

use first soap and water. Apply ether, alcohol, or tincture of iodin to render the site sterile.

Insert the needle-point at the summit of a pinchedup fold of the sterilized skin (Fig. I 74). For hypodermic medication the skin of the arm, forearm, or the thigh may be selected, fleshy parts favoring rapid absorption. Avoid superficial veins and deeper vessels, as direct entry of the drug into the blood-current might give rise to a too rapid effect. 
Sutures.-The interrupted suture is made by passing catgut or silk through the skin from one side of the wound to the other; then both ends are drawn together and tied in a double knot. The continuous suture is the ordinary over-and-over stitch from one end of the wound to the

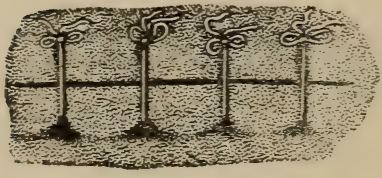

Fig. I75.-Interrupted suture. (Bernard and Huette.)

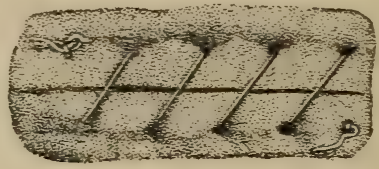

Fig. 176.-Continued or Glover's suture. (Bernard and Huette.)

other. The button suture is made by passing a double stitch across the bottom of the wound, bringing out the ends about $I$ inch from the edge of the wound and secure each end by passing through a button. The shotted suture is one in which the ends of the suture, after it is

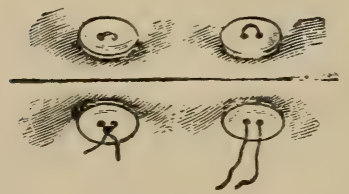

Fig. 177.-Button suture. (Bryant.)

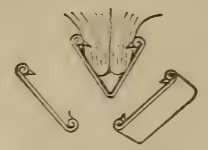

Fig. 1 ?8.-Metal suturing clamps.

introduced, are passed through a perforated shot, which is then clamped.

Counterirritation or revulsion is a method of producing artificial irritation upon one portion of the body surface to alter the progress of disease in distant parts. It acts directly by drawing blood away from the diseased 
area or through the nervous system, and may be used in cases of localized inflammation or congestion to overcome neuralgic pain and in conditions of general depression or shock.

The methods employed may be mild or severe in their effects. Of the milder means used for the purpose, the mustard foot-bath is one of the best. It consists in soaking the feet and legs of the patient in a bucket two-thirds full of water at a temperature of from $110^{\circ}$ to $140^{\circ} \mathrm{F}$., to which has been added one to two tablespoonfuls of ground mustard. The patient's body should be protected by blanketing during the bath, which may continue for from ten to twenty minutes. Tincture of iodin is used for a similar purpose in chronic inflammation of joints or glands. It may be applied with a swab or brush to the parts. Application must not be made oftener than once in two to four days to patients having tender skins.

Mustard-plaster, made by mixing up I part of ground black mustard to 5 parts of wheat flour or flaxseed in a little water, and applied upon a cloth or folded newspaper to the parts, will of ten prove useful in widespread inflammation or irritations. A fresh mustard-plaster should not be applied for a longer period than twenty or thirty minutes, else it may give rise to local injury to the skin and directly underlying tissues.

Turpentine Stupe.-This method of producing counterirritation consists in the application to the inflamed parts of a flannel cloth which has been wrung out in hot water and sprinkled or dipped and wrung out in either the spirits or oil of turpentine. The skin should be anointed with vaselin if the application causes too 
much pain or irritation. Spice-plasters or bags are often ordered in the treatment of children. The mixture consists of equal parts of ground ginger, cloves, cinnamon, allspice, to which add and thoroughly mix onefourth part of Cayenne pepper; wet with hot water, alcohol, or whisky before applying. The so-called warming plaster consists of Burgundy pitch 12 parts, cantharides cerate I part.

Heat and cold are identical in effects.

Use--(I) Locally as a stimulant (if of moderate intensity and applied but for a short time and if followed by immediate reaction); also as a sedative (if of long application, very intense, and if no reaction occurs). (2) Constitutional: (a) Heat may be used as a pyretic in shock, collapse, insanity; $(b)$ cold as an antipyretic in acute fever, sunstroke.

Application.-(I) Heat--(a) Dry (in the form of hot-water bags or bottles, hot bricks, hot sand or salt bags, heated stovelids, hot-air-oven apparatus, hot blankets); (b) Moist, poultice (flaxseed, oatmeal, or hops, mixed with water, is sterilized by boiling); hot bath; hot pack; hot douche; hot fomentation (gauze, flannel, or towel wrung out in hot water, hot antiseptic solution; change when cooled). A ready method of producing diaphoresis (sweating) is by pouring water upon hot bricks wrapped in flannel.

(2) Cold.-(a) Dry (applied in the form of crushed ice in thin rubber bags, bladders, ice water passed through coils of rubber tubing); cold air (by exposure); (b) Moist (irrigation, ice-water compresses, cold pack-wringing sheet out in ice water and wrapping it around the patient; keep it wet by sprinkling); 
tepid bath (gradually reduced); sponge-bath (keep the patient's body surface moist, fanning him all the time); alternating douche of hot and of cold water.

Vaccination is the inoculation of an individual with the virus of cow-pox.

The implements needed are a needle, lancet, or ivory point; fresh virus (bovine or humanized).

Vaccination is performed as follows: (a) Render skin surface aseptic (select by choice upper and outer third of arm, inner side of thigh); $(b)$ abrade the skin until serum exudes; $(c)$ carefully work in the moistened virus; $(d)$ protect surface of spot until dry. Avoid exposure.

The times to perform vaccination are: (I) About the third month; (2) seventh year; (3) at puberty; (4) repeat whenever small-pox is prevalent.

Liniments.-These are local stimulants useful in mild neuralgic or rheumatic pains: (a) Ammonia; (b) chloroform; (c) camphor; (d) turpentine. Apply upon a cloth or by rubbing into the parts for a period of from five to twenty minutes; anoint with vaselin after each application to prevent abrasion.

Ointments.-Mildly stimulating and emollient: $(a)$ Mercurial (blue ointment); (b) ichthyol; (c) belladonna; $(d)$ boric acid; $(e)$ resorcin; $(f)$ iodin. Do not use iodin locally where there will be a possibility of a future cutting operation, because the skin becomes like leather and heals badly.

Ointments should be applied upon gauze or lint, nicked to allow for the escape of discharge if present.

Cupping.-I. Dry Cups.-In dry cupping no blood is lost. The operation is performed by means of special 
cupping-glasses or wineglasses. Exhaust the air by burning a little roll of paper, piece of lint, or paper dipped in alcohol and lighted. Before the flame is extinguished rapidly invert the glass upon the skin surface.

2. Wet Cups.-(a) Prepare the skin by cleansing with soap and water, dry thoroughly, and apply dry cups; $(b)$ scarify with a bistoury or by means of a spring scarificator upon the cupped sites; $(c)$ reapply the cups
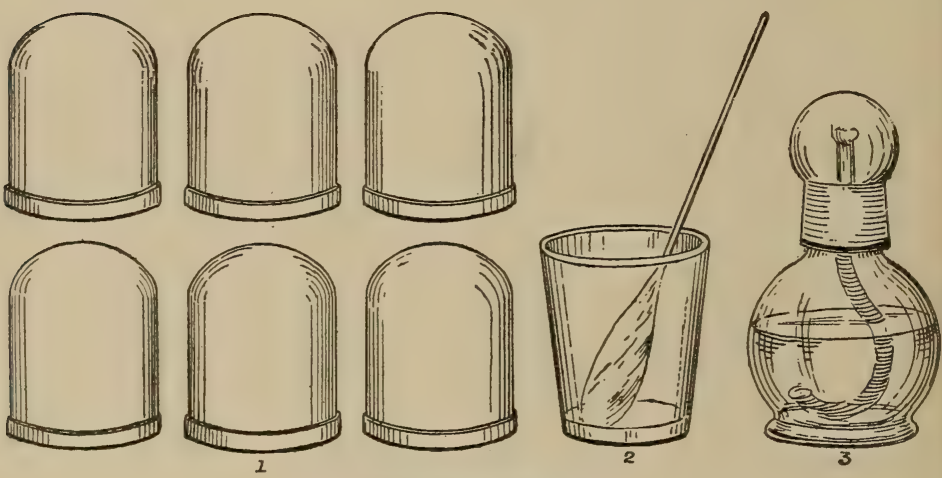

Fig. I79.-Instruments for wet cupping: I, Cupping glasses; 2 , swab in alcohol; 3, alcohol lamp; 4, scalpel. (Morrow.)

to the incised areas; $(d)$ treat the scarification wounds antiseptically.

Cupping is employed to produce local depletion; wet cups are better in serous inflammations.

Leeching.-(a) American leech (draws about a teaspoonful-4 c.c. -of blood).

(b) Swedish leech (draws three or four-12 or $\mathbf{1 6}$ c.c.teaspoonfuls). 
A mechanical leech consists of a scarifier, cup, and exhausting air-pump attachment.

Method.-Prepare the skin surface by cleansing with soap and water; dry thoroughly; apply the leech to the area moistened with blood or milk; confine the leech to the moistened area by means of an inverted glass tumbler. To remove the leech sprinkle a little salt upon its head. To preserve the life of the leech, strip it of the sucked blood and replace in a jar of water having a perforated cork. Dress the wound antiseptically, apply a compress, nitrate of silver torsion, acupressure for continuous bleeding.

Leeching is employed to secure local depletion.

Venesection.-This procedure is performed to relieve tension in elevated blood-pressure, such as in acute kidney disease, pneumonia, and pulmonary edema.

The simplest method is to insert a large caliber needle directly into the vein after the venous circulation has been dammed back by a tourniquet. Frequently it is necessary to expose and incise a vein. For this proceeding the following instruments are necessary: Small scalpel, scissors, plain and tooth tissue forceps, small retractors, needles, sutures, and ligatures.

Under local anesthesia a small skin incision is made over the vein which is exposed and dissected free. A double ligature is then passed under the vein. The upper one is tied and the lower one is left loose. A small opening is then made in the vein between the two ligatures and the blood caught in a basin. When enough has been taken, the lower ligature is tied and the skin wound sutured and a dressing applied.

Intravenous Infusion.-This is the best treatment to 
combat traumatic and surgical shock, and is used after a severe hemorrhage. The same instruments are used as for a venous section, and, in addition, an irrigating can, rubber tubing, and an infusion needle are necessary. These must all be sterilized. One quart of normal salt solution is the usual fluid used. In severe shock a dram of adrenalin chlorid solution is added. At times it is possible to use a sharp-pointed needle for this procedure, and plunge it directly into the vein without incising the skin. (See Venesection.)

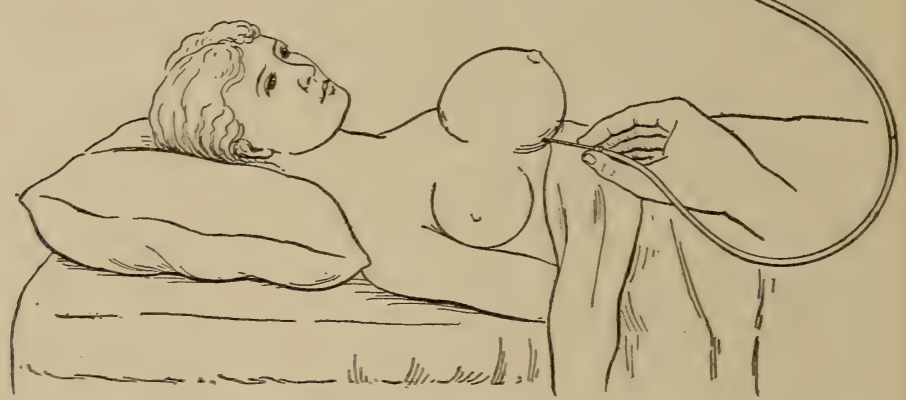

Fig. I80.-Giving hypodermoclysis under the left breast. (Ashton.)

Hypodermoclysis.-This is another method of giving salt solution in cases of shock and hemorrhage. A sharppointed large caliber needle is attached to an irrigating can by rubber tubing. The needle is usually plunged under the breast near the chest wall, the skin being first thoroughly disinfected and the can held about 3 to 4 feet above the patient while the solution is being run in. 
The breast is massaged so as to quicken the absorption of the fluid. Every nurse should be able to prepare and give hypodermoclysis.

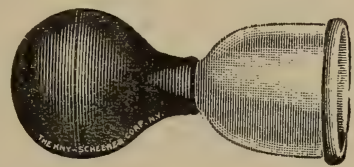

Fig. I8r.-Bier's vacuum treatment apparatus for boils.

Bier's Hyperemia.-This treatment has for its principle the increase of blood to the part, which therefore increases the number of leukocytes. It is used in infected areas. The principle is the same as cupping, in that a

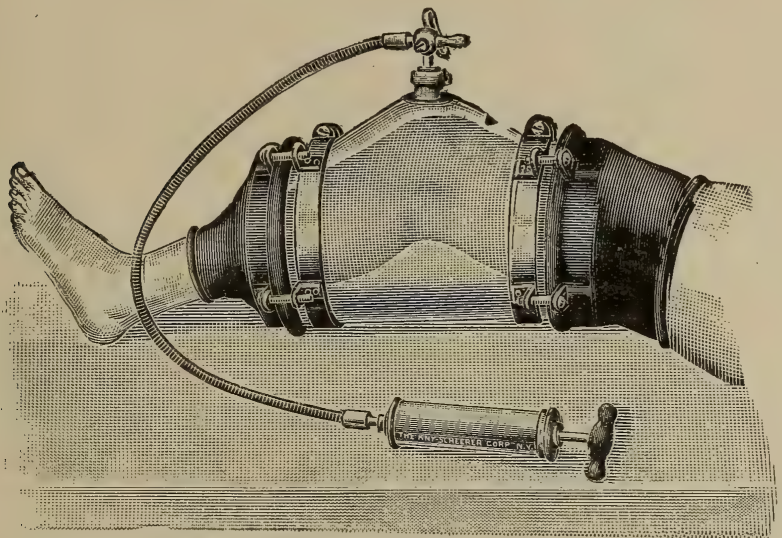

Fig. I82.-Bier's air suction apparatus for treating stiff knee.

vacuum is formed, but it is not as mild. Special apparatus is needed. It may be obtained in the extremities by placing a tourniquet around the arm or thigh sufficiently tight to particularly obstruct the venous return. 
Normal saline solution is made to correspond as nearly as possible with the normal serum of the blood. It contains calcium chlorid $0.25 \mathrm{gm}$, potassium chlorid O.I gm., sodium chlorid $9 \mathrm{gm}$. to I quart of distilled water. It not only gives the heart a better fluid to work upon, but it restores to the blood that coagulable quality which is diminished or lost by hemorrhage.

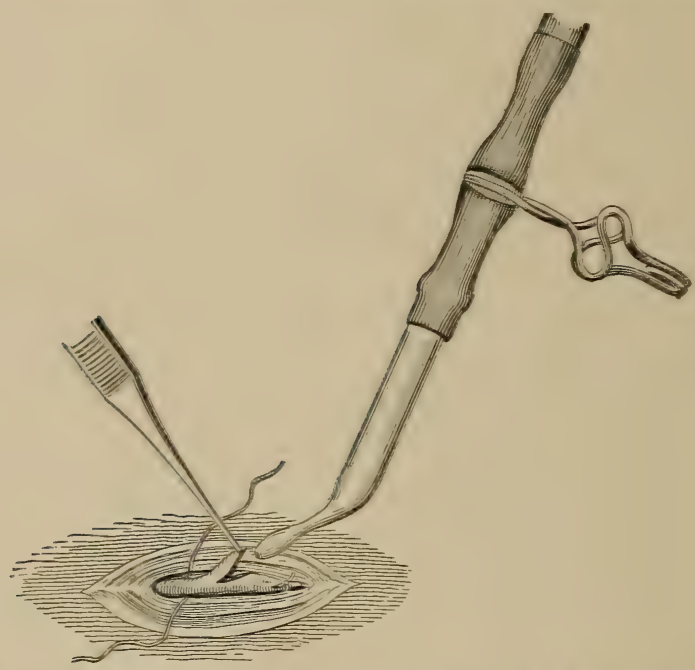

Fig. I83.-Intravenous saline infusion. Manner of incising vein and inserting glass tube. (Senn.)

Tablets containing this formula have been devised. and are usually used. One tablet added to I quart of water gives the correct strength. In the absence of the tablets I teaspoonful of table salt is added to I pint of water. It is absolutely necessary, whatever formula is used. that the solution and all the apparatus used should be properly sterilized. If the water contains particles that cannot 
be strained out and there is no filter at hand, the water should stand until the sediment settles, when the fluid can be poured off, resteril-

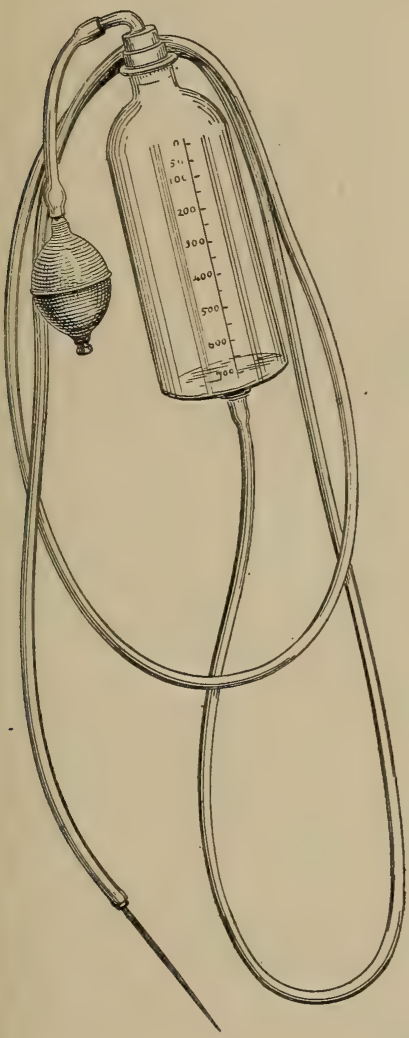

Fig. 184.-Apparatus for hypodermoclysis. (Hirst.) ized, and used. This solution is placed in an irrigator or a fountain-syringe

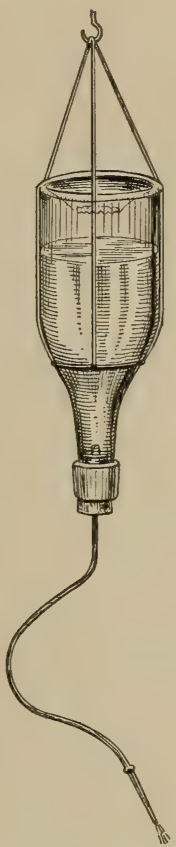

Fig. 185.-Improvised apparatus for the irrigation of a wound. (DaCosta.)

which has been thoroughly sterilized. The temperature of the solution should be about $110^{\circ} \mathrm{F}$.

In hospitals it is customary to keep on hand flasks of 
saline solution. These flasks are sterilized before filling; afterward they are stoppered with sterile cotton plugs and sterilized again by boiling for one hour on three successive days.

Normal salt solution is used for irrigation and for injections in cases of shock, in acute diabetic and uremic coma, hemorrhage, puerperal infection, and eclampsia.

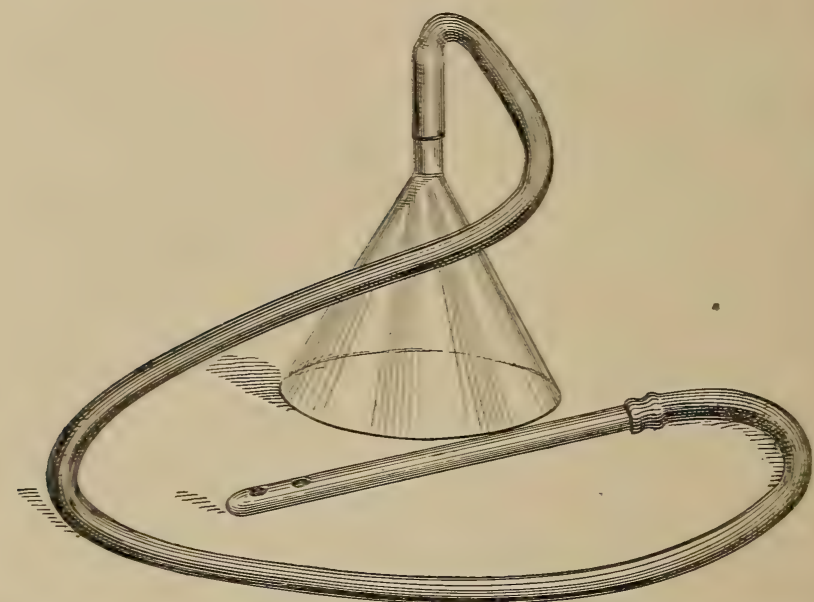

Fig. I86.-Apparatus for douching the abdominal cavity. (Hirst.)

Scarification.-This consists in the making of small linear incisions through the skin and subcutaneous or mucous tissues for the purpose of securing depletion to relieve tension.

Puncturation is the operation of making punctures with a sharp-pointed bistoury through the skin or mucous tissues. It is performed to secure local depletion or to relieve pressure. 
Incision of Abscess for Drainage.-The nurse should have sterilized knife, scissors, hemostats, and tissue forceps. Rubber dam and tubing for drainage, gauze dressing, bandages, and pus basin. Some use disinfecting solutions, such as iodin, Harrington's, and bichlorid. These should be at hand, as should also cotton sponges.

Hot-air or Baking Treatment.-This treatment is used for acute and chronic conditions of joints and for tenosynovitis, sprains, effusions, and fractures.

The part must be protected with blankets or flannel bandages, the temperature at which it is used varies from $100^{\circ}$ to $200^{\circ} \mathrm{F}$. There are special bakers or types of apparatus on the market for this treatment.

Deep puncture and incision with a sharp-pointed bistoury is sometimes performed-(a) To relieve tension; $(b)$ to secure drainage.

Plasters.-(a) Belladonna (use as a local sedative in neuralgia, mastitis, adenitis; remove if dryness of throat or disordered vision occurs-the first symptoms of belladonna-poisoning); (b) mercury (used for its resolvent effect upon indurated glands, chronic arthritis); (c) adhesive, "American surgeon's adhesive plaster" (contains rubber and adheres without heating); (d) resin plaster (requires heating to adhere).

Collodion and cotton are used to support and seal external flaps and wounds.

Massage consists of manual manipulations of a part for the purpose of stimulation. May be applied twice daily, once daily, or every other day; each application may last from twenty minutes to one hour.

The movements of massage are: (I) Rubbing (stroking movements, gentle at first, afterward of increasing 
firmness); (2) kneading (rolling, circular, pinching movements); (3) tapping (percussion over the surface with the leveled finger-tips produced by flexion, ulnar side of the hand, or by the use of a mechanical musclebeater); (4) passive motion (elevation, flexion, and contraction of the parts produced by the operator).

Clinical Thermometer.-May be of Fahrenheit (common form) or Centigrade scale. To reduce readings(I) Fahrenheit to Centigrade: Subtract 32 from the number of Fahrenheit degrees and multiply the remainder by $\frac{5}{9}$; (2) Centigrade to Fahrenheit: Multiply the number of Centigrade degrees by $\frac{9}{5}$ and add 32 .

Fig. I87.-Clinical thermometer.

Thermometers may be-(a) straight, self-registering $\left(90^{\circ}\right.$ to $110^{\circ}$ F. $-33.3^{\circ}-44.4^{\circ}$ C.) ; (b) surface, coiled or bulb $\left(80^{\circ}\right.$ to $110^{\circ} \mathrm{F} .-26.6^{\circ}-44.4^{\circ} \mathrm{C}$.)

Temperature may be taken in- $(a)$ Mouth; (b) axilla; $(c)$ rectum; $(d)$ vagina. Most exact in vagina and rectum. Mouth-temperature is higher than that of the axilla and less than that of the rectum. Axilla-temperature is somewhat less than a degree below the rectal.

Electricity is used (a) As a muscle tonic; (b) for nervesedative action employ that form of electricity which gives the best contractions with the least amount of pain and discomfort to the patient; $(c)$ electrolysis (used in the treatment of aneurysm, tumors, for the removal of superfluous hair); $(d)$ cautery, ecraseur (is followed by least hemorrhage when used at a dull-red heat). 
The thermocautery, known also as the Paquelin cautery, because of its invention by Paquelin, of Paris, is frequently employed in surgery to control bleeding, and also to produce counterirritation. The efficacy of this instrument depends on the fact that when the vapor of some highly combustible carbon compound is driven over heated platinum its rapid incandescence is sufficient to maintain the heat of the metal. Platinum points of various shapes and sizes are attached to a rubber tube,

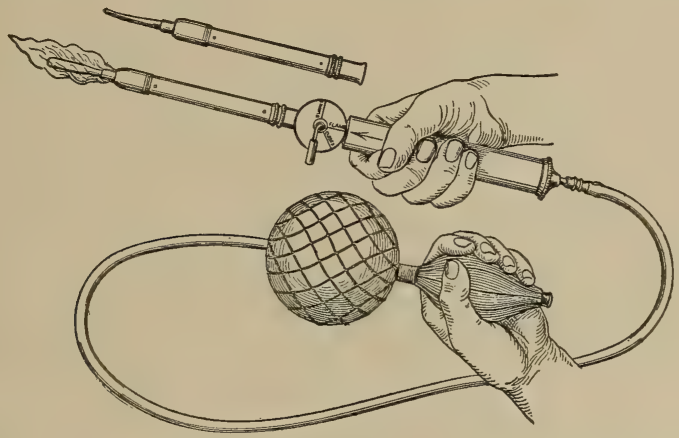

Fig. I88.-Paquelin's cautery. Note that the benzin is contained in the handle of the apparatus. (W. E. Ashton.)

which is connected with a metal container half full of benzin or alcohol, the vapor of which is pumped through the tubing and holder into the platinum point. In order to prepare the instrument for use, benzin (above $65^{\circ} \mathrm{F}$., Baume) is the best combustible, but wood alcohol, naphtha, benzol, gasolene, ammonia-water, or ether may be used.

After using the container should be completely closed, and the points while hot must be removed from the handle and laid away to cool; they must not be put into 
water, but wiped perfectly clean. The handle when cool must be removed from the tubing, and each part must be laid in its own compartment in the case.

Where possible electric thermocauteries are preferable for the reason that they do not get out of order.

\section{POISONS AND ANTIDOTES}

Acids, Mineral.-Give chalk, flour, white of egg, magnesia (plaster torn off the wall may be used in an emergency); a solution of carbonate of soda; emollient drinks; fixed oils (sweet oil, olive oil, cod-liver oil). Give plenty of water to dilute the acid.

Acid, Carbolic.-Any soluble sulphate (magnesia), alcohol acts as a direct antidote if given during the first ten or fifteen minutes; whisky may be employed for the purpose.

Acid, Hydrocyanic.-Secure plenty of fresh air; carry on artificial respiration; apply cold affusion; ammoniainhalation and intravenously in a vein.

Aconite.-Give emetics; stimulants (external and internal); keep up the body heat; patient is to be placed flat on his back.

Antimony Tartrate.-Give vegetable acids-tannic acid (gr. $\left.\quad \mathrm{v}-\mathrm{xv}-0.333^{-I} \mathrm{gm}.\right)$, catechu (f $5 \mathrm{j}-\mathrm{ij}-4-8$ c.c.).

Arsenic.-Give freshly precipitated hydrated sesquioxid of iron (made by adding magnesia to any iron solution).

Atropin, Belladonna, Stramonium--Emetics (mustard flour in water); apply cold to the head; give physostigma (gr. $\frac{1}{10}-\frac{1}{5}-0.006-0.013 \mathrm{gm}$.) or pilocarpin (gr. $\frac{1}{8}-0.008 \mathrm{gm}$.). 
Cantharides.-Give emetics; emollient drinks; opium (gr. $\frac{1}{4}-\frac{1}{2}-0.016-0.033 \mathrm{gm}$.) by mouth and rectum; large drafts of water to flush the kidneys.

Chlorin-water.-Give albumin (white of egg, milk, flour). Chloroform.-Secure plenty of fresh air, carry on artificial respiration (inclining head down, pull the patient's tongue forward); brandy and ammonia intravenously; hypodermic injection ( 15 min.-I c.c.) of tincture of digitalis; gr. $\frac{1}{60}$ (0.00I gm.) of atropin.

Colchicum.-Give emetics, followed by demulcent drinks; keep up external heat. If coma is present, brandy, ammonia, coffee. Opium in large dose.

Conium.-Give emetics; stimulants (external and internal).

Copper Sulphate.-Give yellow prussiate of potash (may be given freely if pure); soap.

Corrosive Sublimate-Give allumin (white of egg $-4 \mathrm{gr}$. (0.266 gm.) of sublimate requires the white of one egg), flour, milk; equal parts of lime-water and milk; emetics or stomach-pump.

. Croton Oil.-Give emetics; wash out the stomach; mucilaginous fluids containing opium.

Digitalis.-Give emetics; recumbent position; tincture of aconite (I-5 drops-0.066-0.333 c.c.); opium (gr. $\frac{1}{4}-\frac{1}{2}-0.16-0.033 \mathrm{gm}$.).

Elaterium.-Give demulcent drinks; enemata of opium; external heat.

Hyoscyamus.-Stomach-pump; give emetics; stimulants. (external and internal); physostigma. (gr. $\frac{1}{10}$ 0.0006 gm.) ; pilocarpin (gr. $\frac{1}{8}-0.008$ gm.).

Illuminating-gas.-Hypodermic injection (I min.0.066 c.c.) of nitroglycerin; carry on artificial respiration. 
Iodin.-Give emetics; demulcent drinks (starch or flour in water); opium (gr. $\frac{1}{4}-\frac{1}{2}-0.016-0.033 \mathrm{gm}$.); external heat.

Lead Salts.-Give any soluble sulphate (magnesia or soda). Follow with emetics, opium (gr. $\frac{1}{4}-\frac{1}{2}-0.016-0.033$ gm.), and milk.

Lobelia.-External and internal stimulation.

Morphin; Opium.-Atropin (gr. $\frac{1}{100}-0.006$ gm.) hypodermically until respirations number eight a minute; stomach-pump; stimulants (external and internal); brandy; strong coffee; cold affusion; ammonia to nostrils; galvanic shocks; compelling patient to move about; artificial respiration; permanganate of. potassium; cocain (gr. $\frac{1}{4}-\frac{1}{2}-0.016-0.033$ gm.) ; repeat if necessary.

Oxalic Acid.-Give lime (plaster, lime-water, milk of lime).

Phosphorus.-Sulphate of copper in emetic dose as a. chemical antidote; emetics; purgatives. No oils.

Potash and Soda Salts.-Dilute acetic acid; citric acid; lemon-juice; vinegar; fixed oils; demulcent drinks.

Silver Nitrate.-Solution of common salt; demulcent drinks; emetics.

Strychnin; Nux Vomica.-Give 30 grains (2 gm.) of chloral and 60 grains (4 gm.) of bromid of potassium; nitrate of amyl.

Tobacco.-Emetics; stimulants (external and internal); strychnin (gr. $\frac{1}{30}-\frac{1}{15}-0.0022-0.0044$ gm.).

Zinc Salts.-Carbonate of soda; emetics; warm demulcent drinks.

Poisonous Fish.-Emetics to wash out the stomach; purgatives; stimulants. 


\section{CHAPTER XIII}

\section{OBSTETRIC NURSING, CARE OF INFANTS, ETC.}

Professor Hirst has employed printed slips containing the following directions to the nurse:

\section{BEFORE LABOR}

I. Have ready towels; ether, $\frac{1}{2}$ pound; brandy, 2 ounces; vinegar, 4 ounces; hot water; a bottle of antiseptic tablets; a large, new sponge; a roll of narrow tape or skein of bobbin; a fountain-syringe; bed-pan; new, soft-rubber catheter; 4 dozen small, 2 dozen large, pads; small package of salicylated cotton; absorbent cotton.

II. Give a rectal injection (a pint of soapsuds with teaspoonful of turpentine) as soon as labor-pains are well established.

\section{AFTER LABOR}

III. No vaginal injection to be given unless ordered.

IV. Take the temperature three times a day-morning, noon, and evening.

V. Place large pad under patient. Occlusive bandage to be used as directed.

VI. The external genitals to be washed off four or five times a day with a warm corrosive sublimate solution, I : 2000. Use absorbent cotton.

VII. If, at the end of twelve hours, the bladder cannot be emptied naturally, use a catheter. Afterward, if necessary, catheterize patient three times a day. 
VIII. The patient is to lie on her back; she may be moved from one side of the bed to the other several times a day; her limbs may be rubbed with alcohol and water or bathing whisky once a day.

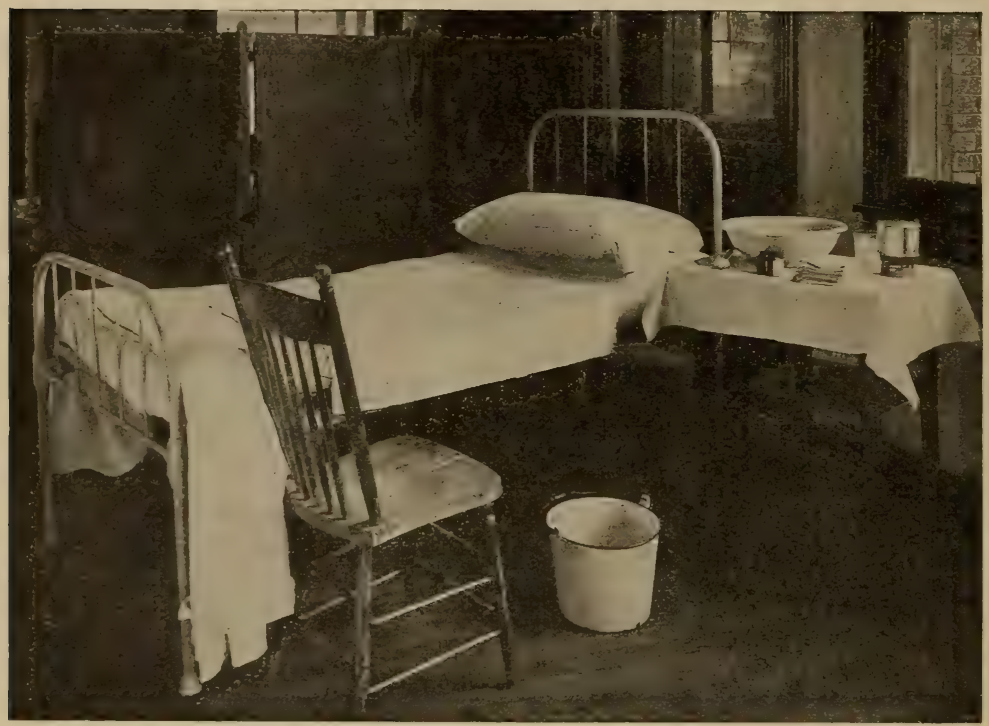

Fig. I 89.-Bed arranged for childbirth: The mattress is protected by a mackintosh, over which a clean sheet is spread. The upper bedclothes are rolled up at the foot of the bed. The woman's buttocks rest upon a square yard of nursery cloth. The chair is for the obstetrician; at his feet is a waste-bucket, into which the pledgets of cotton used to clean the anus are thrown. The table, in easy reach, has upon it a large basin of sublimate solution, I : 2000 , in which are many large pledgets of cotton; a small tin cup on an alcohol lamp to boii the scissors for the cord; a halfdozen clean towels; a pot of carbolated vaselin, a tumbler of boric acid solution with squares of clean soft linen in it for the child's eyes and mouth; a tube of sterile silk for the cord. (Hirst.)

IX. The nurse's hands are to be washed with nailbrush, soap and water, and rinsed in a 1 :3000 sub- 
limate solution before catheterizing the patient, cleansing the genitals or breasts.

Diet.-First Forty-eight Hours.-Milk, $\mathbf{I} \frac{1}{2}-2$ pints a day, gruel, soup, one cup of tea a day, toast and butter.

Second Forty-eight Hours.-Milk-toast, poached eggs, porridge, soup, cornstarch, tapioca, wine jelly, small raw oysters, one cup of coffee or tea a day.

Third Forty-eight Hours.- Soup, white meat of fowl, mashed potatoes; beets in addition to above.

After sixth day return cautiously to ordinary diet. In addition to three meals a day give three or four glasses of milk through the day.

Child.-I. After being well rubbed with sweet oil, the child is to be bathed in water of $90+{ }^{\circ} \mathrm{F}$.; this should be the temperature of the daily bath. Use a bath-thermometer, or else the water will often be too hot.

II. The cord is to be dressed with salicylated cotton. Observe carefully for bleeding.

III. It should be bathed daily, about midday, in the warmest part of the room. Use Castile soap and a soft sponge; avoid the eyes.

IV. The bowels of a healthy infant are moved four times a day, the urine voided six to twenty times. It is usually necessary to change the diapers eighteen to twenty-four times a day. Use compound or borated talcum powder, lycopodium, zinc oxid, or rice flour. In case of chafing, cold cream and borated talcum flour. Note the color of stools.

Nursing.- The child is to be put to the breast every four hours during the first two days. No other food is to be given it. After the second day it should be nursed every two hours from 7 A. M. to 9 P. M., and twice during 
the night ( $\mathrm{I}$ and 5 A. M.). After every nursing the nipples are to be carefully washed with a piece of absorbent cotton, warm water and Castile soap, and then smeared with a little sweet oil.

Clothing.-If born during the winter season a baby should be clothed as follows: A binder of flannel or knit wool twice around abdomen; a knit shirt, diaper, knit woolen shoes, and two skirts, the first flannel (in midsummer, linen), and finally its dress. The skirts should

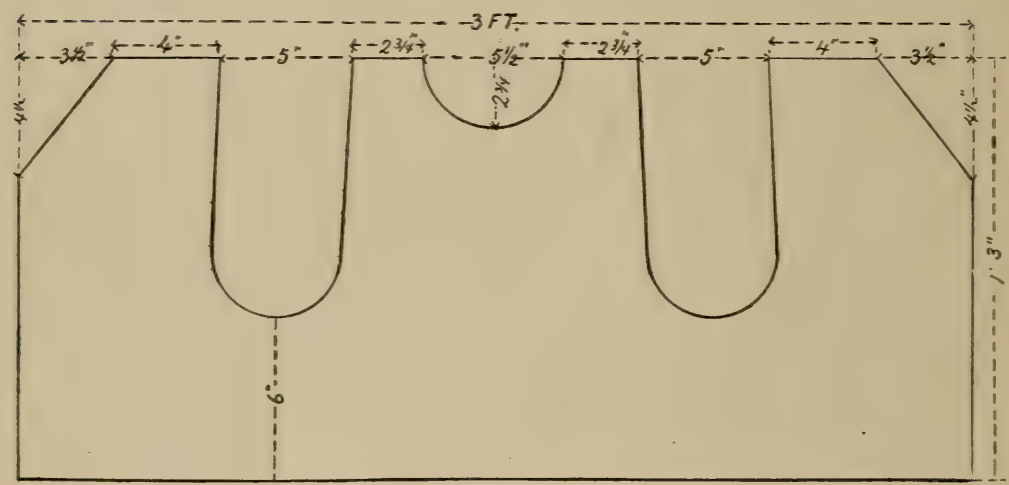

Fig. I90.-The Murphy breast-binder.

be supported from the shoulders by sleeves or tapes. A knit jacket may be worn over the dress. A light flannel shawl or cap will protect the child from attacks of head cold (coryza).

Feeding.-The average stomach capacity of a newborn infant is I ounce, and it increases I ounce per month up to six months. A child should never be nursed while it lies in its crib, but be taken up in the arms. Young mothers experience great pleasure in suckling a child, and may put it to the breast every fifteen 
or thirty minutes, giving rise to derangement of the infant's bowels which may become serious.

Artificial Feeding.-Asses' and goats' milk are most like human milk. An infant cannot begin to digest starchy foods under nine months of age, hence all pre-
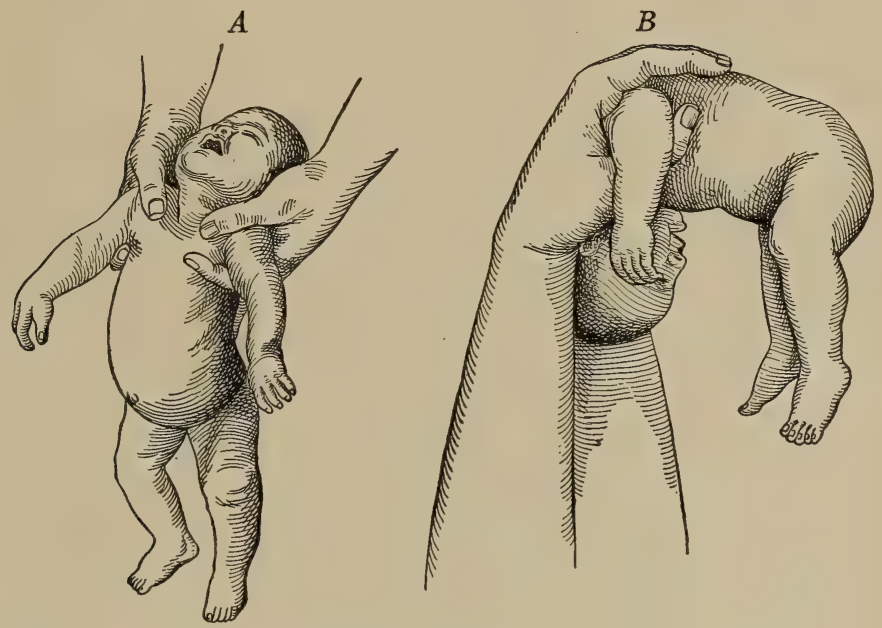

Fig. I9I.-Schultze's method of artificial respiration: $A$, Inspiration; $B$, expiration. (Hirst.)

pared foods are injurious according to the amount of starch contained.

Milk Mixtures.-(a) For first twelve or fourteen days take:

Condensed milk,

Boiled water,

Cream,

Lime-water,
I teaspoonful.

3 tablespoonfuls.

I teaspoonful.

I

Stir. 
(b) After fourteenth day up to third month the following may be used:
Milk,
I tablespoonful.
Boiled water,
5 teaspoonfuls.
Cream,
I teaspoonful.
Lime-water,
I
Maltine (Merck's),
Io grains.

Stir.

After the third month increase the amount of milk to 5 teaspoonfuls, and reduce the boiled water to 4 teaspoonfuls.

(c) A mixture for general use may be made according to the following formula:

Milk, I ounce,

Boiled water, I ounce,

Cream,

Lime-water,

Malt sugar (malt extract), I coffeespoonful.

Stir together.

Absolute cleanliness of all milk bottles, spoons, dippers, and rubber nipples is necessary, or deranged digestion if not serious bowel disorders will assuredly result. They should be boiled.
2 tablespoonfuls.

2

2 teaspoonfuls.

2

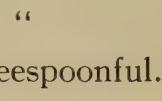




\section{CHAPTER XIV}

\section{OPERATIONS; PREPARATION OF THE OPERAT- ING-ROOM; THE SURGEON AND HIS AS- SISTANTS}

SURGERy has two objects, to prolong life and to relieve suffering. If it accomplishes either of these objects it succeeds. To prolong life or to relieve suffering divides operations into several classes, because they occur with more or less urgency according to the condition the patient is in.

We often hear it said of an operation that it is one of necessity; of another, that it is one of emergency; and of another, that it is one of expediency. For convenience, operations are divided into two classes: First, operations of necessity; second, operations of expediency; and the first class may be subdivided into emergency and elective operations.

Operations of expediency are those which it would be well to perform for the health of the patient, as, for instance, the removal of a malignant growth of the breast. If left to itself, the growth will slowly and gradually invade the internal organs and in a very few years will end life; while if removed, the patient will in all probability live a number of years, and there may be immunity for a long period before the disease returns.

Operations of necessity are performed to save the life of the patient, as, for example, in cases of intes- 
tinal obstruction, in hemorrhage from rupture of an extra-uterine pregnancy, etc.

Emergency operations are those which must be performed immediately, without any choice, such as tracheotomy.

An elective operation is at the choice of the patient, as in a hernia.

Preparation of the Operating-room.-The operatingroom should be made as aseptic as possible; the walls and floor should be washed with corrosive sublimate solution (I : 2000). The operating-table, stands, chairs, and other furniture, which are usually of glass and iron, should be washed with the sublimate solution. The sterilizer, which has been packed with the dressings, blankets (2), sheets (2), towels, caps, suits, and gowns for the operator, assistants, and nurses, should be started two hours before the operation. The instruments should boil fifteen minutes for their final sterilization before the operation in a I per cent. soda solution. Everything that will be needed for the operation and for possible accidents must be in the operating-room, and within easy reach. The solutions used should be quite warm, both for the surgeons and patient. We often come across a nurse who when she has filled the basins will put in her non-sterile hand to see if the water is too hot or too cold. We can readily tell from the outside of the basin if the water is of the proper temperature.

At all major operations four nurses are necessarythe head nurse, who has charge of the instruments; a second nurse, to take charge of the sponges; a third nurse, to keep ready for the operator a basin of sterile water to enable him at any time to quickly rinse his 
hands to remove septic fluid or to free his fingers from blood and clots, and attend to the irrigation, etc.; a fourth nurse, to handle unsterilized articles. Each nurse should have a clear idea of her duties, and discharge them without undertaking the duties belonging to another. If the dry technic is used, the head nurse can hand the sponges as well as the instruments, and this gives a nurse to wait on her exclusively. Under no consideration should the head nurse be left alone for a single moment, as the operator might call for something which she, being "surgically clean," could not touch, and so cause a probable delay in the operation.

The duties of the nurses in the operating-room are the same for all operations. The dress must be of washable material, preferably white; it should be fresh for the operation and as far as possible sterilized. A dress that has been through the wards is not clean; neither is one that has been worn a day or half a day. The dress-sleeves should be unbuttoned so that they can be rolled up above the elbow, to allow the arms to be made as sterile as possible, and so that the sleeves may not come in contact with anything used in the operation itself. The finger-nails must be cut short. On first going to the operating-room the hands and forearms should be scrubbed with a brush and green soap and running water as hot as can be borne for ten minutes by the clock. The cleaning of the finger-nails is very important, as many of us would be surprised to find the large number of germs taken from under the finger-nails as the result of one cleansing.

The hands and forearms are then rendered sterile by putting them first into a saturated solution of perman- 
ganate of potassium until they are of a deep-brown color from the tips of the fingers to the elbow, then into a hot saturated solution of oxalic acid until all the permanganate stain has been removed; they are then washed in sterilized hot water, and finally are soaked for three minutes in a solution of corrosive sublimate ( $\mathrm{I}: \mathbf{I 0 0 0}$ ). The solutions reach those corners and crevices in the finger-nails that cannot be reached by the brush.

Some surgeons prefer ether and alcohol for cleansing the skin. After the hands have been scrubbed thoroughly in hot soapsuds and the finger-nails cleaned, the hands are washed in ether, which removes from the skin all oily and fatty substances; they are next washed in pure alcohol for one minute, and finally soaked for three minutes in a solution of corrosive sublimate ( $\mathrm{I}$ : I000). The field of operation is cleansed in the same manner with ether, alcohol, and the sublimate solution, or painted with 5 per cent. tincture of iodin. In using iodin be sure no water has been on the area for several hours; if so, wash first with alcohol (95 per cent.). Bichlorid of mercury should not be used with iodin, as a burn will be produced.

The nail-brushes used should be absolutely sterile. They must be new, and need to be boiled for one-half hour on the day of the operation. A dirty nail-brush is the haven of myriads of germs and their spores, and by using such a one we place more germs on our hands than were there before they were touched.

Before going to operation nurses and doctors should be attired in sterile suits, caps, and masks. They should then disinfect their hands and long sleeved gowns and rubber gloves be put on. The cuffs of the sleeves should 


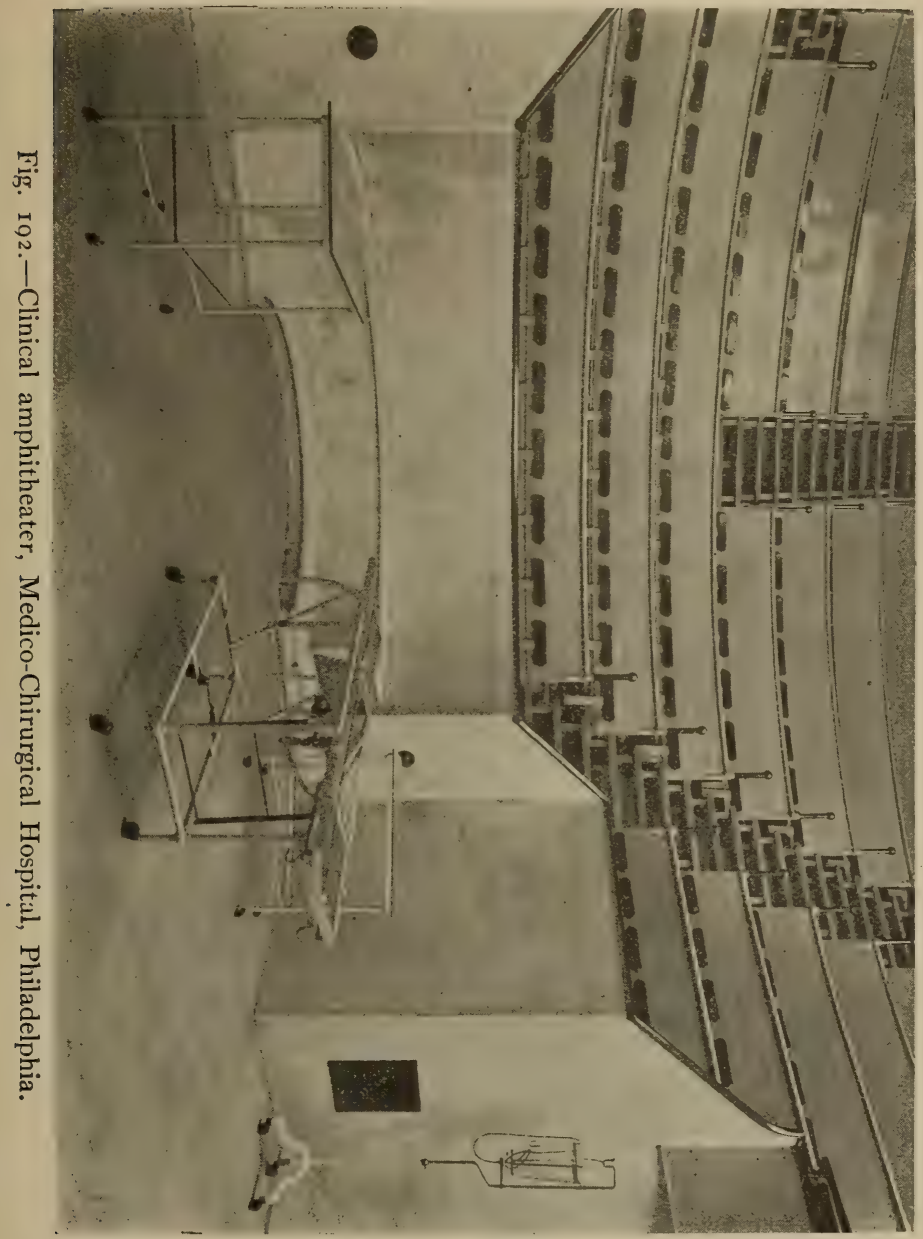

be encased in the rubber gloves. After making the hands aseptic it is essential that they do not come in contact with anything that has not been made aseptic before the 
operation is commenced, for such is very easy to occur unless the nurse is constantly on her guard against it.

The surgeon and his assistants prepare for the operation very much the same as does the nurse. Many surgeons before operating take a corrosive sublimate
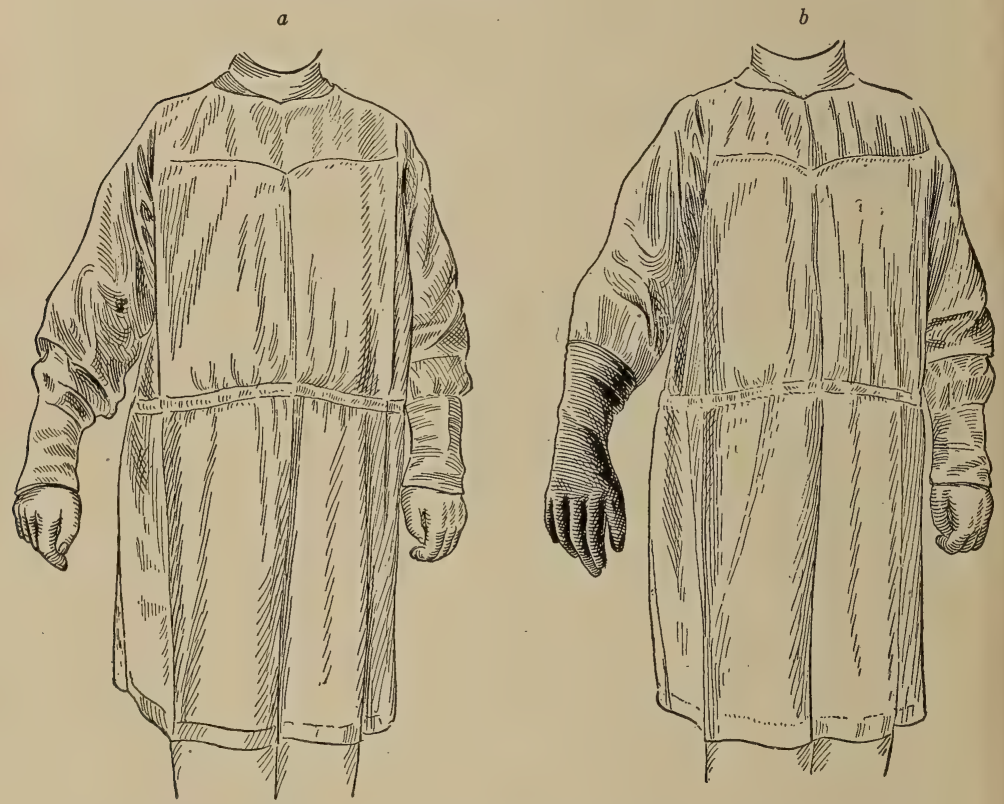

Fig. 193. - $a$, Long-sleeved gown; $b$, the same, showing glove with gauntlet turned up over wristband of gown. (Hirst.)

bath ( $1: 500$ ), after which they put on clean linen suits or long gowns and prepare their hands and forearms. The suits, which have been sterilized in bags or folded in a sheet, are taken from the sterilizer by the head nurse, and placed in the dressing-room about one hour before the arrival of the surgeons, 


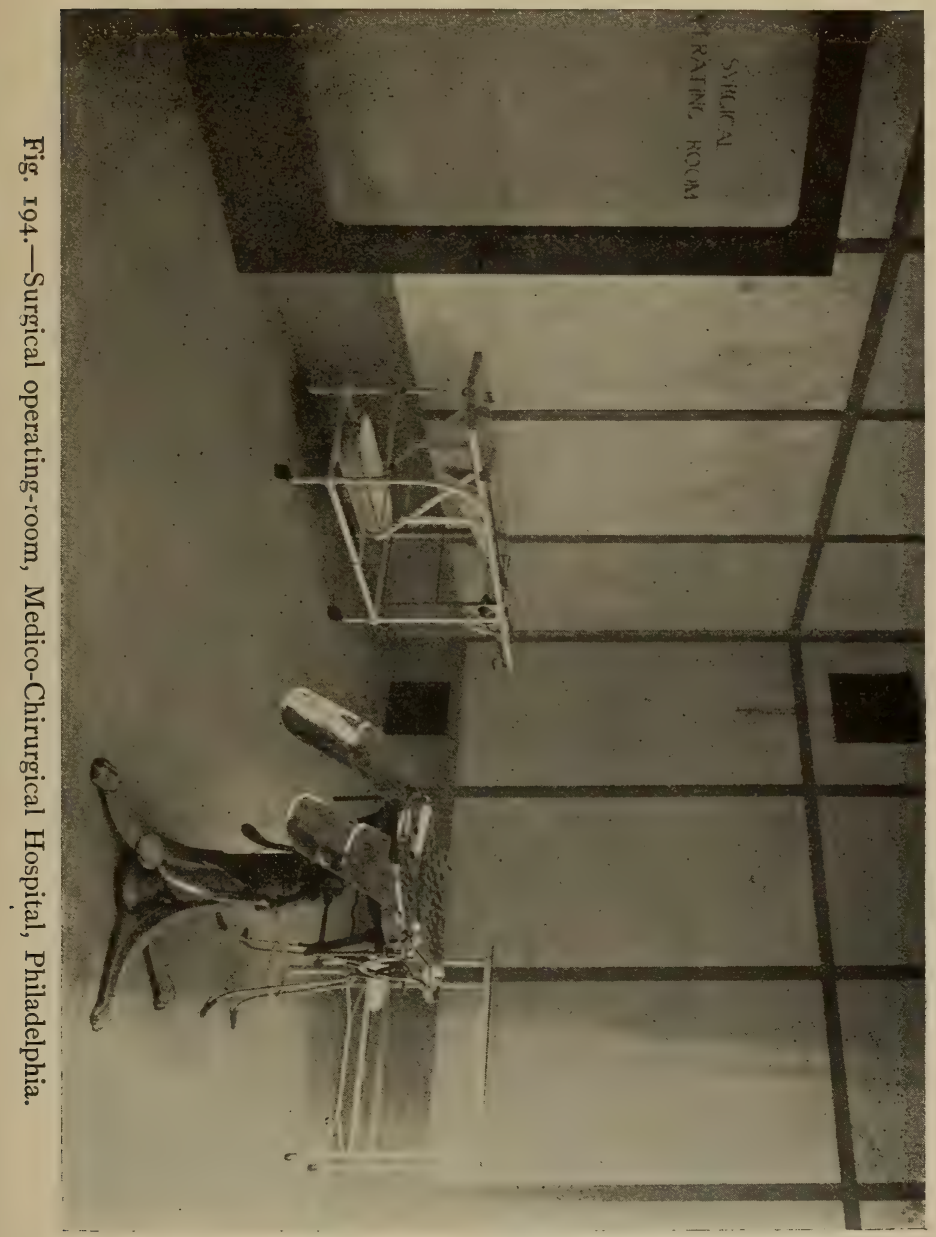

so that they may be perfectly dry when required for use. They should not be hung over the back of a chair or laid over a table for dust to collect upon them. 
We must bear in mind that after sterilization there is always the danger of contamination, and the articles must be carefully protected as soon as they are removed from the sterilizer. To avoid confusion, each suit and bag should be distinctly marked with the owner's name, as should also the white canvas shoes which some surgeons wear. The caps must be laid in the dressing-room, together with long strips of sterilized gauze to cover the beard and mustache.

Spectators should remove their coats and wear long sleeveless linen gowns. The nurses should not leave the operating-room unless it is absolutely necessary, and there should be no unnecessary opening of doors, which allows cold air to enter. Constant moving also causes dust to become stirred up. The temperature of the operatingroom should be $80^{\circ} \mathrm{F}$., and the air kept perfectly pure by thorough ventilation, which should be so arranged that drafts will be avoided.

With the kind permission of Dr. F. W. Johnston, of Boston, I extract the following from his paper on "Two Years' Work with the Sprague Sterilizer in the Gynecologic Department at St. Elizabeth's Hospital, Boston, Mass.," which shows the great necessity of absolute cleanliness and how easily infection takes place from dust in the room:

"I was especially anxious to ascertain if any pusproducing organisms should be found in the dust.

"The operating-room is kept as clean as soap and water and corrosive sublimate can effect the cleanliness of its floor and walls.

"The following is the report of E. A. Darling, formerly Assistant in Bacteriology, Harvard Medical School: 
"Four Petri double dishes containing films of sterilized and coagulated blood-serum were exposed in various parts of the operating-room during a celiotomy, the period of exposure varying from one hour and twenty minutes to one hour and fifty minutes.

"The plates were exposed during the middle of the forenoon of December 28, I 897 .

"One dish was placed on the floor, where we supposed the dust would be kept in the most active motion by our feet and the nurse's dress; one was placed on the stand holding the sponge-pails; one was placed on the patient's knees raised in the Trendelenburg position, and one was

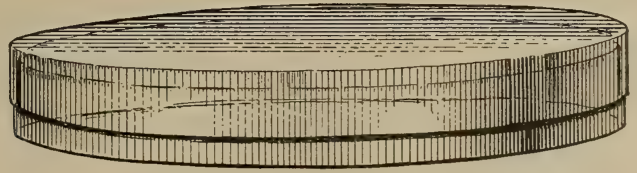

Fig. I95.-Petri dish for making plate cultures.

placed on the table beside the instrument tray. The dishes were uncovered just as the knife went through the skin.

"At the conclusion of the operation the dishes were covered, conveyed to the bacteriologic laboratory, and placed in the incubator at $37^{\circ} \mathrm{C}$. for several days.

"After twenty-four to seventy-two hours the plates were opened and the colonies counted.

"At the same time an attempt was made to determine the varieties of bacteria present, and particularly to demonstrate the presence or absence of the pyogenic forms.

"Cover-glass preparationsıand cultures were made from 
as many different kinds of colonies as could be distinguished.

"The results are, in brief, as follows:

"Plate A. Sponge table, exposed I hour 50 minutes: after 24 hours showed 216 colonies; 72 hours, 296 colonies.

"Plate B. Knees of patient, exposed I hour $20 \mathrm{~min}$ utes: after 24 hours showed 156 colonies; 72 hours, 280 colonies.

"Plate C. Floor, exposed I hour 50 minutes: after 24 hours showed 296 colonies; 72 hours, 428 colonies.

"Plate D. Instrument table, exposed I hour $40 \mathrm{~min}-$ utes: after 24 hours showed 216 colonies; 72 hours, 256 colonies.

"The varieties of bacteria present were studied minutely on Plate B (the one on the patient's knee), less carefully on Plate D (the one on the instrument table). Of the recognized pyogenic cocci, two varieties were found-the Staphylococcus albus ( 15 colonies on Plate B, 20 colonies on Plate D) and the Staphylococcus aureus ( 3 colonies on Plate $\mathrm{B}, 4$ colonies on Plate D).

"The remaining colonies on both plates were sarcinæ of several kinds, yellow, orange, and white molds, and several varieties of unrecognized bacilli and cocci.

"As would be expected, the plate from the floor showed the largest number of colonies. Plate B (the one on the patient's knee) most interested me.

"The finding by Dr. Darling of fifteen colonies of the Staphylococcus albus and three colonies of the Staphylococcus aureus on this small plate within a few inches of the opened abdominal cavity was certainly an object lesson, and has given lots of food for reflection." 


\section{CHAPTER XV}

\section{TRANSPORTATION; PREPARATION OF PATIENT FOR OPERATION; CARE OF PATIENT DUR- ING AND AFTER OPERATION}

Transportation.-The entire duty of attending to the transfer of a patient to or from home and hospital may fall upon the nurse. The following suggestions are made by Mr. Scully, who conducts a private ambulance business in New York. The transportation of a patient, in order that it may be safely and pleasantly accomplished, requires attention to detail. The nurse or friends of the patient should attend to the requirements for admittance by the hospital authorities, such as the hours of admission, financial details, and presentation of a written statement of diagnosis by the family physician. Other things being equal, it is better in the summer months to remove a patient early in the morning or toward evening; in the winter, near midday. Give as much notice as possible in order to secure the best attention from the ambulance service. Have the patient ready at the hour arranged. Nothing is more trying to the patient than to be delayed, either by friends or by non-arrival of the ambulance. Do not disturb the patient by insisting on a perfect toilet; an ample supply of covering is the chief necessity. Necessary articles of clothing which a patient should bring 
to a hospital are: 4 night-gowns or pyjama suits; 4 suits of underwear; 4 pairs of stockings; slippers, bathrobe; hair-brush and comb; tooth-brush and tooth powder or paste; handkerchiefs, and other toilet articles. The nurse should accompany the patient in the ambulance, to give any needed attention and complete the arrangements with the hospital authorities. Jewelry and valuables should be checked at the hospital office. In transporting to and from railroads and steamships ample notice must be given to make connections. For all distances up to thirty-five miles, direct transportation by ambulance is preferable to train service, especially in cases of very sick patients.

Preparation for Operation.-The methods given here for preparing the patient for abdominal operations may serve as a reliable guide to the nurse, who is more or less responsible for preparatory treatment. The methods of preparation of all kinds are subject to change in detail, because surgical methods are constantly advancing and changing, though the general principles remain. It should be remembered that patients rally much better from an operation when they have been properly prepared both externally and internally.

Day Before Operation.-The patient receives a full bath and the hair is washed. A cathartic is givencastor oil, citrate of magnesium, or salts. The diet should be nourishing and light. Milk is not given before an abdominal operation, because the stomach may not digest it thoroughly, and its curds may remain in the intestines and act as an irritant. Gruel is nourishing and easily digested. No food is given after midnight. 


\section{PREPARATION OF FIELD OF OPERATION}

I. Scrub the parts with green soap and stiff brush.

2. Shave from nipples to rectum. Chemical hairremover may be used; acts by dissolving the hair, but may prove too irritating to some skins.

3. Scrub again and rinse thoroughly with sterile water.

4. Rub well with alcohol, followed with ether, to remove fats.

5. Wash with corrosive sublimate (I : I000), and put on an antiseptic dressing, consisting of five dressingpads, one layer of common cotton, one dressing over that, then abdominal binder. The patient must be instructed not to put her fingers underneath the dressing nor to disturb it in any way.

A simpler method, and one frequently used, consists in a tub- or bed-bath.

Completely shave the parts to be operated upon at least six hours before the operation.

Paint the operative area (excepting vulva or rectum) with tincture of iodin ( 5 per cent.).

Prepare the vaginal canal by shaving the parts and giving a warm douche (lysol, I per cent.) and cover the vulva with a dressing. Use perineal straps to keep the dressing and abdominal binder in position. See that the dressings are kept wet with the antiseptic ordered until the patient is taken to the operating-room. This preparation should be made twelve hours before an operation.

Biniodid of mercury is sometimes dissolved in the ether, making a solution of I : Iooo, which, besides removing all fatty substances from the skin, is also a disinfectant. When the skin is very dirty it is scrubbed 
with benzin, then with alcohol, and then with the biniodid solution.

Day of Operation.-Flush out the colon and give a bath; take off all flannels, put on a gown open at the back, and cotton-flannel stockings. Cleanse teeth, mouth, nose, and throat with a boric acid solution and brush. Catheterize just before sending the patient to the anesthetizing room if the operation is on the uterus or its appendages. Always catheterize in other opera-

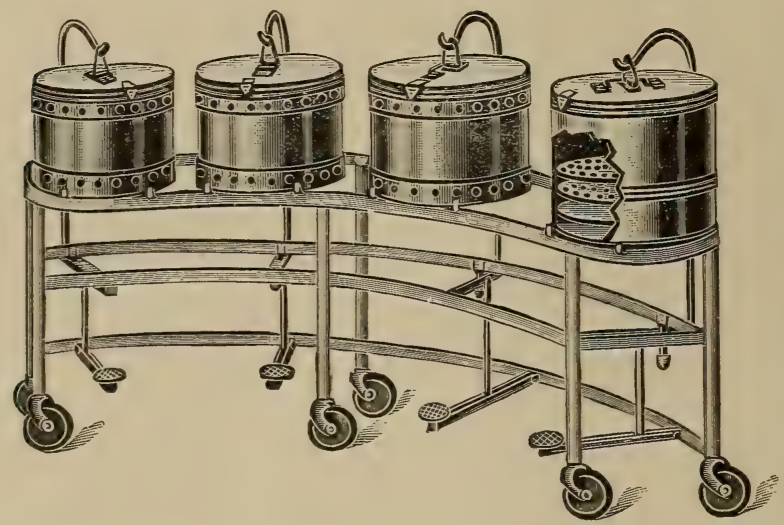

Fig. I96.-Solution basins stand.

tions if the patient is unable to urinate. Envelop the hair in a sterilized towel.

Remove all rings and ear-rings; also false teeth, whether a whole or a partial set, as there is danger of their being swallowed. Envelop feet and lower limbs in a warm blanket securely pinned around the hips with safety-pins. Besides preserving the heat, this arrangement will prevent the patient from tossing the limbs about while taking the anesthetic. Many operators give morphin (gr. $\frac{1}{4}$ ) 
and atropin ( $\frac{1}{100}$ grain), hypodermically, half an hour before the operation to quiet the patient and prevent an increase in the saliva.

Arranging the Patient for the Operation.-The patient having been placed on the operating-table, the clothes are removed from the part to be operated upon, and sterilized blankets are tucked about the chest, the edges being tucked under the back to reduce as far as possible the loss of body heat, and the bandage and pad are removed from the field of operation, which is again thoroughly cleansed with soap and water and disinfectants. An assistant nurse hands the sterilized water, green soap, and scrubbing-brush to the assistant surgeon. The soapsuds are rinsed off with sterile water, the - part is sponged with alcohol and bichlorid solution. This final scrubbing should be done in the anesthetizing room if possible while the patient is being anesthetized, to avoid delay in the operating-room. A far simpler method is to paint the part with a 5 per cent. solution of

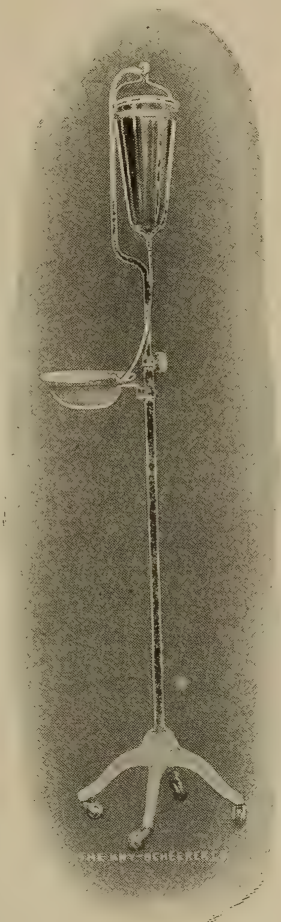

Fig. 197.-Irrigator. iodin. A sterilized sheet, having an oval opening in the center through which the section is made, and towels are then arranged around the field of operation. The instruments are taken from the sterilizer and placed in 
trays containing sterile water or upon dry sterile towels. A written statement of the instruments laid out must be made. The number before and after the operation must tally.

Some surgeons use the prepared sponges. These must be reliably counted before the operation by the operator and assistants, and the number written down, so as not to trust to memory. Sponges must be squeezed

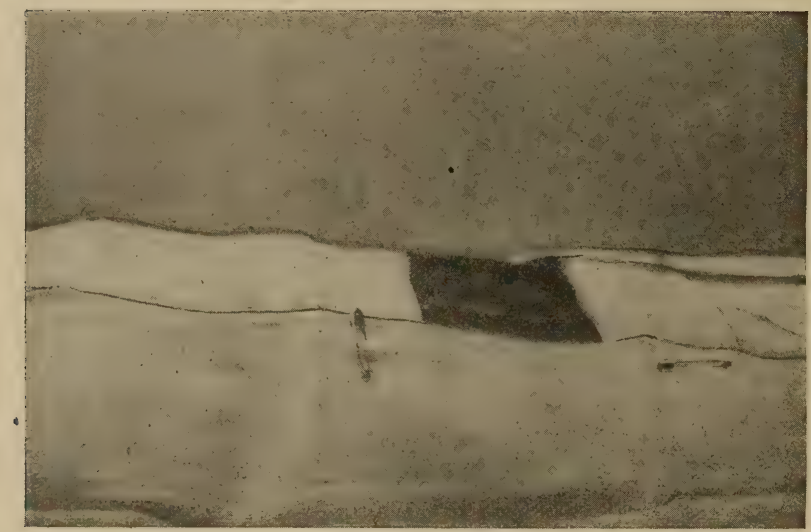

Fig. 198.-Towels pinned over rubber dam, leaving no skin surface exposed. (Hirst.)

almost dry before they are handed to the surgeon, because it is only in an almost dry condition that they are of service. The nurse should not, while waiting to hand a fresh sponge, rest her hands or forearms on the pail. She should count the sponges before the surgeon begins to sew up the wound, and then should be very sure that she has the exact number employed in the operation. The large square sponges used for covering the intestines, 
or walling off small areas, should have a long piece of tape attached, and to this a forceps, so that if one should slip out of sight it can be readily located and recovered without undue handling of the bowel. After being used, the sponges are put into a pan or basin, and should not be disposed of until they have been accounted for before the abdomen is closed.

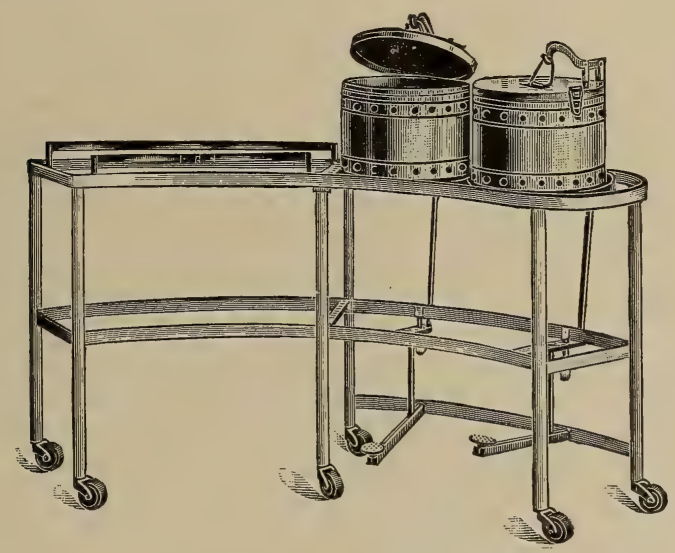

Fig. 199.-Dressing table.

Whatever has been removed from the body must be placed in a basin and laid aside in a safe place until the surgeon gives his directions as to whether or not he wishes it to be sent to the laboratory for examination to make sure of its character, with a view to clearing up some obscure point about the nature of the disease.

The head nurse attends to the instruments, sutures, and ligatures. If the dry technic is used, a basin of dry gauze sponges is placed on a table within easy reach of the operator's assistants.

The assistant nurses must be on the alert to change 
the hand solutions when necessary, and to wipe the moisture from the face of the operator and his assistant with a sterilized towel, to prevent drops falling into the wound, and this must be done at a moment when the surgeons are not bending over the wound. They must move about the room very quietly but quickly. If asked to do anything that they do not understand, they should always inform the head nurse, who will make the duty clear. When emergencies arise and the operator is dealing with exceptional difficulties, the nurses must be on the alert to do quickly anything they may be called upon to do, each nurse discharging her duties without undertaking those belonging to another. It is absolutely necessary on such occasions to exercise self-control, and to follow the directions given without excitement or confusion.

Just before the wound is closed the soiled towels are removed and replaced by fresh ones and a report given of the number of instruments and sponges missing, if they are not all accounted for. After the dressing has been applied the patient is raised, wiped perfectly dry, and a bandage put on. The blankets used to cover the feet and chest of the patient during the operation should be tucked closely about the body and underneath, and not merely be thrown over.

Pneumonia and pleurisy after operation may follow as the result of chilling when in the operating-room, or exposure during the removal from the operating-room to the patient's room.

When the patient is replaced in bed, which has been thoroughly warmed during the operation, the nurse should be present to take charge. The pillow should be removed and a towel placed for the head to rest upon. 
The foot of the bed is elevated, this posture being maintained for several hours, after which the bed is lowered. This is especially indicated in cases that have had spinal anesthesia. The heaters are placed about the patient's body outside a blanket; one thing being kept constantly in mind-not to burn the patient. A towel should be placed under the chin of the patient, and a small basin should be at hand to receive the vomited mucus, and this should be removed during quiet intervals. Nausea and vomiting may be relieved by saturating a towel with fresh, strong vinegar and holding it a few inches from the patient's face, laying it over the nostrils, or hanging it from the bedstead so that it will be near the patient's head. Oxygen hastens the recovery of consciousness and lessens the nausea. If administered with the anesthetic there is almost complete absence of nausea-usually none as soon as the patient is fully conscious.

Dryness of the mouth and lips and thirst (which is often a troublesome feature) may be relieved by placing wet cloths on the lips, by allowing the patient to rinse out the mouth with cool water, and by frequent bathing of the hands and face with alcohol and tepid water or with plain water. If thirst is extreme, an enema of saline solution (I pint) is given slowly.

Infections of the Abdomen.- It is now an almost uniform custom to place the patient in Fowler's position (sitting), and give them enteroclysis either by the Murphy drop method or frequent small enemas. A Gatch bed is the most satisfactory method of obtaining the Fowler position.

The patient should not be left alone for a single moment during the first thirty-six hours after an ab- 
dominal section if it can be avoided. The patient can do nothing for herself, and every want should be instantly supplied. I have known patients so eager to allay their thirst that they would get out of bed and drink water from the water-pitcher on the wash-stand and reach down for the hot-water bottle at the feet and drink part of the contents. One ward patient drank the water from an irrigator standing by the side of the next bed; another patient while in a semiconscious condition took the drainage-tube out of the abdomen, and when found by the nurse after a moment's absence from the room was sitting up on the edge of the bed. Watching a patient recover from anesthesia is often monotonous; but if this duty is closely attended to, many dreadful accidents will be avoided.

A roll should be placed under the knees, so as to relax the abdominal muscles and also to remove the strain the patient would have to make in order to keep up the knees. A small flat pillow placed under the hollow of the back will relieve the backache of which so many patients complain.

Bladder and Bowels.-The catheter should be passed every six or eight hours if necessary, according to directions, the most rigid aseptic precautions being taken. Flatulence may be very distressing : consequently passage of gas by the rectum is of good omen, as it shows that the bowels have regained their normal tone and there is no obstruction. After an abdominal operation the muscular walls of the intestines share in the weakness of the patient, and are not strong enough to orercome the contraction of the sphincter muscle. The accumulation of gas distends the muscular fiber of the intestines, and, if not re- 
lieved, would soon result in paralysis of the intestines. To prevent this a rectal tube is inserted to keep the sphincter dilated and to allow the gas to escape when it reaches that point. Purgatives, such as calomel (gr. $\frac{1}{10}$ every hour until I grain has been taken), are usually given twenty-four hours after the patient has recovered from the anesthetic to stimulate the intestines and keep up peristaltic action.

Much fluid is not given for a few hours after the operation, as it might cause vomiting or acute dilatation of the stomach.

After recovery from the anesthetic, if there is no vomiting, cool water or toast-water is given in teaspoonful doses every fifteen or twenty minutes, the quantity being gradually increased and the intervals lengthened. The familiar cup of freshly made tea is sometimes the best drink to begin with; it is always a pleasure under the circumstances to see the patient enjoy it, since it is not only refreshing but stimulating. If the stomach behaves well, tablespoonful doses of gruel or beef-essence may be given every half-hour. Milk is not given as a rule, as the curd may pass along the intestines and act as an irritant. For the first three days, and if there is no vomiting, nothing but liquids is given; and after the third day soft and easily digestible food, which is gradually changed to a more solid diet.

The external genitals should be kept perfectly clean, the body bathed, the bed- and body-linen kept sweet and clean, the teeth brushed, and the hair combed. Every want of the patient should be anticipated, and she should be made as comfortable as possible. Sponging the palms of the hands, the arms, and the legs will lead 
to the comfort of the patient. The luxury of a change into a fresh bed will often secure a good night's rest. Under no consideration should morphin be given except by the surgeon's directions, and every moral influence should be exerted to induce the patient to endure pain rather than resort to the drug.

The nurse should not ascertain whether the patient is comfortable by continual questioning, but by unobtrusive observation. Questioning may alarm a patient and lead her to think too much about herself.

No visitors should be admitted without the surgeon's consent. The mind of the patient is to be kept perfectly free from worry and excitement, and the whole atmosphere of the room should be bright, pleasant, and cheerful, no matter what trouble is going on outside.

A slight rise of temperature the day following operation usually marks reaction from shock. On the eighth day the dressings are removed and the stitches taken out. The following week the patient sits up, and at the end of the third week she goes home.

Many surgeons now shorten the time in bed to seven days.

The following diet-list, dating from the third day, will be of assistance in varying the food.

\section{FOURTH DAY}

Breakfast.-Mutton-broth with bread-crumbs.

Lunch.-Milk-punch.

Dinner.-Oyster broth, thin bread (with crust removed) and butter, sherry wine.

Lunch.-Cup of hot beef-tea.

Supper.-Milk-toast, jelly. 


\section{FifTh DAY}

Breakfast.-Oatmeal with sugar and cream, cup of cocoa. Lunch.-Soft custard.

Dinner.-Chicken soup or small piece of white meat of chicken, baked potato.

Lunch.-Glass of milk.

Supper.-Buttered milk-toast (crust removed), jelly, cocoa.

\section{Sixth Day}

Breakfast.-Soft-boiled egg, bread and butter, coffee. Lunch.-Milk-punch.

Dinner.-Chicken soup, tender sweetbreads, Bavarian cream.

Lunch.-An egg-nog.

Supper.-Tea, raw oysters, bread and butter.

\section{Seventh Day}

Breakfast.-Oatmeal with sugar and cream, a tender sweetbread, creamed potatoes, coffee, graham bread and butter.

Lunch.-Glass of milk.

Dinner.-Chicken panada, baked potato, bread, tapioca cream.

Lunch.-Cup of hot chicken broth.

Supper.-Buttered dry toast (crust removed), wine jelly, banquet crackers, tea.

\section{EIGHTH DAY}

Breakfast.-An orange, scrambled egg, oatmeal with sugar and cream, soft buttered toast, coffee.

Lunch--Milk-punch. 
Dinner.-Cream of celery soup, a small piece of tenderloin steak, baked potato, snow pudding, wine, bread.

Lunch.-An egg-nog.

Supper.-Calf's foot jelly, soft-boiled egg, bread and butter, cocoa.

\section{Ninth Day}

Breakfast.-Oatmeal, poached egg on toast, coffee.

Lunch.-Cup of chicken broth.

Dinner.-Chicken soup, small slice of tender roast beef, baked potato, rice-pudding, bread.

Lunch.-Glass of milk.

Supper.-Baked apples, raw oysters, bread and butter, orange jelly, tea.

\section{Tenth Day}

Breakfast.-Orange, mush and milk, scrambled eggs, cream-toast, coffee.

Lunch-Cup of soft custard.

Dinner.-Mutton soup, small piece of tender beefsteak, creamed potatoes, sago pudding, bread, wine.

Lunch-Cup of beef-tea.

Supper.-Sponge-cake with cream, buttered dry toast, wine jelly, cocoa.

\section{Eleventh Day}

Breakfast.-Broiled fresh fish, oatmeal, graham bread, coffee.

Lunch.-Chicken broth.

Dinner.-Potato soup, breast of roasted chicken, masked potatoes, macaroni, blanc mange.

Lunch-Cup of mulled wine.

Supper-Cream-toast, lemon jelly, chocolate.

The diet for other days may be selected from previous ones. The change of diet may cause a temporary rise in the temperature and pulse. 


\section{CHAPTER XVI}

\section{SEQUELAE OF OPERATIONS; SHOCK, HEMOR- RHAGE, SEPTIC PERITONITIS, ACCIDENTS DURING OPERATION, ETC.}

As a rule, the average abdominal case passes into convalescence, especially when the case is in skilled hands and the operation has been performed in a finished surgical way. Complications, however, are liable to arise in the simplest case, and throw great responsibility on both surgeon and nurse. It is in these, cases that the knowledge and skill of the nurse mean so much, and where the greatest triumphs of surgery are scored.

A nurse has no moral right to take charge of a surgical case unless she has at her finger-ends the complications liable to arise, their symptoms, and the various means of meeting them until the arrival of the surgeon.

Shock is great depression of the vital functions of the body brought on by injury or surgical operation. It is produced through the agency of the nervous system. The greater the injury, the longer the anesthesia, the greater the shock. The anesthetic enables the patient to undergo the operation without consciousness, but it does not prevent shock coming on afterward from the opening of the abdomen, the uncovering of the viscera, the handling of the intestines, and the exposure of the delicate sympathetic nerves in that part to the air and to touch. If to all this is added a long anesthesia, then 
the prostration produced by the anesthetic is added to the effects of the operation. Dr. George W. Crile has lately combined local and general anesthetics, so that the nervecenters will not receive any injuries. He calls his method anoci-association.

Different individuals are differently affected: most persons are more susceptible to shock after months of hard work, or when the system is run down after an illness. Invalids stand shock very well, and indifferent persons stand it better than those who are despondent. The mental influence is very great: anything that depresses the mind aggravates shock. It is here that the offices of the Church have such an effect on some patients in quieting apprehension and in adding fortitude.

Age modifies shock. In old people shock is usually more severe and prolonged, especially if there is any organic disease. Children recover readily from shock if there has been very little loss of blood. Shock is combated to a certain extent by the patient's drinking a large amount of fluid for forty-eight hours before the operation, so that the blood-vessels of the vital organs will be well supplied with fluid during the operation. Experiments have been made which show that when the abdomen is opened the abdominal veins dilate, and as a consequence a large amount of blood in the body flows into them, thus leaving the heart and the vessels conveying blood to the important nerve-centers at the base of the brain with very little fluid to work upon, and shock ensues. The output of the heart, as we know, is in proportion to the venous pressure, and if this is lowered the heart and the important nerve-centers at the base of the brain will be supplied with a diminished amount of 
blood. The intravenous injection of saline solution causes a rise in the venous pressure and an increase in the output of the heart.

Two very important points to be considered in case of shock or of hemorrhage are the temperature and the condition of the patient's mind. In shock the temperature at first is normal or very little below normal, and the senses are dull in proportion to the degree of shock present; in hemorrhage the temperature is subnormal, the mind is bright, keen, and alert, and there is an anxious expression on the face, as if the patient were anticipating danger.

The symptoms of shock are a weak, rapid, and irregular pulse; sighing, rapid, irregular, and shallow respiration; a normal or slightly subnormal temperature; a pale face with a pinched look; a cold, clammy skin, and dulness of the mind. There may be involuntary movements of the bowels and urine as a result of loss of muscular power; nausea and vomiting may also be present.

The treatment of shock consists in lowering the patient's head and raising the foot of the bed to increase the supply of blood to the vital centers; in the application of heat to all parts of the body, particularly the sides, between the legs, and to the feet; in placing a mustardplaster over the heart; in administering whisky, brandy, or nitroglycerin hypodermically; in giving hot black coffee by the rectum, or saline solution by hypodermoclysis or enteroclysis. Strychnin is a powerful stimulant, and should be given in doses of $\frac{1}{20}$ grain every half-hour for four doses. Tincture of digitalis in 15 -minim doses may be given every half-hour for four doses. As a rule in cases of shock there is a disposition on the part of 
nurses to do too much. Everything must be done in a prompt, quiet manner. For immediate stimulation in threatened collapse camphorated oil ( 15 minims) or adrenalin chlorid, hypodermically, are valuable. They are used for quick effect only, and not for prolonged stimulation of the heart's action. Stimulants must be given carefully, and time allowed to observe the effects produced, other measures being determined accordingly. An enema of $\frac{1}{2}$ ounce of turpentine, a well-beaten raw egg, and 3 ounces of warm water constitutes a powerful stimulant.

It must be remembered that in serere shock the function of absorption by the stomach and intestines is almost wholly suspended, and anything given by the rectum must be introduced high up. When the respiration of the patient is fast failing, everything depends on maintaining the heart's action. To this end artificial respiration must be persistently practised. A serious danger in performing artificial respiration is that in our hurry we may make the motions too rapidly and not give the lungs time to fill thoroughly nor allow the air to be expelled before filling the lungs again. The motions should not be more frequent than sixteen to eighteen in the minute, so as to imitate as nearly as possible the natural rhythm of respiration.

Recovery may be rapid or very slow; it is manifested by "reaction"- the pulse becomes more full, slow, and regular, the temperature rises, the body becomes warm, and a general improvement takes place. In rare cases the reaction becomes excessive and develops into traumatic delirium, which may be mild, low, and muttering, or of the wildest character. 
The skin is hot and flushed, the pulse full and regular, and the temperature above normal. This condition may subside and recovery take place, or it may be followed by collapse.

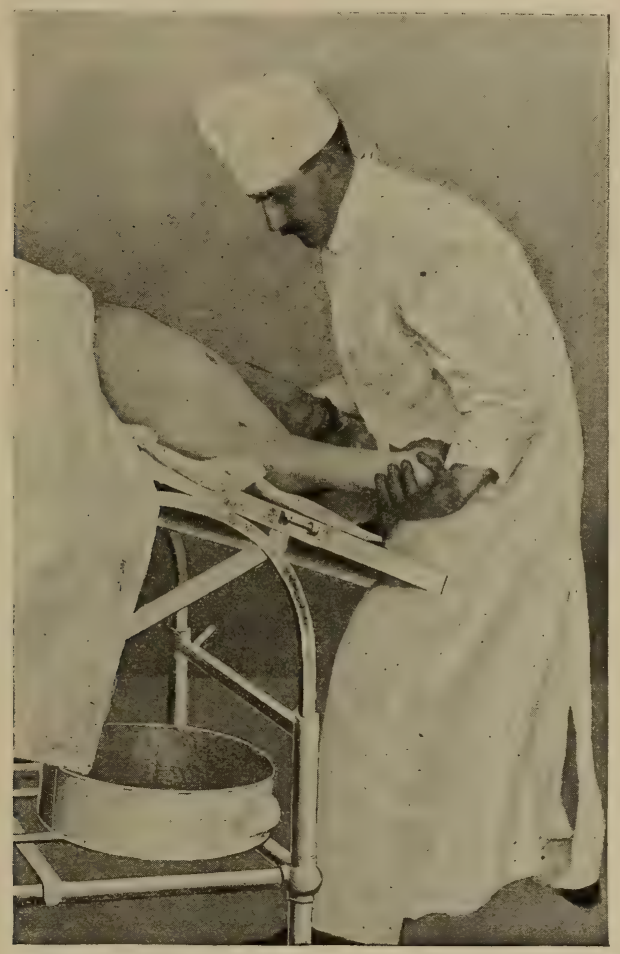

Fig. 200.-Sylvester's method of artificial respiration (inspiration). (Fowler's Surgery.)

Artificial Respiration.-As soon as respiration ceases the mouth should be examined, if possible, for any obstruction to the air-passages. If obstruction is found to be present; it should be removed or tracheotomy performed. 
The most satisfactory method of artificial respiration consists in placing the patient with the upper portion of the abdomen resting upon a roll of material about $\mathbf{I}$ foot high. The head should be turned to one side. Then

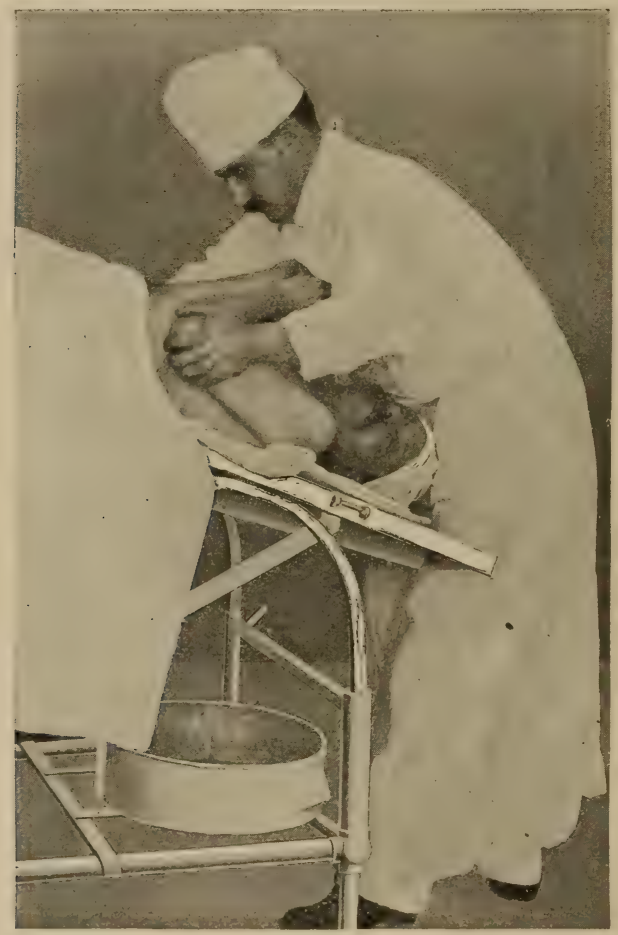

Fig. 20I.-Sylvester's method of artificial respiration (expiration). (Fowler's Surgery.)

rhythmic pressure should be made upon the lower ribs twenty times per minute.

Sylvester's Method.-With the head and neck fully extended and the tongue drawn forward, the elbows are 
usually indicate that there is hemorrhage by a flow of blood through the tube. This, however, cannot be relied upon, as only a moderate quantity of blood may flow through the tube, the abdomen being filled with clots.

The symptoms of internal hemorrhage are restlessness, thirst, faintness, an anxious expression, pale
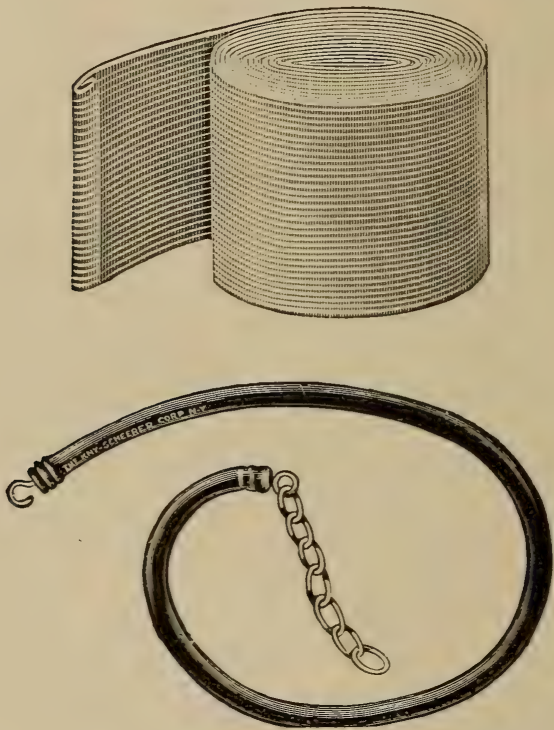

Figs. 203 and 204.--Esmarch's tourniquet, consisting of 9 feet of elastic webbing $2^{\frac{1}{3}}$ inches wide, 3 feet tubular strap with chain.

face, dilated pupils, cold skin, frequent and irregular or sighing respiration, subnormal temperature, and a weak, rapid pulse ( 120 to I40). In rare cases the pulse is not greatly accelerated.

Treatment.-The patient must be kept perfectly quiet on her back, the head being lowered and the 
foot of the bed elevated. If symptoms of shock supervene, heat is to be applied to all parts of the body by warm blankets and hot-water bottles. Stimulants are given only when the pulse is failing, as they excite the heart's action and increase the hemorrhage. When the hemorrhage has been excessive, infusion of saline solution is resorted to, the fluid that the body has lost being thus replaced. Transfusion of blond is frequently indicated. Bandaging the limbs from their extremities upward is sometimes of use in keeping the blood in the vital organs. When the hemorrhage comes from a

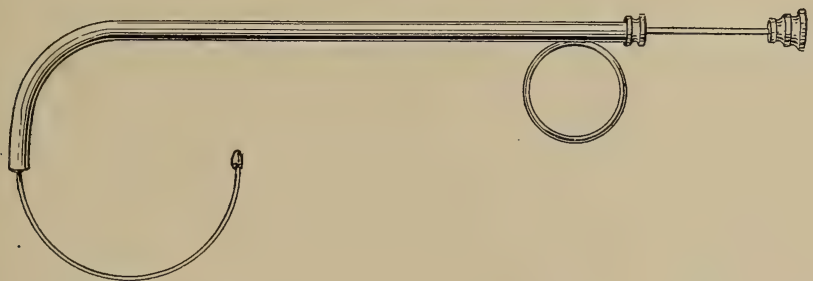

Fig. 205.-Bellocq's cannula, used for passing a cord through the nose, to be drawn out of the mouth, and gauze or cotton plugs attached for packing the nasal cavity for hemorrhage. (Morrow.)

slipped ligature with large vessels pouring blood into the abdominal cavity, the abdomen is reopened and the vessel ligated. Everything should be ready for operative interference when the surgeon arrives, the same aseptic precautions being observed as in the original operation. For the free oozing from torn adhesions the tube is emptied frequently-every ten minutes. The drier the pelvic cavity is kept, the sooner will the hemorrhage cease.

A noted surgeon has said that if an abdominal case escapes shock or hemorrhage, there is still a third danger 
to which the patient is liable, that of septic peritonitis. This is due to the entrance of germs into the peritoneal cavity, either from without or from ruptured abscesses or wounds. It may set in at any time from a few hours to six days after operation. The symptoms are pain in the abdomen and exquisite tenderness, distention, vomiting, constipation, icterus, restlessness, sleeplessness.

The temperature rises a little, rarely going for a few days above $100^{\circ}$ or $\mathrm{IOI}^{\circ} \mathrm{F}$; ; but the pulse creeps up rapidly to $\mathrm{II} 5, \mathrm{I} 20$, or $\mathrm{I} 30$ beats per minute, and is weak and thready; although sometimes it is hard and "wiry" in the beginning. Then the temperature rises to $103^{\circ} \mathrm{F}$. or above. The rectal or vaginal temperature may show a much higher rise than that of the mouth or axilla. In one typical instance the temperature taken in the mouth ranged between $101^{\circ}$ and $102^{\circ} \mathrm{F}$., the skin was cold and clammy, and the patient complained of intense thirst and a "burning up" feeling. The vaginal temperature was $108^{\circ} \mathrm{F}$. In some of the worst cases the writer has seen the temperature was below normal, but the prostration was severe. The abdomen is distended, due to distention of the transverse colon by gas. There are nausea and vomiting. First the contents of the stomach are vomited, then bile, then a dark coffee-colored fluid which becomes more and more fecal in odor; a cold perspiration appears; the patient has a very anxious, pinched expression, and is restless and talkative; the eyes are unusually bright, and there is a faint yellowish look about the skin and conjunctivæ. As the disease continues the general system becomes poisoned.

The treatment consists in providing drainage for the infection. The patient is placed in Fowler's position; 
salt solution is given by the Murphy method; if vomiting occurs, the stomach should be washed out. Any stimulants that may be required are given hypodermically. All food by the mouth is stopped. If improvement does not follow, the surface of the body becomes cold and clammy; the face pinched and sunken and of a dusky hue; the restlessness increases, also the thirst, which becomes very great, and to the last the patient calls for water, which is vomited immediately after being taken, so should not be given. The mind usually remains clear to the end.

Antistreptococcic serum has been used with fairly good results. It comes in glass tubes, sealed hermetically, and is injected hypodermically with antiseptic precautions into the thigh or the side of the breast, where there is considerable loose subcutaneous connective tissue. Another procedure of value is infusion of normal saline solution for the purpose of diluting the toxins in the blood and of removing them by the increased flow of urine which infusion brings about.

Tympanites is often one of the earliest signs of septicemia, and when accompanied with a high temperature is usually a cause for anxiety, though it may be due to constipation, and in such cases is usually without significance. The treatment consists in the application of turpentine stupes, high enemata, and the insertion of the rectal tube for about Io inches. Pituitrin in $\frac{1}{4}$-grain doses or eserin salicylate ( $\frac{1}{40}$ grain) are valuable adjuncts.

Fermentation fever is due to the absorption of fibrin ferment and the products of aseptic tissue necrosis. It causes a slight rise in temperature which need occasion no anxiety. 
Intestinal obstruction may be due to strangulation of a knuckle of intestine beneath inflammatory bands, or to its enclosure between the sutures in the wound. There is usually distention of the abdomen and later nausea and vomiting. Note should always be made if gas is heard rumbling in the intestines, and also if gas is passed and how often; also the result of the enemata which are administered to relieve the distention.

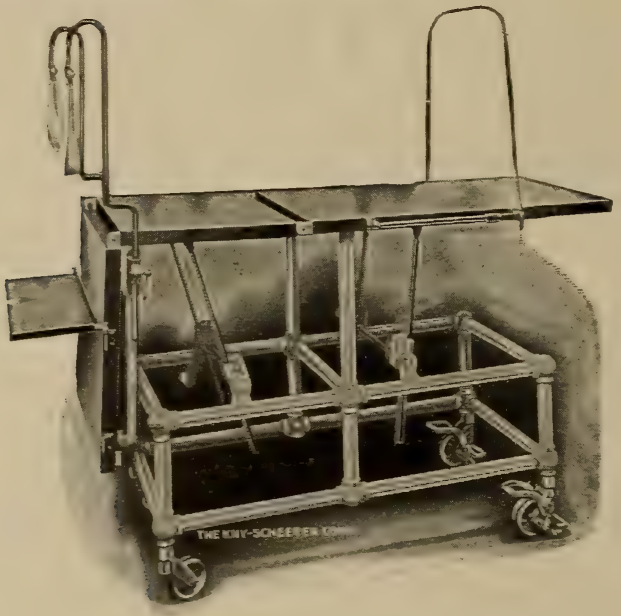

Fig. 206.-General operating-table.

Postoperative hernia is a sequel rather than a complication of abdominal operations, and is due to a failure of union between the cut edges of the muscles and fasciæ. As a rule, it does not occur until some weeks after the patient has returned home. It is to prevent this accident that such stress is laid upon not allowing the patients to help themselves in any way without the surgeon's permission, so that the abdominal muscles may have suff- 
cient time to become firmly united. This is also the reason why patients should wear an abdominal supporter for some months after their discharge. If hernia occurs, it is usually treated by a secondary operation.

A sinus is often caused by imperfectly sterilized ligatures or non-absorbable ligatures, which may cause an abscess around the point of ligation. This abscess may discharge itself into the intestine or vagina, or into the tract occupied by the drainage-tube through the abdominal wall. The sinus keeps open until the ligature is discharged or removed by another operation.

Accidents During Operation.--Many times in difficult abdominal or vaginal operations the walls of the bladder may be torn, or one of the ureters or the intestines may be injured. When the ureter or bladder is injured, the urine sometimes passes through the incision to the dressing. This is called a urinary fistula. When the intestines are injured, fecal matter is discharged through the wound. This is a fecal fistula.

Vaginal hysterectomy is the most serious of vaginal operations, but the nursing is the same as every operative case requires. If clamps are used, they usually remain attached for forty-eight hours. The handles are usually supported on a pad of absorbent cotton. In the handling of the clamps great care must be used, as, for instance, when the patient is lifted on the bed-pan one nurse should lift the clamps.

Postoperative insanity is an extremely rare complication and is usually associated with premature menopause produced by the removal of both ovaries. The symptoms are usually greatly ameliorated or cured by the administration of ovarian extract. 


\section{CHAPTER XVII}

\section{SPECIAL OPERATIONS}

Operations Upon the Head.-Nursing after operations upon the brain calls for special diligence in watching the patient during the first hours subsequently. Unlooked for symptoms may arise, and a change for better or worse in those accompanying the condition for which operation was performed; delirium, acute mania, or paralysis of some part or of the half of the body may develop, or, having been present, become rapidly altered in degree and aspect. Care to prevent the patient from injuring himself, falling from the bed or disturbing the dressing and doing direct injury after a trephining is necessary. Especially should the nurse be on her guard to prevent such patients being burned by hot-water bottles. Head operations being often long ones, or done for acute conditions in which the degree of shock is marked, the efforts to revive can easily be overdone in the matter of temperature of the hot-water bag with a subsequent further complication of the case from a bad body burn. As a general rule, it is safest to never put a bag directly against the patient's body, but to place it outside the blanket.

Eye, ear, nose, and throat cases, besides the general care and watchfulness necessary, require to be observed for shock or hemorrhage, where, as in the case of the eye, serious functional injury might be done; or special symptoms complained of relating to the particular'sense-organ operated upon. 
Operations upon the neck generally require the patient to assume the supine position. The chief danger is from accidental postoperative secondary hemorrhage, and this contingency may occur up to the third or fourth day when due to slipped ligatures. After intubation and tracheotomy operations the nurse must be watchful lest the tube becomes displaced, coughed out, or clogged by exudate or false membrane shreds. Rapid cyanosis or a

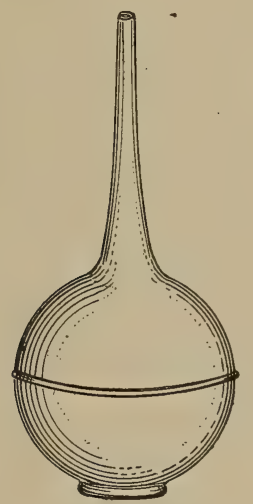

Fig. 207.- Soft-rubber nasal and ear syringe. (J. P. C. Griffith.)

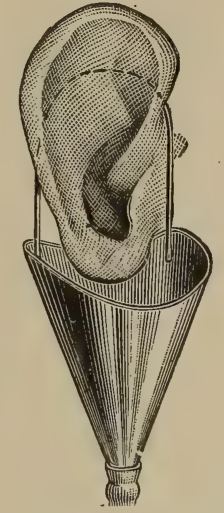

Fig. 208.-Syringe cup to hang upon patient's ear to catch the drip when irrigating the aural canal.

blowing-bellows action sounding through the tracheal slit are the signis calling for immediate correction of the difficulty, to avoid an immediate fatal termination of the case from total closure of wound or tube. If the tracheotomy tube is occluded, remove the inner tube, clean, and insert. If the case is one of tracheotomy with a displaced tube, the nurse should make no attempt at readjustment, but quickly should remove the tube and send for the surgeon. 


\section{CHAPTER XVIII}

\section{OPERATIONS IN PRIVATE PRACTICE}

In private practice the preparation of the patient is just the same and should be carried out as thoroughly as in a hospital. If it is not possible within twenty-four or thirty-six hours to make the preparation, then we cannot say that our attempts to obtain asepsis approach perfection. In emergency cases when there is not sufficient time to permit a thorough cleansing, freedom from sepsis is not so certain, and these cases do not cause the same anxiety as those that are sent to a hospital, where every effort to obtain complete asepsis is made. We must remember, in making the preparations, to make as little bustle and noise as possible, and to carry on the preparations in a quiet and cheerful manner, so as not to frighten the patient and family. When the surgeon and his assistants arrive they must be shown to a room in which they can change their clothing. The patient is not anesthetized until everything is in readiness.

One difficulty which a nurse will have to encounter in private practice is likely to trouble her a great deal, inasmuch as she will find surgeons who conduct details of cases in a way to which she is not accustomed, and which may appear to her wrong, and which indeed may very often be crude and unscientific. In these cases she should not be too ready to show her superior wisdom and instruct the surgeon, and inform him under whom she 
received her training, because there is not the slightest likelihood that he will act upon her suggestions, but will naturally be offended.

The directions for preparing for the operation will be given by the surgeon in charge. Have the temperature

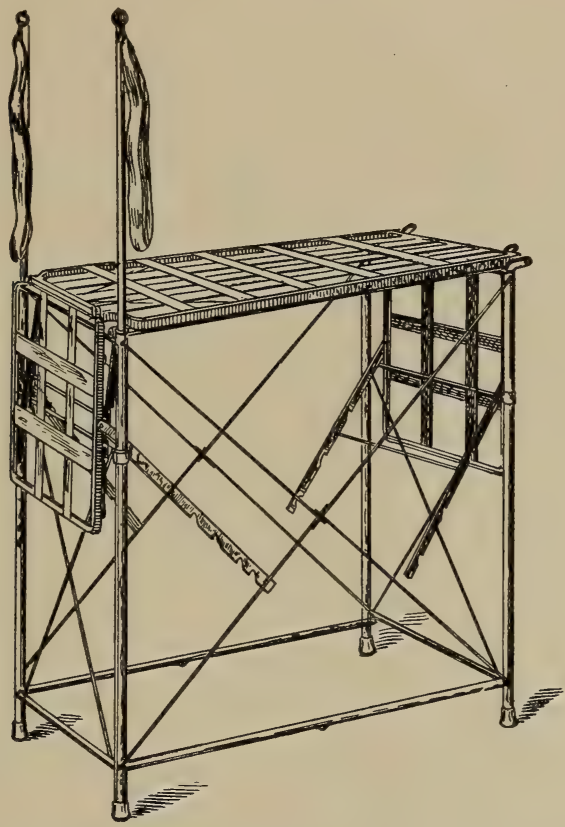

Fig. 209.-Portable operating-table set up for a vaginal operation. (Hirst.)

at about $75^{\circ} \mathrm{F}$. In some houses there may be a separate room for the operation, while in others the nurse will have to prepare the patient's bedroom. In the latter case the brightest end of the room must be selected for the operation, to afford the surgeon plenty of light. A screen must be put up before the bed, so that the patient will 
not see the preparations. The nurse should remove from the room all movable furniture; sheet any large piece, as piano; lay oilcloths or newspapers covered with a damp sheet on the carpet, and pin them securely to it, and fasten a curtain across the window, so that the operation cannot be viewed from the opposite side of the street; or the panes may be frosted by lathering with soapsuds or Sapolio. The remaining furniture and window-frames should be washed with carbolic acid solution ( $1: 60$ ), and on the morning of the operation should be mopped with a cloth wrung out of the solution. The articles necessary for the operation can be placed on the operatingtable, covered with a sterile sheet, and be left outside the room until the patient is fartly etherized, when they may be carried in.

Have everything ready the night before when possible. If a separate room can be had, one with a northern light is to be preferred; and if possible it should be near the bath-room and convalescent chamber. Fill the bathtub half full with I : 1000 bichlorid solution for washing pitchers, plates, wash-bowls. Unless the nurse has twenty-four hours' notice in which to prepare the room for operation, it should not be disturbed, because if swept and dusted immediately before the operation dust is stirred up and the air is so filled with germs that it would not be safe to open the abdomen in the room. If the nurse has a few days in which to prepare for the operation, all unnecessary furniture should be removed, the hangings taken down, the room thoroughly swept, and the walls and remaining furniture washed with carbolic acid solution ( $1: 200$ ) and exposed to the action of the sun and air for about twelve hours, when the windows are to be closed, 
the room thoroughly dusted with a damp cloth, and not again disturbed.

When the operation must be performed in the patient's bedroom, push the bed up in one corner.

A word regarding the bed. If possible, it should be an iron bedstead with a fresh horsehair mattress and pillow. The tall wooden bedsteads which we so

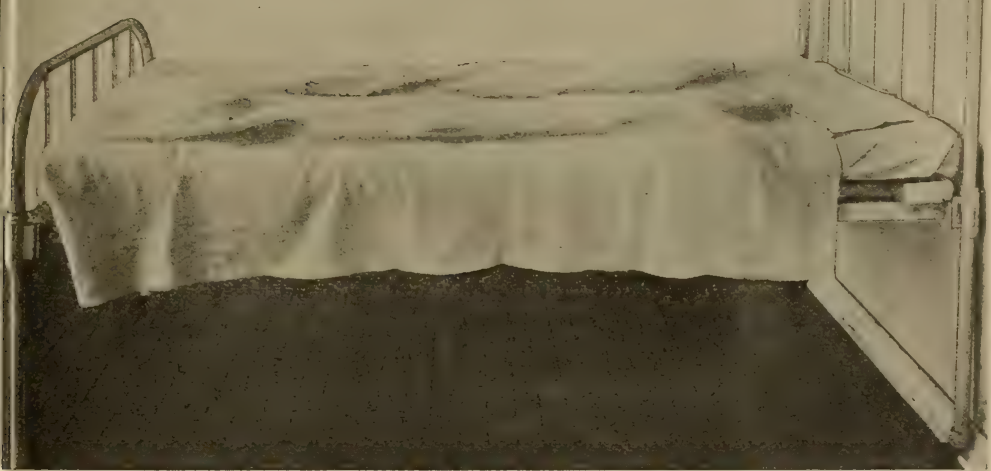

Fig. 210.-Bed arranged for reception of patient: A trough is made under the blanket by hot-water bags on either side. A towel is pinned to the lower blanket under the patient's head. (Hirst.)

often find are perhaps heirlooms which have witnessed every illness that has visited the family, and also the deaths. They cannot be disinfected so thoroughly as can iron bedsteads.

The operating-table should not be wider than 25 inches nor higher than 37 inches, because if low and wide the surgeon will have to stoop and bend forward. A kitchen- 
table, or a dining-rcom table with the leaves hanging, and a small table at one end for the patient's head, or two dressing-tables, one placed across the head of the other,

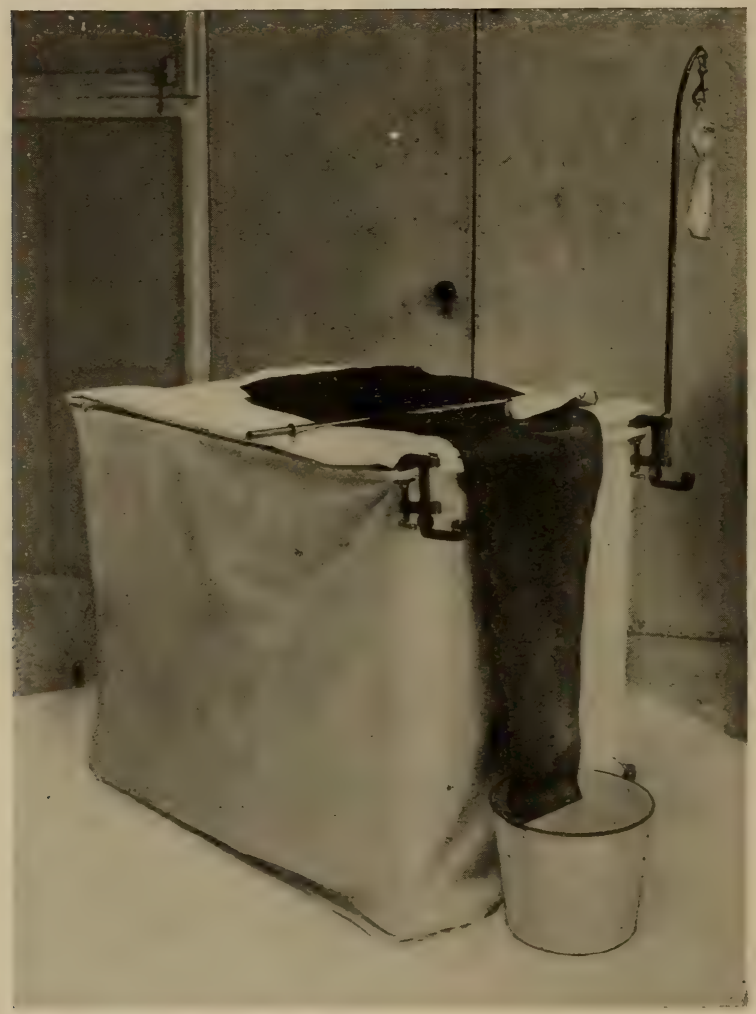

Fig. 211.-Kitchen table prepared for gynecologic operation, showing Kelly draining-pad and leg supports. (Hirst.)

will make a good narrow operating-table; or three chairs, with two planks; a leaf from an extension-table, or an ironing board laid across them, may suffice. 
A word of caution here: The nurse should not use any old blanket or comforter to cover the operatingtable, for it is likely to be filled with germs. The top cover may be rubber bedcloth, oilcloth, or folded sheet, tied to the table by means of a muslin bandage. A Kelly pad may be improvised by means of a blanket rolled army fashion and covered with a piece of rubber cloth.

A square-backed wooden chair should be at hand in case the Trendelenburg position is necessary, and two wooden

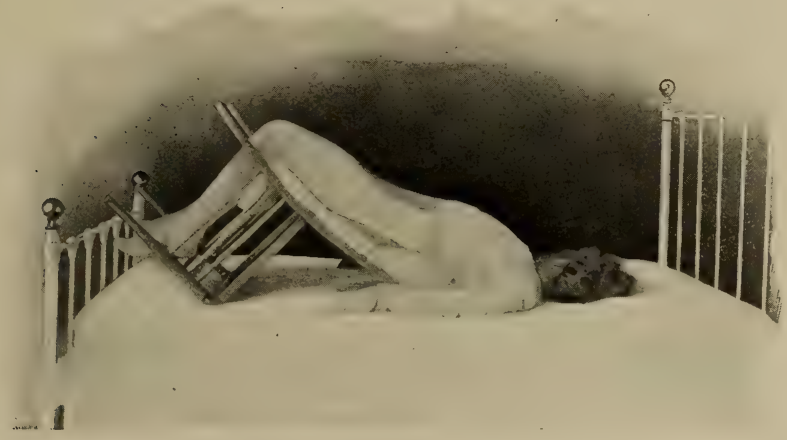

Fig. 212.-The Trendelenburg posture in bed, using a chair to elevate the pelvis. (DeLee.)

boxes for the surgeon to stand upon when using this posture.

An easier method is to elevate one end of the table upon a box.

The lithotomy position can be quickly obtained by using a well-padded cane or broom handle placed under the patient's knees and bound in place by means of a twisted sheet passed around the patient's neck, over one shoulder, beneath the other.

Improvise a sterilizer for instruments and dressings 
by using a wash-boiler fitted with a light wood inside crate to hold the dressings above the water. Sterilize glass tips and syringe bags by placing in a towel hammock or muslin sling hung from the handle of the boiler.

The evening before the operation the nurse should boil a wash-boilerful of water and then fill covered pitchers, the wash-boiler and pitchers having first been made

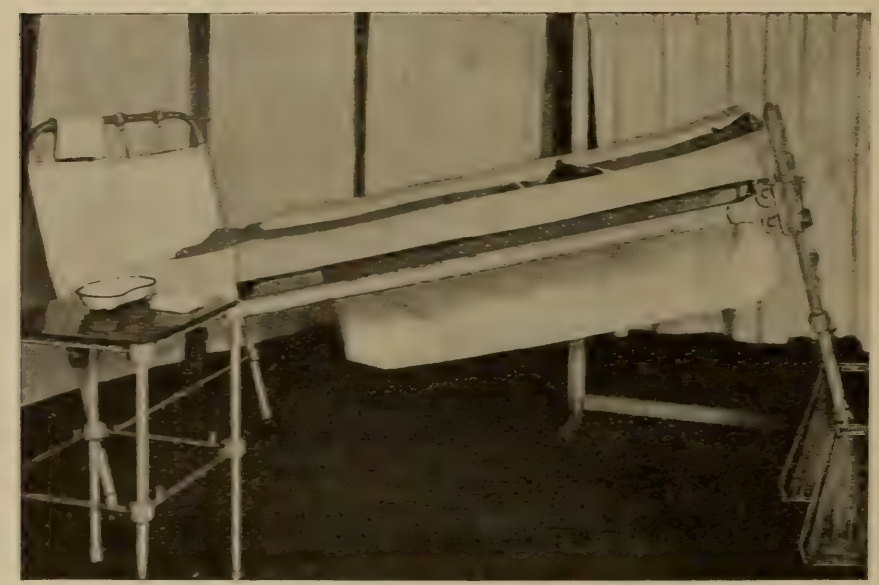

Fig. 2I3.-Ether bed with the foot elevated. (Sanders.)

thoroughly aseptic. The water is conveyed from the briler to the pitchers by means of a perfectly clean pitcher or tin ladle.

On the morning of the operation there should be sterilized in the boiler or in an oren six sheets, two blankets, twelve towels (not new). The heat should be kept up for fully one hour before the operation. The dry technic, by which is meant the use of dry sponges and gauze, is 
usually employed in private practice. They can be purchased sterile at any good drug store.

There will be needed several clean recently boiled basins for the various solutions, etc. Two tables will

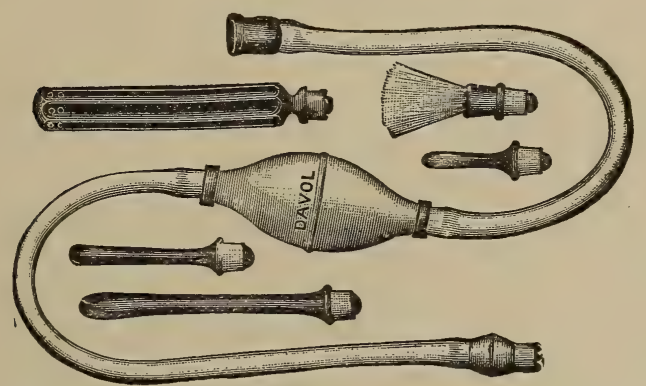

Fig. 2I4.-Household bulb-syringe. (Davidson.)

be needed-one for the instruments, the other for the assistant. They should be covered with freshly washed and ironed sheets or towels. There will also be needed a pail or a wash-tub for the soiled water, a tin dish or a

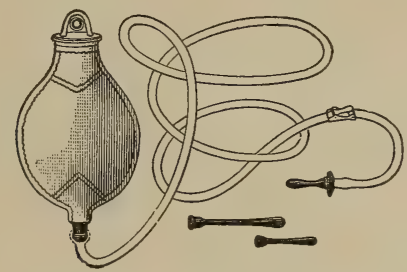

Fig. 215.-Fountain-syringe.

flat bake-pan for the instruments, brandy, a hypodermic syringe filled with the required solution, usually strychnin sulphate ( $\frac{1}{25}$ grain), a small tumbler, a Davidson or a fountain-syringe, table salt for salt solution, safety-pins, 
two new nail-brushes, ready for use in a I : 40 carbolic acid solution, Castile soap, green soap, a razor, hot-water bottles, two blankets, alcohol, vinegar, and matches. The surgeon will bring the necessary sterile dressings, towels, sheets, etc., in his kit with the instruments.

The instruments are to be wrapped in a towel and allowed to boil for ten minutes in a saucepan, tin pail, or a fish-kettle of boiling water, to which have been added two teaspoonfuls of washing-soda to each pint of water, to prevent rusting. The pail of water should be on the fire and the water boiling when the surgeon arrives, so that the instruments can be put in at once.

If the nurse is asked to give the anesthetic she should not attempt anything else. None but novices give the anesthetic and watch the operation. The experienced anesthetizer constantly watches the patient. If the nurse is asked to assist the surgeon, she must be neither too enthusiastic nor too quick nor too slow. She must see the patient safely out of the anesthetic influence and carry the case along as she would any other.

Sometimes a nurse is called to an emergency operation in a very poor family, where there are no conveniences. In such instances the kitchen can be cleaned and prepared as an operating-room in a few minutes. If she is called in the night and goes to the case with the surgeon, she should, while the surgeon is making his examination of the patient, start a fire and put on the wash-boiler, to make sure of plenty of boiling water. She should then get six sheets and twelve towels, if possible. There may be no clean towels, and the nurse will have to wash some dirty ones. The sheets and towels can be soaked first in 
boiling water and afterward placed in corrosive sublimate solution ( $\mathrm{I}: \mathrm{IO00}$ ) until the surgeon is ready to use them. Boiling water is one of the best antiseptics, as it kills germs. Unfortunately it cannot be used in rendering our hands and the field of operation aseptic, but it can be used in the preparation of the sheets, towels, sponges, and instruments.

The kitchen should be rendered as clean as possible. The kitchen-table should be prepared for the operatingtable, and there should be two small tables, one for the instrument tray and one for the sponges. If small tables cannot be had, chairs covered with a sheet or towels wrung out of the corrosive solution will answer the purpose. If there is no gaslight, as many lamps as can be obtained should be arranged near the surgeon, but not too near the ether, because ether is inflammable.

To fasten a sheet gown upon the operator, fold the sheet to a proper length, standing in front of the surgeon, so that the top of the fold is on a level with the axilla; draw ends up under the arms behind. Cross each end to the opposite shoulder and pin in front to form sleeves.

Improvise a stretcher by means of two curtain poles passed through a folded and pinned sheet and double blanket.

After the surgeon has made the examination the part must be shaved, washed, an enema given to clear the bowels, and the urine drawn. While the patient is being anesthetized the nurse may arrange the tables and sterilize a flat bake-pan or meat-pan for the instruments. If sponges have been forgotten, a clean sheet can be torn up and folded into flat sponges. China 
basins can be used for the antiseptics, the sponges, and the surgeon's hands; china pitchers for hot and cold water; a wash-tub for the soiled water; and hot bricks, plates, stove-lids, bags of salt or beer bottles for heaters.

Cool boiling sterile water for immediate use during operation by pouring out in pitchers, which are then to be set in vessels containing ice-water and cracked ice.

In cases of contagious diseases, place all cleaning cloths and left-over dressings in paper bags or newspaper cornucopias to burn. 


\section{CHAPTER XIX}

\section{GYNECOLOGIC EXAMINATIONS AND OPERATIONS}

PeRfect asepsis is of special importance in gynecologic examinations and operations, because in many instances the peritoneal cavity, which is highly susceptible to septic influences, is invaded by them. We must bear in mind that the whole genital tract communicates directly with the peritoneum, and infection at any point may cause peritoneal sepsis. Infection has taken place through the introduction of a dirty sound, and fatal peritonitis has followed perineorrhaphy and trachelorrhaphy.

The technic for major operations is usually perfect, but for minor operations carelessness is liable to creep in. We have no right to expose a patient to danger no matter how small the operation to be performed; and if our technic is not as perfect as we can make it with the means at our command, then we expose the patient to the greatest of all dangers, that of peritoneal sepsis, which usually means death. Success in surgery is due to minute attention to a careful technic, and a careless nurse may be the means of introducing sepsis, which may result in death after a most brilliant and skilfully performed operation. The most skilful surgeon is dependent upon his assistants for the perfection of his technic, and only those nurses who have been thoroughly instructed in the practice of asepsis and antisepsis should 
be allowed to assist at an operation or examination, however small.

\section{GYNECOLOGIC EXAMINATIONS}

The positions which a patient may occupy when undergoing an examination are the knee-chest, dorsal, Sims, and the upright.

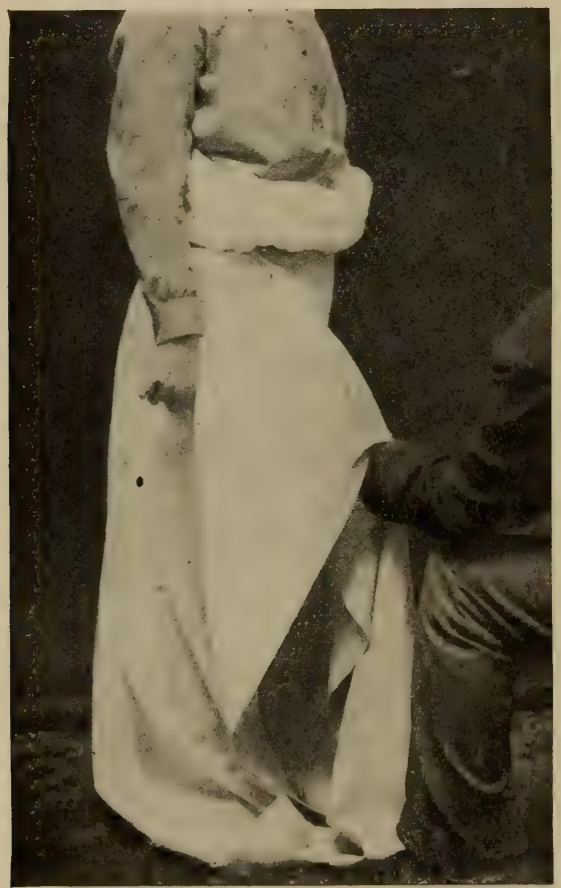

Fig. 216,-Examination in the erect posture. (Hirst.)

The upright, or the erect, position is rarely used for the purpose of making a diagnosis, but is sometimes preferred in verifying a diagnosis, especially that of 
uterine displacement, previously made with the patient in another position. Around the waist is pinned a sheet which extends to the floor, under which the clothing of the patient is drawn up. The patient stands with limbs separated, one foot resting on a stool or the rung of a chair.

Dorsal Position.-The patient lies on her back with the knees drawn up and separated; the hips are brought down near the edge of the table. The heels are placed in foot-rests which extend out from the table about 8 inches. A sheet having an oval slit in the center long

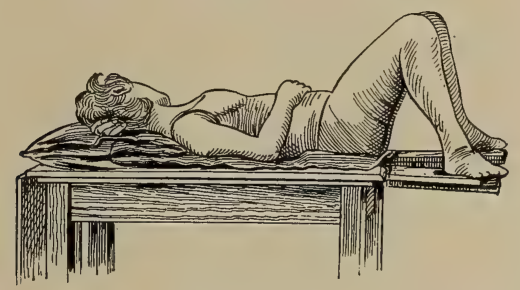

Fig. 217.-Dorsal recumbent posture.

and wide enough to expose the parts is thrown over the patient. In this position there is naturally a certain amount of flexion of the pelvis upon the trunk, and almost complete relaxation of the abdominal muscles is secured.

Sims' Position (also called the Latero-abdominal Position).--In the Sims position the patient lies on the left side of her chest, with her head and left cheek resting on a low pillow, and the left arm is drawn behind the body or hangs over the edge of the table. The hips are brought down to the left-hand corner of the table, so that her body lies diagonally across it, the head and shoulders be- 
ing at the right-hand side, with the left hand and arm hanging over the table-edge. The thighs are flexed upon

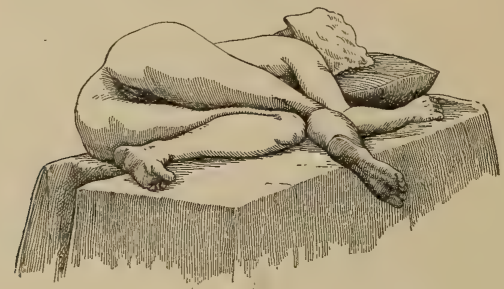

Fig. 218.-Sims' posture, anterior view.

the abdomen, the right thigh being so flexed that it lies just above the left knee, and the feet rest upon the righthand corner of the table.

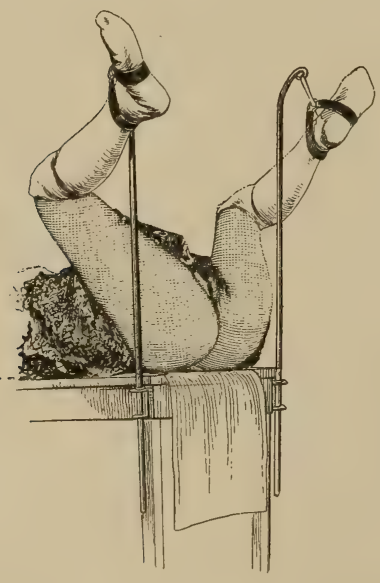

Fig. 2I9.-Edebohls' dorsal posture (lithotomy position). This position is one in which there is a tendency for the intestines to ascend, and this causes the vagina to be filled with air and thus brings the uterine cervix within easy reach.

The lithotomy position is used when operating upon the rectum and in some conditions of the bladder. The position is obtained by placing the patient upon her back, knees and thighs flexed and separated, the feet being held in stirrups, as seen in the diagram.

The knee-chest; or genupectoral, position is used for inspection of the rectum, bladder, vagina, and cervix of 
the uterus. In some cases of displacement of the uterus the patient may have to take this position many times

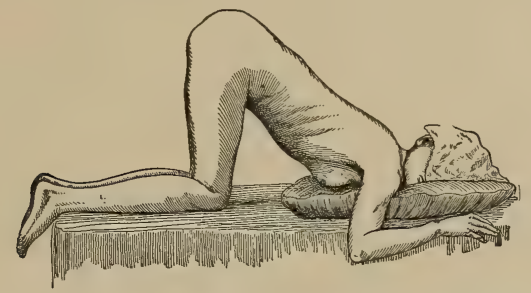

Fig. 220.-Knee-chest or genupectoral posture.

daily. The patient first kneels on the edge of the table or bed, then bends forward and rests her chest on a low pillow, her head lying just beyond, so that her back slopes down evenly, her arms clasping the sides of the table. In this position the abdominal organs are thrown toward the diaphragm; the air enters the vagina and balloons it out, so to speak, so that there is an unobstructed view of the canal and the cervix.

The Walcher position for increasing the size of the outlet of the pelvis during childbirth; action is secured by means of elastic and body weight extension. Seldom

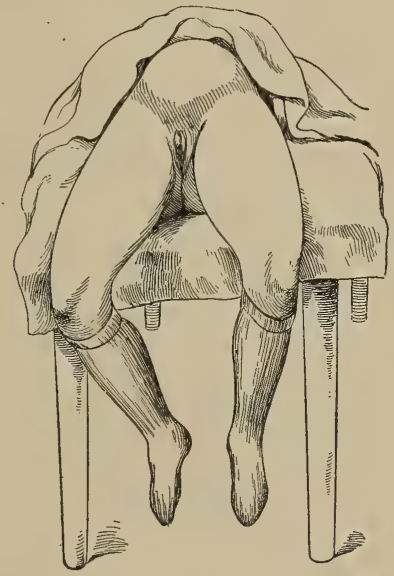

Fig. 22I.-Walcher posture. used.

Examination of the Rectum.-The patient is usually placed in the Sims position. Either the rectal speculum, or in its absence a Sims speculum (small blade), is used. 
When the instrument is introduced the rectum becomes distended with air so that its walls are well exposed. If the patient is not in such a position that the buttocks are in a good light, a head-mirror, or an electric headlight may be needed. It is well to have these at hand in case they should be called for.

For an examination of the bladder the knee-chest position is sometimes used; though, as a rule, the dorsal position is chosen, with the hips elevated high above the abdomen by means of cushions or pillows, which allows the intestines to gravitate toward the chest; and when the urethra is opened the bladder becomes distended with air and its interior is thus easily seen. Sometimes the patient is anesthetized for the examination, but local anesthesia of the urethra is usually sufficient.

Preparation for Gynecologic Examination.-To prepare a patient for examination the genital parts should be cleansed, so that there will be no danger of carrying septic material to the upper part of the genital tract; the bladder and bowels should be emptied. The uterus lies between the bladder and the rectum, and the distention of either of these organs will alter the position of the uterus. As a rule, no douche should be given before the examination, since the surgeon may want to see the character of the discharge. All bands around the waist must be loosened, also the corsets; a single tight band around the waist will crowd down the contents of the abdomen and displace the uterus. Around the patient is thrown a sheet, beneath which she can raise her clothing above the waist, and tien step upon a chair and thence to the examining-table without there being the slightest exposure. 
For examination in private practice, the patient is usually placed transversely across the bed with each foot on a chair and the buttock drawn well down to the edge of the bed. The legs and thighs should be draped with sheets. The usual requirements are: pair of rubber gloves, sterile vaselin, vaginal speculum, uterine forceps, and tenaculum.

The speculum should be warmed by placing it in the warm sterile water. The same aseptic precautions are used during an examination as during an operation. The instruments should be sterilized. Sometimes a cleansing douche of corrosive sublimate $(\mathrm{I}: 2000)$ is administered after an examination.

\section{PREPARATION FOR OPERATION}

The preparation for gynecologic operations, such as perineorrhaphy, etc., are the same as for an abdominal operation, excepting the difference of the field of operation to be prepared. In case the operation is a minor one upon the uterus or vagina, the preparations may be somewhat modified according to the individual preference of the operator, but the general rules of asepsis are always the same; and they must be the more strictly observed in these operations because the dangers of infection are increased by our inability to get the genital tract thoroughly clean. In abdominal surgery there is not this difficulty.

The preparation of a patient in a private house for a minor gynecologic operation should be as thorough as in a hospital. If the operation is to be performed with the patient in bed, there will be needed a wide board or an ironing-board for insertion between the mattress 
and sheet, thus making a hard surface for the patient to lie upon.

A piece of rubber cloth or oilcloth will serve for a Kelly pad. The material used is folded at the top and sides, covered with a towel, and the unfolded end draped into a pail or wash-tub. When the patient is anesthetized the bed is turned toward the window to afford the surgeon a good light - a northern light if possible. A bay window should be avoided, because it gives cross-lights.

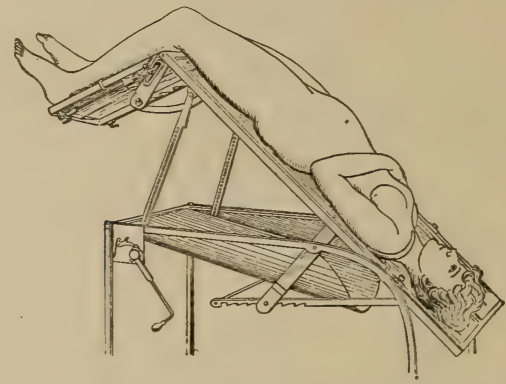

Fig. 222.-Trendelenburg position. (Ashton.)

The limbs are flexed, the hips brought to the edge of the bed, and the Kelly pad placed under them, so that the water used in bathing the external parts is conducted by the cloth into the pail or tub. When holding the patient's limbs the nurse should let the heel of one foot rest in the palm of her hand; the knee of the patient will then rest against the chest of the nurse, whose free hand is passed over and holds the other limb in position at the knee. If the nurse is asked to hold the speculum, she should grasp the handle from below with her right hand; the angle of the speculum will thus lie in the hollow between the thumb and forefinger, and the convexity of 
the blade will rest on the dorsum of the hand. The upper labia are raised by the left hand. If the speculum or regular retractors cannot be obtained in the emergency, retractors can be improvised by bending the handles of four large spoons to the appropriate angle. Two are used to retract the lateral walls, the other two being applied to the anterior and posterior parts of the vagina.

After-care.-After a vaginal operation (trachelorrhaphy) the patient will probably be catheterized for a few days. We must always remember the risk of cystitis. Many patients have fully recovered from the operation proper, but convalescence has been delayed by this complication.

After passing the catheter the nurse should be careful that when removing it the urine does not drop on the stitches; the parts are afterward sprayed with the ordered solution and dried. When giving douches the nurse must insert the tube carefully away from the stitches, and after the douche is over she should separate the labia and wipe the vagina dry with sterilized cotton or gauze held in dressing-forceps. The same care must be used when giving enemas, in order that the rectal and vaginal stitches be not broken by the tube. The patient must be instructed not to strain when the bowels are moved or the stitches may break. When dressings are applied they may require frequent changing in order to keep them clean and free from discharges. Strict antisepsis must be observed, the genital parts must be kept perfectly clean, otherwise septic material will readily find access and probably result in infection of the wound and suppuration, or a stitch abscess. If the uterus is packed with gauze, the pulse and temperature 
are usually taken every two hours; and should the temperature rise to $\mathrm{IOI}^{\circ} \mathrm{F}$. the packing is removed.

Diet.-A liquid diet is usually ordered until after the third day, when the bowels will have been moved; after which, if all is well, the amount of food is increased until it attains its customary proportions.

The patient is generally kept in bed two weeks, and the sutures removed on the ninth day in the order in which they were introduced. After the removal of the stitches many operators order a vaginal douche two or three times a day, the amount of water varying from 2 to 4 quarts. This treatment is successful only when the douches are given at the proper time and temperature. 


\section{CHAPTER XX}

\section{DIET RECIPES}

From the following carefully prepared and longused foods for the sick the nurse will be enabled to quickly choose a change of diet from day to day, enabling her to secure the fresh, dainty daily surprise for her. patient:

Water.-Boiled water is the safest and best for the sick. Reaërated by pouring out in flat receptacle. It may be cooled by keeping in ordinary milk bottles set on ice.

Albumin Water.-Beat up the white of one egg; strain through a cloth; add a glass of water. Stir in a teaspoonful of lemon juice, one of sugar, and a pinch of salt. Serve set in a bowl of cracked ice.

Apple Water.-Bake two apples soft, mash; pour a cup of boiling water over the mass; cool; strain; sweeten to taste. Serve with shaved ice, or set in a bowl of cracked ice.

Lime Water.-Take a lump of unslaked lime the size of an egg, and place it in $\frac{1}{2}$-gallon bottle of pure cold water. Keep the bottle corked; after a few moments the lime water is ready for use, the clear liquid being poured off as needed. So long as any lime remains the bottle may be restocked by the mere addition of cold water.

Barley Water.-Stir 2 ounces of pearl barley in $I \frac{1}{2}$ pints of cold water; boil for half an hour over a slow fire in a 
covered vessel; strain. Add thin cuts of lemon, or pieces of sugar rubbed over the lemon to flavor.

Lemonade.-Cut a lemon in half after rolling; squeeze one-half into a glass, removing the seeds; add a little water and stir in a heaping dessertspoonful of sugar. Fill up the glass with water; stir in more sugar if necessary.

Effervescing Lemonade.-Add half a teaspoonful of bicarbonate of soda to the above, or Vichy water may be used.

Egg Lemonade.-Shake up the white of one egg in a cup of water, to which add two teaspoonfuls of lemon juice and sugar; shake. Serve at once.

Imperial Drink.-Add a teaspoonful of cream of tartar to I pint of boiling water; squeeze and add the juice of half a lemon; add a dessertspoonful of sugar. Serve cold.

Tamarind Water.-Stir a tablespoonful of preserved tamarinds up in a cupful of boiling water; allow to cool; strain. Serve with shaved ice.

Currant Juice.-To a tablespoonful of currant jelly add a cupful of boiling water, stirring; sweeten to taste; set aside to cool. Serve with ice.

Orangeade.-Peel an orange; pour a cupful of boiling water over the peeling; squeeze and add the juice of the orange and a dessertspoonful of sugar; let cool; strain. Serve cold with shaved ice. A teaspoonful of lemon juice may be added to vary the taste.

Milk Diet.-This consists of 2 or 3 quarts of milk daily.

Koumiss.-Dissolve a third of a cake of compressed yeast in a little lukewarm water; add this to I quart of 
fresh, warm milk; stir in a tablespoonful of sugar. Put the mixture in stoppered bottles; cork and set away for twelve hours in a temperature of about $70^{\circ} \mathrm{F}$. Then put the bottles upside down on ice until ready for use.

Toast Water.-Remove the crust from a slice of stale bread; toast without burning. Break the slice up and put the fragments into a small crock or pitcher; add a couple of pieces of orange peel or lemon. Pour over all I pint of boiling water; cover with a napkin; let cool; strain for use. Must be made fresh.

Toast Soup.--Toast a thin slice of stale bread. While hot spread butter over it, having no excess. Break into fragments and place in a pitcher; add $\frac{3}{4}$ pint of boiling water; add a pinch of salt and pepper. Serve hot.

Flaxseed Tea.-Add one-half cup of flaxseed to I quart of boiling water. Boil for one-half hour over a slow fire. Allow to set near the fire for fifteen or twenty minutes; add a teaspoonful of lemon juice; sweeten to taste; strain. Serve hot or cold.

Slippery elm bark may be added to the above mixture, allowing $\frac{1}{2}$ ounce of the bark to I pint of liquid.

Milk and Cinnamon.--To $\frac{1}{2}$ pint of new milk add enough broken cinnamon sticks to flavor; add to this a teaspoonful of sugar; strain. Serve cold or hot.

Arrowroot Gruel.- Stir up half a tablespoonful of arrowroot flour with a little cold water; add a cupful of water, stirring in half a dessertspoonful of sugar and a pinch of salt. Boil slowly for twenty minutes, stirring constantly; add a cupful of milk; boil; strain. Serve hot.

Barley Gruel.- Stir up a tablespoonful of barley flour in a little water; add a cupful of water in which has 
beer mixed half a dessertspoonful of sugar and a pinch of salt; heat; bring to a boil, continuing it for twenty minutes: stir constantly; add a cupful of milk; bring to a boil; strain. Serve hot.

Cracker Gruel.-Dissolve half a teaspoonful of sugar and a pinch of salt in a cupful of water; apply heat. Mix up two tablespoonfuls of grated cracker in a little water and add to the heated water. Boil for five minutes; add a cupful of milk and again bring to a boil. Serve hot.

Flour Ball.-Tie up half a pint of flour in a square of cheese-cloth very tight; place in a pot of boiling water; cook for five hours. After removing the cloth peel the outside of the ball and grate; dry in the oven and keep in a closed jar. This may be used for making gruels; also to dilute milk for young children.

Tapioca Jelly.-Soak a cupful of tapioca for two hours; when soft, place in a saucepan; add a dessertspoonful of sugar; the rind and juice of one lemon; a pinch of salt and I pint of water; heat. stirring the mixture until boiling; turn into a mold and set out to cool before serving.

Tapioca Soup.-Boil I pint of meat broth: stir in I cunce of washed tapioca. Set on the back of the stove to simmer, corering the ressel. Skim and serve hot.

Eggs.-Boil eggs by dropping them into boiling water, and continue for three minutes.

Poached Eggs.-Bring water to a boil in a saucepan; add a pinch of salt; slip the egg carefully broken in a saucer into the salted water. Cook until the white is firm but jelly-like: remove with a skimmer and serve on a thin piece of buttered tcast: sprinkle a little salt and 
pepper on the top; garnish with parsley sprig. Serve at once.

Scrambled Eggs.-Beat up two eggs thoroughly; add two tablespoonfuls of milk; a pinch of salt. Pour into a very hot buttered frying pan; stir constantly for about two minutes. Serve on buttered toast at once.

Shirred Eggs.- Heat up the shirring cups. Put in each cup a bit of butter; break into each an egg. Allow to remain on the stove for a moment, then serve hot in the cup, adding a pinch of salt.

Panado.-Take a slice of wheat bread and break up into fragments; sprinkle a teaspoonful of ground cinnamon over the whole; add I pint of boiling water; boil for five minutes; add a teaspoonful of sugar and a little grated nutmeg. Serve hot.

Milk Toast.-Prepare two slices of crisp toast. Heat a cup and a half of milk to the boiling-point; add a pinch of salt and a small bit of butter. Pour the milk mixture over the toast in a closed dish. Serve hot.

Rennet.-One pint of warmed milk, sweetened, and flavored with nutmeg, cinnamon, or lemon; add one large teaspoonful of liquid rennet; stir for one minute; set aside to cool and set. Serve with sugar and cream.

Boiled Rice.-Rice must continue to boil until every grain is softened without dissolving into a shapeless mass.

Plain Rice.-Two tablespoonfuls of rice are to be washed and placed in a shallow baking dish; add two tablespoonfuls of sugar; flavor with lemon peel or vanilla; add I quart of milk. Bake for three hours in a moderate oven, stirring every twenty minutes. Cool for an hour before using. Serve cold. 
Tapioca Pudding.-Soak one-half cup of tapioca over night in cold water; put it over the fire and heat to clearness. Mix up I pint of milk and two eggs to form a custard by heating the mixture until almost boiling, then stir in two tablespoonfuls of sugar and cook for three minutes in a double boiler, stirring gently all the time. When done it should be as thick as cream. If allowed to cook too much it separates and is spoiled. Add the milk custard to the tapioca; sweeten and flavor to taste; bake in a quick oven. Set aside to cool. Serve cold.

Cornstarch.-To one tablespoonful of cornstarch add cold water enough to make a smooth paste. Add to this $\frac{1}{2}$ pint of milk; boil for five minutes, stirring all the time; add a pinch of salt; sweeten to taste, and add a flavoring extract. Serve cold.

Beef Essence.-Cut up I pounà of fresh lean beef into small pieces; sprinkle a little salt over the mass; place the cut-up meat into a stout stone jug; place the jug in a vessel of cold water and bring to a boil; cork the jug tightly when steam begins to issue from the mouth. Continue boiling for at least four hours; strain through a cloth and season the meat juice obtained with pepper and salt to taste.

Invalid's Soup.-To I pint of beef essence made quite hot add $\frac{1}{2}$ pint of cream, likewise hot, to which the yolk of a fresh egg has been stirred. Mix carefully together in a lined saucepan; season and serve .

Beef Broth.-Take I pound of beef (neck or shoulder) and slice it up; place in a pan and salt, then pour on $\mathbf{I}$ quart of cold water; place on the fire and bring to a simmer; keep so over a slow fire for an hour and a half; set back on the range for half an hour; strain; serve. 
Mutton Broth.-Cut up I pound of good mutton into small pieces and sprinkle with salt; allow to simmer over a slow fire, after adding I quart of cold water, for an hour and a half; boil for half an hour; strain; serve.

Beef Juice.-Take $\frac{1}{2}$ pound of lean beef and cut it up in pieces of about the size of a pigeon's egg; toast the pieces over hot coals; squeeze out the juice with a meat presser or lemon squeezer; add a pinch of salt before serving.

- Chicken Broth.-Take a small chicken, removing skin and fat between the muscles; divide it in two down the back; remove the lungs as wëll as everything adhering to the side bones and back; cut up the halves in thin slices; place them in a pan and sprinkle with salt, then add I quart of cold water; bring to a simmer over a slow fire; allow to remain for an hour and a half. Then remove from the fire to a place where the heat will still be kept up for half an hour longer; strain; serve hot. During the cooking a sprig of celery may be added, or a clove, or half a dozen pepper-corns to give it a flavor. 


\section{CHAPTER XXI}

\section{SIGNS OF DEATH; AUTOPSIES}

Winslow, one of the professors at the University of Paris, and who had twice been taken for dead, was the first to make a scientific investigation of the signs of death. After Winslow came Louis, and since their time eminent men, especially in countries prescribing rapid burial, have endeavored to find certain and reliable signs of death before decomposition begins.

\section{SIGNS OF DEATH}

Absence of respiration is not a sure sign of death, as it may be due to syncope or to the person being in a

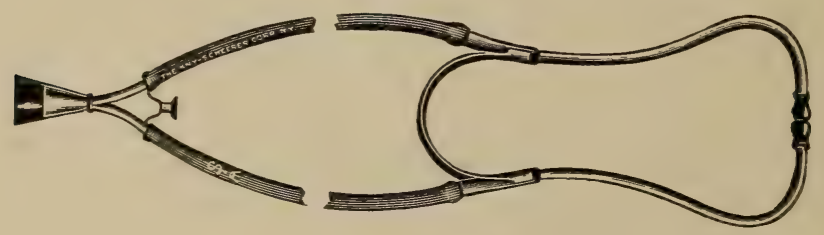

Fig. 223.-Stethoscope.

trance; nor is absence of the heart-beat, unless determined by means of a stethoscope in experienced hands. Coldness and rigidity may be due to collapse or catalepsy or in persons who are frozen stiff.

In doubtful cases of apparent death which occur suddenly or from external violence the following tests are usually applied: 
I. The absence of the heart's action is carefully determined by a stethoscope or phonendoscope.

2. Absence of the circulation is ascertained by tying a string tightly around a finger or a toe; if the tip becomes blue, life is not extinct, though this may occur in cases where there has been great loss of blood, and in other cases where the heart is too weak to send the arterial blood into the capillaries of the fingers.

3. Absence of respiration is determined by placing the surface of a mirror before the mouth; if the surface becomes moist, respiration has not ceased.

4. If a subcutaneous injection of aqua ammonia is given a red or purple spot will form if life still exists.

5. If a needle is inserted into the flesh of a living person blood will escape, but not if life is extinct; still, if there has been a large loss of blood there will be no escape of blood in the living.

Rigor mortis (postmortem rigidity or stiffness of death) begins in the upper part of the body, usually in the maxillary muscles, and spreads gradually from above downward. It disappears in the same order. It comes and goes quickly after great muscular effort or excitement, and when once it has been broken up it does not return. The time it sets in after death varies from ten minutes to twelve or even twenty-four hours. Rigor mortis is considered the most positive sign of death, because it indicates death of the muscle itself.

Death of the body as a whole takes place first, and at intervals of an hour or even several hours death of one or other of the involuntary muscles follows.

Hypostasis, cadaveric lividity, or congestion of blood in the capillaries, which forms in all the dependent parts 
of the body, is considered a valuable sign of death, but this purple color may be due to contusion, and has been seen in cholera patients before death.

The body temperature at and from one to two hours after death may be very high, $107^{\circ}$ or $112^{\circ} \mathrm{F}$. Patients dying from cholera and yellow fever have high temperatures for several hours after death; but, as a rule, the body is cold to the touch in from six to ten hours.

\section{AUTOPSIES}

Every nurse should do all in her power to assist the physician or surgeon to obtain autopsies, and with a little tact the necessary permission can usually be obtained. Every well-conducted autopsy adds more or less to medical knowledge. It verifies the diagnosis of the illness, and in many cases it explains or shows the cause of symptoms the explanation of which could not be determined before death. In surgical work, when a patient dies in less than twelve or fourteen hours after an operation, the autopsy, when made by a competent bacteriologist and pathologist, will show whether death was due to sepsis or to some organic disease over which the surgeon had no control.

In a private house the autopsy should be held in the room giving the best light, and if possible in the daytime, in order to obtain the correct color-interpretation, for if made in artificial light the observations will not be entirely trustworthy.

At the present time an autopsy is preferably held almost immediately after death and before putrefactive changes have taken place. The undertaker should always be warned not to inject the body, because the fluids 
usually employed, which contain among other things corrosive sublimate and arsenic in large quantities, change the color and consistency of the organs to such an extent that it is difficult to recognize the pathologic processes. Then, again, the punctures made during the embalming process may open an abscess or other cavity and thus distribute the contained pus or exudates. Embalming fluid has been poured into the mouth, and having found its way into the lungs and stomach has greatly changed the appearance of those organs.

The clothing on the body should - be removed and a large sheet spread over it; or if preferred, a night-dress or skirt open down the middle may be put on.

If the corpse is female, braid the hair in two plaits after combing a part extending from ear to ear over the crown. Coil each plait securely with hair-pins.

The things a nurse should provide are:

I. Large rubber sheet, old oil-cloth, old quilts, or papers to put under trestle to protect the floor.

2. Small table for instruments.

3. Three wash-bowls: one for corrosive sublimate, one for dirty instruments, and one for the organs removed.

4. Two pails for dirty water.

5. Old towels and a number of old sponges.

6. Plenty of hot and cold water.

7. About 4 quarts of fine sawdust, or oakum, or excelsior packing, absorbent cotton, or common cotton for filling up cavities, any one of which will prevent fluid oozing through the incisions. When these are not obtainable, bran, cloth, or newspapers may be used. Fine sawdust is the best material, as it packs easily, does not interfere with the sewing by getting into the stitches, and keeps the needle dry. 
8. Six wide-mouthed bottles in which to place specimens from the various organs, and which can be securely corked.

9. About 3 yards of fine twine or carpet-thread, and a large darning-needle or a large curved needle.

Should the autopsy take place in a house where there are no conveniences, the body can be left lying on the undertaker's stretcher covered with a sheet, the clothing remored, and a large napkin put on. There should be several old newspapers to protect the floor, and on which to place the dirty instruments and organs removed; an old sheet, a pail, a wash-bowl, and a pitcher of warm water can always be obtained.

The sheet is torn into four pieces. Two pieces are used, one for each side of the neck and trunk, covering the arms, leaving the chest and abdomen free for the surgeon to operate; the third piece is placed beneath the head: and the fourth piece is tucked in below the genitals, thus covering the lower extremities. The bowl contains the large dampened sponge, and, together with the pail, should be placed within convenient reach.

Absolute cleanliness is essential at a private autopsy. Blood-stains must be washed from the walls, floor, dishes, the rubber or oil-cloth; the papers. cld sponges, and cloths should be burned, and the body must be washed perfectly clean. The room must be left in perfect order-just as it was before the postmortem. Ground coffee thrown on a few live coals will remove all odor from the room.

For removing the odor from the hands, turpentine will be found serviceable, or a solution of permanganate of potassium and oxalic acid, or a dilute solution of formaldehyd. The result of the autopsy must be kept secret and revealed to no one. 


\section{CHAPTER XXII}

\section{HYGIENE; PERSONAL CONDUCT OF A NURSE'S LIFE; OF THE REWARDS; SUCCESS}

THE care of her own person must not be forgotten by the aspiring nurse, else she may gain the coveted post of trusted helper to physicians at the price of loss of her bodily health. Rest and regularity in conducting her mode of life are the chief factors for securing a continuation of sound health which every nurse should possess who attempts the work of caring for the sick. Futile as it may seem to suggest rest and regularity to one whose professional life is largely made up of activity and irregularity of mode of personal life, it is nevertheless essential for a good nurse to learn how to save up energy during ordinary times that she may have sufficient vital capital force to meet the emergency demands.

Sufficient sleep and a regular time for eating is as important for the well as the sick, and in the matter of eating it must be recalled that a mouthful of food which has been well masticated before swallowing will give much greater return in energy than many of the hurried mouthfuls which nurses are too prone to take.

Attention to the calls for emptying of the bladder and the bowels are for the most part made a matter of convenience rather than considered as most important functional activities to be attended to without delay.

Daily stimulation of the skin of the entire body by bathing, even if but a sponge-bath taken from a wash- 
bowl or a basin, is to be recommended, for while the average nurse may be forced to scrub her hands and arms too often for either health or comfort, there is seldom allowed time enough for sufficient body bathing.

The presence of decayed teeth, corns, bunions, varicose veins in the legs, and hemorrhoids are all common affections which may be borne a long time, but the nurse who has such things may come to a time of final failure in her professional career. Upon the very first appearance of the handicapping conditions mentioned she must seek relief, for the best that medical and surgical advice and treatment can give is hers by right. Aside from the ordinary affections which arise from ill-fitting shoes, nurses are particularly liable to the condition called "foot-sore," student nurses being special sufferers. While the hard floors of modern hospitals are responsible for the condition during the earliest days of a nursing career, later its control is a matter of proper care of the feet themselves. A nurse must seek foot comfort and health, not by wearing her oldest, run-down shoes, but a well-fitting. ample-sized shoe which allows her toes to lie uncramped. The other essential for comfort is to keep the feet dry. Perspiration quickly softens the skin of the feet, and allows swelling in the soft cellular tissue beneath to take place. While a perspiring foot is by no means unhealthy, the relaxation which accompanies it calls for treatment. To overcome the effects of excess the following measures will be found useful: A daily change of shoes; one or more changes of stockings during the day; stimulating foot-baths, alternating hot and cold water, accompanied by rubbing with a coarse towel and massage; alcohol bath and rub; 
painting the soles of the feet with a ro to 20 per cent. formalin solution once or twice a week; talcum powder, rice flour, fuller's earth dusted in the shoes will be found invaluable in keeping the feet both dry and warm. A daily change may be made at the time of dressing. In general, high laced shoes with low heels will prove more comfortable than the low light-weight ties. Rubber heels are restful, as they greatly reduce body-jarring. Tendency to flattening of the arches of the feet, manifested by a continuous ache upon standing, may be overcome by massage, strapping, and bandaging, or supported by sole-plates.

The continual scrubbing and immersions in the various antiseptic solutions of hands and arms which the modern nurse is compelled to undergo often gives rise to discomfort, if not to well-marked skin disease. Drying up of the normal oil of the skin is the earliest direct cause of roughness, cracking, and scaling skin. There is a peculiar sensitiveness of certain individuals' skins for such drug solutions as carbolic acid, bichlorid of mercury, and oxalic acid, which act toward them as special irritants and which is known by the term "idiosyncrasy." In general, to keep the hands pliant by massage and the free use of cold cream, lanolin, or some such bland ointment will suffice. In cases which fail of relief rubber gloves must be worn.

The importance of cultivating her powers of observation can hardly be estimated, so much will the nurse's reliability be thereby increased. After making the first general observation her duty is to note changes, to see and jot down facts, not bias her observing faculty by evolving opinions. 
A good nurse makes no noise herself, and acts as a perpetual noise preventer in and around the sick-room.

The stricter a nurse holds herself to the prescribed uniform of her school the better, thus fancy collars and neckwear, jewelry, hair ornaments, and fingerrings detract her personality from the rôle she plays.

The calling of a nurse demands that she be always neat and trim in the matters of her personal appearance and in clothing effects, and that her professional relationship with the patient, his family, and the physician call for but the ordinary dignity which becomes a woman's greatest charm when least assumed.

While the mental caliber of the successful nurse is from necessity large. she will do well not to continually tax herself with the requirements of her art. Proper amusements have their place, and will the better equip her for the serious work hours.

Nurses will do well to study surgical supply catalogues. so as to know the cost of supplies and keep abreast of what is new. A postal request will suffice to supply her.

No matter how physically well a nurse may conduct her life, it becomes a necessity for her to secure a change of scene during a month or two of the year. which may be obtained by means of a "traveling case," by connecting herself with work in some distant part of the country through correspondence. or the channels of a medical journal's advertisement columns, or by expending part of her year's savings for board in the country or at the seashore. Every nurse's bureau should have its correspondence department to provide for this "exchange" system in practice over the country. Besides rest in change of environment the results will be better, because 
broader, educated nurses. Of the rewards for conscientious work the nurse's outlook is a bright one, for better salaries are offered and more may be expected to be paid in the future for high-class work than ever before. The matter of money loss to nurses, which occurs between "cases," is to be overcome by a mutual division of expenses, as is customary in large communities. Five or six nurses "keep house" in a few rooms, the one who is professionally unemployed acting as "housekeeper." By this means direct communication is kept up between doctors and nurses. While the agency system for hiring nurses is good, a sure plan for a nurse to gain cases is by periodic personal visitations upon doctors. A nurse who calls upon a physician and tells him what she can do and the scale of her prices for her work has made an impression and she will be remembered by the doctor when in need of a nurse's aid.

Individual success for the nurse, as in any other vocation, must be the sum-up of her whole life's work. If at the commencement of her career she learns to know herself as a helper-one whose life's work is dedicated to the sick and to a loyal devotion to the medical profession, of which she is herself a most important part-such a one is well started in her career and is on the high road toward success and honor. 



\section{GLOSSARY.}

\section{A.}

Abdominal binder. A wide bandage dressing used to support the walls of the abdomen after open operations or the womb after childbirth. Muslin, flannel, or towelling may be used, and is applied snugly by overlapping tails and fastening or by safety-pins.

Abdominal operation. An operation which involves opening the abdominal cavity as a preliminary.

Abdominal section. An operation in which the belly cavity is opened.

Abscess. A circumscribed collection of pus.

Acetic fermentation. Souring with the production of acetic acid or vinegar.

Actinomycosis. A disease of cattle which may be transmitted to man; it is due to the ray fungus.

Active hyperemia. Steady increase of the quantity of blood in the vessels of a part.

Acupressure. Compression of a blood-vessel by twisting with an inserted needle.

Acute disease. One active in onset, energetic in course, and of short duration.

Aërobic. Requiring the presence of oxygen for development.
Albumose. A substance formed during the digestion of albumin.

Alimentary canal. The digestive tube extending from the mouth to the anus.

Alterative. A medicine having a gradual and general tendency toward the production of health.

Anaërobic. Requiring absence of oxygen for growth to take place.

Anesthetic. Producing unconsciousness to pain.

Aneurysm. A disease of bloodvessels due to stretching or rupturing of one or more of the coats.

Aniline derivative. An agent prepared from coal-tar.

Anthrax. A contagious disease of cows and sheep often transmitted to man, due to the Anthrax bacillus.

Antiseptic. An agent by whose action germs are destroyed or their growth prevented.

Antiseptic agent. One which inhibits the growth or destroys germs.

Antiseptic surgery. The various procedures which are carried out with the idea of preventing or destroying germ contamination.

Antistreptococcic serum. A protective blood-water taken from an animal which has successfully recovered from graded injections of virulent pus germs. 
Antitoxin. A defensive proteid developed in a body for its protection from microbic assaults; a curative blood serum.

Aqua ammonia. Ammonia-water. Arterioles. Smallest branching arteries.

Artificial inoculation. Attempt to produce a disease by injection or local application of the germs, their pruducts, or the virus producing it.

Artificial media. An agent capable of supporting germ life outside of the body.

Asepsis. Freedom from septic poisoning; clean.

Aseptic. Free from germs; sterile. Astringent. An agent which causes contraction of tissues and the lessening of secretions. ing.

Atomizer. An appliance for spray-

Aural. Pertaining to the ears.

Aural canal. The ear passage.

Autopsy. The examination of a dead body, a post mortem.

Autopsy room. A room set aside for the examination of dead bodies.

Axilla. The arm-pit.

B.

Bacilli. Rod-shaped germs, as tubercle bacilli, the cause of consumption.

Bacteria. Minute organisms; microbes.

Bacteriologist. One who studies and experiments with germ life.

Bacteriology. The study of germs.

Bed heater. An appliance for heating a bed, as with a hot-water bag, hot bricks, etc.

Beef essence. Concentrated beef extract.
Bistoury. A sharp narrow-bladed surgeon's knife; may be sharp or dull pointed; curved.

Blastomycete. Yeast-forming germ.

Blood serum. The watery portion of animal fluids.

Boroglycerid. A pasty compound made by slowly dissolving two parts of boric acid in three parts of hot glycerin.

Bouillon. Strained beef soup; a culture-medium.

Bronchi. The first division of the windpipe.

Bronchioles. The finest divisions of the windpipe.

Bronchorrhea. Excessive flow of mucus from the windpipe.

Bubonic plague. An acute, contagious disease characterized by a malignant type of fever and formation of buboes or glandular swellings throughout the body.

Buttocks. The fleshy parts back of the hips.

\section{C.}

Cancer. A morbid growth whose tendency is to spread and to cause ultimate death.

Capillaries. The finest divisions of the blood-vessels.

Capillary hemorrhage. Oozing of blood.

Carcinoma. One form of cancer; common seat is the female breast.

Catalepsy. Condition of partial or complete suspension of will and consciousness, with rigidity of voluntary muscles.

Catheterization. The act of drawing off the urine.

Catheterize. To draw off the urine. 
Cellular tissue. Loose fatty spaces beneath the skin and between organs.

Cerebrospinal fluid. Serous fluid contents of the cavities of the brain and spinal cord.

Cervical canal. Channel in the neck of the womb connecting the vagina with the body cavity of the womb.

Chemic. Chemical; relating to chemistry.

Chill. A nervous symptom usually marking the onset of disease, in which the patient has rigors and complains of being cold; in malarial fever the temperature is really highest at this time.

Chlorinated soda. Soda which has been combined with chlorin.

Chlorin-water. A saturated solution of chlorin in distilled water.

Citronella. A fragrant Asiatic grass from which is obtained a volatile oil, useful, when applied to the person, in driving away mosquitoes.

Clammy. Moist and cold.

Clamp. An instrument with detachable handles to apply to the broad ligament; in operations for removal of the uterus through the vagina, six or eight are applied upon each side. A hemostatic forceps to control hemorrhage from vessels that cannot be reached to apply ligation.

Clostridium. A bacillus distended at its center by a large spore.

Coagulable quality of blood. The power to clot.

Cocainization. The act of producing cocain anesthesia.

Collapse. General failure of the vital powers without loss of consciousness.

Colony. A localized, unmixed growth of micro-organisms.
Complication. A disease appearing during the course of another, which may modify the termination.

Contagious. Capable of being transmitted from one individual to another; catching.

Contagious affection. A disease directly transmissible from one ferson to another.

Contagious disease. One which may be directly transmitted from one to another.

Convalescence. The feriod of uninterrupted recovery from illness.

Convulsion. A nervous condition giving rise to violent, continued, or intermittent muscular contractions.

Corrosive sublimate. Bichlorid of mercury.

Coryza. Cold in the head.

Cranioclast. An obstetrical instrument to aid in the delivery of a child's head by crushing.

Crystalline. Colorless; clear as crystal.

Culture-media. Substances upon which germs are exferimentally grown.

Cumol catgut. Catgut sterilized for surgeon's use by superheating in a solution of cumol, a product of coal-tar.

Curetting of uterus. Clearing out of the contents of the womb or scraping the membranous lining of its cavity.

Cyanosis. The symptoms arising when the supply of oxygen is greatly lessened, as in strangulation.

Cyst. A circumscriked membranous cavity occurring abnormally and containing fluid, semifluid, or solid contents. 
Cystitis. Inflammation of the bladder

Cystoscopic examination A study of the bladder by the use of an instrument which brings its surface directly into view.

\section{D.}

Decomposition. Act of decaying; rotting; separation into elements.

Delirium. Mental state in which there is a rapid flight of ideas which are incoherent and often unintelligible.

Depletion. Reduction of the amount of fluid, as blood or serum, in a part.

Diabetic coma. Ioss of consciousness due to the action of poisons in diabetes.

Diaphragm. The great breathing muscle separating the chest from the abdomen.

Dilatation of cervix. Act of stretching the mouth and neck of the womb.

Disinfectant. An agent capable of destroying microbes or the products of their growth.

Disinfection. The act of rendering free from micro-organisms or their effects; purifying.

Distillation. The act of heating a solid or liquid in an apparatus, so that the vapors given off may be collected.

Douche. A more or less forcible flushing of a cavity or part of the body for purposes of cleansing and stimulation.

\section{E.}

Eclampsia. Convulsions during the childbearing period caused by kidney disease.
Ecraseur. An instrument used to squeeze its way through tissue causing least amount of bleeding by employing a gradually tightening wire or string.

Eczematous condition. One in which peeling and crusting of the skin occurs with more or less itchiness.

Edema. Swelling due to excess of serous fluid within a tissue.

Effervescence. Bubbling.

Elaborated. Developed; produced

Electrolysis. Decomposition by electricity.

Elimination. The act of throwing off; expelling.

Emergency operation. One made necessary by the serious condition of the patient.

Emesis. Vomiting.

Emetic. A substance causing vomiting.

Emulsion. A fiuid containing fat suspended in very fine particles, forming an opaque, milky white mixture.

Endocarditis. Inflammation of the lining membrane of the heart. The process is usually confined to the valves.

Endometritis. Inflammation of the lining of the womb.

Enemata. Rectal injections; solutions used to cleanse the lower bowel.

Enteroclysis. The administration of a rectal injection.

Epidemic. A general invasion of a community by a given disease.

Epidemic cerebrospinal meningitis. A microbic disease giving rise to inflammation of the lining membranes of the brain and spinal cord with convulsions, irregular fever, and a rash.

Epidermic. Injected; relating to the skin. 
Epidermis. The surface-covering of the body; the skin.

Epithelial cells.

Microscopic units; flat upon the skin, gobletshaped on mucous membranes, forming the surface layers of these tissues.

Epithelium. Skin covering.

Eruptive fever. One attended with a rash; scarlet fever.

Erysipelas. An acute contagious skin disease caused by streptococci, giving rise to irregular fever, and with a tendency to relapse.

Erythema. Redness of the skin; blushing.

Eucalyptus. An Australian gum tree from which is obtained an oil used in medicine. This oil produces sweating, is tonic, stimulant, and antiseptic.

Eustachian catheter. A tubular instrument designed to pass through the nasal cavity to the opening of the Eustachian tube. This latter is a canal leading from the back of the mouth to the middle ear.

Evaporation. Loss of water by the action of heat.

Excretions. Products of body waste; urine.

External jugular vein. The largest superficial vein in the neck, running downward midway upon both sides.

\section{F.}

Fallopian tubes. Two trumpetshaped pipes, each about four inches long, connecting the womb with the abdominal cavity, through which ova pass.

Fascia. Strong, glistening fibrous sheaths separating muscles.

Feces. Body and food waste from the bowels.
Fermentation. The change effected by the action of a ferment; souring.

Fetus. A young child within or taken from, its mother's womb before it has fully developed.

Fibrils. Thread-like connective tissue.

Fibrin. Fine elastic strands formed during clotting and inflammation.

Fibrin-ferment. A substance causing the formation of fibrin.

Fistulæ. Disease tracts indisposed to heal.

Flacherie. A contagious disease of silkworms caused by micrococci.

Flat wines. Wines spoiled by begin ning acid fermentation.

Flatulence. Excess of gas in the stomach or bowels; wind colic.

Fuller's earth. A finely powdered earth used as an absorbent.

Fumigate. To free from infection by the use of vapors.

Fungi. The lowest order of nonflowering plants living upon animal matter; in bacteriology, a micro-organismal moss.

\section{G.}

Gangrene. Local death of the part.

Germ theory. The theory that all specific disease is due to the presence or action of micro-organisms.

Germicidal solution. A germ killer.

Glanders. A disease of horses caused by the bacillus mallei which affects the air-passages and skin and is transmissible to man.

Globulins. A form of albumin.

Gonococcus. The germ that causes the venereal disease called 
gonorrhea; consists of a double, dumbbell coccus.

Gonorrhea. A sexual disease caused by the transfer and activity of a germ called the gonococcus from one individual to another.

Granulation tissue. Reddish, budlike projections found upon the surface of a healing wound.

Gynecologic. Relating to the sexual organs of a woman.

\section{H.}

Heart paralysis. A condition in which the heart's action is rapidly weakened or ceases.

Hemorrhage. Bleeding; generally used to designate a profuse loss of blood from the vessel affected.

Hemorrhoids. Dilated and elongated blood-vessels about the opening of the lower bowel; piles.

Hernia. An abnormal protrusion of an organ or tissue.

High enemata. An injection made high into the bowel by aid of gravity and a rectal tube.

Hives. Common name for a skin disease giving rise to an evanescent eruption associated with severe itching.

Hydrophobia. A disease of dogs and kindred animals communicated to man by direct inoculation; rabies.

Hypodermic injection. Deposit of a solid or tluid beneath the skin by means of a syringe and hollow needle.

Hypostasis. The settling of blood or fluid to the lowest parts of the body by gravitation after death, or loss lof pressure-controlling power in a given set of blood-vessels.

Hysterectomy. Removal of the womb by operation.

\section{I.}

Icterus. Bile-stained; jaundiced.

Immunity. A condition in which a body resists the development of micro-organisms or the action of their poisons.

Immunizing unit. A standard strength agent to subdue the powers of a given quantity of micro-organisms or their products.

Infectious disease. One capable of being transmitted from one person to another.

Infective. Likely to produce disease.

Infective puerperal endometritis. Purulent inflammation of the lining of the womb after childbirth.

Inflammation. Reaction of a part to an irritant.

Infusion. Charging the veins with fluid by injection.

Inoculation. The act of directly implanting disease.

Inoculous. Rendered sterile.

Insomnia. Unable to sleep.

Inspissated. Dried and thickened from loss of water.

Intestinal adhesion. Union of two peritoneal surfaces of the bowel caused by inflammatory action.

Intestines. The bowels.

Intracerebral injection. Deposit within the cavities of the brain.

Intravenous. Within the veins.

Intravenous injection. An injection forced directly into a vein or cellular tissue.

Intubation. Operation of passing a tube through the larynx when closed by disease, as in diphtheria.

Isolation. Setting apart from all communication with others. 
K.

Knuckle of intestine. A short length of gut sharply bent upon itself.

Kraske's operation. Operation devised by the surgeon whose name it bears for the removal of cancer growing high up in the rectum. The diseased area is exposed by chiselling away the coccyx and portions of the sacrum.

\section{L.}

Lanolin. A bland, fatty substance prepared from sheep's wool and used as the base of many ointments.

Laparotomy sheet. Linen sheet covering containing a longitudinal opening through which patient's abdomen is exposed.

Lavage. Washing by irrigation.

Leprosy. A chronic obscurely contagious disease caused by the bacillus of leprosy, and giving rise to various inflammatory lesions of the skin and internal organs.

Leprous nodules. One form of skin lesion caused by leprosy consisting of firm, irregular elevations, which later break down and become ulcers.

Leukocytes. Unit masses of protoplasm or the physical life principle.

Ligation. The tying off of bloodvessels, the ovarian tubes, the appendix, or a tumor by means of a gut or silk string.

Liquefied. Changed from a solid to a liquid state.

Listerism. Antiseptic surgery according to the principles first laid down by Sir Joseph Lister. Litholapaxy. The operation of form. removal of stone from the bladder by crushing and washing out the fragments.

Lithotomy. The operation of cutting for stone.

Lithotrite. An instrument for crushing stones within the bladder.

Lubricant. A substance used to diminish friction; rendering slippery.

Lymphatic vessels and glands. The great system of absorbents with their connecting channels.

\section{M.}

Malady. Sickness, disease.

Malignant tumor. One which has undergone cancerous change.

Masticated. Chewed.

Meatus. Anatomical name for the mouth of a canal.

Media. The means of transmission; substances favorable for the growth of bacteria.

Mediastinum. The middle space of the chest cavity between the lungs, and containing the heart and great blood-vessels.

Medicaments. Medicines.

Menstruum. A fluid carrier or solvent for a drug.

Miasm. Infection carried in the emanations from the soil.

Miasmatic. Caused by infectious particles rising in vapors from the soil; said of malaria before its cause was known.

Micrococci. Germs having a spherical shape.

Micro-organisms. Any form of germ life.

Minim. A fluid drop.

Monomorphous. Having but one 


\section{N.}

Narcotized. Poisoned by the action of a narcotic, as opium.

Natural rhythm of respiration. Normal breathing.

Nerve-center. One of the countless impulse generators or reflectors in the body.

Neutralization. The act of rendering free or open.

Nidus. Center of activity.

Nutrient. Having food value.

\section{0.}

Occlusion. Closing up.

Ophthalmic. Relating to the eye.

Organic ferment. The microbic action which gives rise to souring.

Organized exudate. A fluid discharge made solid by the formation of fibrin.

Otitis media. Inflammation of the chambers of the middle ear.

Ora. Eggs.

Ovaries. The two egg-bearing organs in the female.

Oxidation. Burning up.

Oxygenation of the blood. Refreshing of the blood by the action of the red cells in taking up oxygen.

\section{P.}

Parasitic organisms. Dependent upon other forms of life for their food; may live in or upon the sustaining organism. Gonococci are parasites, as are also tapeworms and lice.

Pasteur chamber and filter. An apparatus for sterilizing and filtering by the action of superheated steam, varied in pressure by means of an airpump.
Pathogenic bacteria. Disease producers.

Pathologist. One engaged in the study of the causes and results of discase.

Pebrin. A hereditary contagious disease of silkworms consisting of the derelopment of peculiar parasitic corpuscles which invade the eggs, blood, and tissues of the worms, causing black spots to appear externally.

Pedicle. An elongated support.

Pedicle silk. Strong silk used to tie off the base of tumors before removal for security against bleeding.

Pellicle. Surface scum; an outer limiting mezabrane.

Pelvic cavity. Space within the pelvis.

Pelvimeter. Curved diriders used by the obstetrician in calculating the size of a woman's pelvis.

Pelvis. The bony framework at the base of the spinal column supporting the trunk and affording attachment for the thighs.

Perforator. A sharp, spear-headed instrument used by obstetricians to pierce the skull (to facilitate delivery) of a dead infant or one whose life must be sacrificed for the good of the mother.

Perineal lithotomy. The breech operation of cutting for stone.

Perineorrhaphy. The operation of sewing up a torn breech of a woman.

Peristalsis. The muscular wavemotion of the bowels.

Peristaltic action. The motion which propels the contents of the bowrels.

Peritoneal cavity. The space occupied by the abdominal organs.

Peritoneum. The lining mem- 
brane of the belly cavity and covering of the organs contained.

Peritonitis. Inflammation of the lining membrane of the organs and cavity of the abdomen.

Petri dishes. Small double dishes for the cultivation of micro-organisms.

Phagocytes. Body cells whose supposed function is to devour other cells as micro-organisms.

Phagocytosis. The function of active destruction by devouring or englobing of one cell by another.

Pharyngeal paralysis. Loss of voluntary power of swallowing, with dropping of the soft palate.

Placenta. The late womb connection between a fetus and its mother.

Plague. An acute contagious disease commonly appearing in epidemic form due to micro-organisms characterized by bubo formation and high death-rate.

Plasma. The fluid portion of - blood or lymph.

Pleurisy. Inflammation of the pleura or membranous covering of the lungs and lining of the chest walls.

Pneumonia. Inflammation of the lungs.

Precipitated. Thrown down by chemical action.

Preparatory treatment. Making a patient ready for an operation, consists in local cleansing, attention to bowels and bladder, food, etc.

Prone. Lying upon the abdomen.

Prophylaxis. Preventive measures.

Protective dressing. A waterproof material placed next to a wound according to the direction of Sir Joseph Lister.
Puerperal. Relating to childbirth.

Puerperal fever. Elevation of body temperature occurring in infection after childbirth.

Puerperal infection. Systemic poisoning by the action of microorganisms in a child-bearing woman.

Pure culture. Containing but one variety of germs.

Purgative. A substance which moves the bowels.

Pus. Matter given off from an open sore.

Putrefaction. Separation of an organic compound into the elements of which it is composed by the action of micro-organisms; rotting.

Pyroxylin. Gun-cotton; made by immersing raw cotton in nitric and sulphuric acids.

\section{R.}

Raw surface. An open wound or abrasion; a condition in which the skin or outer lining of a part or organ is broken through.

Reaction. The restoration of vitality after shock.

Rectum. The lower extremity of the large intestine.

Recurrent. Returning again.

Regurgitation. A back flow.

Respiration. Breathing.

Retention of urine. That condition in which the urine, while it continues to be formed by the kidneys, cannot be passed from the body; inability to pass water.

Revulsion. A rejection; counterirritation.

Rigor. Sense of coldness accompanied by a superficial convulsive seizure. 
s.

Salicylated. Containing a given amount of salicylic acid.

Saliva. Spittle.

Saprophytic organisms. Those living in or on decaying organic matter.

Sarcoma. A form of cancer of rapid growth and occurring most often in the young.

Saturated. Fully filled; soaked.

Scapula. The shoulder-blade.

Scarify. To cut into.

Scarlet fever. An acute contagious disease of childhood giving rise to high fever, rapid pulse, a rose-red rash, and with a marked tendency to be followed by kidney disease.

Scultetus bandage. An overlapping many-tailed bandage dressing.

Secretions. Special substances thrown off by functionally active organs.

Sedative. Soothing; softening.

Septic. Relating to putrefaction or pus-germ infection.

Septic discharge. Purulent; containing pus germs.

Septic peritonitis. Inflammation of the lining membrane of the organs and cavity of the abdomen caused by the action of pus germs.

Septicemia. A severe form of blood poisoning in which both germs and their products are current in the blood.

Sequelæ. After-effects of disease.

Sequestrum. A dead mass, as a fragment of a dead bone.

Serum. The watery part of drawn blood separating on standing; the fluid in a blister.
Shock. The constitutional effect of a disease or injury.

Sinus. A disease tract or channel left after the discharge of a purulent collection.

Specific bacteria. Germs directly responsible for the given disease.

Sphincter muscle. Anatomical name for muscles whose actions are to close openings, as at the mouth and anus.

Spica. A spiral bandage done with a roller in a series of figure eights. Most used for the shoulder, groin, thumb, and great toe.

Spirilla. Spiral-shaped germs, as the spirillum of cholera (also called the comma bacillus).

Splenic fever. Disease due to the anthrax bacillus; wool-sorter's disease.

Spore. A germ seed.

Spotted fever. Epidemic cerebrospinal meningitis or cerebrospinal fever; a specific infectious disease of the membranes of the brain and spinal cord and accompanied by a peculiar dusky rash.

Sterilization. Act of rendering free from germs.

Sterilize. To kill all germ life.

Stethoscope. An instrument for listening to the flow of air or blood inside the body.

Stimulation. Arousing to greater action; urging.

Subcutaneous injection. One made beneath the skin.

Subnormal temperature. Degree of body heat below $98^{\circ} \mathrm{F}$.

Supine. Outstretched upon the back.

Suppression of urine. A condition in which the kidneys cease to act, no urine being formed. 
Suppuration. The last stage of inflammation, manifested by destruction of tissue with pus formation.

Suprapubic lithotomy. Cutting operation for stone in the bladder attacked from above.

Surgically clean. As nearly as is possible to be free from germ life.

Sutures. The material with which a surgeon sews; the stitches themselves.

Syncope. Sudden loss of power and consciousness; fainting.

\section{T.}

Tampon. A gauze or cotton plug; may have a string or tape attached for withdrawal.

Technic. The mode of working; plan or method of work.

Tepid. Moderately warm.

Tetanus. Lockjaw; a very dangerous germ disease characterized by locking of sets of muscles due to the presence of a poison developed by tetanus bacilli.

Therapeutics. The science of the application of medicines for the cure of diseases.

Thoracic cavity. The chest.

Toxicity. Degree of poison.

Toxin. Poison formed by germ life.

Trachelorrhaphy. Operation for the repair of a torn mouth of the womb.

Tracheotomy. Operation of cutting open the windpipe below the larynx for the purpose of admitting air to the lungs; done for closure of the upper air-passages.

Traumatic delirium. Brain exciteinent following serious body injury.
Trikresol. A refined mixture made from carbolic acid.

Tubercles. Local effects of the action of tubercle bacilli consisting of cheesy masses.

Tuberculosis. An infectious disease giving rise to general or local disorganization caused by the tubercle bacillus; consumption.

Tumefaction. A swelling.

Turpentine stupe. A piece of cloth or flannel dipped in spirits of turpentine after wringing out in hot water.

Tympanites. Distention of the abdomen caused by excess of gas in the stomach and bowels; may become drum-like.

\section{U.}

Ulcer. A sore, attended by discharge.

Ulceration. Superficial death of a part.

Ulcerative endocarditis. A severe inflammation of the heart, ending with destruction of the valve leaflets.

Undertaker's stretcher. A portable board and trestle inclined table upon which a corpse is laid during the process of embalming.

Uremic coma. Loss of consciousness and physical condition following the absorption of urinary poisons in the late stages of kidney disease.

Ureter. The tube leading from the kidney to the bladder. It is of the diameter of a goose quill and about sixteen inches in length.

Urethra. The water pipe from the bladder.

Urethral calibrator. An instrument for determining the size of the canal. 
Urination. The act of passing water.

Uterine appendages. The ovaries, Fallopian tubes, broad and other attaching ligaments of the womb.

Uterus. The womb; the hollow, pear-shaped pelvic organ which is destined to retain the child from the moment of its conception until the time of its expulsion at birth.

\section{V.}

Vaccination. Inoculation of cowpox lymph into the arm as a protection from small-pox.

Vacuum. Space in which there is no air.

Vagina. The female genital canal.

Vaginal discharge. A flow from the genital canal.

Vaginal hysterectomy. Removal of the womb through the lower genital canal.

Vascular. Pertaining to vessels.
Venesection. Bleeding; opening a vein to let out blood.

Venom. Animal poison.

Venous pressure. The weight and flow power of the blood stream in the veins.

Venules. Smallest branching veins. Vertex. The crown of the head; highest point of the skull.

Vestibule. The beginning of the female genital canal.

Virulence. Poison-strength.

Virulent. Highly poisonous; destructive.

Virus. Any form of organic poison.

Viscera. The contents of the large cavities of the body.

Viscosity. Stickiness.

Vulva. The external genitals, private parts, the female external organs of generation.

\section{W.}

Wound drainage. A method of providing for the escape of pus or serum drip from a wound. 


\section{INDEX}

AвDомen, infections of, after operation, 257

Abdominal cavity, apparatus for douching of, 226

operations, instruments for, I3I

Abscess, incision of, for drainage, 227

Absorbent cotton, 180

Accidents during operation, 275

Acclimatization, immunity, 39

Acids, mineral poisoning by, 230

Aconite poisoning, 230

Actinomycosis, communication of, to man, 22

Adhesive plaster, 93

figure-of- 8 of knee, 95

moleskin, 93

pelvic binder, 95

resin, 93

rubber, 93

strapping of ankle-joint, 96

of chest, 94

of joints, 95

of leg ulcers, 95

zinc oxid, 93

Aërobic bacteria, 34

Age, effect of, on bacteria, 34

Air, effect of, on bacteria, 34

Akoin anesthesia, I7I

Albumin water, 299

Alcohol as germicide, 60 rubs after fracture, IoI

Alimentary canal, entrance of bacteria in, 35

Allis' ether inhaler, ${ }^{5} 5^{2}$

Alypin anesthesia, I 7 I

Amphitheater, clinical, 243

Amputating knives, 132

Anaërobic bacteria, 34

Anesthesia, I44

care of bowels before, I44

of patient in, 147
Anesthesia, chloroform, I 55

conduction, I69

delayed poisoning in, 167

diet before, I 45

drugs before, I 45

endoneural, I69

ether, I50. See also Ether.

ethyl chlorid, 158

first stage, I 49

infiltration, 169

intrapharyngeal inhalation, $\mathrm{I} 60$

intratracheal insufflation, I6I

local, I68

cocain, I68

cracked ice and salt, I68

ethyl chlorid, I68

method of holding jaw in, ${ }_{54}$

nitrous oxid, 156 ether, 158

oil-ether colonic, I66

perineural, $\mathbf{1 6 9}$

physical examination before, I46

precautions in, I44

preparation for, I44

of mouth and teeth for, I45

rectal, I66

scopolamin-morphin, $\mathrm{x} 66$

second stage, I 49

special methods of, 160

spinal, I72. See -also Spinal anesthesia.

stages of, 148

third stage, I 49

vapor apparatus for, I $5 \mathrm{I}$

Anesthetic paralyses, postoperative, I67

Anesthetics, varieties of, I44

Anesthetist's supplies, I47, I48

Aneurysm needle, Deschamp's, 136

Ankle-joint, adhesive plaster strapping of, 96

Anoci-asşociation, 264 
Anthrax bacillus, discovery of, 20 discovery of bacterial nature of, 23

Antidotes, 230-232

for carbolic acid, 59

for corrosive sublimate, 57

Antimony tartrate poisoning, 230

Antisepsis, origin of, 22

Antiseptics, 53 abuses of, 63

Antiseptic solutions, 64 surgery, 20

Antistreptococcic serum in peritonitis, 273

therapeutic value of, $5 \circ$

Antitoxic theory of immunity, 4I

Antitoxin, cerebrospinal meningitis, 50

diphtheria, dose of, 49

process of making, 46 status of, 49

method of injecting, $5 \mathrm{I}$

reactions from, $5 \mathrm{I}$

streptococcus, preparation of, 47

tetanus, $5 \circ$

therapeutic action of, 47

tuberculosis, preparation of, 47

Antitoxins, 45

theory of, 45

Antituberculosis serum, $5 \mathrm{I}$

Antityphoid vacrine, 50

Apple water, 299

Argyrol as disinfectant, 61 as germicide, $6 \mathrm{I}$

Aristol as germicide, 63

Arrowroot gruel, 301

Arsenic poisoning, 230

Artificial respiration, 267

in surgical shock, 266

Asepsis in gynecologic examinations, 280

Aspirator, Potain's, I 37

Assistant nurses, duties of, at operation, 256

Atropin poisoning, 230

Autopsies, 306, 308

cleanliness in, 310

instruments, etc., for, 309

preparation of body for, 309

time for, 308

Auvard's self-retaining speculum, 138
BABCOCK's solution for spinal anesthesia, I77

Bacilli, 29

Bacillus aërogenes capsulatus, 43 anthrax, discovery of, 20 coli communis, 42 comma, discovery of, 25 melitensis, 27

of bubonic plague, discovery of, 26

of diphtheria, 44

discovery of, 25

of glanders, discovery of, 25

of influenza, discovery of, 26

of membranous croup, 44

of pneumonia, discovery of, 25

of tetanus, 43

of tuberculosis, 25,43

pyocyaneus, 43

typhoid, discovery of, 24

Back, figure-of- 8 bandage of, 76

Bacteria, 29

aërobic, 34

agents capable of destroying, 54

anaërobic, 34

as causes of disease, 28

conditions influencing growth of, 33

definition of, 28

distribution of, 17

effect of age on, 34

of air on, 34

of drying on, 34

of sunlight on, 33

entrance of, into alimentary canal, 35

into respiratory tract, 35

forms of, 28,29

incubation period of, 38

mode of entrance of, 34

pathogenic, 29

reproduction of, 32

by binary division, 32

by fission, 32

by sporulation, 32

sizes of, 28

soil required for, 34

Bacteriology, 17

history of, I7

progress in, 18

Baking treatment, 227

Balsam of Peru, 194 
Bandage, application of, 66

Barton's, 68

Christy knife for cutting, 67 demigauntlet dorsal, 84 palmar, 85

double crossed, of both eyes, 74

figure-of- 8 , of back and chest, 76

of head and neck, 74

Gibson's, 69

Liebreich's eye, 72

machine for, 65,66

materials for, 65

mitre box for cutting, 67

occipitofrontal, 7 I

of breast, compressor, 74

double, 75

suspensory, 74

of eye, crossed, 72

of finger, spiral, $8_{3}$ reverse, 84

of groin, descending spica, 86 double spica, 87

single spica, ascending, 85

of leg, figure-of- 8,88

of lower leg, spiral reverse, 80

of knee, figure-of- 8,87

of stump, recurrent, 87

of thumb, spica, 84

plaster-of-Paris, 98

application of, 98

removal of, 99

recurrent, 70

double head, $7 \mathrm{I}$

removal of, 68

rolling by hand, 65

scultetus, 92

shoulder, descending spica of, 79

spica, of shoulder, 77

to overlap, 67

to recur, 67

to reverse, 67

to secure, 68

Velpeau's, 78

Bandaging, 65

Barley gruel, 3 о I water, 299

Barton's bandage, 68

Basin, pus, Ir 2

Bath thermometer, 208

Beck's bismuth paste, I94

Bed arranged for childbirth, 234
Bed, ether, 284

Gatch, I 86

Bed-pan sterilizer, I I I

Beef broth, 304

essence, 304

juice, 305

Belladonna poisoning, 230

Bellocq's cannula, $27 \mathrm{I}$

Bichlorid of mercury as germicide, 56

Bier's hyperemia, 223

Bigelow's evacuator, 142

Bismuth paste, Beck's, I94

Bladder, care of, after operation, 258

irrigation of, 202

Blastomycetes, 29

Boiling water, sterilization with, 55

Bone gouge, I4I

Bone-cutting forceps, I4I

instruments, Macewen's, I4I

Bone-plating, instruments for, 139

Boric acid as germicide, 63

Bowels, care of, after operation, 258

Breast bandage, compressor, 74 double, 75

suspensory, 74

Breast-binder, Murphy, 236

Broth, beef, 304

chicken, 305

mutton, 305

Brushes, 184

Bubonic plague bacillus, discovery of, 26

Buck's extension, 97 mastoid curet, 126

Button suture, 216

CABINET for instruments, IO2

Cannula, Bellocq's, 27 I

Luer's trachea, I 27

Cantharides poisoning, 23I

Carbolic acid, 52

as germicide, 58

poisoning, 59,230

Cargile membrane, 188

Carotid arteries, instruments for ligation of, 129

Catgut, 190 chromicized, 192 iodin, I9I 
Catgut, sterilization of, 190

Catheter, Gouley's tunneled, I42 introduction of, 201 straps, 98

Catheterization, 200 cystitis from, 200

Catheters, glass, 200 sterilization of, 200

Catling's amputating knives, I32

Cautery, Paquelin, 220

Cerebrospinal meningitis, antitoxin in, $5^{\circ}$

cause of, 26

Cervix, instruments for dilation of, 135 for repair of, I 35

Chart, medical, I 2 I keeping of, II6

Chest, figure-of- 8 bandage of, 76 instruments for operations on. I 3 I strapping of. with adhesive plaster, 94

Chicken-broth, 305

Childbirth, bed arranged for, 234

Chlorid of lime as disinfectant, 6I

Chlorin-water poisoning, 23I

Chloroform anesthesia, I 55 poisoning, 23I

Christy knife for cutting bandages. 67

Chromicized catgut, I92

Cigarette-drain, I85

Cinnamon and milk, 3 or

Circulation, absence of, as sign of death, 307

Circumcision, instruments for, I 43

Clamps, Michel's, I94

Clinical thermometer, 228

Clothing for infant, 236 hospital, for patient, 250

Coaptation splints, roo

Cocain local anesthesia, I68 poisoning, treatment of, I7O

Cocci, 29, 30 morphology of, 30

pus-forming. 30 pyogenic. 30

Colchicum poisoning, 23I

Cold, therapeutic use of, 218

Coley's serum for malignant tumors, 50 reaction from, 5 I
[ Collins' retractor, I37

Collodion, 227

dressing, 183

Colon tube with funnel, $2 \mathrm{I} 3$

Comma bacillus, discovery of, 25

Compresses, IOI

Compressor bandage of breast, 74

Conduction anesthesia, 169

Conium poisoning, 23I

Continuous suture, 216

Copper sulphate poisoning, 23I

Cornstarch, 304

Corrosive sublimate as germicide, 56

poisoning, 23I

tablets, 57

Cotton, 227

absorbent. I8I

gloves. ISS

Waste. I SO

Cotton-gauze dressings, I 80

Counterirritation. 2I6

Cracked ice and salt for local anesthesia, I 68

Cracker gruel, 302

Creolin as germicide, 60

Crile's anoci-association, 264

Croton oil poisoning, 23I

Cupping, 2I 8

instruments for, 220

Curet, Buck's mastoid, I 26

DeRoalde's adenoid, I 28

Sims' sharp, I38

Thomas' dull, I38

Curetment of uterus, instruments for, $I_{35}$

Currant juice, 300

Cystitis from catheterization, 200

Cystoscopy, instruments for, I 43

DEATH, signs of, 306

absence of circulation, 307

of heart-beat, 307

of respiration, 307

hypostasis, 307

insertion of needle. 307

rigor mortis, 307

subcutaneous injection of ammonia, 307

temperature. 308

Delirium, traumatic, 266 
Deodorants, 53

DeRoalde's adenoid curet, $\mathrm{r} 28$

Deschamp's aneurysm needle, I36

Desmarre's lid retractor, I 30

Dewitt's appliance for rectal irrigation, 2 IO

Diet after childbirth, 235 after gynecologic operations, 298 before anesthesia, I45 milk, 300 recipes, 299

Diet-list after operation, 260-262

Digitalis poisoning, 23I

Dilator, Goodell-Lentz uterine, I40 Sinexon's nasal, I 27 uterine, I40

Diphtheria antitoxin, dose of, 49 process of making, 46 status of, 49

bacillus of, 44 discovery of, 25

Diplococci, 30

Diplococcus intracellularis meningitidis, 26 pneumonix, 43

Disease, bacteria as causes of, 28 in man, fungi connected with, 29

Dish, Petri, 247

Disinfectants, 53

Disinfection, 54 by steam, 55

Dorsal position, 29I

Douche, vaginal, 207 antiseptic, 208 apparatus for, 209

Draeger pulmotor, 269

Drainage, incision of abscess for, 227

of wounds, 185

postural, I86

Drainage-tubes, 185,188 care of, 187 rubber, preparation of, 187

Dressings, 180 collodion, 183 cotton-gauze, I8o

forceps for, 133

gauze for, 180

Sayre's, 93 table, 255

tray, instruments for, I 22

Dressing-room ledger, II 4
Dressing-room outfit, I84

Drop method of ether anesthesia, I 53

Dry cups, 2 I9

Drugs before anesthesia, I45

EAR operations, instruments for, I 25

Ecgonin, I69

Edebohls' dorsal posture, 292

Eifervescing lemonade, 300

Egg lemonade, 300

Eggs, 302

poached, 302

scrambled, 303

shirred, 303

Elaterium poisoning, 23I

Electricity, 228

Elevator, Langenbeck's periosteal, I 26

Emergency bundles, I 84 operations, 286

Emmett's angular bent scissors, I 33

Endoneural anesthesia, I69

Enema for tympanites, 214 stimulating, 2I 3

Enemata, purgative, 2 I4

Enteroclysis, 209

Ermold's tonsillotome, I 28

Esmarch's tourniquet, 270

Essence, beef, 304

Ether anesthesia, 150 cases suitable for, 150 closed inhaler for, I $5 \mathbf{I}$ drop method of, I 53

Gwathmey apparatus for, $\mathbf{I}_{52}$ open method, $15 \circ$ semi-open method, I5I vapor method of, I 52 bed, 284 inhaler, Allis', $\mathrm{I}_{52}$

Ethyl chlorid anesthesia, ${ }^{5} 8$ local, I68

tube, 158

Eucain anesthesia, I7 I

Evacuator, Bigelow's, I42

Examinations, gynecologic, 289, 290. See also Gynecologic examinations.

Extremities, instruments for operations on, I 35

Eye, bandage of, crossed, 72 
Eye, bandage of, Liebreich's, 72 double-crossed bandage of, 74 instruments for operations on, I 29

Fecal fistula, 275

Feeding of infant, 236 artificial, 237

Feet, care of nurses', 31 2

Fermentation fever after operation, 273

Finger cots, 189 spiral bandage of, 83

reverse bandage of, 84

Fire, destruction of germs with, 54

Fish, poisoning by, 232

Fission, 32, 33

Fistula, fecal, 275 urinary, 275

Flacherie, 24

Flaxseed tea, 3 or

Flesh, proud, 199

Flexner's serum for infantile palsy, $5 \mathrm{I}$

Flour ball, 302

Foot-bath, mustard, 21 7

Forceps, bone-cutting, I4I dressing, I33

Hudson's cranial rongeur, I 23 iris, 130

Linnartz's stomach clamp, I36

placental, I40

Richards' tonsil-holding, I 28

Segond's volsella, I34

Stone's tissue, 133

Tait's hemostat, I34

Formaldehyd as disinfectant, $6 \mathrm{I}$ generator, 62

Fountain syringe, 285

Fowler position, I 86

Fox's eye speculum, I30

Fracture, alcohol rubs after, Ior care of soft parts after, IOI

Fracture-box, Ioo

Fungi connected with disease in man, 29

GALL-BLADDER, instruments for operations on, I3 1

Gant's pile clamp, 143
Gastric lavage, 207

Gatch bed, I 86

Gauze for dressings, 180

iodoform, I8I

medicated, 180

packing, $\mathrm{I} 83$

pads, 179

sponges, $\mathrm{I} 78$

sublimate, 180

Generator, formaldehyd, 62

Genupectoral position, 292

Germ theory of disease, 20

Germicides, 52

abuses of, 63

chemical, 56

Gibson's bandage, 69

Gigli wire saw, I 23

Glanders bacillus, discovery of, 25

Glands of neck, instruments for removal of, I 29

Glass trays, II 2

Glovers' suture, 2I6

Gloves, 188

Goodell-Lentz uterine dilator, I40

Goiter, instruments for operation on, 129

Gouge, bone, I4I

Gouley's tunneled catheter, 142

Gowns, I84 operating, 244

Gram's method of staining, streptococcus, $3 \mathrm{I}$ solution, 3 I

Green soup, I96

Griffith's anesthetizing stethoscope, I 48

combined inhaler, $15^{8}$

wire-frame chloroform inhaler, I 55

Groin, descending spica of, 86 double spica of, 87 single spica of, ascending, 85

Gruel, arrowroot, 3 OI

barley, 301 cracker, 302

Guard, Stacke's, for facial nerve, I 26

Gwathmey apparatus for ether anesthesia, I52

Gynecologic examinations, 289, 290 asepsis in, 289

positions in, 290 
Gynecologic examinations, positions in, dorsal, 29I

Edebohls' dorsal, 292

genupectoral, 292

knee-chest, 292

latero-abdominal, 29I

lithotomy, 292

Sims', 29I

upright, 290

Walcher, 293

preparation for, 295

operations, 289

after-care, 297

asepsis in, 289

diet after, 299

HANDS, preparation of, 242

Harrington's solution as germicide, 60

formula for, $6 \mathrm{I}$

Hartmann's round tonsil punch, I 26

Head, figure-of- 8 bandage of, 74 nurse, duties of, at operation, 253 operations, instruments for, I 22 operations on, 276

Heat, effect of, on spores, 33 sterilization by, 55

therapeutic use of, 218

Hemorrhage after operation, 269 symptoms of, 270 treatment of, 270

Hemorrhoids, instruments for operations on, I43

Hemostat forceps, Tait's, I34

Hernia, postoperative, 274

Herniotomy, instruments for, I3I

High-tension steam, sterilization with, 55

History of patient, taking, I 16

Hoffman's uterine irrigator, I38

Horsehair, 193

Horsley's wax, I96

Hospital clothing for patient, 249

Hot air, disinfection with, 55 treatment, 227

Hudson's cranial rongeur forceps, I 23

trephine, I 24

Hydrocyanic acid poisoning, 230

Hydrogen dioxid as disinfectant, 6I
Hydrophobia, Pasteur treatment for, 25

Hygiene for nurses, 3 II

Hyperemia, active, 198

Bier's, 223

Hyphomycetes, 29

Hypodermic injection, 21 5

method of, 2I5

Hypodermoclysis, 222

apparatus for, 225

Hyoscyamus poisoning, 23I

Hypostasis, 307

Hysterectomy, vaginal, 275

ICE-BAG, I98

Ichthyol, I94

Illuminating gas poisoning, $23 \mathrm{I}$

Immunity, 38

acclimatization, 39

acquired, 39

artificial, 40

natural, 39

phagocytosis theory of, 40, 4I

racial, 39

Imperial drink, 300

Incision, deep, 227

of abscess for drainage, 227

Infant, care of, 235

clothing for, 236

feeding of, 236

artificial, 237

nursing of, 236

Infiltration anesthesia, I69

Inflammation, causes of, 199

definition of, 197

function of, 198

phenomena of, 197

Influenza bacillus, discovery of, 26

Infusion, intravenous, 221 saline, 224

Inhalation anesthesia, intrapharyngeal, r6o

Inhaler, chloroform, Griffith's, I55

Injection, hypodermic, 215 rectal, 209

Insanity, postoperative, 275

Instruments, cabinet for, $\mathrm{IO}_{2}$

care of, 102

for dressing tray, 122

for operations, abdominal, I3I

bone-plating, I39 
Instruments for operations, cir- $\mid$ Iris forceps, ${ }_{3} 30$ cumcision, I 43

curetment of uterus, I35

cystoscopy, I43.

dilation of cervix, I35

glands of neck, removal of, I 29

laminectomy, I24

ligation of carotid arteries, 129

on chest, I3I

on ear, I25

on extremities, 135

on eyes, I 29

on gall-bladder, I3I

on goiter, I 29

on head, I 22

on hemorrhoids, 143

on hernia, I3I

on intestines, I3I

on kidney, I35

on liver, I $3 \mathrm{I}$

on male genital organs, I 39

on nose, I 25

on stomach, I3I

on throat, I 25

on uterus, 135

osteoplastic grafting, I39

perineorrhaphy, I35

removal of tongue, I 29

repair of cervix, I35

resection of rectum, I43

submucous resection, I 28

list of, I 22

required for operations, II 6

roll, II9

sterilization of, Io6

trays for, IIo

Insufflation anesthesia, intratracheal, I6r apparatus for, I62-I64 technic of, I 65

Interrupted suture, 216

Intestinal obstruction after operation, 274

operations, instruments for, I3I

Intradermic injection, 215

Intravenous infusion, 22I

Iodin catgut, I9I poisoning, 232

tincture of, as germicide, 57

Iodoform as germicide, 62

gauze, I8I

poisoning from, 62

knife, I30

scissors, I30

spatula, I30

Irrigation of bladder, 202

of wounds, apparatus for, 225 rectal, 209

Irrigator, 253

Hoffman's uterine, I39

Invalid's soup, 304

JACKSON's laryngoscope, I65

Jelly, tapioca, 302

Joints, adhesive plaster strapping of, 95

KANGAROO tendon, I92

Kelly's curved round needles, I34 retractor, I37

Kidney, instruments for operation on, I35

Kirchner's theory of disease, I8

Kit, surgeon's, II6 contents of, II8 packing of, II 8

Knee bandage, figure-of- $8,87,95$

Knee-chest position, 292

Knife, iris, I30

Koch's circuit to prove specific pathogenic powers of microbe, 36

discovery of tubercle bacillus, 25 tuberculin, 26

Koumiss, 300

LABARRAQUE'S solution, 64

Labor, diet after, 235 nurses' duties after, 233 before, 233

Laborde's method of artificial respiration, 269

Laminectomy, instruments for, I 24

Lange's theory of disease, I8

Langenbeck's periosteal elevator, I 26

Laryngoscope, Jackson's, 165

Latero-abdominal position, 29 I

Lavage, gastric, 207

Lead salts, poisoning by, 232 
Ledger, dressing-room, II4 operating-room, II 2 -I I 5

Leeching, 220

Leg, bandage of, figure-of- 8,88 lower, spiral reverse of, 88 ulcers, adhesive plaster strapping of, 95

Lemonade, 300

effervescing, 300 egg, 300

Lentz's cranial chain tourniquet, I 23

Leprosy, discovery of bacterial origin of, 24

Liebreich's eye bandage, 72

Ligatures, 190

Lime-water, 299

Liniments, 219

Linnartz's stomach clamp forceps, I 36

Lister's antiseptic surgery, 20

Liston's amputating knives, I32

Lithotomy position, 283,292

Lithotrite, 142

Liver, instruments for operations on, $\mathrm{r} 3 \mathrm{I}$

Live steam, sterilization with, 55

Lobelia poisoning, 232

Local anesthesia, I68 alypin, I7I

akoin, I7I

eucain, I7I

novocain, I 70

phenol, I7I

Schleich's solutions for, I 70 tropacocain, I7I

with cracked ice and salt, I68

Lombard nasal tube for ether anesthesia, I $5 \mathrm{I}$

Luer's hypodermic syringe, I46 trachea cannula, I 27

Lysol as germicide, 60

MACENEN'S bone-cutting instruments, I4I

Malaria, cause of, 27

Male genital organs, instruments for operations on, I39

Malta fever, cause of, 26

Marine sponges, I79.

Massage, 227
Mayo's operating scissors, I33 scalpel, 132

Mayo-Simpson's self-retaining retractor, 136

Medical chart, I i I

Medicated gauze, I8o

Membrane, cargile, I 88

Membranous croup, bacillus of, 44

Meningitis, cerebrospinal, cause of, 26

Mercury bichlorid as germicide, 56 poisoning from, 57

Metchnikoff's theory of phagocytosis, 4I

Metric system, 64

Michel's clamps, I94

Micrococcus lanceolatus, 43

Milk and cinnamon, 301 diet, 300

mixtures, 237, 238 toast, 303

Mineral acids, poisoning by, 230

Miter box for cutting bandages, 67

Molds, 29

Moleskin adhesive plaster, 93

Montgomery straps, 98

Morphin poisoning, 232

Mosetig-Moorhof wax, 195

Mosquito transmission of malaria, 27

of yellow fever, 26

Murphy breast-binder, 236 button, I36

drop method of rectal irrigation, 210

Mustard foot-bath, 2 I 7 plaster, 2I7

Mutton-broth, 305

NECK, figure-of-8 bandage of, 74 operations on, 277

Needles, I 22 insertion of, as sign of death, 307 Kelly's curved round, I34

Needle-holder, Noble's improved Reiner's, I34

Nitrous oxid anesthesia, ${ }_{5} 6$ administration of, 157 apparatus for, ${ }_{15} 6$ ether anesthesia, 158 
Noble's improved Reiner's needleholder, I34

Nose, instruments for operations on, I 25

Novocain anesthesia, 170

Nozzle, vaginal douche, 209

Nurses' conduct in sick-room, 3I4 feet, care of, 3I 2

hygiene for, 3 II

life, personal conduct of, 3 II periods for relaxation, $3 \mathrm{I} 4$ personal appearance, 3 I4

conduct of, 3 IO preparation of, for operation, 24 I rewards, success of, 278

Nursing of infant, 235 obstetric, 233

Nux vomica, poisoning from, 232

OBSTETRIC nursing, 233

Occipitofrontal bandage, $7 \mathrm{I}$

Oil-ether colonic anesthesia, I66

Ointments, 219

Operating gown, 244

Operating-room, 245

care of, 102

duties of nurse in, 24I

equipment of, I05

ledger, I I 2-I I 5

preparation of, 239, 240

spectator's dress for, 246

Operating-table, 274

Operations, 239

accidents during, 275

arranging patient for, 253

blank. I 20

care of bladder and bowels after, 258

patient after, 256

diet-list after, $260-262$

dress for, 242

duties of assistant nurses at, 256 of head nurse at, 255

emergency, preparations for, 286 fermentation fever after, 273

gynecologic, 280. See also Gynecologic operations.

hemorrhage after, 260. See also Hemorrhage after operations.

infections of abdomen after, 257 in private practice, 278
Operations in private practice, articles required for, 284 , 285

giving anesthetic in, 286

operating-table for, $28 \mathrm{I}, 282$ preparations for, 280

instruments for II6, I22-I43.

See also Instruments for operations.

intestinal obstruction after, 274 of election, 240

of emergency, 240

of expediency, 239

of necessity, 239

on head, 276

on neck, 277

peritonitis after, 272

preparation of field of, $25 \mathrm{I}$

patient for, 250

day before, $25^{\circ}$

on day of, $25^{2}$

sequelæ of, 263

shock after, 263

sinus after, 275

special, 276

tympanites after, 273

varieties of, 239

visitors after, 260

Opium poisoning, 232

Orangeade, 300

Osteoplastic grafting, instruments for, I39

Oxalic acid as germicide, 63 poisoning, 232

PAcking, gauze, I 83

Pads, gauze, 179

Pagenstecher sutures, I93

Palmer bandage, demigauntlet, 84

Panado, 303

Paquelin cautery, 220

Paralysis, infantile, Flexner's serum in, 51

Paralyses, postoperative anesthetic. I67

Paste, Unna's, I05

Pasteur's germ theory of disease, 20 treatment of hydrophobia, 25

Patient, arranging of, for operation, 253

care of, after operation, 256 
Patient, hospital clothing for, 250 preparation of, for operation, 250 day before, 250 on day of, 252

taking history of, II 6 transportation of, 249

Pathogenic bacteria, 29

Pelvic binder, adhesive plaster, 95

Perineorrhaphy, instruments for, I 35

Perineural anesthesia, I69

Peritonitis after operation, 272 antistreptococcic serum for, 273

treatment of, 272

Personal conduct of nurse's life, 3 II

Petri dish, 247

Phagocytes, 40

Phagocytosis, 40

Phenol anesthesia, I7I

Phosphorus poisoning, 232

Pile-clamp, Gant's, I43

Pébrine, 24

Plasmodium malariæ, 27

Plaster, 227

adhesive, 93

Plaster-of-Paris bandage, 98 application of, 98 removal of, 98 splints, roo

Pneumococcus, 43 discovery of, 25

Pneumonia, bacillus of, 43 mode of infection in, 35

Poached eggs, 302

Poisoning from carbolic acid, 59 cocain, treatment of, I 70 from corrosive sublimate, 57 from iodoform, 62 from mercury bichlorid, 57

Poisons and antidotes, $230-232$

Postoperative hernia, 274 insanity, 275

Postural drainage, 186

Potain's aspirator, I 37

Potash poisoning, 232

Potassium permanganate as germicide, 59

Private practice, operations in, 278

Proctoclysis, continuous, apparatus for, 2 II

method of, 2I 2
Proud flesh, ro9

Pudding, tapioca, 304

Puerperal fever, Semmelweis' theory of, 23

Pulmotor, Draeger, 269

Punch, Hartmann's round tonsil, I 26

Puncturation, 226

Puncture, deep, 227

Purgative enemata, 2I4

Pus, 109 basin, I 2

Putrefaction, cause of, 29

Pyogenic cocci, 30

Reaction. See Test.

Recipes, diet, 299

Rectal anesthesia, I66 injections, 209 irrigation, 209

Rectum, examination of, 293 instruments for resection of, I43

Reiner's needle-holder, Noble's improved, I34

Rennet, 303

Resin plaster, 93

Respiration, absence of, as sign of death, 307 artificial, 267

Respiratory tract, entrance of bacteria into, 35

Retractor, Buck's mastoid, I 26

Collins', I37

Desmarre's lid, I 30

Kelly's, I 37

Mayo-Simpson's self-retaining, I36

Volkmann, I 37

Rice, boiled, 303

plain, 303

Richard's tonsil-holding forceps, I 28

Rigor mortis, 307

Rochester sterilizer, Io8

Rongeur forceps, Hudson's cranial, I 23

Rubber adhesive plaster, 93

dam, I84

sterilization of, $\mathrm{I} 88$

drainage-tubes, preparation of, 187 
Rubber-glove solution, I89 mesh, is 4 tissue, $\mathrm{I}_{4}$

Rubber gloves, I 88

SALINE infusion, intravenous, 224 solution, normal, 224 .

Saprol, 59

Saprophytes, 29

Sarcinæ, 30

Saw, Gigli mire, I 23

Sayre's dressing, 03

Scalpel, Mayo's, I32

Scarification, 226

Schizomycetes, 29

Schleich's solutions for local anesthesia, I69, I70

Scissors, curbed, I33

Emmett's angular bent, I 33

iris, $\mathrm{I} 30$

Mayo's operating, I33

Scopolamin-morphin anesthesia, I66

Scrambled eggs, 303

Scultetus bandage, 92

Segord's volsella forceps, I34

Semmelweis' theory of puerperal fever, 23

Sequelæ of operations, 263

Serum therapy, 44, 45

Sheets, 184

Shirred eggs, 303

Shock, surgical, age factor in, 264 artificial respiration in, 266 mental condition in, 265 susceptibility to, 264 symptoms of, 265 temperature in, 265 treatment of, 265

Shotted suture, $2 \mathrm{I} 6$ :

Shoulder, spica bandage of, 77 descending, 79

Signis of death, 306. See also Death, signs of.

Silk ligatures, I92

Silkworm-gut, I93

Silver nitrate poisoning, 232

Sims' position, 291

sharp curet, I 38

speculum, I 38

Sinus after operation, 275
Sinexon's nasal dilator, I 27

Sleep, twilight, I66

Slings, 92

Snare, tonsil, I 27

Soap, green, 196

Soda salts, poisoning by, 232

Solutions, antiseptic, 64

Sound, Simpson's uterine, I 40

Soup, invalid's, 304

tapioca, 302

toast, 301

Sozal, 59

Spatula, iris, I30

Speculum, Auvard's self-retaining, I 38

Fox's eye, I30

Sims', I 38

Spice-plasters, 218

Spinal anesthesia, $I 72$

apparatus for, $\mathrm{I} 72$

Babcock's solution for, I 77

contra-indications to, 177

points for injection in, 173

postoperative treatment, 177

steps of, 175, I 76

technic of, I 74

Spirilli, 29

Spirochæta pallida, 44 discovery of, 27

Splenic fever, discovery of bacterial nature of, 23

Splints, 99

coaptation, Ioo

plaster-of-Paris, I00

Sponges, gauze, I 78

keeping count of, 254

marine, I79

Spores, effect of heat on, 33

formation of, 32

resistance of, 33

Sporulation, 32

Spotted fever, cause of, 26

Stacke's guard for facial nerve, $\mathbf{I} 26$

Staphylococci, 30 demonstration of, $3 \mathrm{I}$

Staphylococcus epidermidis albus, 42

pyogenes albus, 42

aureus, 30,42

citreus, 43

Steam, disinfection by, 55

Stegomyia fasciata, 26 
Sterilization, 54, I05

by heat, 55

fractional, 55

intermittent, 55

methods of, IO2

of catgut, I90

of instruments, I06

of.rubber dam, ISS

with boiling water, 55

Sterilizer, 104

bed-pan, III

Rochester, I08

Sterilizing outfit, I09

room, 107, IIO

Stethoscope, 306

Griffith's anesthetizing, I4 8

Stomach-contents, examination of, 205

instruments for operations on, I3I

tube, 206

method of passing, 205

Stone's tissue forceps, I33

Stone-searcher, Thompson's, I42

Stramonium poisoning, 230

Straps, catheter, 98 Montgomery, 98

Streptococci, 30

Gram method of staining, 3I antitoxin preparation of, 47

Streptococcus lanceolatus, 43 pyogenes, 42

Stretcher, house, I03 wheeled, IO3

Strychnin poisoning, 232

Stump, recurrent bandage of, 87

Stupe, turpentine, 2I7

Sublimate gauze, 180

Submucous resection, instruments for, I 28

Sunlight, effect of, on bacteria, 33

Superheated steam, sterilization with, 55

Surgeon's kit, I 6 contents of, II 8 packing of, II 8

Surgery, antiseptic, 20 objects of, 239

Surgical applications, 194 procedures, minor, 2I5 technic, 65

Suspensory bandage of breast, 74
Sutures, I90

button, 2 I 6

continuous, 2 I 6

glovers', 2 I6

horsehair, I93

interrupted, 2 I6

Pagenstecher, I92

shotted, 2 r6

varieties of, 2 I 6

wire, I93

Suturing clamps, 2 I 6

Sylvester's method of artificial respiration, 267, 268

Sypnilis, organism producing, 27 ,

44

Syringe cup, 277

fountain, 285

household bulb, 285

Luer's hypodermic, I46

nasal and ear, 277

TAIT's hemostat forceps, I34

Tamarind water, 300

Tampons, vaginal, I8I, I82

Tapioca jelly, 302 pudding, 304

soup, 302

Tea, flaxseed, 3 oI

Technic, surgical, 65

Temperature as sign of death, 308 in surgical shock, 265

Tendon, kangaroo, 192

Test, tuberculin, 52

Von Pirquet, 52

Wassermann, $5^{\mathrm{I}}$

Widal, 52

Test-breakfast, 205

Tetanus antitoxin, 50

bacillus of, 43

Tetrads, 30

Thermocautery, 229

Thermometer, bath, 208 clinical, 228

Toast, milk, 303

soup, 30I

water, 30 I

Thomas' dull curet, I3 8

Thompson's stone-searcher, I42

Throat, instruments for operations in, 125

Thumb, bandage of, spica, 84 
Thymol-iodid as germicide, 63

Tincture of green soap, 196

Tobacco poisoning, 232

Tongue, instruments for, removal of, I 29

Tonsil snare, $\mathrm{I} 27$

Tonsillotome, Ermold's, I 28

Tourniquet, Esmarch's, 270 Lentz's cranial chain, I 23

Towels, 184

Transportation of patient, 249

Traumatic delirium, 266

Trays, glass, II 2 instrument, IIO

Trendelenburg position, 283,296

Trephine, Hudson's cranial, I 24

Treponema pallidum, discovery of, 27

Tropacocain anesthesia, I $7 \mathrm{I}$

Tuberculin, Koch's, 26 test, 52

Tuberculosis antitoxin, preparation of, 47

bacillus of, 43 discovery of, 25

climatic control of, 37

mode of infection in, 35

sites of infection in, 36

tests for presence of, 52

Turpentine stupe, 217

Twilight sleep, I66

Tympanites after operation, 273 enema for, 2I4

Typhoid bacillus, discovery of, 24 mode of infection in, 35

UNNA's paste, I95

Upright position, 290

Urinary fistula, 275

Uterus, instruments for operations on, $\mathrm{I} 35$
VACCINATION, 2I9

Vaccine, antityphoid, $5^{\circ}$

Vaginal douche, 207

antiseptic, 208

apparatus for, 209

nozzle, 209

hysterectomy, 275

tampons, I8I, I82

Vapor apparatus for anesthesia, I $5 \mathrm{I}$ method of ether anesthesia, 152

Velpeau's bandage, 78

Venesection, 22I

Visitors after operation, 260

Volkmann retractor, I 37

Volsella forceps, Segond's, I34

Von Pirquet test, 52

Vulva, virginal, 20I

WALCHER position, 293

Wassermann test, 5 I

Water, 299

albumin, 299

apple, 299

barley, 299

coil, I08

lime-, 299

tamarind, 300

toast, 301

Wax, Horsley's, I96

Mosetig-Moorhof, 195

Wecker's iris scissors, I3O

Wet cups, 220

Widal test, 52

Wire sutures, 193

YeAsts, 29

Yellow fever, method of transmission, 26

ZINC oxid adhesive plaster, 93 salts, poisoning by, 232

Zoöglea, 30 




\section{Books for Nurses}

Pueushate Br

\section{W. B. SAUNDERS COMPANY \\ West Washington Square \\ Philadelphia}

London: 9, Henrietta Street, Covent Garden

\section{Sanders' Nursing a NEW WORK}

Miss Sanders' new book is undoubtedly the most complete and most practical work on nursing ever published. Everything about every subject with which the nurse should be familiar is detailed in a clean cut, definite way. There is no other nursing book so full of good, practical information-information you need.

Modern Methods in Nursing. By Georgiana J. SAnders, formerly Superintendent of Nurses at Massachusetts General Hospital. I2mo of 881 pages, with 227 illustrations.

Cloth, \$2.50 net.

\section{Dunton's Occupation Therapy}

\section{JUST ISSUED}

Dr. Dunton gives those forms likely to be of most service to the nurse in private practice. You get chapters on puzzles, reading, physical exercises, card games, string, paper, wood, plastic and metal work, weaving, picture puzzles, basketry, chair caning, bookbinding, gardening, nature study, drawing, painting, pyrography, needlework, photography, and music.

Occupation Therapy for Nurses. By William Rush Dunton, Jr., M. D., Assistant Physician at Sheppard and Enoch Pratt Hospitals, Towson, Md. I2mo of 240 pages, illustrated. Cloth, \$1.50 net. 


\section{Stoney's Nursing}

Of this work the American Journal of Nursing says: "It is the fullest and most complete and may well be recommended as being of great general usefulness. The best chapter is the one on observation of symptoms which is very thorough." There are directions how to improvise everything.

Practical Points in Nursing. By EMILY M. A. STONEY, formerly Superintendent of the Training School for Nurses in the Carney Hospital,

South Boston, Mass. I2mo, 495 pages, illustrated. Cloth, \$r.75 net.

\section{Stoney's Materia Medica}

NEW (3d) EDITION

Stoney's Materia Medica was written by a head nurse who knows just what the nurse needs. American Medicine says it contains "all the information in regards to drugs that a nurse should possess."

Materia Medica for Nurses. By EMILY M. A. STONEY, formerly Superintendent of the Training School for Nurses in the Carney Hospital, South Boston, Mass, Immo volume of 300 pages. Cloth, $\$ 1.50$ net.

\section{Stoney's Surgical Technic}

NEW (3d) EDITION

The first part of the book is dovoted to Bacteriology and Antiseptics; the second part to Surgical Technic, Signs of Death, Bandaging, Care of Infants, etc.

Bacteriology and Surgical Technic for Nurses. By EMILY M. A. Stoney. Revised by Frederic R. Griffith, M. D., New York. I2mo volume of 3 II pages, fully illustrated. Cloth, \$r.50 net.

\section{Goodnow's First-Year Nursing zd EDIrIoN}

Miss Goodnow's work deals entirely with the practical side of first-year nursing work. It is the application of text-book knowledge. It tells the nurse how to do those things she is called upon to do in her first year in the training school-the actual ward work.

First-Year Nursing. By MinNiE GoOdNOW, R. N., formerly Superintendent of the Women's Hospital, Denver.

12 mu of 354 pages, illustrated.

Cloth, \$r.5o net. 


\section{Aikens' Hospital Management}

This is just the work for hospital superintendents, trainingschool principals, physicians, and all who are actively interested in hospital administration. The Medical Record says: "Tells in concise form exactly what a hospital should do and how it should be run, from the scrubwoman up to its financing."

Hospital Management. Arranged and edited by Charlotte A. AIKenS, formerly Director o. Sibley Memorial Hospital, Washington, D. C. I2mo of 488 pages, illustrated. Cloth, $\$ 3.00$ net

\section{Aikens' Primary Studies}

NEW (3d) EDITION

Trained Nurse and Hospital Review says: "It is safe to say that any pupil who has mastered eren the major portion of this work would be one of the best prepared first year pupils who ever stood for examination."

Primary Studies for Nurses. By Charlotte A. Aikens, formerly Director of Sibley Memoria! Hospital, Washington, D. C. I2mo of 47 I pages, illustrated.

Cloth, \$r.75 net.

\section{Aikens' Training-School Methods and the Head Nurse}

This work not only tells how to teach, but also what should be taught the nurse and how much. The Medical Record says: "This book is original, breezy and healthy."

Hospital Training-School Methods and the Head Nurse. By CHARLotTe A. Aikens, formerly Director of Sibley Memorial Hospital, Washington, D. C. I2me of 267 pages. Cloth, \$r.50 net.

\section{Aikens' Clinical Studies}

NEW (2d) EDITION This work for second and third year students is written on the same lines as the author's successful work for primary students. Dietetic and Hygienic Gazette says there "is a large amount of practical information in this book."

\footnotetext{
Clinical Studies for Nurses. By Charlotte A. Aikens, formerly Director of Sibley Memorial Hospital, Washington, D. C. I2mo of 569 pages, illustrated Cloth, \$2.00 net
} 


\section{Bolduan and Grund's Bacteriology}

The authors have laid particular emphasis on the immediate application of bacteriology to the art of nursing. It is an applied bacteriology in the truest sense. A study of all the ordinary modes of transmission of infection are included.

Applied Bacteriology for Nurses. By Charles F. BOLduan, M.D., Assistant to the General Medical Officer, and MARIE GRUND, M.D., Bacteriologist, Research Laboratory, Department of Health, City of New York. I2mo of 166 pages, illustrated.

Cloth, \$r.25 net.

\section{Fiske's The Body}

A NEW IDEA

Trained Nurse and Hospital Review says "it is concise, wellwritten and well illustrated, and should meet with favor in schools for nurses and with the graduate nurse."

Structure and Functions of the Body. By Annette Fiske, A. M., Graduate of the Waltham Training School for Nurses, Massachusetts. I2mo of 221 pages, illustrated.

Cloth, \$r.25 net

\section{Beck's Reference Handbook NEw (3d) EDItToN}

This book contains all the information that a nurse requires to carry out any directions given by the physician. The Montreal Medical Journal says it is "cleverly systematized and shows close observation of the sickroom and hospital regime."

A Reference Handbook for Nurses. By AMANDA K. BECK, Grad= uate of the Illinois Training School for Nurses, Chicago, III, $32 \mathrm{mo}$ volume of 244 pages. Bound in flexible leather, $\$ \mathrm{I}_{2} 25$ net.

\section{Roberts’ Bacteriology \& Pathology}

This new work is practical in the strictest sense. Written specially for nurses, it confines itself to information that the nurse should know. All unessential matter is excluded. The style is concise and to the point, yet clear and plain. The text is illustrated throughout.

Bacteriology and Pathology for Nurses. By JAY G. ROBERTS, Ph. G.。 M. D., Oskaloosa, lowa. r2mo of 206 pages, illustrated. \$r.25 net. 


\section{DeLee's Obstetrics for Nurses}

Dr. DeLee's book really considers two subjects-obstetrics for nurses and actual obstetric nursing. Trained Nurse and Hospital Review says the "book abounds with practical suggestions, and they are given with such clearness that they cannot fail to leave their impress."

Obstetrics for Nurses. By JosePh B. DeLeE, M. D., Professor of Obstetrics at the Northwestern University Medical School, Chicago. r2mo volume of 508 pages, fully illustrated. Cloth, \$2.50 net.

\section{Davis’ Obstetric \& Gynecologic Nursing}

\section{NEW (4th) EDITION}

The Trained Nurse and Hospital Review says: "This is one of the most practical and useful books ever presented to the nursing profession." The text is illustrated.

Obstetric and Gynecologic Nursing. By EdwaRD P. Davis, M. D., Professor of Obstetrics in the Jefferson Medical College, Philadelphia. I2mo volume of 480 pages, illustrated. Buckram, \$r.75 net.

\section{Macfarlane's Gynecology for Nurses}

\section{NEW (2d) EDITION}

Dr. A. M. Seabrook, Woman's Hospital of Philadelphia, says: "It is a most admirable little book, covering in a concise but attractive way the subject from the nurse's standpoint."

A Reference Handbook of Gynecology for Nurses. By CATHARINE MaCfarlane, M. D., Gynecologist to the Woman's Hospital of Philadelphia. $32 \mathrm{mo}$ of ${ }^{156}$ pages, with 70 illustrations. Flexible leather, $\$ 1.25$ net.

\section{Asher's Chemistry and Toxicology}

Dr. Asher's one aim was to emphasize throughout his book the application of chemical and toxicologic knowledge in the study and practice of nursing. He has admirably succeeded.

rzmo of rgo pages. By Philip Asher, PH. G., M. D., Dean and Professor of Chemistry, New Orleans College of Pharmacy. Cloth, $\$ 1.25$ net. 


\section{Aikens' Home Nurse's Handbook}

The point about this work is this: It tells you, and shows you just how to do those little things entirely omitted from other nursing books, or at best only incidentally treated. The chapters on "Home Treatments" and "Every-Day Care of the Baby," stand out as particularly practical.

Home Nurse's Handbook. By Charlotte A. Aikens, formerly Director of the Sibley Memorial Hospital, Washington, D. C. r2mo of 276 pages, illustrated.

Cloth. \$r.50 net

\section{Eye, Ear, Nose, and Throat Nursing}

This book is written from beginning to end for the nurse. You get antiseptics, sterilization, nurse's duties, etc. You get anatomy and physiology, common remedies, how to invert the lids, administer drops, solutions, salves, anesthetics, the various diseases and their management. New (2d) Edition.

Nursing in Diseases of the Eye, Ear, Nose and Throat. By the Committee on Nurses of the Manhattan Eye, Ear and Throat Hospital. r2mo of 29 I pages, illustrated.

Cloth, \$r.50 net

\section{Paul's Materia Medica}

NEW (2d) EDITION

In this work you get definitions-what an alkaloid is, an infusion, a mixture, an ointment, a solution, a tincture, etc. Then a classification of drugs according to their physiologic action, when to administer drugs, how to administer them, and how much to give.

A Text-Book of Materia Medica for Nurses. By George P. PAul,M.D., Samaritan Hospital, Troy, N. Y. I2mo of 282 pages. Cloth, $\$$ r. 50 net

\section{Paul's Fever Nursing}

NEW (3d) EDITION

In the first part you get chapters on fever in general, hygiene, diet, methods for reducing the fever, complications. In the second part each infection is taken up in detail. In the third part you get antitoxins and vaccines, bacteria, warnings of the full dose of drugs, poison antidotes, enemata, etc.

Nursing in the Acute Infectious Fevers. By GeORGe P. PAUL, M. D. I $2 \mathrm{mo}$ of 275 pages, illustrated.

Cloth, \$r.oo net 


\section{McCombs' Diseases of Children for Nurses}

NEW (2d) EDITION

Dr. McCombs' experience in lecturing to nurses has enabled him to emphasize just those points that nurses most need to know. National Hospital Record says: "We have needed a good book on children's diseases and this volume admirably fills the want." The nurse's side has been written by head nurses, very valuable being the work of Miss Jennie Manly.

Diseases of Children for Nurses. By RoBert S. MCCOMBS, M. D., Instructor of Nurses at the Children's Hospital of Philadelphia. Izmo of 470 pages, illustrated.

Cloth, \$2.00 net

\section{Wilson's Obstetric Nursing NEW(2d) EDITION}

In Dr. Wilson's work the entire subject is covered from the beginning of pregnancy, its course, signs, labor, its actual accomplishment, the puerperium and care of the infant. American Joumal of Obstetrics says: "Every page empasizes the nurse's relation to the case."

A Reference Handbook of Obstetric Nursing. By W. REYNOLDS Wilson, M.D., Visiting Physician to the Philadelphia Lying-in Chatty. 32 mo of 355 pages, illustrated.

Flexible leather, $\$ 1.25$ net.

\section{American Pocket Dictionary NEw (9th) EDITION}

The Trained Nurse and Hospital Review says: "We have had many occasions to refer to this dictionary, and in every instance we have found the desired information."

American Pocket Medical Dictionary. Edited by W. A. Newman Dorlánd, A. M., M. D., Loyola University, Chicago. Flexible leather, gold edges, \$r.oo net; with patent thumb index, \$r.25 net.

\section{Lewis' Anatomy and Physiology $\begin{gathered}\text { THIRD } \\ \text { EDITION }\end{gathered}$}

Nurses Joarnal of Pacific Coast says "it is not in any sense rudimentary, but comprehensive in its treatment of the subjects." The low price makes this book particularly attractive.

Anatomy and Physiology for Nurses. By LeRoy Lewis, M.D., Lecturer on Anatomy and Physiology for Nurses, Lewis Hospital, Bay City, Mich. I2mo of 326 pages, I50 illustrations. Cloth, \$1.75 net. 


\section{Böhm \& Painter's Massage}

The methods described are those employed in Hoffa's Clinic -methods that give results. Every step is illustrated, showing you the exact direction of the strokings. The pictures are large. You get the technic used in Professor Hoffa's Clinic.

Octavo of $9^{1}$ pages, with 97 illustrations. By МАХ ВОНМ, М. D., Berlin, Germany. Edited by Charles F. PAinter, M. D., Professor or Orthopedic Surgery, Tufts College Medical School, Boston.

Cloth, $\$ 1.75$ net

\section{Grafstrom's Mechano-therapy \\ SECOND}

Dr. Grafstrom gives you here the Swedish system of mechanotherapy. You are given the effects of certain movements, gymnastic postures, medical gymnastics, general massage treatment, massage for the various conditions. The illustrations are full-page line drawings.

Mechanotherapy (Massage and Medical Gymnastics). By AxEL V. Grafstrom, B. Sc., M. D., Attending Physician Gustavus Adolphus Orphanage, Jamestown, New York. 16 mo of 200 pages.

Cloth, \$I.25 net

\section{Friedenwald and Ruhrah's Dietetics for} Nurses

NEW (3d) EDITION

This work has been prepared to meet the needs of the nurse, both in training school and after graduation. American Journal of Nursing says it "is exactly the book for which nurses and others have long and vainly sought."

Dietetics for Nurses. By Julius FriedenwaLD, M. D., Professor of Diseases of the Stomach, and JoHn RUHRAH, M.D., Professor of Diseases of Children, College of Physicians and Surgeons, Baltimore. r2mo volume of $43 \mathrm{r}$ pages.

Cloth, \$r.5o net

\section{Friedenwald \& Ruhrah on Diet FOURTH}

This work is a fuller treatment of the subject of diet, presented along the same lines as the smaller work. Everything concerning diets, their preparation and use, coloric values, rectal feeding, etc., is here given in the light of the most recent researches.

Diet in Health and Disease. By Julius FRIEDENWALD, M.D., and John RUhrah, M.D. Octavo volume of 857 pages. Cloth, $\$ 4.00$ net 


\section{Pyle's Personal Hygiene}

Dr. Pyle's work discusses the care of the teeth, skin, complexion and hair, bathing, clothing, mouth breathing, catching cold; singing, care of the eyes, school hygiene, body posture, ventilation, heating, water supply, house-cleaning, home gymnastics, first-aid measures, etc.

A Manual of Personal Hygiene. Edited by Walter L. Pyle, M. D., Wills Eye Hospital, Philadelphia. 12mo, 543 pages of illus. \$r.50 net

\section{Galbraith's Personal Hygiene and Physical Training for Women \\ ILLUSTRATED}

Dr. Galbraith's book tells you how to train the physical powers to their highest degree of efficiency by means of fresh air, tonic baths, proper food and clothing, gymnastic and outdoor exercise. There are chapters on the skin, hair, development of the form, carriage, dancing, walking, running, swimming, rowing, and other outdoor sports.

Personal Hygiene and Physical Training for Women. By AnNA M. Galbraith, M.D., Fellow New York Academy of Medicine. I2mo of 37 pages, illustrated.

Cloth, \$2.00 net

\section{Galbraith's Four Epochs of Woman's Life}

This book covers each epoch fully, in a clean, instructive way, taking up puberty, menstruation, marriage, sexual instinct, sterility, pregnancy, confinement, nursing, the menopause.

The Four Epochs of Woman's Life. By ANNA M. GALBRAITH, M. D. With an Introductory Note by JOHN H. MUSSER, M. D., University of Pennsylvania. I2mo of 247 pages.

Cloth, \$r.5o net

\section{Griffith's Care of the Baby new (6th) EDItion}

Here is a book that tells in simple, straightforward language exactly how to care for the baby in health and disease; how to keep it well and strong; and should it fall sick, how to carry out the physician's instructions and nurse it back to health again.

The Care of the Baby. By J. P. CROzer GRIfFith, M.D., University of Pennsylvania. 12mo of 458 pages, illustrated. Cloth, $\$$ r.50 net 


\section{Aikens' Ethics for Nurses}

JUST READY

This book emphasizes the importance of ethical training. It is a most excellent text-book, particularly well adapted for classroom work. The illustrations and practical problems used in the book are drawn from life.

Studies in Ethics for Nurses. By Charlotte A. Aikens, formerly Superintendent of Columbia Hospital, Pittsburg. I2mo of $3 \times 8$ pages.

Cloth, \$r.75 net.

\section{Goodnow's History of Nursing readY soon}

Miss Goodnow's work gives the main facts of nursing history from the beginning to the present time. It is suited for classroom work or postgraduate reading. Sufficient details and personalities have been added to give color and interest, and to present a picture of the times described.

History of Nursing. By Minnie Goodnow, R.N., formerly Superintendent of the Women's Hospital, Denver. I2mo of 300 pages, illustrated.

\section{Berry's Orthopedics for Nurses}

The object of Dr. Berry's book is to supply the nurse with a work that discusses clearly and simply the diagnosis, prognosis and treatment of the more common and important orthopedic deformities. Many illustrations are included. The work is very practical.

Orihopedic Surgery for Nurses. By JOHn MCWILliams BerRY, M.D., Clinical Professor of Orthopedics and Rontgenology, Albany Medical College. I2mo of 100 pages, illustrated.

\section{Whiting's Bandaging}

This new work takes up each bandage in detail, telling youand showing you by original illustrations-just how each bandage should be applied, each turn made. Dr. Whiting's teaching experience has enabled him to devise means for overcoming common errors in applying bandages.

Bandaging. By A. D. Whiting, M.D. Instructor in Surgery at the University of Pennsylvania. 12mo of $15 \mathrm{I}$ pages, with 117 illustrations. Cloth, \$r.25 net. 


\section{Hoxie \& Laptad's Medicine for Nurses}

Medicine for Nurses and Housemothers. By GEORGE; Howard HoxIE, M. D., University of Kansas; and PEARL L. LAPTAD. 12 mo of 351 pages, illustrated. Cloth, $\$ 1.50$ net.

New (2d) Edition.

This book gives you information that will heip you to carry out the directions of the physician and care for the sick in emergencies. It teaches you how to recognize any signs and changes that may occur between visits of the physician, and, if necessary, to meet conditions until the physician's arrival.

\section{Boyd's State Registration for Nurses}

State Registration for Nurses. By LouIE CrofT Boyd, R. N., Graduate Colorado Training School for Nurses. Octovo of 149 pages. Cloth, $\$ 1.25$ net. Nerw (2d) Edition.

\section{Morrow's Immediate Care of Injured}

Immediate Care of the Injured. By ALBERT S. MorRow, M. D., New York City Home for Aged and Infirm. Octavo of 354 pages, with 242 illustrations.

Cloth, $\$ 2.50$ net.

New (2d) Edition.

\section{deNancrede's Anatomy}

NEW (7th) EDITION

Essentials of Anatomy. By CHARtES B. G. DENANCREDE, M. D., University of Michigan. $12 \mathrm{mo}$ of 400 pages, 180 illustrations.

Cloth, $\$ 1.00$ net.

\section{Morris' Materia Medica}

NEW (7th) EDITION

Essentials of Materia Medica, Therapeutics, and Prescription Writing. By HENRY MORRIS, M. D. Revised by W. A. BASTEDO, M. D., Columbia University, New York. $12 \mathrm{mo}$ of 300 pages, illustrated.

Cloth. $\$ 1.00$ net.

\section{Register's Fever Nursing}

A Text Book on Practical Fever Nursing. By EDwARD C. Register, M. D., North Carolina Medical College. Octavo of 350 pages, illustrated. Cloth. $\$ 2.50$ net. 


$$
P_{R D}-55
$$









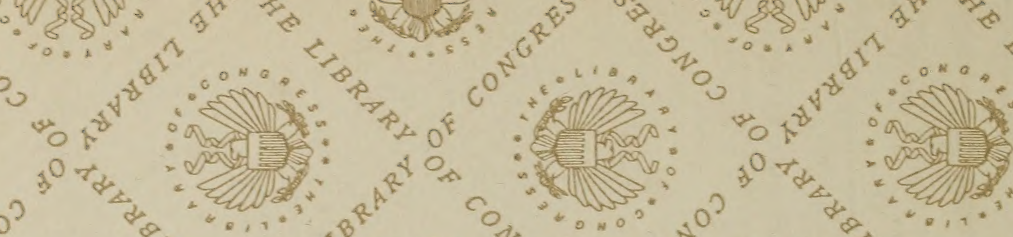

: 1) $+40^{2}$

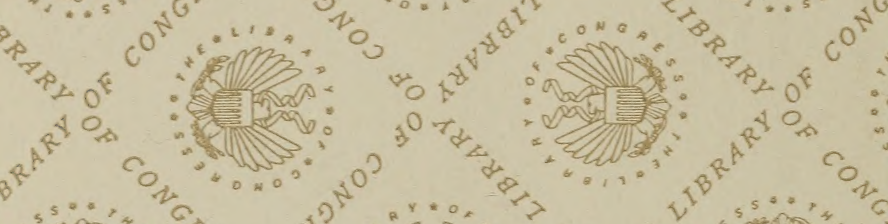

: An: "

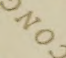

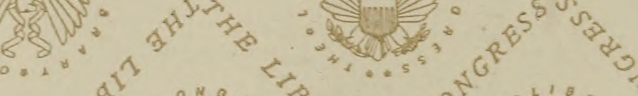

(1)

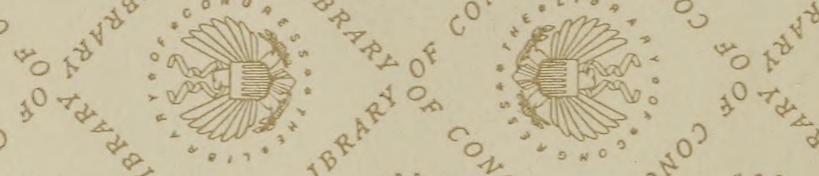

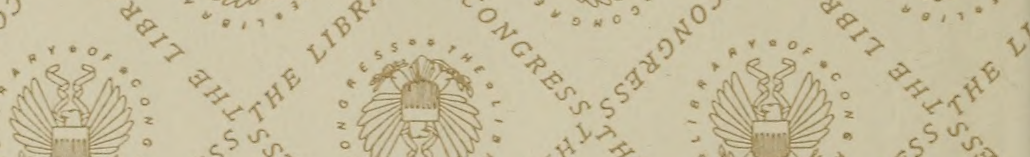

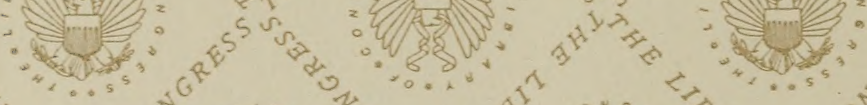


$0^{20}+\cdots$,

0
0

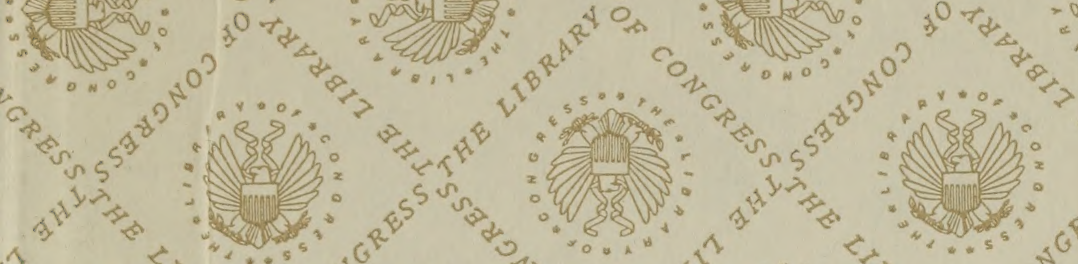
$\cdots$

Cât :

$x^{4} 0_{\mathrm{A}}$

s

"

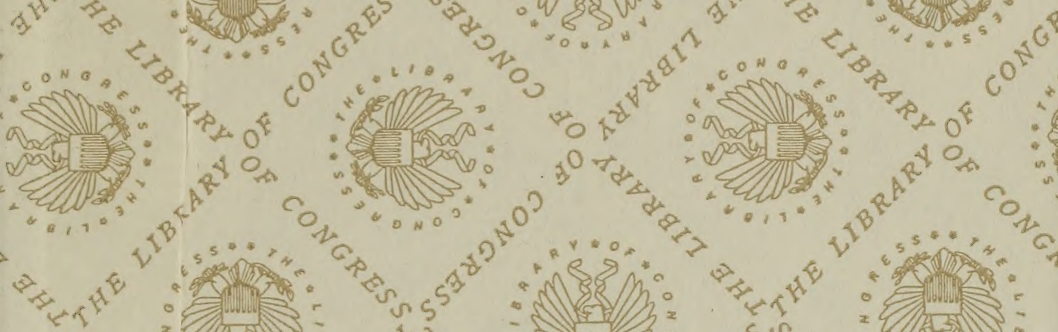

> $30^{2}+\cdots$

(6)

10

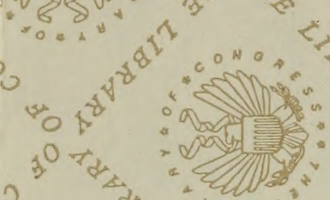

$\sqrt{3} s^{2}$

s) 1)

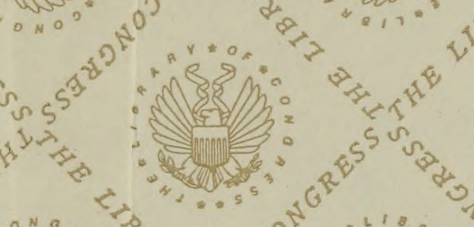

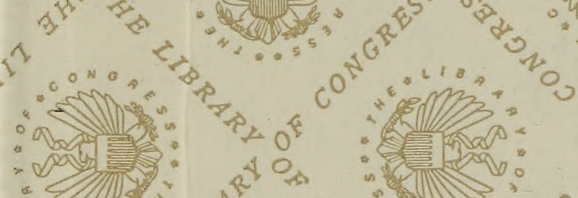

40

(.)

of

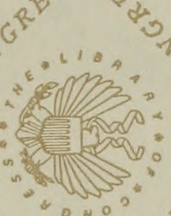
$\sin _{3 \rightarrow 5^{2}}$ 
LIBRARY OF CONGRESS

|||||||||||||||||||||||||||||||||||||||||

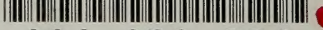

00210689345 